University of South Florida

DIGITAL COMMONS @ UNIVERSITY OF SOUTH FLORIDA
Digital Commons @ University of South Florida

$11-1-2007$

\title{
Moving the Bus Back Into Traffic Safely - Signage and Lighting Configuration Phase I
}

CUTR

Follow this and additional works at: https://digitalcommons.usf.edu/cutr_nctr

\section{Recommended Citation}

"Moving the Bus Back Into Traffic Safely - Signage and Lighting Configuration Phase I," National Center for Transit Research (NCTR) Report No. CUTR-NCTR-RR-2005-01, Center for Urban Transportation Research, University of South Florida, 2007.

DOI: https://doi.org/10.5038/CUTR-NCTR-RR-2005-01

Available at: https://scholarcommons.usf.edu/cutr_nctr/118

This Technical Report is brought to you for free and open access by the National Center for Transit Research (NCTR) Archive (2000-2020) at Digital Commons @ University of South Florida. It has been accepted for inclusion in Research Reports by an authorized administrator of Digital Commons @ University of South Florida. For more information, please contact digitalcommons@usf.edu. 
Moving the Bus Back into Traffic Safely Signage and Lighting Configuration Phase I

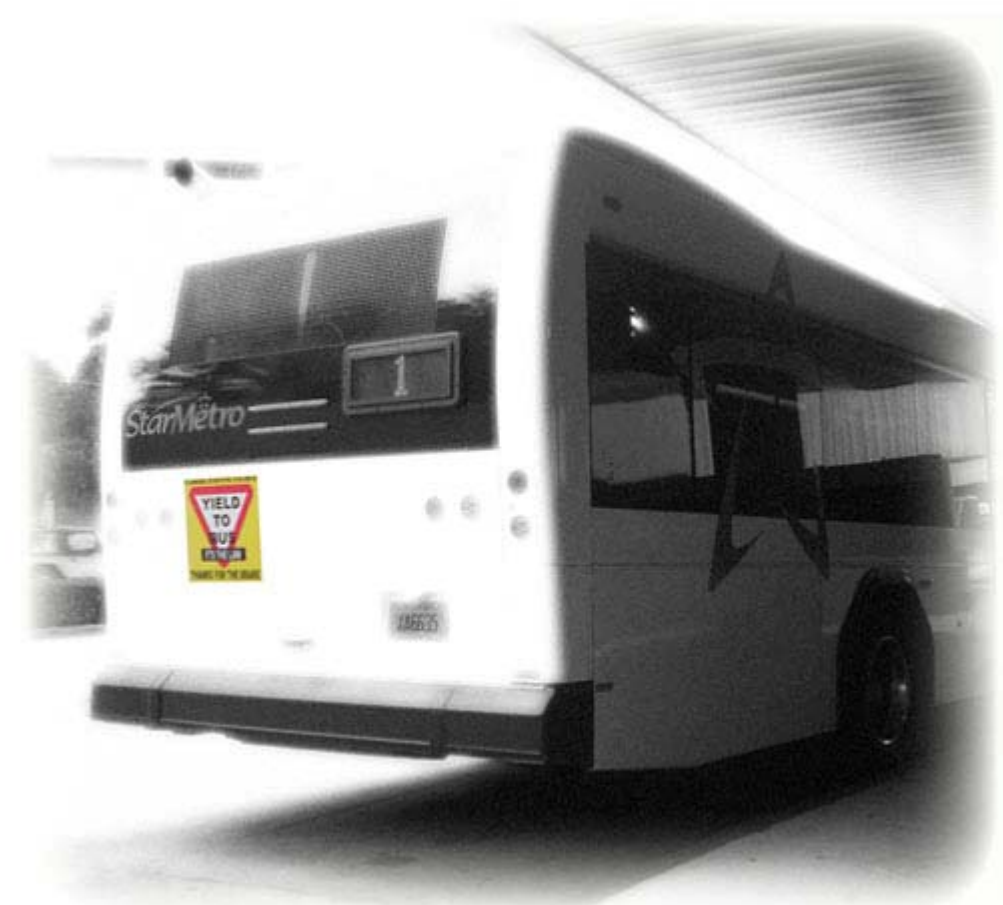

FDOT BD 549-34

Final Report

November 2007 


\section{Moving the Bus Back Into Traffic Safely - Signage and Lighting Configuration Phase I}

Final Report

November 2007

Prepared for

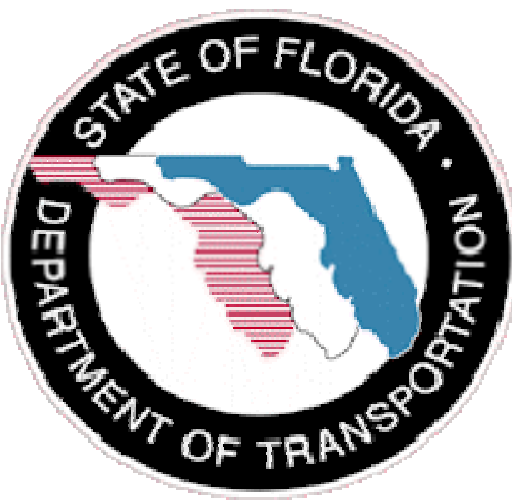

Florida Department of Transportation

BD 549-34

\section{Project Manager:}

Amy Datz

Prepared by

Huaguo Zhou, Ph.D., P.E., Senior Research Associate

Stephanie Bromfield, Graduate Research Assistant

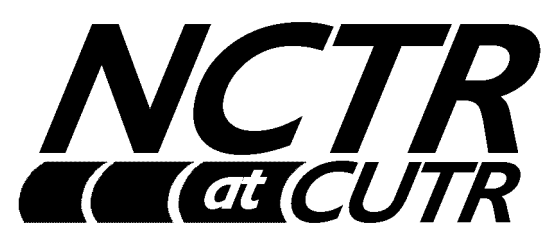

National Center for Transit Research

Center for Urban Transportation Research

University of South Florida

4202 E. Fowler Avenue, CUT 100

Tampa, FL 33620-5375

(813) 974-3120

http://www.nctr.usf.edu 


\section{DISCLAIMER}

The opinions, findings, and conclusions expressed in this publication are those of the authors and not necessarily those of the State of Florida Department of Transportation or the US Department of Transportation. 
TECHNICAL REPORT STANDARD TITLE PAGE

\begin{tabular}{|c|c|c|}
\hline $\begin{array}{l}\text { 1. Report No. } \\
\text { NCTR } 77610-00, \text { FDOT BD 549-34 }\end{array}$ & 2.Government Accession No. & 3. Recipient's Catalog No. \\
\hline \multirow{2}{*}{\multicolumn{2}{|c|}{$\begin{array}{l}\text { 4. Title and Subtitle } \\
\text { Moving the Bus Back into Traffic Safely - Signage and Lighting Configuration } \\
\text { Phase I - Final Report }\end{array}$}} & $\begin{array}{l}\text { 5. Report Date } \\
\text { November } 2007\end{array}$ \\
\hline & & 6. Performing Organization Code \\
\hline \multicolumn{2}{|l|}{$\begin{array}{l}\text { 7. Author(s) } \\
\text { Huaguo Zhou and Stephanie Bromfield }\end{array}$} & $\begin{array}{l}\text { 8. Performing Organization } \\
\text { Report No. }\end{array}$ \\
\hline \multirow{2}{*}{\multicolumn{2}{|c|}{$\begin{array}{l}\text { 9. Performing Organization Name and Address } \\
\text { National Center for Transit Research } \\
\text { Center for Urban Transportation Research } \\
\text { University of South Florida } \\
4202 \text { E. Fowler Avenue, CUT } 100 \\
\text { Tampa, FL 33620-5375 }\end{array}$}} & 10. Work Unit No. \\
\hline & & 11. Contract or Grant No. \\
\hline \multirow{2}{*}{\multicolumn{2}{|c|}{$\begin{array}{l}\text { 12. Sponsoring Agency Name and Address } \\
\text { Office of Research and Special Programs, } \\
\text { U.S. Department of Transportation } \\
\text { Washington, D.C. } 20590 \\
\text { Florida Department of Transportation } \\
\text { Office of Public Transportation } \\
605 \text { Suwannee St. MS } 26 \text {, Tallahassee FI. 32399-0450 }\end{array}$}} & $\begin{array}{l}\text { 13. Type of Report and Period } \\
\text { Covered }\end{array}$ \\
\hline & & 14. Sponsoring Agency Code \\
\hline
\end{tabular}

16. Abstract

With an increase in the number of bus pull-out bays in Florida, a growing number of bus operators find that it is very difficult to merge back into traffic from a bus pull-out bay. Some transit agencies do not support building new bus pull-out bays because of concerns that it will cause additional delays and safety problems. Bus operators sometimes refuse to use the existing bus pull-out bays because they know the difficulty of moving bus back into traffic. Without the proper traffic control devices, motorists do not know when or how they should yield to bus, which is part of the Florida Statutes requiring motorists to yield at specifically designated bus pull-out bays. This makes enforcement of existing yield-to-bus (YTB) laws very difficult. Field observations and conflict studies showed that additional delays and many traffic conflicts were caused when buses attempted to move back into traffic from a pull-out bay.

This research uses bus operator surveys, crash data analysis, and field studies to develop recommendations for lighting and signage on the back of the bus, roadway signs, and Florida YTB statues. The study found that the decal currently affixed to the back of Florida buses has no significant safety and operational effect. There are no roadside signs or pavement markings for YTB. Proper signage and lighting were recommended to help the bus move back into traffic safely, decrease bus delay, and improve bus operations however; it must be accompanied by adequate laws and law enforcement.

\section{Key Words}

Transit Safety, Signage and Lighting Configurations,

Yield-to-Bus Program, Bus Pull-out Bays, Survey, MUCTD
18. Distribution Statement

\begin{tabular}{|l|l|l|l|}
\hline \multicolumn{1}{|l|}{} & \multicolumn{2}{l|}{$\begin{array}{l}\text { 21. No of } \\
\text { Pages } \\
140\end{array}$} & 22. Price \\
19. Security Classif (of this report) & $\begin{array}{l}\text { 20. Security Classif. (of this page) } \\
\text { unclassified }\end{array}$ & unclassified & \\
\hline
\end{tabular}

Form DOT F 1700.7 (8-69) 


\section{ACKNOWLEDGEMENTS}

The project team would like to thank the following people for their assistance and input in this research:

- Amy Datz, Florida Department of Transportation

- Greg Brackin, Hillsborough Area Regional Transit

- Paul Goyette, Lee County Transit

- Walt Lenz, Pinellas Suncoast Transit Authority

- Bill Mayer, Volusia County Transit

- Scott Penvose, Lynx

- Samuel Scheib, StarMetro

- Gail Stewart, Lynx

- Joseph Trottie, Jacksonville Transportation Authority

- Robert Westbrook, Florida Department of Transportation

- Tara Bartee, Florida Department of Transportation

- Steve Polzin, Center for Urban Transportation Research

- Amber Reep, Center for Urban Transportation Research

- Ed Bart, Center for Urban Transportation Research

- Vicki Zambito, Center for Urban Transportation Research

- Joel Volinski, Center for Urban Transportation Research

- Dennis, Hinebaugh, Center for Urban Transportation Research

The project team also wishes to thank the many bus operators who took the time to participate in the survey. 


\section{EXECUTIVE SUMMARY}

The Florida Department of Transportation (FDOT) has been working on the issue of crash reduction in transit vehicles for over the past 4 years. Much work has been accomplished in the analysis of bus crash data and in making recommendations for the potential reduction of crashes. Safety is one of the department's most important issues. Although bus crashes do not usually result in harm to the transit bus drivers or passengers, the drivers of the vehicles that crash into the buses are usually harmed more severely. Bus crashes are also a cause of traffic congestion, resulting in time loss by those not involved in the crash and increased air pollution.

A recent study of bus crash data by FDOT found that the most common cause of bus crashes was inattentive or careless driving on the part of private automobile operators. The study recommended the installation of more bus pull-out bays on state roads, more effective lighting configurations on the rear of buses, and state-wide bus stop design standards. These results led us to look at the engineering side of the YTB program to develop the recommendations to address the issue. This report provides hard core engineering recommendations for both engineering and public information solutions.

This report addresses four potential avenues of safety improvement:

1) Yield to Bus (YTB) LED lighting configuration on the back of the bus.

2) Improved pavement markings and roadside signage.

3) YTB public information campaign to inform the public of the issues at hand.

4) An amendment of the YTB statutes may be required to accomplish these goals.

\section{Bus Pull out Bays and Lighting Configurations}

One method used in Germany to improve transit service is to change existing bus bays into street based stop areas called buscapes. If the traffic will not stop to allow the bus back into traffic then moving the pedestrian areas closer to the bus and improving the buscape will decrease the route delay but increase the delay of the cars. Creating a bus dominated design would reduce rear end collisions into the back of the bus.

Everything has a trade off. By using bus bays, air pollution is decreased and the frustration of the driving public is calmed but the incidents of traffic failure to YTB and bus rear end collisions are increased. The research indicates that a flashing YTB sign on the back of the bus like those allowed by state law in California and Oregon may be the most effective bus modification to improve operation and safety. A very large majority (73\%) of the bus drivers interviewed indicated they felt the flashing LED signs would be the most effective technology in North America rather than the YTB decal on the back of the bus which they thought was so ineffective that it might as well not be there. The majority of the bus operators felt the LED light made merging safer. The YTB LED lights cost between $\$ 250$ and $\$ 600$ per bus which is cheaper than a rear end bus collision. This is minimal in comparison to the money lost by the transit agency having a bus out of commission and the fuel loss by traffic congestion created by bus accidents. The YTB 
LED light is activated by a control switch and released when the left turn signal is released providing reduced distraction to the bus operator.

\section{Roadside Signs and Pavement Markings}

The second engineering solution would be to develop MUTCD accepted roadside signage potentially including flashing lights and pavement markings in specific locations where the potential for rear end collisions are greatest. This is especially true in areas with high traffic volumes and shorter headways where bus pull-out bays are present. This engineering solution may impact re-entry delay, relay propagation and schedule adherence depending on the number of lanes, location of the stop, and distance to the nearest intersection, hourly traffic volumes, speed limit and bus headway.

The YTB LED lighting should be supplemented with a standardized program of using the flashing warning lights so that motorists can understand what the sign means. Other states require a public awareness campaign to let motorists know about the YTB laws. A system should be set up to evaluate the necessity of the law based on the total number of traffic collisions, congestion and air quality savings, public opinion and the efficiency of transit operations.

Another unexpected result of this project was brought to light during the field observations made in areas where buses were entering the traffic stream from a bus bay. Cars will sharply weave into adjacent lanes to avoid the merging bus or being behind the merging bus. This lane weaving action could create accidents that go unreported as incidents involving the bus; therefore, potentially skewing the bus crash analysis.

\section{Yield to Bus Laws}

The YTB law does not give guidance as to how to implement the law which allows for some innovation in addressing the law. Changing the statutes to improve YTB safety would include:

1) Allowing flashing directional signals on the left rear of the bus to indicate merging into traffic.

2) The merging signal would be used when the bus enters a traffic lane after receiving or discharging passengers even if it is not exiting a bus bay.

3) Transit agencies would not be required to install illuminated flashing lights.

4) A report to the Governor and legislature, 24 months after the effective date of this amendatory act, on the effectiveness of the YTB program shall include but not be limited to any impact on the highway and local road safety and the efficiency of transit operations. This would require law enforcement agencies to report: (A) the total number of traffic collisions causing fatalities or injuries or property damage, (B) Traffic congestion issues, (C) Public opinion (accidents caused by weaving vehicles), (D) Efficiency of transit operations, (E) The impact of the public education program.

5) Each transit agency participating in the YTB program shall undertake a public education program to inform motorists of the requirements of the program relating to the bus rights-of-way. 


\section{TABLE OF CONTENTS}

EXECUTIVE SUMMARY

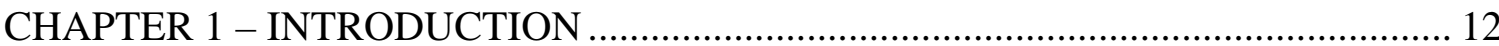

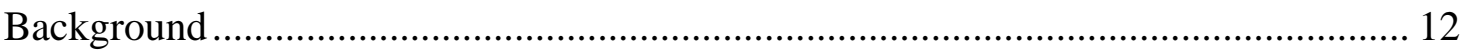

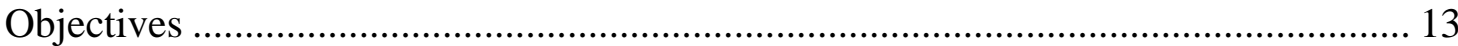

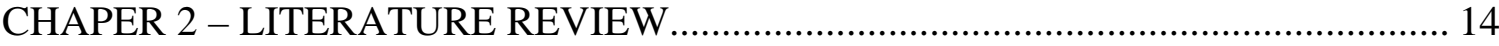

Signage and Lighting Configuration........................................................................... 14

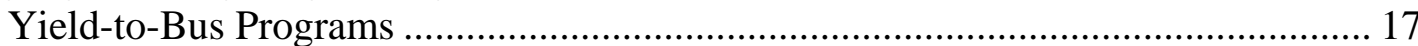

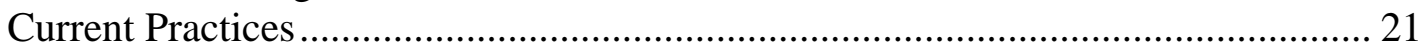

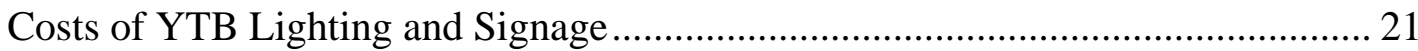

Location of the Yield Sign ........................................................................................... 21

Effects of Different Yield Signals and Lighting ....................................................... 22

Transit Agency Practice Comparisons.................................................................... 34

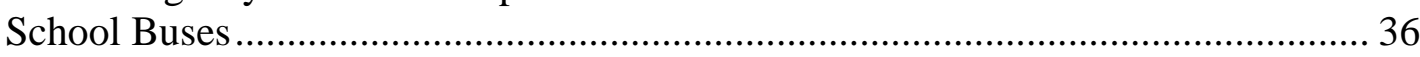

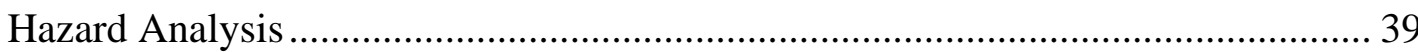

Roadside Signs and Pavement Markings ....................................................................... 41

Bus Stop Location and Design............................................................................ 41

Manual on Uniform Traffic Control Devices ........................................................ 43

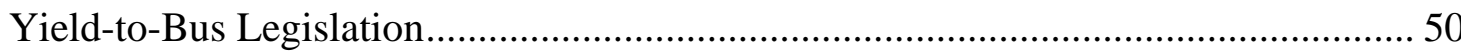

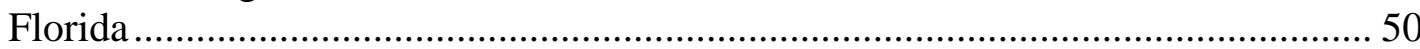

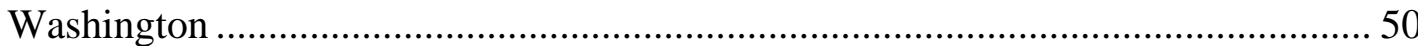

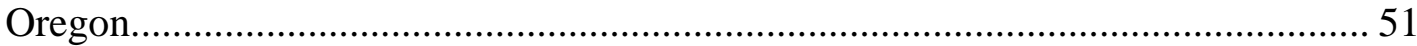

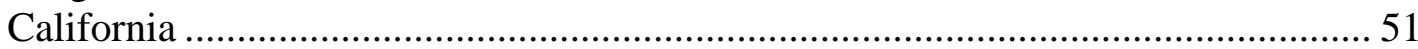

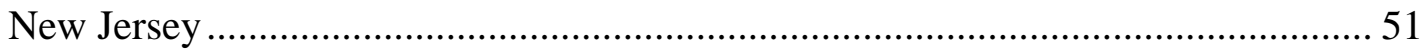

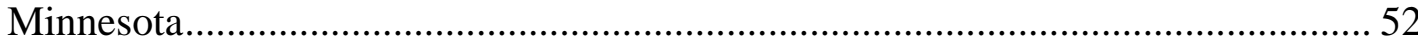

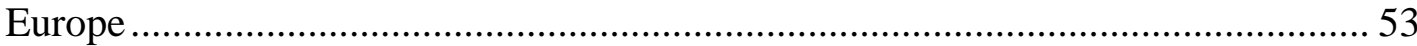

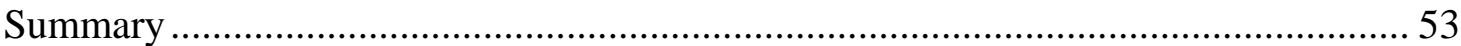

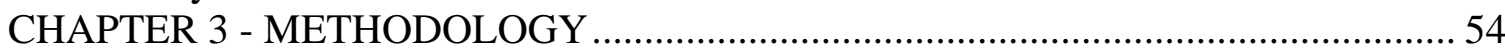

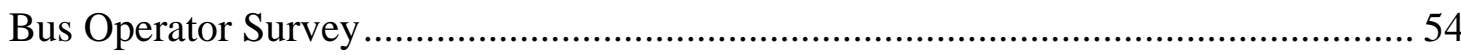

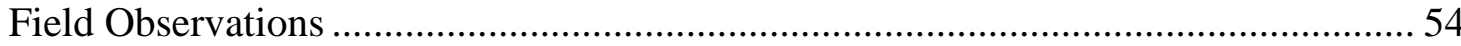

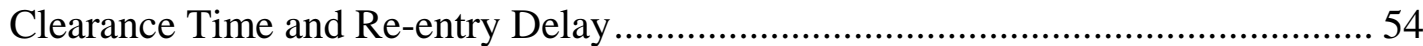

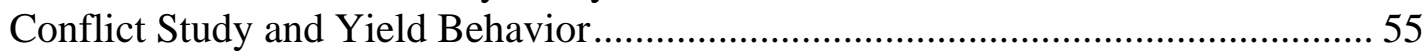

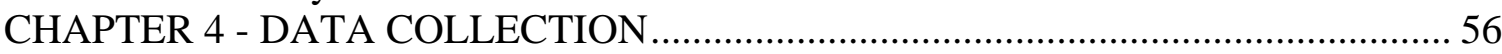

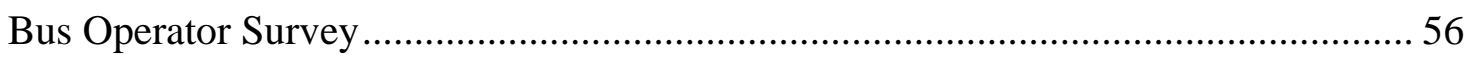

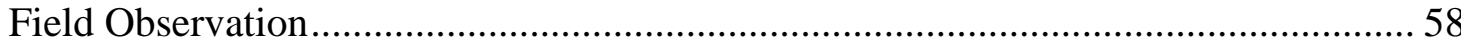

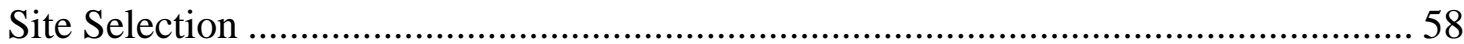

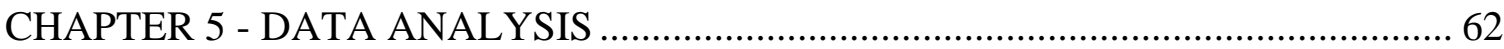

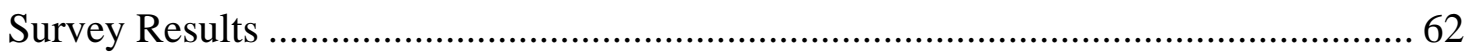

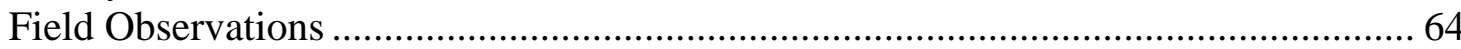

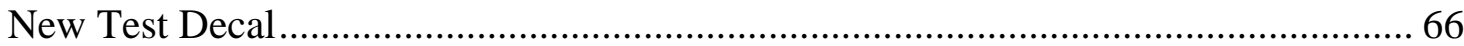

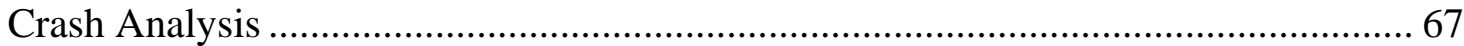

CHAPTER 6 - CONCLUSION AND RECOMMENDATIONS ........................................ 68

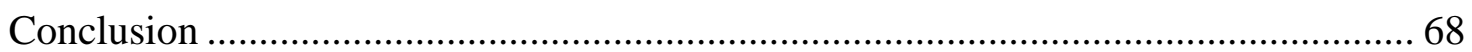

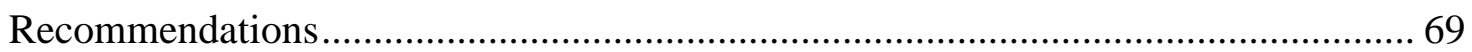

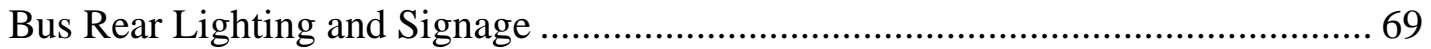

Roadside Signs and Pavement Marking ……………............................................... 69 


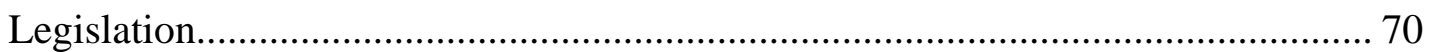

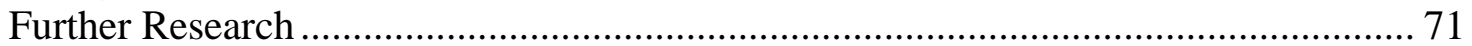

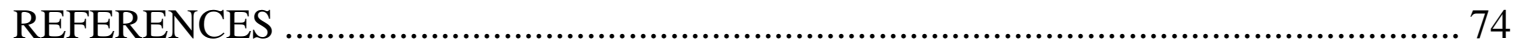

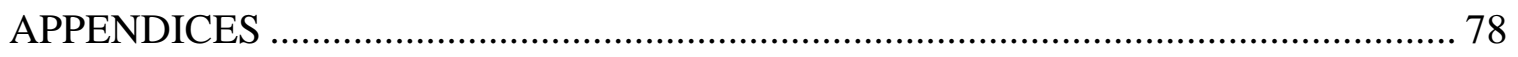

Appendix A: Yield to Bus Laws ............................................................................ 79

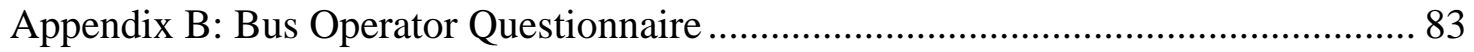

Appendix C: Bus Operator Questionnaire Responses ............................................ 87

Appendix D: Bus Operator Survey Narrative Responses ...................................... 110

Appendix E: Field Data Collection Locations ........................................................ 122

Appendix F: Field Data Pictures ....................................................................... 126

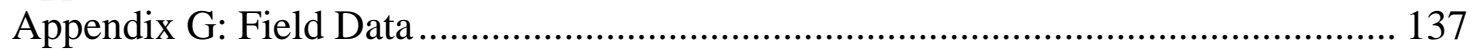




\section{LIST OF FIGURES}

Figure 1 Vertical and Horizontal Light Configurations..................................................... 16

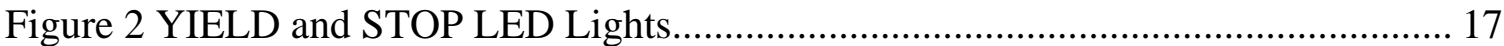

Figure 3 Bus Priority Signs in Australia and Europe...................................................... 18

Figure 4 Yield/Cédez Decal in Canada...................................................................... 19

Figure 5 Bus Priority Sign in Canada ………………............................................... 19

Figure 6 YTB Decal 1 (Broward County Transit) ........................................................... 22

Figure 7 Operators' Perception of Improved Safety for Decal 1....................................... 23

Figure 8 Drives' Yield Behavior for Decal 1............................................................ 23

Figure 9 YTB decal 2 (Coast Mountain Bus Company)................................................. 24

Figure 10 YTB-related decal signs by CMBC.............................................................. 24

Figure 11 Operators' Perception of Improved Safety by Decal 2 ……............................ 25

Figure 12 Perception of Drivers' Yield Behavior by Decal 2 ........................................... 25

Figure 13 Metro Transit with YTB decal ..................................................................... 26

Figure 14 Bus Operators' Survey Response.................................................................. 27

Figure 15 Locations of Decal 1 and Decal 2............................................................... 27

Figure 16 Comparison of Bus Operators' Perception of Yield Behavior .......................... 28

Figure 17 Comparison of Two Decals in Perception of Yield Behavior .......................... 28

Figure 18 British Columbia Transit YTB decal and Yield LED Sign ............................... 29

Figure 19 Tri-Met LED Yield sign .............................................................................. 30

Figure 20 Tri-Met Bus Operators' Perception of Safety .................................................. 30

Figure 21 Tri-Met Bus Operators' Perception of Yield Behavior....................................... 31

Figure 22 Santa Clara Valley Transportation Authority Bus with LED Yield Sign ........ 32

Figure 23 Santa Cruz Metropolitan Transit Bus with Yield LED Sign ............................. 32

Figure 24 VTA Bus Operators' Perception of Yield Behavior ............................................ 33

Figure 25 VTA Bus Operators' Perception of Flashing Yield Signal................................ 33

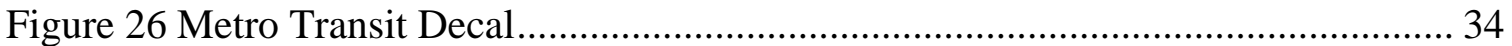

Figure 27 Comparison of Three Transit Agencies on the Perception of Safety With Yield

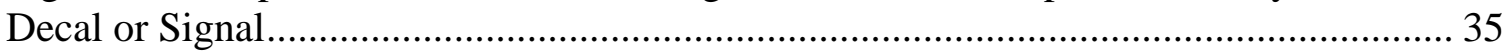

Figure 28 Comparison of Bus Operators' Perception of Yield Behavior for Decal 1

(BCT) and Decal 2(CMBC) ...................................................................................... 35

Figure 29 Comparison of LED Yield Sign 2 and LED Yield Sign 3 Perception of Driver

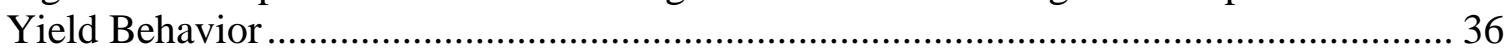

Figure 30 Transpec Merge Alert LED Sign.................................................................... 38

Figure 31 Advanced Safety Wheel and Hubs Alert System.............................................. 39

Figure 32 Bus Bay Configuration ............................................................................... 42

Figure 33 Queue Jumper Bus Bay Configuration............................................................ 43

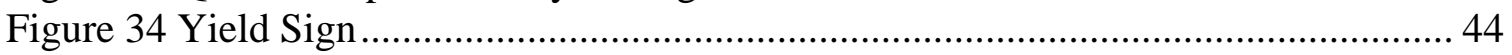

Figure 35 Yield to Pedestrians Signs ............................................................................ 44

Figure 36 Yield Pavement Markings ............................................................................. 45

Figure 37 Placement of Yield Markings ......................................................................... 46

Figure 38 Yield Marking for Roundabout ..................................................................... 47

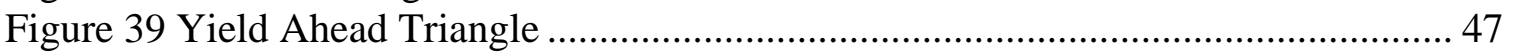

Figure 40 Begin Right Turn Lane Yield to Bikes Sign .................................................. 48

Figure 41 No Parking Signs Related to Transit Stops ………………….......................... 49

Figure 42 Operators Perception of Motorists’ Awareness of YTB Laws.......................... 52 
Figure 43 Counties Involved in Survey ………………............................................... 57

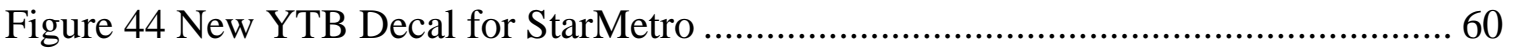

Figure 45 Differences in Yield Behavior Reported by Bus Operators ............................. 62

Figure 46 Bus Operators' Perception of Safety Effects ....................................................... 63

Figure 47 Bus Operators' Perception of the Helpfulness of YTB Signs............................. 63

Figure 48 Bus Operators' Use of Right-turn Lane or Shoulder .......................................... 64

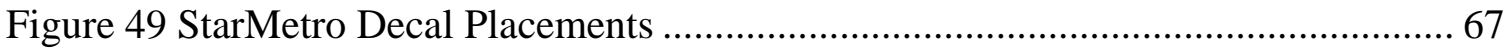

Figure 50 Yield-to-Bus Roadway Signs ..................................................................... 70

Figure 51 Yield-to-Bus Roadway Flashing Beacons.................................................. 71

Figure 52 Aerial View of Fletcher Ave and Bruce B Downs Blvd ................................ 122

Figure 53 Aerial View of Fletcher Ave and Dale Mabry Blvd....................................... 122

Figure 54 Sketch of Hillsborough Ave and Florida Ave ............................................... 123

Figure 55 Sketch of Kirkman Rd and Conroy Rd......................................................... 123

Figure 56 Sketch of Orange Blossom Trail and Holden Ave ....................................... 124

Figure 57 Sketch of John Knox Rd and Monroe St.................................................... 124

Figure 58 Sketch of Georgia St and Macomb St ..................................................... 125

Figure 59 Votran Bus with New LED Sign ................................................................ 126

Figure 60 Leetran Bus with YTB Decal on Upper Part of Bus ...................................... 127

Figure 61 Leetran Bus with YTB Decal on Lower Part of Bus....................................... 128

Figure 62 Leetran Bus Stop Sign with YTB Law........................................................... 129

Figure 63 Lynx Bus with Large YTB Decal and Small YTB Decal ............................... 130

Figure 64 HART Bus with YTB Decal and Dimensions................................................. 131

Figure 65 HART Gillig Phantom Bus ..................................................................... 132

Figure 66 HART Gillig Hybrid Bus ...................................................................... 133

Figure 67 Miami-Dade Bus with YTB Decal ............................................................. 134

Figure 68 StarMetro RTS Bus ................................................................................ 135

Figure 69 StarMetro Gillig Bus ........................................................................... 136 


\section{LIST OF TABLES}

Table 1 Various Lighting Technologies Employed in North America............................ 20

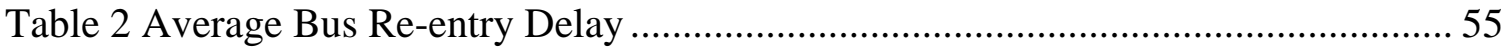

Table 3 Hillsborough and Orange County Field Data Locations .................................. 59

Table 4 Leon County Field Data Locations ................................................................. 60

Table 5 Average Re-entry Delay by Location and AADT ........................................... 65

Table 6 Average Headway, Conflict rate and Yield Behavior from Field Data............... 66

Table 7 Bus Operator Responses for All Counties in Survey ........................................... 87

Table 8 Duval County Bus Operator Responses......................................................... 91

Table 9 Hillsborough County Bus Operator Survey Responses..................................... 93

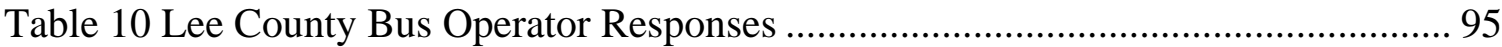

Table 11 Leon County Bus Operator Responses ......................................................... 98

Table 12 Orange County Bus Operator Responses................................................... 101

Table 13 Pinellas County Bus Operator Responses..................................................... 103

Table 14 Volusia County Bus Operator Responses .................................................... 106 


\section{CHAPTER 1 - INTRODUCTION}

\section{Background}

A study was performed in Florida to explore the factors that contribute to bus accidents near bus stops. This research studied all crash reports involving transit vehicles for incidents from 1998 to 2002 over all state roadways within Florida, and resulted in the development of recommendations to address the accident (crash) problems found through the research. The results of that study indicated that 47 percent of all crashes during the five years studied were vehicles having rear-end collisions with buses. It was concluded that one of the primary causes of rear-end crashes at a bus bay or pull-out was the failure of traffic to yield to buses reentering the traffic stream from a stop, bus bay, or pull-out (Luke Transportation Engineering Consultants 2004). According to Wiacek and Najm (1999), rear-end collisions were the most frequent type of crash based on a database study. They used the General Estimates System (GES) crash database for the years of 1992 through 1996 and reported that for this time, period rear end collisions accounted for nearly 25\% of all crashes in the U.S (as cited in Lee et al 2002). McGehee, Dingus, and Mollenhauer (1994) reported that 23.8\% of all crashes were rear-end collisions based on a review of the National Automotive Sampling System's Crashworthiness Data System (NASS CDS) and the National Center for Statistics and Analysis (NSCA) Accident Facts for 1991. When the rear-end collisions were separated into rear-end crashes in which the lead vehicle is moving (LVM) and rear-end crashes in which the lead Vehicle is stationary (LVS), the LVS crashes accounted for 69.7\% of all rear-end collisions (as cited in Lee et al 2002). Florida has a "Yield-to-Bus" law (Florida Statute 316.0815) that requires traffic to yield to buses reentering the traffic stream. However, this applies only to buses leaving a pull-out-bay.

Under contract with the Florida Department of Transportation (FDOT), the Center for Urban Transportation Research (CUTR) through the National Center for Transit Research (NCTR) conducted this project to determine the best practices in signage and lighting configuration for moving a bus back into the traffic flow safely from a pull-out bay.

The overall goal of the project is to help improve transit service by improving on-time schedules and the quality of service by assisting transit vehicles in safely reentering the traffic stream.

Where state roads are congested or carry high-speed traffic, operational devices and/or controls may be installed on buses or on the roadside to assist in the safe entry of buses into the state road travel lanes. A study should be completed to provide recommendations that would lead to the adoption of roadside signage and/or pavement markings in compliance with the Manual on Uniform Traffic Control Devices (MUTCD) that would help to reduce rear-end collisions when buses are merging back into traffic.

Additionally, to reduce the occurrence of rear-end collisions with buses, an improvement of lighting configurations on the back of buses should be studied. A specific study of lighting configurations should be completed to improve auto driver awareness of the presence and operation of the buses and standardize the lighting configurations on buses. 


\section{Objectives}

This project has three primary objectives:

1. To develop recommendations to the National Highway Traffic Safety Administration (NHTSA) on lighting configurations and/or signage for the back of transit buses that will be expected to reduce rear-end collisions;

2. To develop recommendations for MUTCD-compliant signage and pavement markings to address Yield-to-Bus (YTB) safety issues; and

3. To develop recommendations for draft statutory language or modifications to existing statutes that would be needed to help increase viability of the YTB law. 


\section{CHAPER 2 - LITERATURE REVIEW}

The literature review consists of four sections. The first section outlines lighting configurations and signage currently utilized with an emphasis on Florida practices. Included in this section is a review of Yield-to-bus programs and the signs and lights associated with them, as well as the signage and lighting associated with school buses and specific research into signage and rear-lighting technologies. The second section is a review of roadside signs and pavements markings as well as the location and design of bus stops. The third section is a review of current yield-to-bus and bus priority regulations. The fourth section is a brief summary of the literature review.

\section{Signage and Lighting Configuration}

Florida Statute 316.301 requires vehicular hazard-warning signal lamps for all buses 30 feet or more in length or 80 inches or more in width. All buses, whatever their size, must have on the rear two reflectors, one at each side, and one stop light, and buses 80 inches or more in overall width must have, additionally, on the rear two clearance lamps, two reflectors, one at each side. These larger buses must also have on each side:

a. two side marker lamps, one at or near the front and one at or near the rear,

b. two reflectors, one at or near the front and one at or near the rear and,

c. one side marker lamp and one clearance lamp which may be in combination, to show to the front, side and rear.

The Florida Administrative Code (FAC) 14-90.007(1) states that all transit systems must meet the minimum requirements of the Federal Motor Vehicle Safety Standards and Regulations (FMVSS). The National Highway Traffic Safety Administration (NHTSA) has a legislative mandate to issue Federal Motor Vehicle Safety Standards (FMVSS) and Regulations. Manufacturers of motor vehicle and equipment items must conform and certify compliance with NHTSA.

Two stop lamps must be on the rear of the bus that display red or amber light when the brakes, service (foot) brakes or air activated parking brakes are applied, or if the passenger exit door control to open position is activated, according to 14-90.007(9), FAC. The lamps must be securely mounted and visible from a distance of no less than 300 feet. In addition, the FAC requires buses to have clearance lamps and tail lights on the rear of the bus.

Both Florida Statute 316.235(5) and FAC 14-90.007(13) permit but do not require buses to have deceleration lights that caution following vehicles that the bus is slowing, preparing to stop, or stopped. Florida Statutes describe the deceleration lighting system as amber lights mounted in horizontal alignment on the rear of the vehicle at or near the vertical centerline of the vehicle, not higher than the lower edge of the rear window or, if the vehicle has no rear window, not higher than 72 inches from the ground. Deceleration lights must be visible from a distance of not less than 300 feet to the rear in normal sunlight. These lights are permitted to light and flash during deceleration, braking, or 
standing and idling of the bus. Vehicular hazard warning flashers may be used in conjunction with or in lieu of a rear-mounted deceleration lighting system. Several letters were written to NHTSA about the use of flashing deceleration lights and they responded by saying that the simultaneous use of flashing and steady-burning lamps have the potential for creating confusion in vehicles to the rear and impairing the effectiveness of the required stop lamps (Recht 1995). This has caused several agencies in Florida to stop installing deceleration lights on the buses.

FMVSS Standard No. 108 includes lamps, reflective devices, and associated equipment for the reduction of traffic crashes and deaths and injuries resulting from traffic crashes. These devices enhance the conspicuity of motor vehicles on the public roads so that their presence is perceived and their signals understood. The standard requires that multipurpose passenger vehicles, trucks and buses, 80 inches or more in overall width, have two red tail lamps, two red stop lamps, one white backup lamp, two red or amber and two amber turn-signal lamps, a vehicular-hard warning-signal operating unit and flasher, turn-signal operating unit and flasher, three amber and three red identification lamps, two amber and two red clearance lamps, two amber intermediate side marker lamps, and two amber intermediate side reflex reflectors. No additional lamp, reflective device or other motor vehicle equipment shall be installed that impairs the effectiveness of lighting equipment required by these standards.

Federal Motor Carrier Safety Administration - Federal Regulation 393.22 states:

“(a) Permitted combinations. Except as provided in paragraph (b) of this section, two or more lighting devices and reflectors (whether or not required by the rules in this part) may be combined optically if -

(a)(1) Each required lighting device and reflector conforms to the applicable rules in this Part; and

(a)(2) Neither the mounting nor the use of a non-required lighting device or reflector impairs the effectiveness of a required lighting device or reflector or causes that device or reflector to be inconsistent with the applicable rules in this Part.

(b) Prohibited combinations. (1) A turn signal lamp must not be combined optically with either a head lamp or other lighting device or combination of lighting devices that produces a greater intensity of light than the turn signal lamp;

(b)(2) A turn signal lamp must not be combined optically with a stop lamp unless the stop lamp function is always deactivated when the turn signal function is activated;

(b)(3) A clearance lamp must not be combined optically with a tail lamp or identification lamp.”

Federal standards do not implicitly state that additional signs cannot be used on the back of the bus; instead they give guidelines as to the number and type of each light required on the bus and mention that additional lamps should not reduce the effectiveness of required lamps. Regulations from the Federal Motor Carrier Safety Administration permit 
lighting devices and reflectors to be combined optically if the use of a non-required lighting device does not impair the effectiveness of a required lighting device or reflector or causes that device or reflector to be inconsistent with the applicable rules.

The exact placement of these lights and markers vary by bus make and model. The lights are sometimes placed low on the bus close to the bumper, other times they are placed higher up. Lights may be aligned vertically or horizontally as shown in Figure 1, as long as they are located at the corner of the bus.

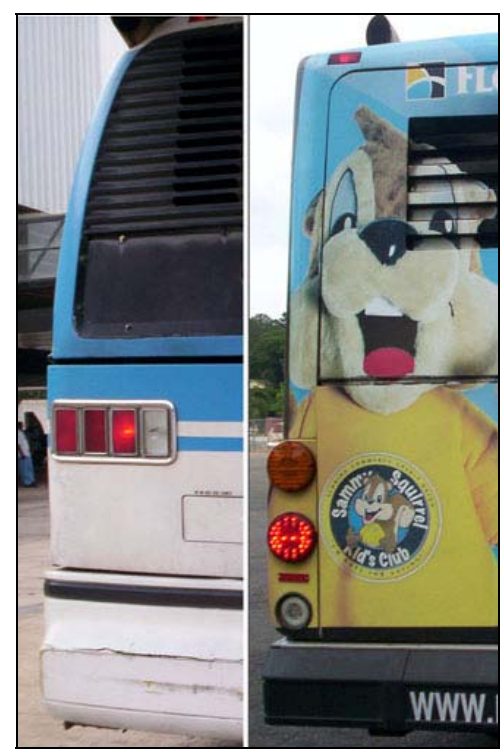

Figure 1 Vertical and Horizontal Light Configurations

Additional light emitting diode (LED) lights and deceleration lights are sometimes added to improve bus safety. Options available in LED lights include lights that spell the word STOP and YIELD (Figure 2). Transit agencies may also change the positions of amber and red lights and increase the size of the lights. Reflective tape is also used to increase the conspicuity of buses. Other lighting used to improve the conspicuity of the bus includes daytime running lights, additional lights around the bus, and strobe lights. LED lights have additional benefits as they are said to have a useful life approximately 100 times greater than incandescent bulbs. Incandescent lights have been traditionally used for the external lighting on buses. 


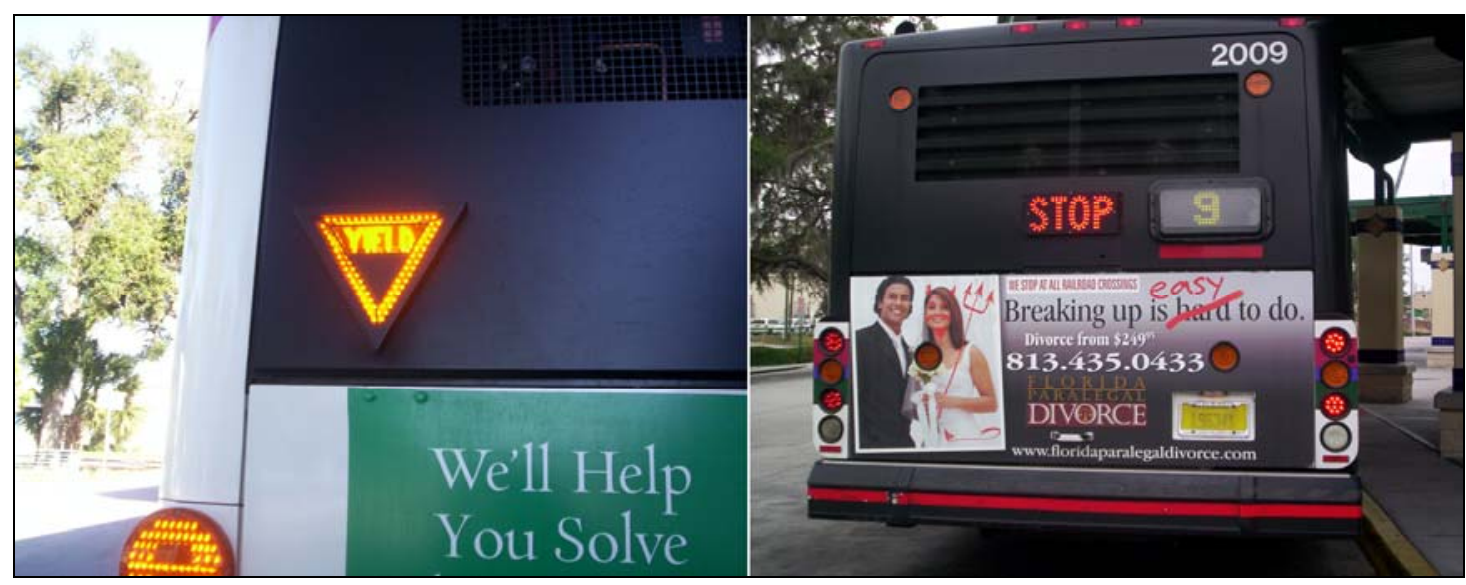

Figure 2 YIELD and STOP LED Lights

NHTSA has received many new ideas for stop lamp improvements over the last 30 years but they are reluctant to alter the current stop lamp configuration because it may create ambiguous signals. NHTSA acknowledges that it is possible to improve the current configuration, but only if there is scientific evidence to demonstrate that the change would yield net safety benefits (Lee et al. 2002).

\section{Yield-to-Bus Programs}

Bus stops located outside of the traffic lane help improve the flow of traffic behind the bus. However, during congested periods, it also creates difficulty for the bus to re-enter back into the flow of traffic. The re-entry delay of buses varies based on the degree of compliance to the laws (Lehman Center for Transportation Research, 2002).Yield-to-Bus (YTB) programs and bus priority programs in Europe were created to improve bus service and safety many years ago. Recently, some U.S. states have also passed laws requiring motorists to yield to buses re-entering a roadway.

\section{YTB Programs in Europe}

In the 1970s, several European countries initiated laws that allowed priority for buses leaving a bus stop. These European programs go under the name of bus priority systems and are comparable to the Yield-to-Bus programs in the United States, but are generally more extensive. Along with bus priority laws, in Germany, Austria, and Scandinavia, the distance between bus stops is widened to reduce the number of times a bus must decelerate, accelerate and re-enter traffic flows. In Western Europe, transit vehicles are given priority in traffic to a greater extent than the U.S.

In Great Britain, the sidewalk is extended to prevent obstructions of parked cars, create more space for queuing riders, and reduce the need for buses to maneuver in and out of the traffic stream (National Research Council 2001). In 1994, there was an initiative in London to improve bus service by setting up the London Bus Priority Network (LBPN). Bus bays have been used in London to allow cars to overtake stopped buses. However, they did have the same problems as the U.S. when attempting to re-enter the flow of traffic. To remedy this situation, one approach of the LBPN is to pave or infill the bus bay in order to re-create a flush curb at which the bus stops in the nearside traffic lane. 
This is intended to enable the bus to resume its route without delay, although it may cause the delay of other vehicles. Another approach is to have bus bays in exclusive bus lanes. Since regular traffic is not permitted in these lanes, there is no longer a problem when merging back into traffic (UK Department of Transportation 2003). The United Kingdom Highway Code 198 for buses, coaches and trams says, "Give priority to these vehicles when you can do so safely, especially when they signal to pull away from stops. Look out for people getting off a bus or train and crossing the road."

One of the aims of the priority system in Germany is to decrease the delay time for transit vehicles. Exclusive lanes are used alongside arterials with high bus volumes and frequent traffic jams. Another method used in Germany to improve transit service includes changing existing bus bays into street based stop areas called "buscape." Buses travel in a straight line along the street and car traffic is stored behind the bus when it makes a stop. This is similar to the treatment used in England; it increases the delay of cars but decreases the delay of buses (Brilon and Laubert 1994). Figure 3 shows the bus priority signs in the Europe and Australia.

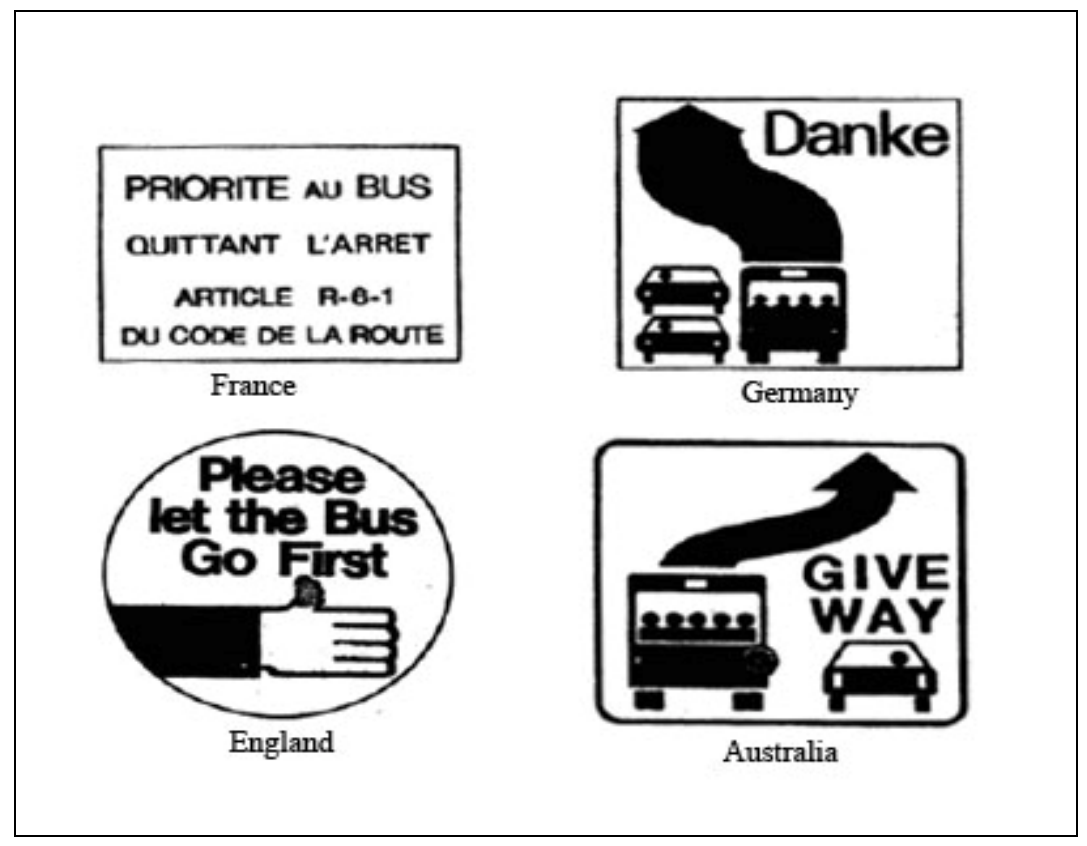

Figure 3 Bus Priority Signs in Australia and Europe

(Source: TCRP Synthesis 49)

\section{YTB Program in Canada}

In 2004, Ontario, Canada passed a Yield-to-Bus law similar to the ones in the U.S. The new law applies to all buses that bear the YIELD / CÉDEZ decal (Figure 4) near the left turn signal on the rear of the bus. When a bus displaying the sign is signaling its intention to leave a bus bay by activating the left turn signal, drivers approaching from the rear in the adjacent lane are required to slow down or stop to allow the bus to re-enter the lane, unless it is unsafe to do so. 


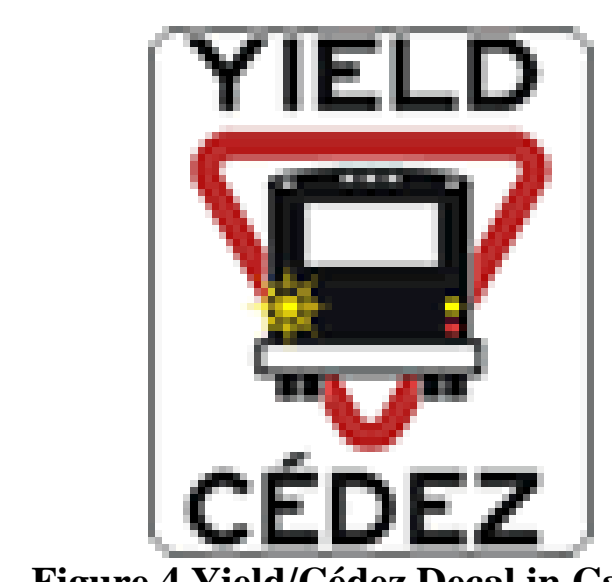

Figure 4 Yield/Cédez Decal in Canada

(Source: http://www.ottawa.ca)

Yield-to-Bus legislation has been in effect in Quebec since 1982. The law was drafted similar to the European laws. A decal is placed on the lower-left corner of the rear window of the bus. The decal consists of an inverted equilateral triangle with sides $38 \mathrm{~cm}$ and a red message on a white back ground (Figure 5).

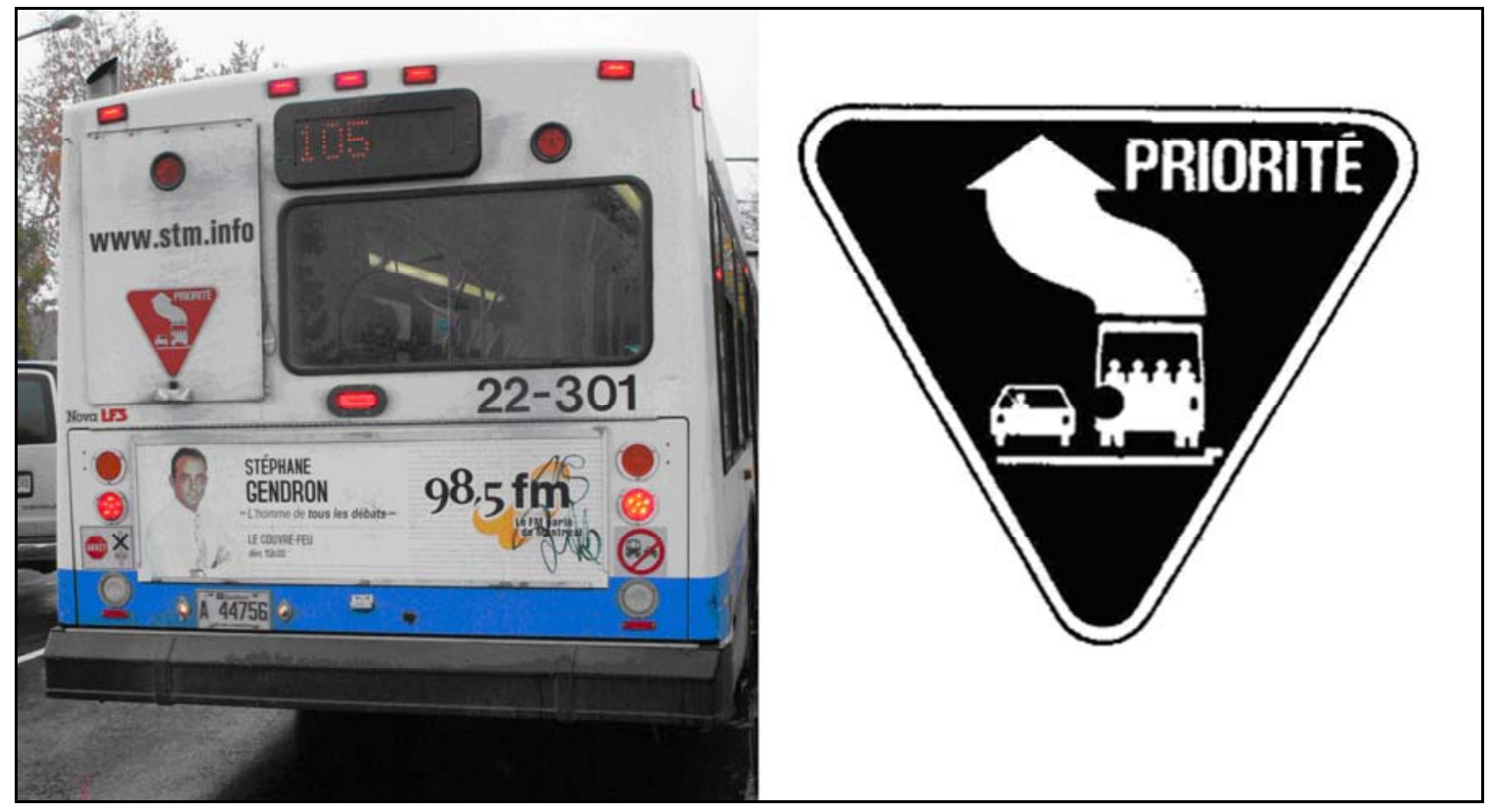

Figure 5 Bus Priority Sign in Canada

(Source: TCRP Synthesis 49)

YTB Program in the US

In the United States, the Yield-to-Bus legislation began in Washington State in 1993. The law is simple and does not specify the type of signs needed. Metro Transit in King County, Washington, created a YTB decal. Other transit agencies joined Metro Transit in 2002 for a public awareness campaign to raise awareness of the Yield-to-Bus law. A more detailed law was passed in Oregon in 1998. 
Different bus manufacturers use different rear lighting configurations for their buses, within the limits of NHTSA standards, and may change the configurations for different models of buses. Transit agencies also perform certain modifications on the buses or order special configurations from the manufacturers. Table 1 shows various modifications employed by transit agencies to improve safety or help with bus operations.

\begin{tabular}{|c|c|}
\hline Transit Agency & Technology \\
\hline Anchorage Transit, Alaska & $\begin{array}{l}\text { Implemented strobe lights and flashers } \\
\text { on the back of the bus since } 1986\end{array}$ \\
\hline British Columbia Transit, Victoria & $\begin{array}{l}\text { Converted from incandescent to LED } \\
\text { lights }\end{array}$ \\
\hline Ames Transit, Iowa & $\begin{array}{l}\text { Installed LED lights in } 1990 \text { and } \\
\text { included three turn lights at each side of } \\
\text { the rear of the bus }\end{array}$ \\
\hline Laketran, Ohio & $\begin{array}{l}\text { Double stop lights on each side of bus } \\
\text { plus } 2 \text { on each side of the rear number } \\
\text { sign. They also have double amber turn } \\
\text { signals, one of which is high-mounted. }\end{array}$ \\
\hline Duluth Transit Authority, Minnesota & $\begin{array}{l}\text { Installed amber flashing lights connected } \\
\text { to the rear door interlock since } \\
\text { passengers exit at the rear }\end{array}$ \\
\hline Houston Metro, Texas & $\begin{array}{l}\text { Experimenting with two additional red } \\
\text { flashing brake lights mounted high in the } \\
\text { center on the rear of the bus. }\end{array}$ \\
\hline Metro Transit, Seattle, Washington & $\begin{array}{l}\text { Uses LED brake lights for its new Gillig } \\
\text { buses. }\end{array}$ \\
\hline Link, Wenatchee, Washington & $\begin{array}{l}\text { Has used strobe lights at the front and } \\
\text { rear of the bus since } 1996 \text {. }\end{array}$ \\
\hline
\end{tabular}

\section{Table 1 Various Lighting Technologies Employed in North America}




\begin{tabular}{ll}
\hline Transit Agency & Technology \\
\hline Mutropolitan Atlanta Rapid Transit & $\begin{array}{l}\text { MARTA acquired buses with } 8 \text { inch } \\
\text { center brake lights that flash when bus is } \\
\text { braking. MARTA also has one bus with } \\
\text { amber lights in the upper corners and } \\
\text { believes this will be effective. MARTA } \\
\text { incorporates a new rear brake light } \\
\text { configuration. They removed the original } \\
\text { eight inch center brake light and } \\
\text { modified the existing amber and red } \\
\text { lights so that they flash when bus is } \\
\text { braking and stopped. MARTA uses } \\
\text { reflective tape on the sides and at the rear } \\
\text { of the bus to increase bus visibility. } \\
\text { High-mounted center red light and two } \\
\text { amber lights on each side of the red light. } \\
\text { The red light is steady while the amber } \\
\text { lights flash alternately when the brake is } \\
\text { pressed. }\end{array}$ \\
$\begin{array}{ll}\text { Plorida } & \text { Installed deceleration lights on their } \\
\text { entire fleet }\end{array}$ \\
\hline
\end{tabular}

\section{Current Practices}

According to TCRP Synthesis 49: Yield to Bus-State of Practice, the yield decals and flashing yield signals are the common lighting and signage currently used in North America on the back of buses to help them move safely back to traffic. Two types of flashing yield signals include (1) a flashing red triangle border with the word "Yield" flashing in the darkened center of the triangle used by transit agencies in California and Oregon; and (2) a white flashing LED yield signal with the word "Yield" in addition to the official yield decal used by transit agencies in British Columbia. The yield decals are similar but vary in size from 6 to 18 in. and display a red or black triangle on a yellow background with "Yield" or "Yield for Buses" messages.

\section{Costs of YTB Lighting and Signage}

The study results of TCRP Synthesis 49 indicated the costs for an installed electronic LED yield signal ranged from $\$ 250$ to $\$ 600$ per bus for the U.S. agencies and from $\$ 600$ to $\$ 800$ CAN (\$390 to $\$ 520$ US) per bus for the transit agencies in British Columbia. The costs for the yield decals ranged from $\$ 5$ to $\$ 20$ per decal.

\section{Location of the Yield Sign}

Another finding in TCRP Synthesis 49 is that the preferred location for the yield sign for two-thirds of transit agencies was approximately half way up and to the left side on the 
rear of the bus. The reason given for selecting the higher location was that the yield sign would be more visible to the second and third vehicles following the bus, those vehicles considered to be the most likely to yield. In Florida, the decals were in the lower-left corner of the bus, just above the bumper.

\section{Effects of Different Yield Signals and Lighting}

The survey results from TCRP Synthesis 49 showed that the different YTB lighting and signage designs had a great impact on the success of the YTB program. Nine of 10 transit agencies using a flashing light-emitting diode (LED) yield signal rated their YTB programs favorably from "satisfactory" to "excellent." However, eight of the nine transit agencies using only a yield decal were less satisfied and rated their YTB program as either "fair" or "poor."

\section{Decal Type 1 (Broward County, Florida)}

As shown in Figure 6, Broward County Transit (BCT) uses a reflective Yield-to-Bus (YTB) decal on the lower-left rear corner above the bumper of the bus. The decal is an equilateral triangle with sides approximately 18 inches in length. The triangle is red on a yellow background with white words on a black background. BCT also considered using an electronic flashing yield sign but they were concerned with electrical power load.

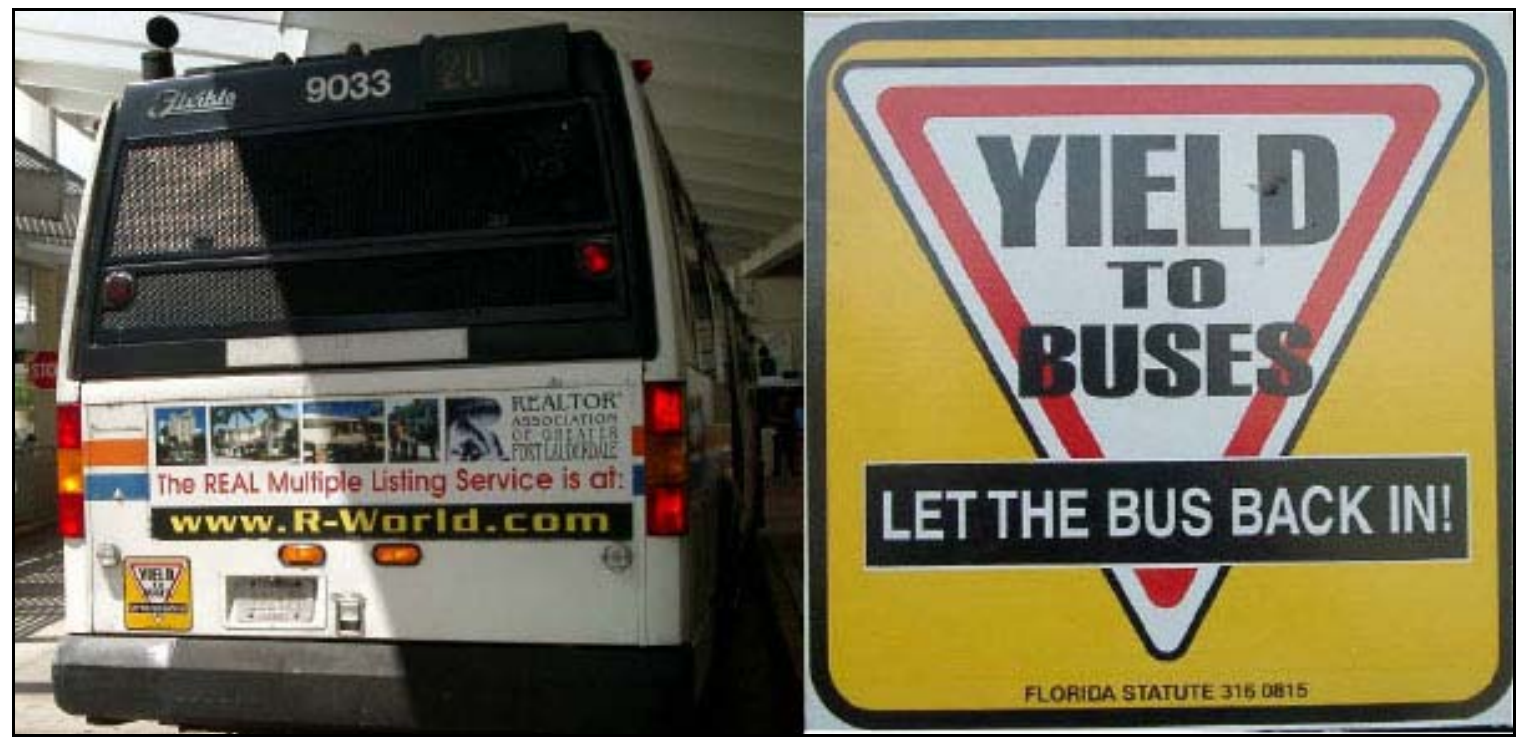

Figure 6 YTB Decal 1 (Broward County Transit)

(Source: TCRP Synthesis 49)

TCRP Synthesis 49 summarized the survey of 150 transit operators from Broward County Transit. When asked whether they believed that the yield sign has made merging from a stop safer, 67 percent of the operators responded that there was no change. The distribution of drivers' perception of safety of Decal 1 is shown in Figure 7. The operators also believed that very few motorists stopped when they indicated their intent to merge back into traffic, with 60 percent of them indicating that less than 10 percent of motorists yield. When asked whether the YTB sign was helpful in driving the bus, 66 
percent of the operators responded that there was no difference. The perception of drivers' yield behavior of Decal 1 is shown in Figure 8 .

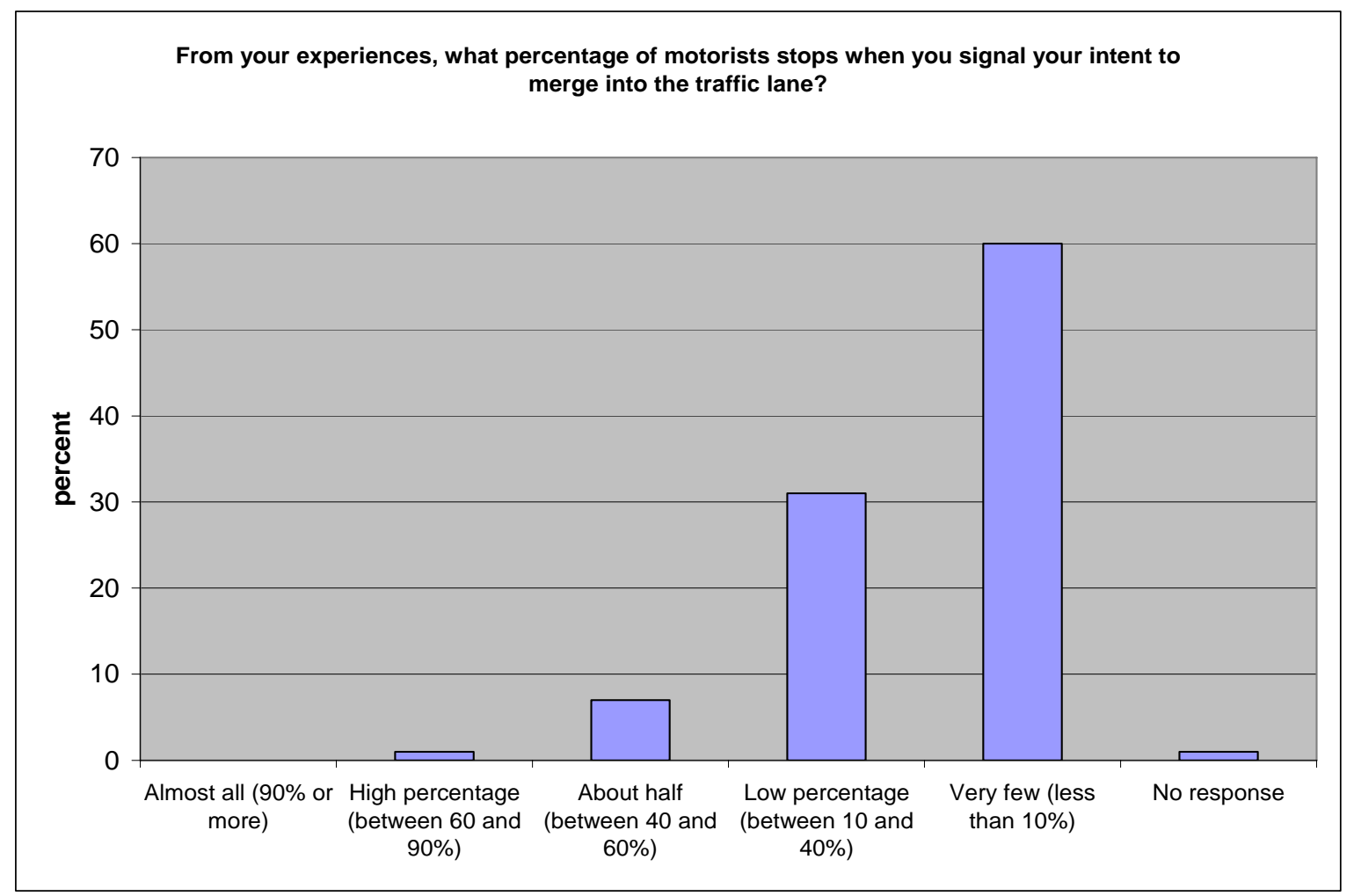

Figure 7 Operators' Perception of Improved Safety for Decal 1

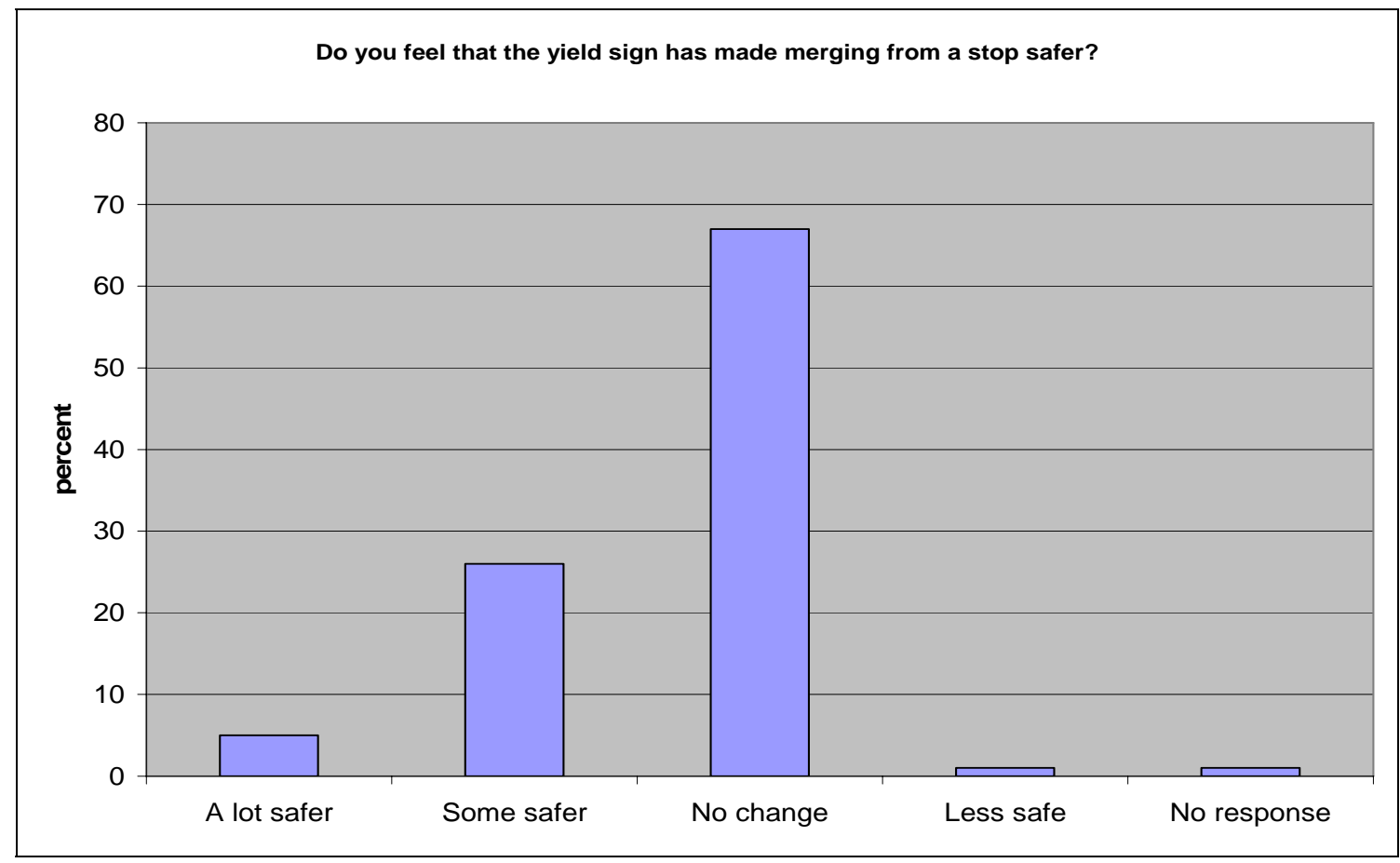

Figure 8 Driver’ Yield Behavior for Decal 1 
YTB Decal 2 (Coast Mountain Bus Company, British Columbia)

As shown in Figure 9, Coast Mountain Bus Company (CMBC) uses a reflective square decal with sides approximately 10 inches in length. Inside the square is a red equilateral triangle on a yellow background. Inside the triangle is white with "Yield" written in black letters and the silhouette of a bus below it. The decal is located to the left of the rear window on the back of the bus. A decal was chosen over the electronic yield sign because the decal was significantly less expensive. However, some CMBC buses that operate in West Vancouver use the LED yield sign in combination with the decal. On the rear bumper, CMBC also includes a YTB-related decal signs that say "Thanks for the Brake" and "Please Yield it's the Law", as shown in Figure 10.

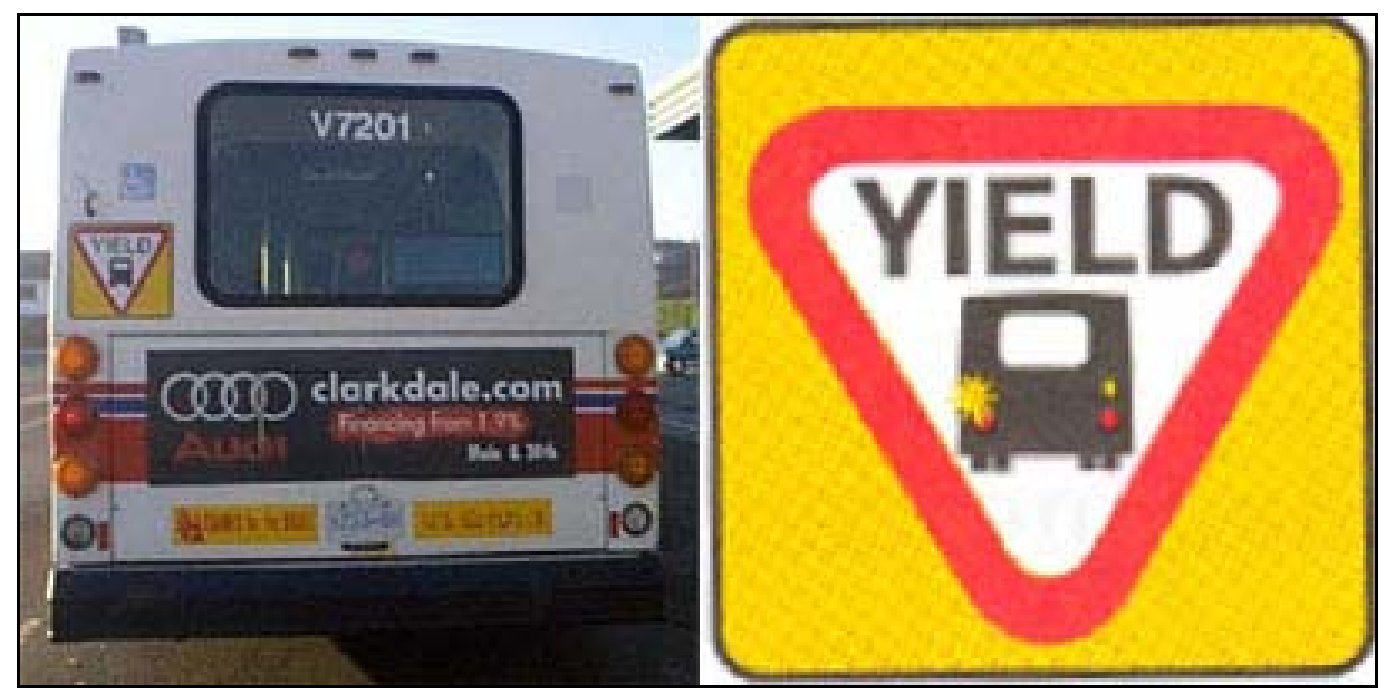

Figure 9 YTB decal 2 (Coast Mountain Bus Company)

(Source: TCRP Synthesis 49)

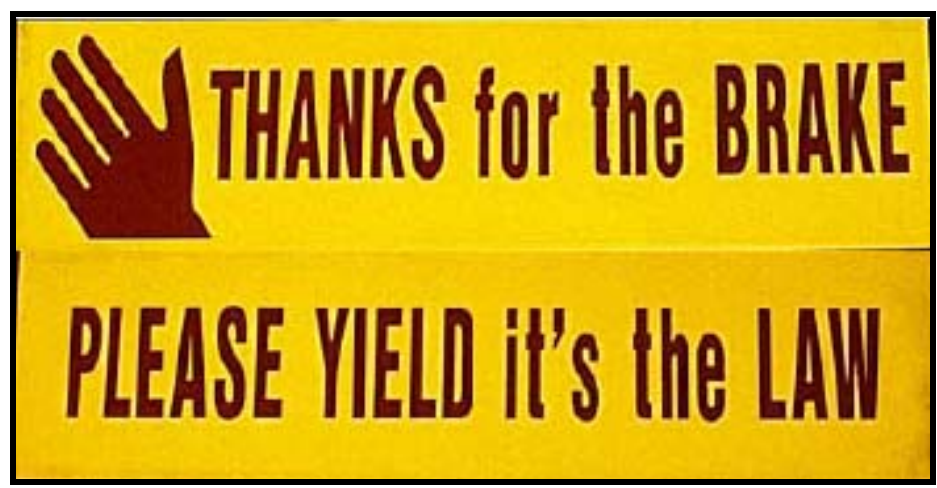

Figure 10 YTB-related decal signs by CMBC

(Source: TCRP Synthesis 49)

TCRP Synthesis 49 summarized the survey of 167 transit operators from Coast Mountain Bus Company. When asked whether they believed that the yield sign has made merging from a stop safer, 59 percent of the operators responded it was somewhat safer. The detailed survey results are shown in Figure 11. When asked what percentage of motorists 
stop when bus operators signal their intent to merge into the traffic lane, most operators responded with a low percentage. The detailed survey results are shown in Figure 12.

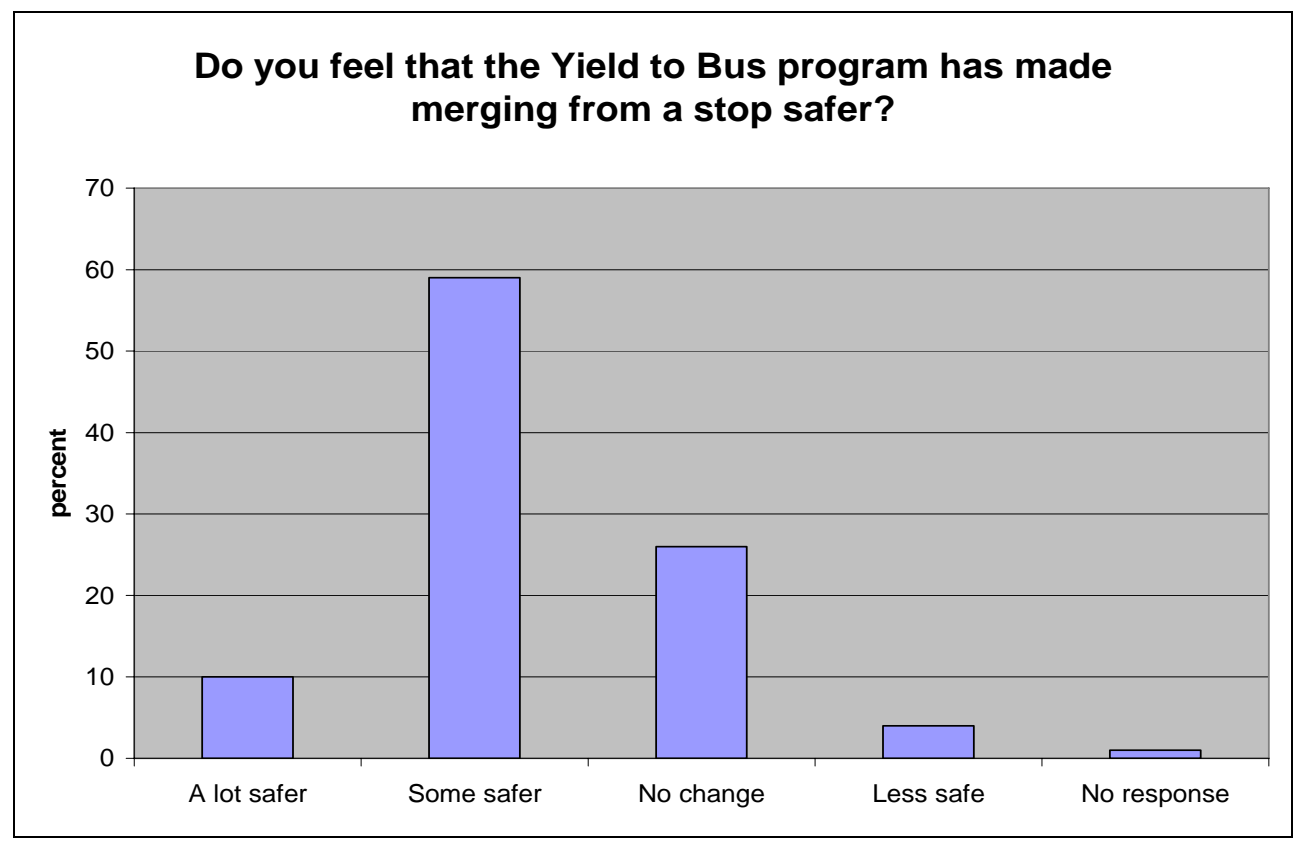

Figure 11 Operators' Perception of Improved Safety by Decal 2

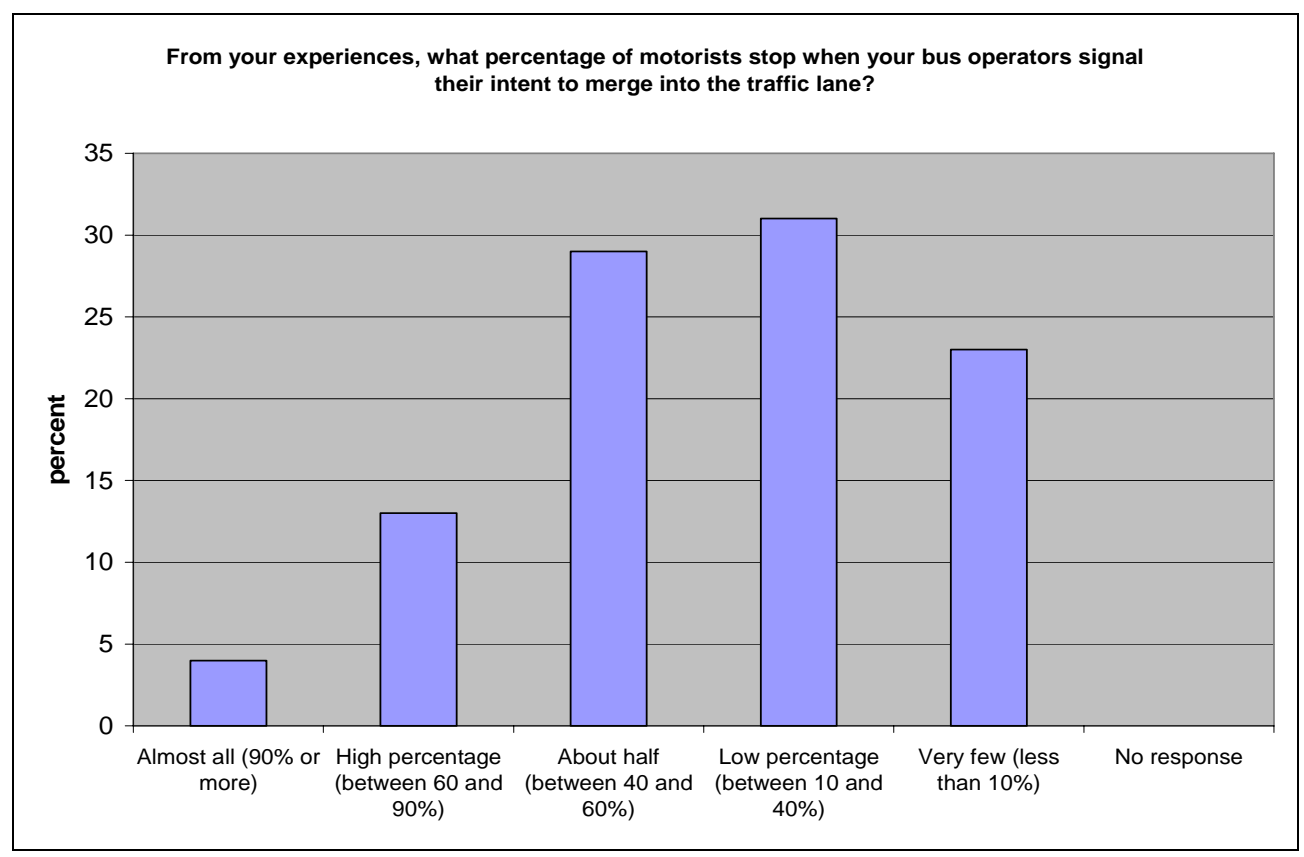

Figure 12 Perception of Drivers’ Yield Behavior by Decal 2 


\section{YTB Decal 3 (Metro Transit, King County, Washington)}

Metro Transit uses a reflective decal located to the left of the rear window on the back of the bus. They chose this location because a lower location was believed to be too difficult for the second and third following vehicle to see. The decal consists of a red triangle on a yellow back ground. Inside the triangle is white with the word "Yield" inside and "For Buses” directly below the triangle as shown in Figure 13.

A survey response from Washington stated that the electronic version of the yield sign is promising but the decal might as well not be there. Figure 14 shows the survey response from Metro Transit bus operators about the effectiveness of the YTB program. Metro Transit also uses LED brake lights at the rear of its new Gillig buses and these buses exhibit a 40 percent lower rear-end accident rate than the buses with conventional brake lights (Technology and Management Systems, Inc. 2001).

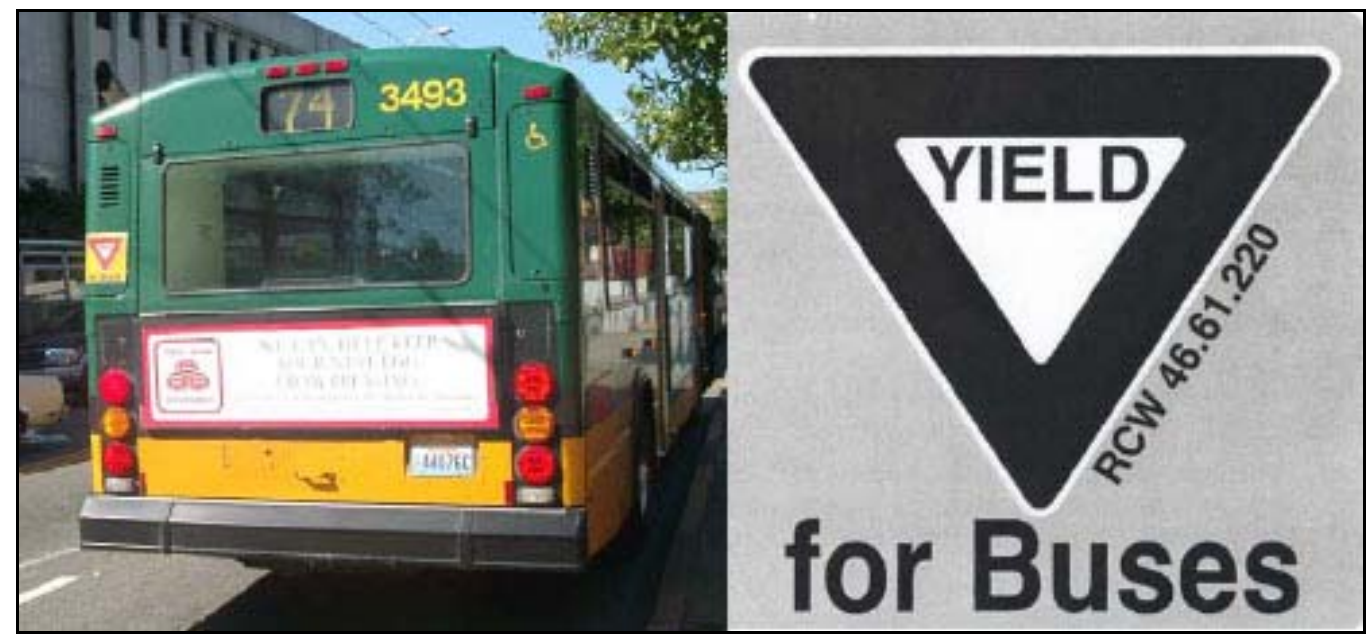

Figure 13 Metro Transit with YTB decal

(Source: TCRP Synthesis 49) 


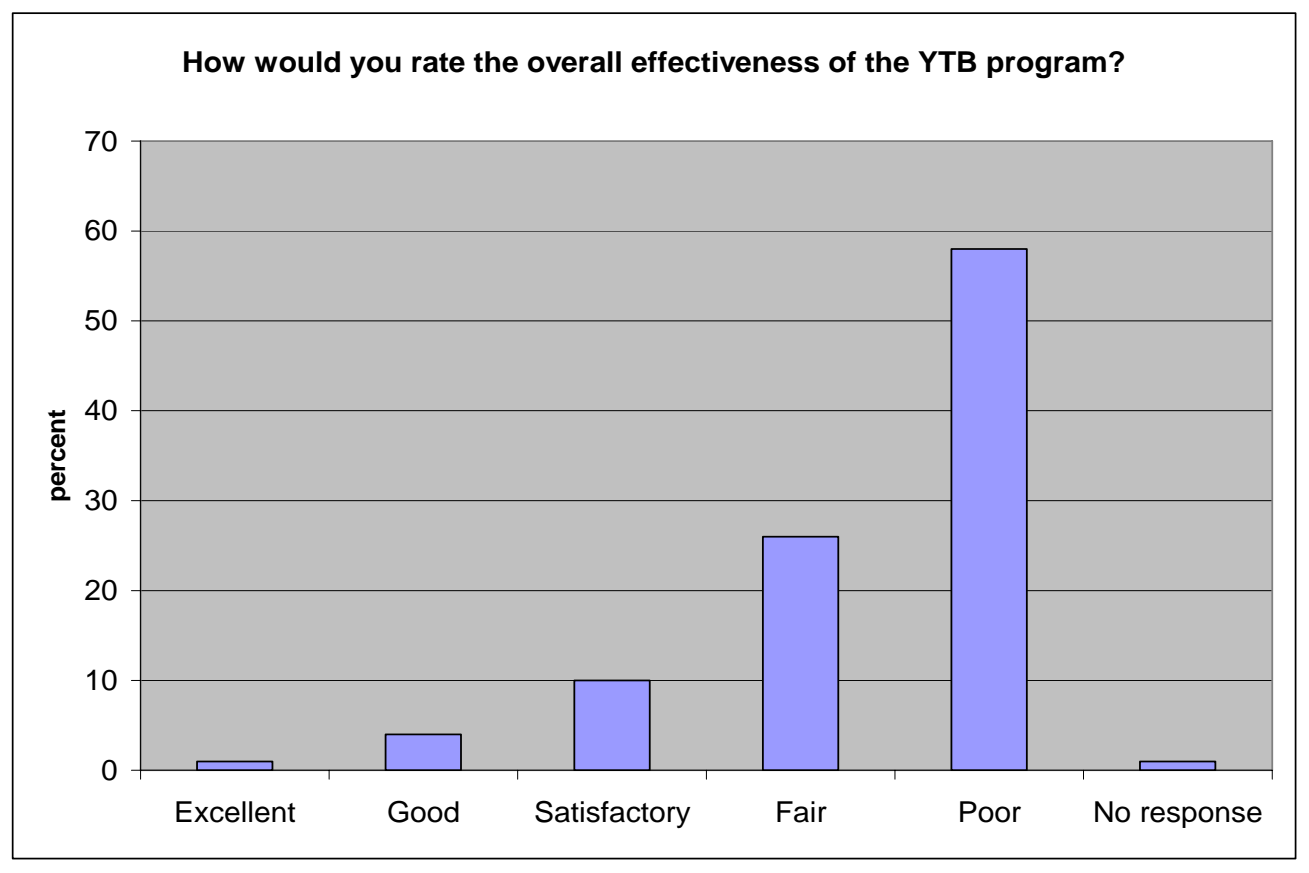

Figure 14 Bus Operators' Survey Response

\section{Comparison of Decal 1 and Decal 2}

Decal 1 and Decal 2 are very similar, except for the location of each decal on the back of bus. Decal 1 is installed just above the bumper, and Decal 2 is installed at half way up and to the left side on the rear of the bus, as shown in Figure 15.

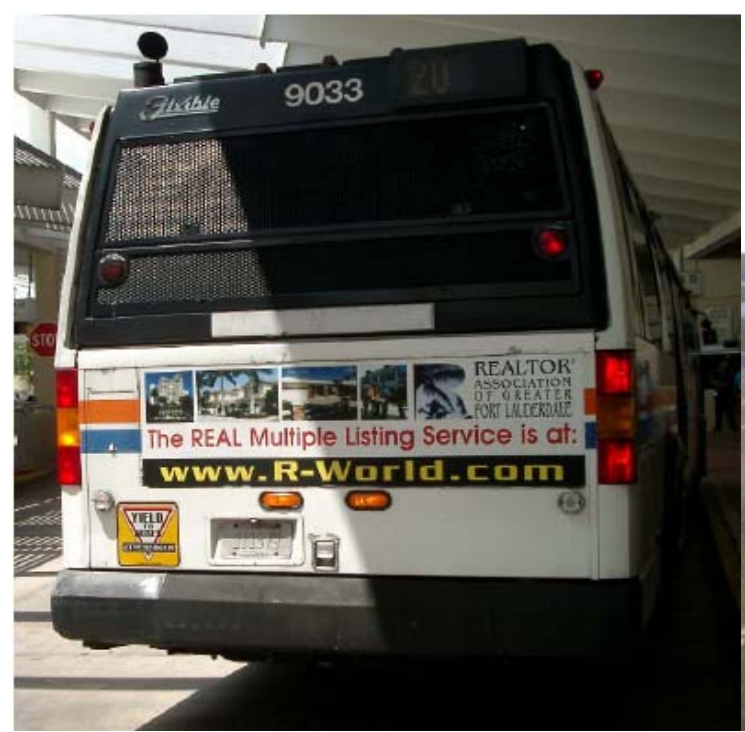

Decal 1

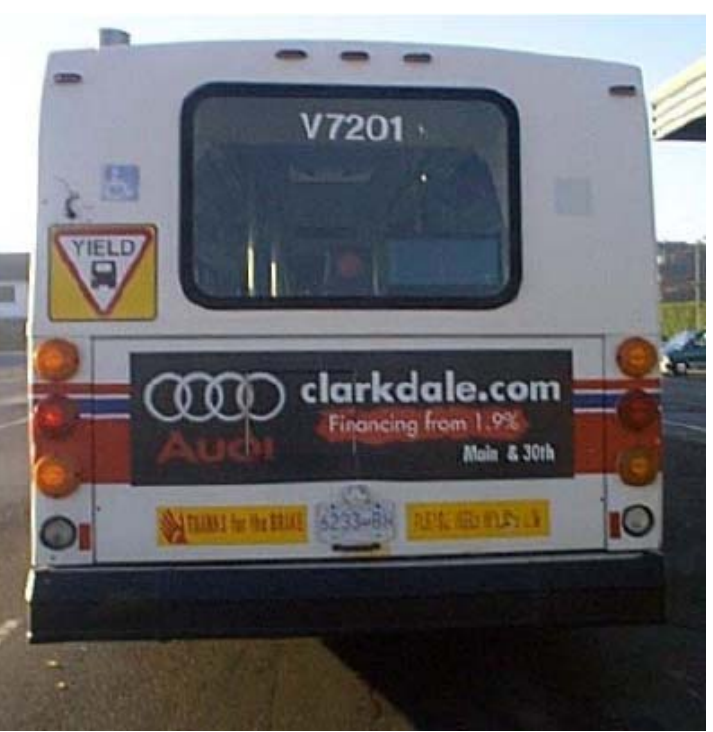

Decal 2

Figure 15 Locations of Decal 1 and Decal 2 
The survey results in TCRP 49 showed the different perception of improved safety and drivers' yield behavior between the two decals, as shown in Figures 16 and 17 . Decal 2 installed at the higher location was found to have a better perception of yield behavior and improved safety.

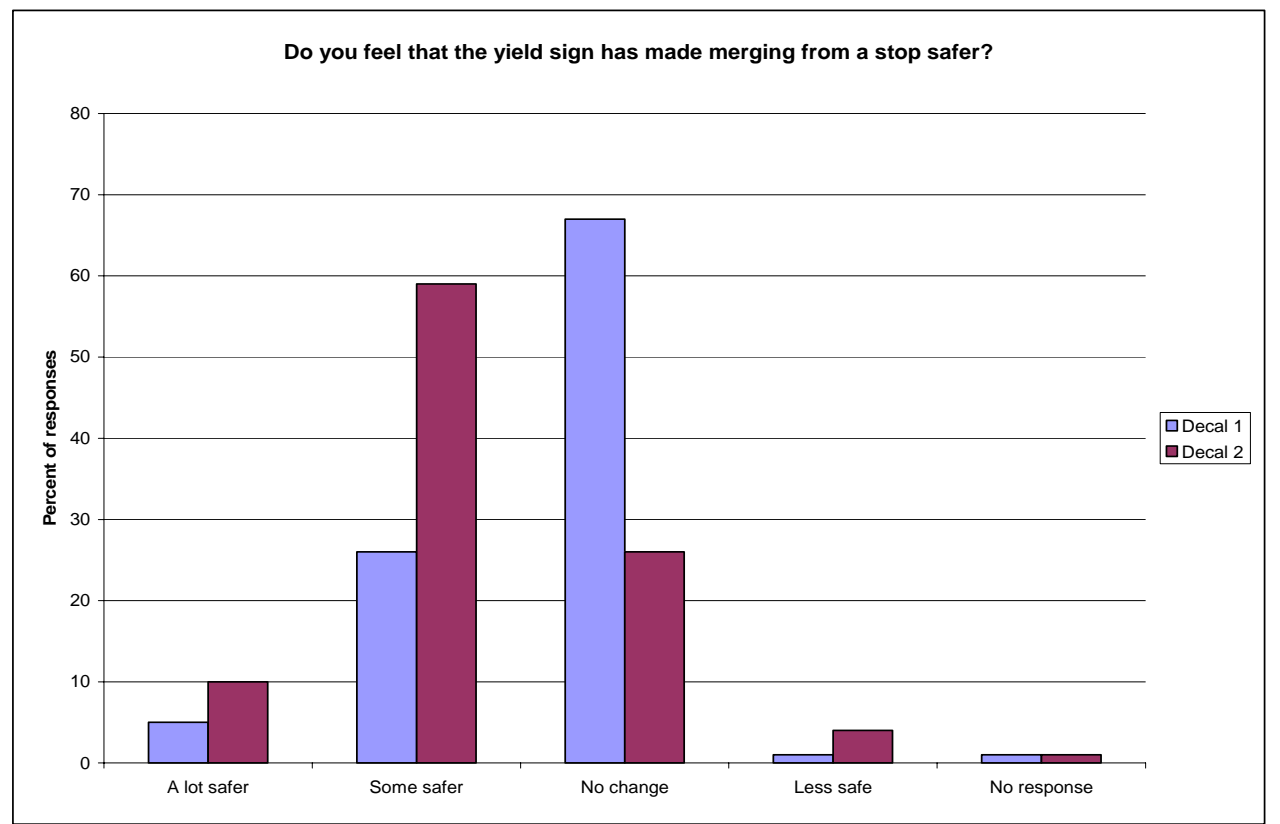

Figure 16 Comparison of Bus Operators' Perception of Yield Behavior

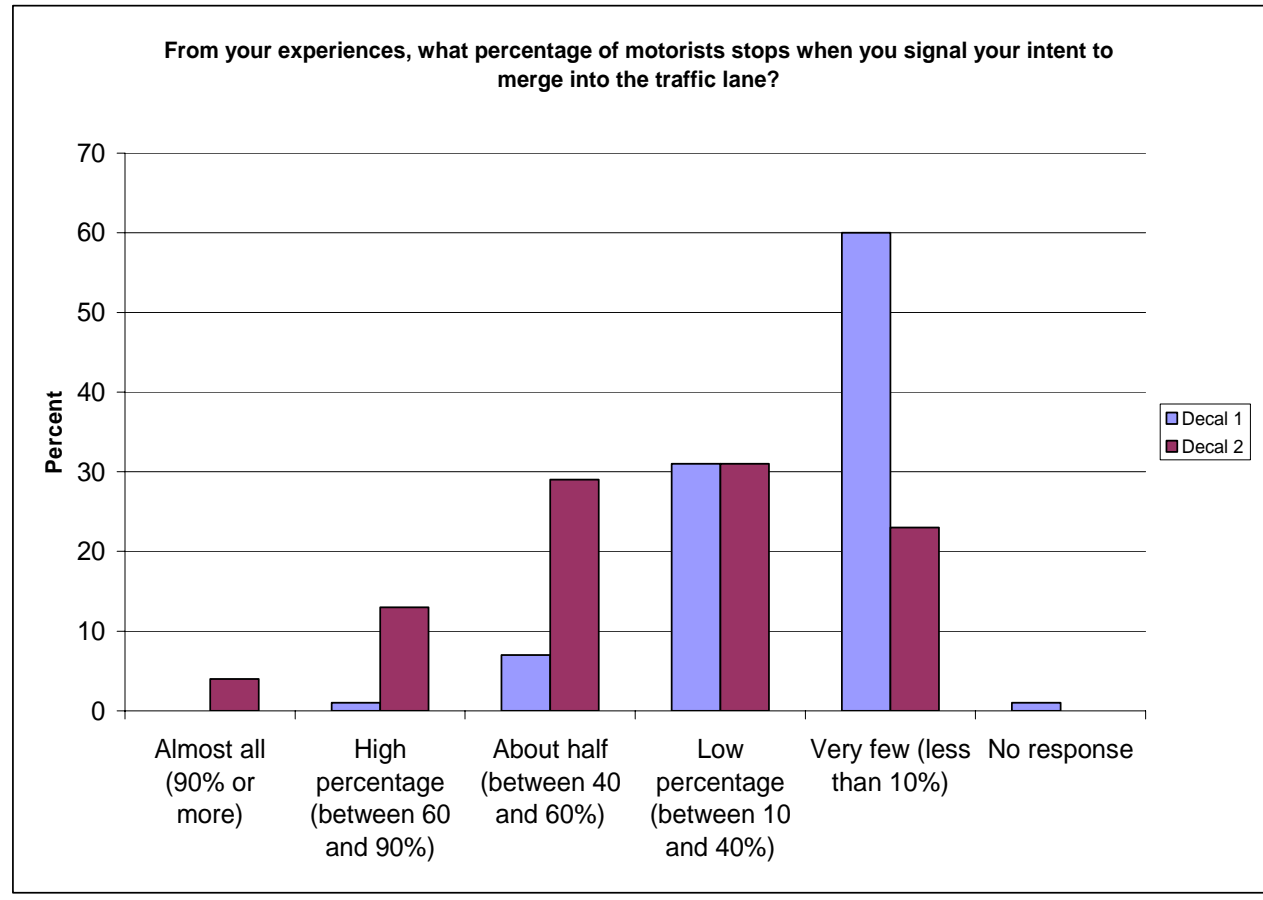

Figure 17 Comparison of Two Decals in Perception of Yield Behavior 


\section{YTB LED Yield Sign 1 (British Columbia Transit)}

British Columbia (BC) Transit uses a six inch square reflective yield decal and a LED yield sign as shown in Figure 18. Inside the square is a red equilateral triangle on a yellow background. Inside the triangle is white with "Yield" written in black letters and the silhouette of a below it. This decal is used throughout British Columbia and is similar to the CMBC decal. The LED yield sign is located in the lower-left corner of the rear window.

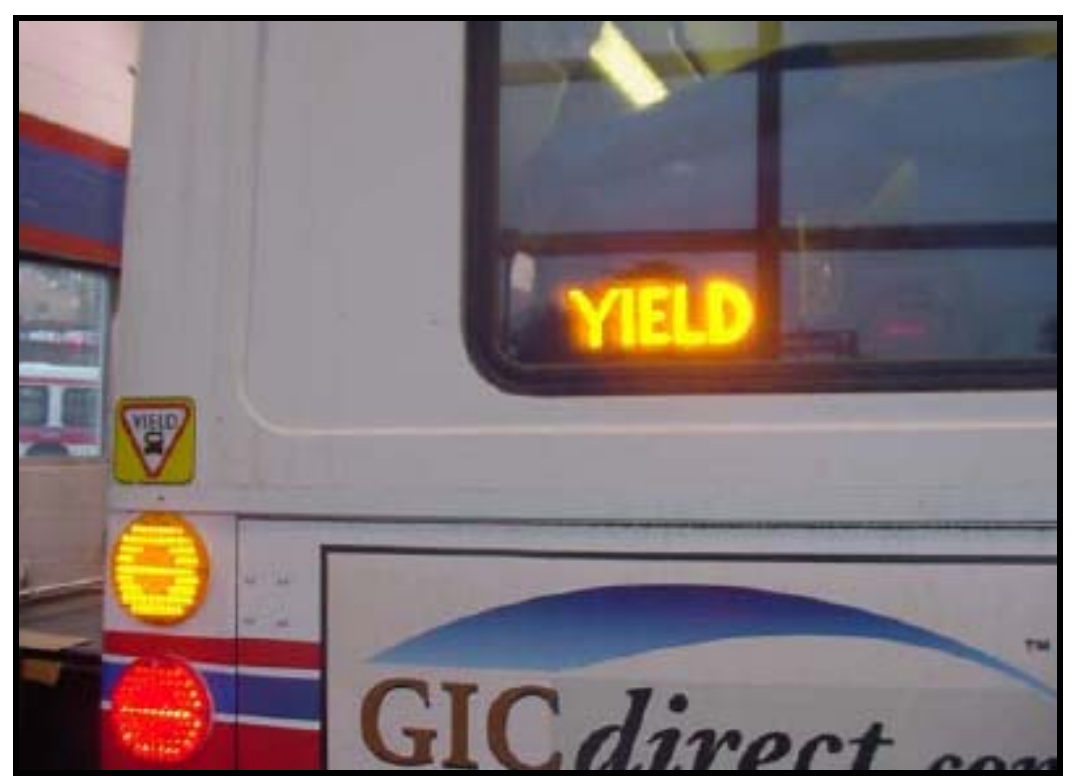

Figure 18 British Columbia Transit YTB decal and Yield LED Sign

(Source: TCRP Synthesis 49)

\section{YTB LED YIELD SIGN 2 (Tri-County Metropolitan Transportation District, Oregon)}

In Oregon, specifications have been developed by the Oregon Transportation Commission for a yield sign that includes a 6.75 inch tall triangle with the word "Yield" inside. Both the triangle and yield message must be red when flashing. Tri-County Metropolitan Transportation District (Tri-Met) uses a red LED flashing yield sign with a triangle that is approximately eight inches on each side as shown in Figure 19. The flashing yield sign is located on the lower-left corner above the bumper. A control switch is used by the bus operator to activate the yield sign. The operator first activates the amber turn signal then the yield sign. The yield sign is deactivated when the left turn signal switch is released. 


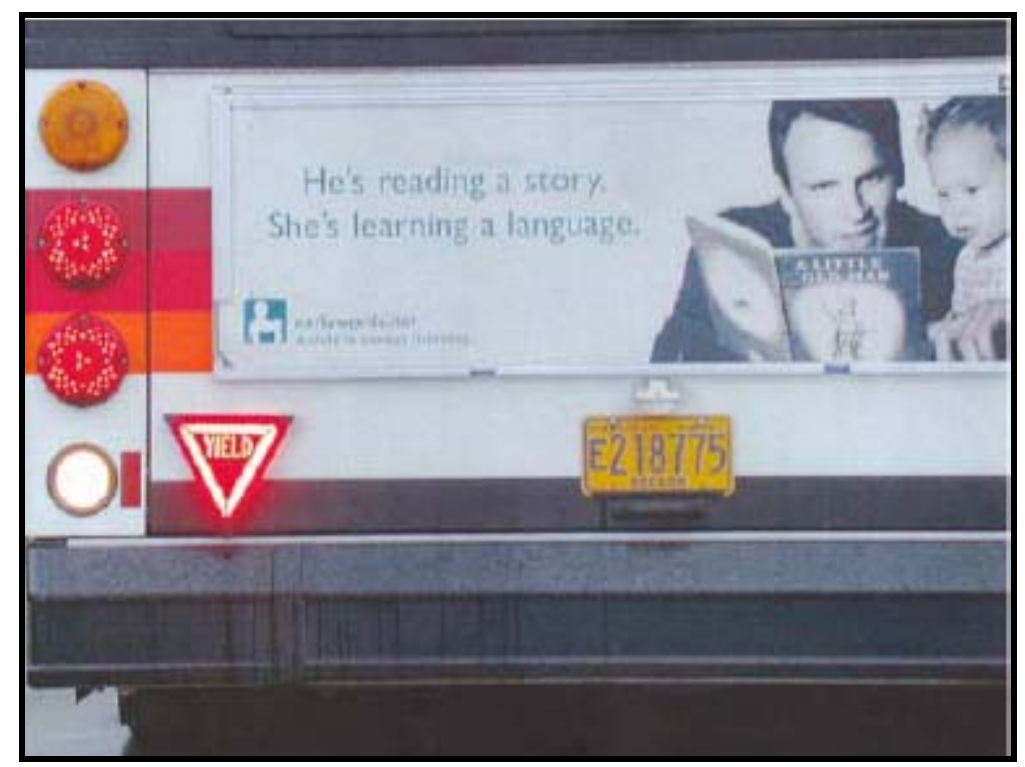

Figure 19 Tri-Met LED Yield sign

(Source: TCRP Synthesis 49)

In the TCRP Synthesis survey of Tri-Met bus operators, there was a positive response for the operators' perception of safety when using the yield signal (Figure 20). The majority of bus operators also felt that other road users allowed them to merge back into traffic most or at least some of the time (Figure 21).

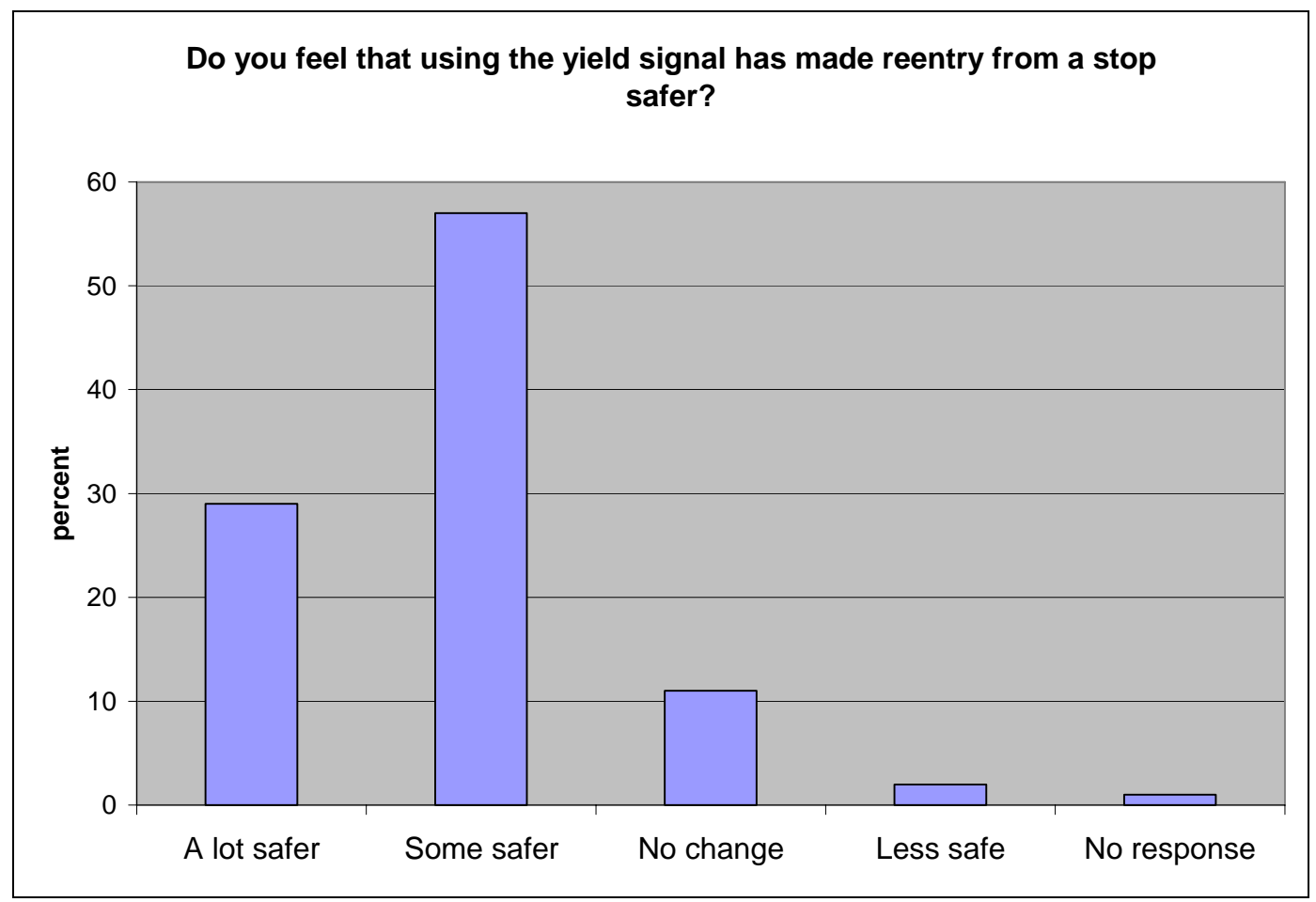

Figure 20 Tri-Met Bus Operators' Perception of Safety 


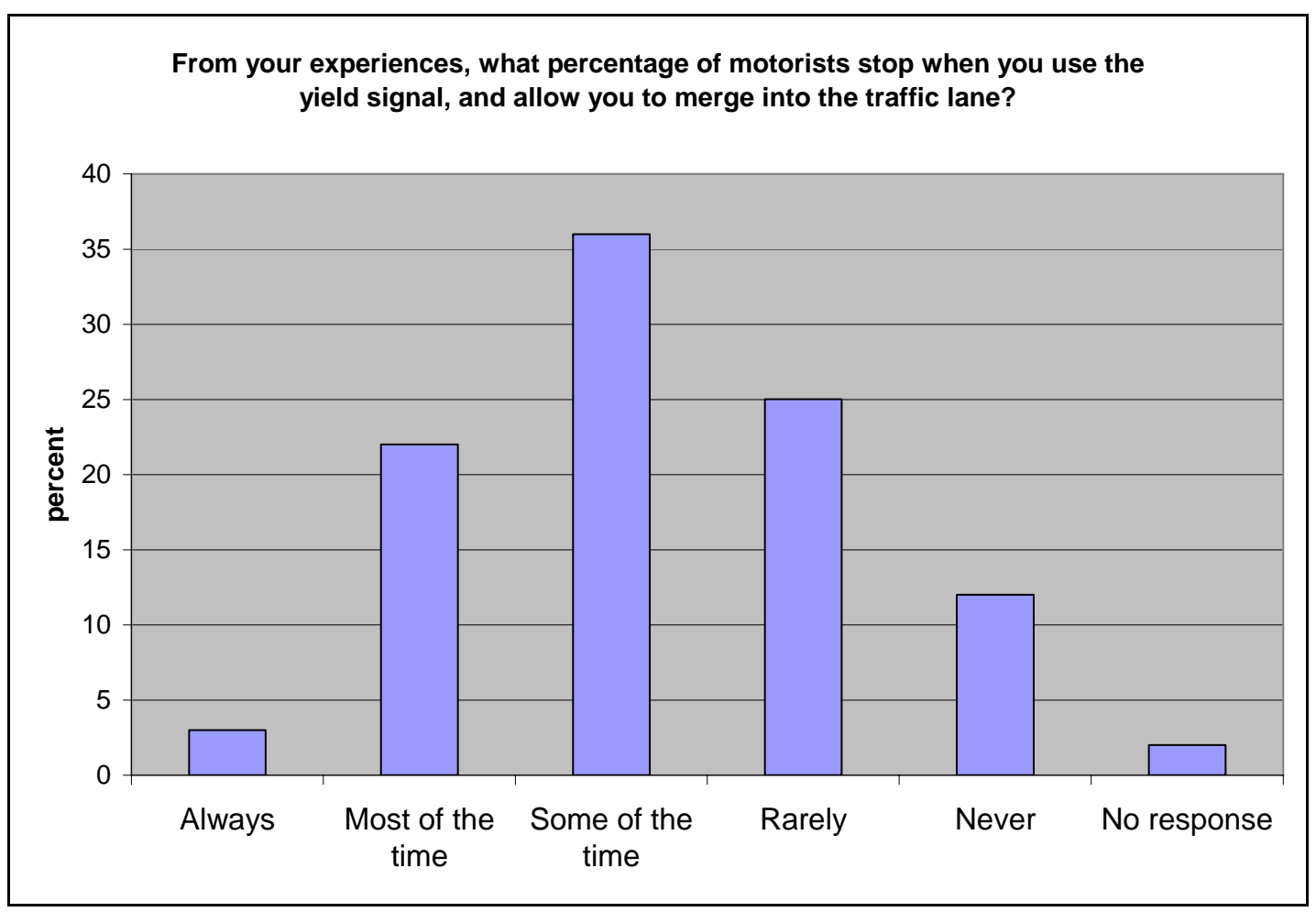

Figure 21 Tri-Met Bus Operators' Perception of Yield Behavior

\section{Santa Clara Valley Transportation Authority and Santa Cruz Metropolitan Transit District, California}

California law requires that buses be equipped with a yield right-of-way sign on the left rear of the bus. The sign must be illuminated by a flashing light when the bus is signaling to enter a traffic lane. The Santa Clara Valley Transportation Authority and the Santa Cruz Metropolitan Transit District use the same flashing yield sign as Oregon, mounted on the rear left of the bus above the engine access door as shown in Figures 22 and 23. The yield sign is activated first, followed by the left turn signal and both signals will stop when the left turn signal is turned off. Arming the yield signal first allows the bus operator to have both hands on the steering wheel when pulling out from a stop. After 10 to 15 seconds, the yield sign deactivates; therefore, if the operator cannot move before then, the left turn signal must be released and the yield control button pushed again. 


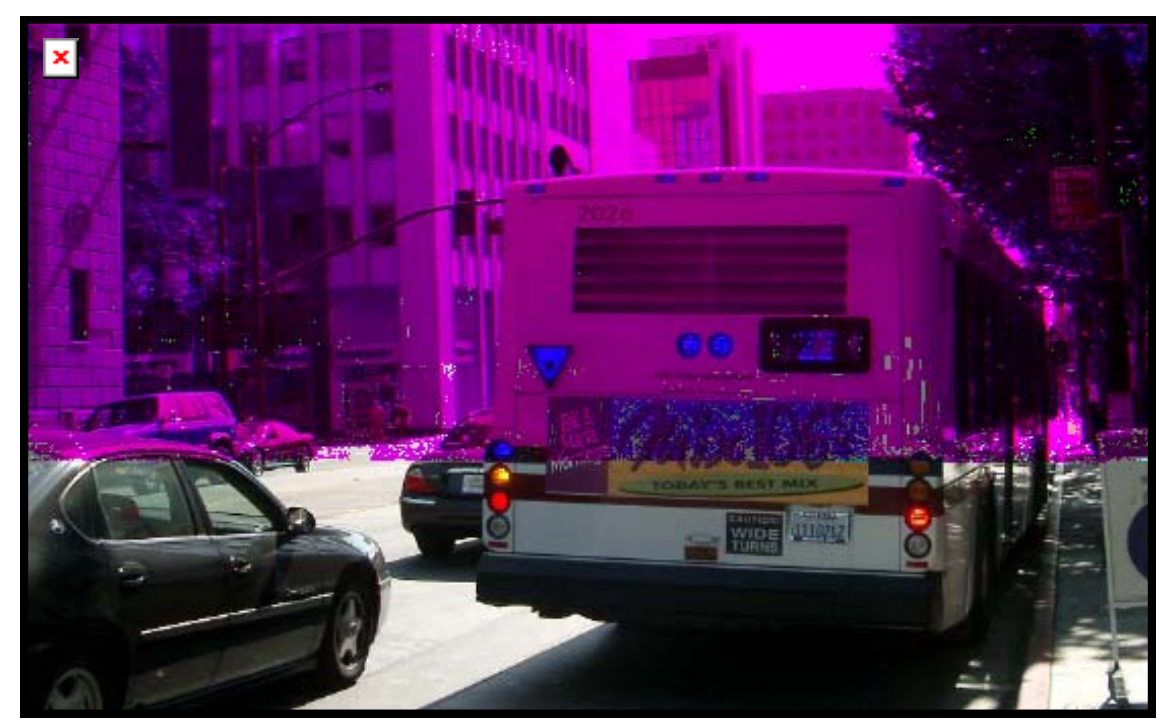

Figure 22 Santa Clara Valley Transportation Authority Bus with LED Yield Sign (Source: TCRP Synthesis 49)

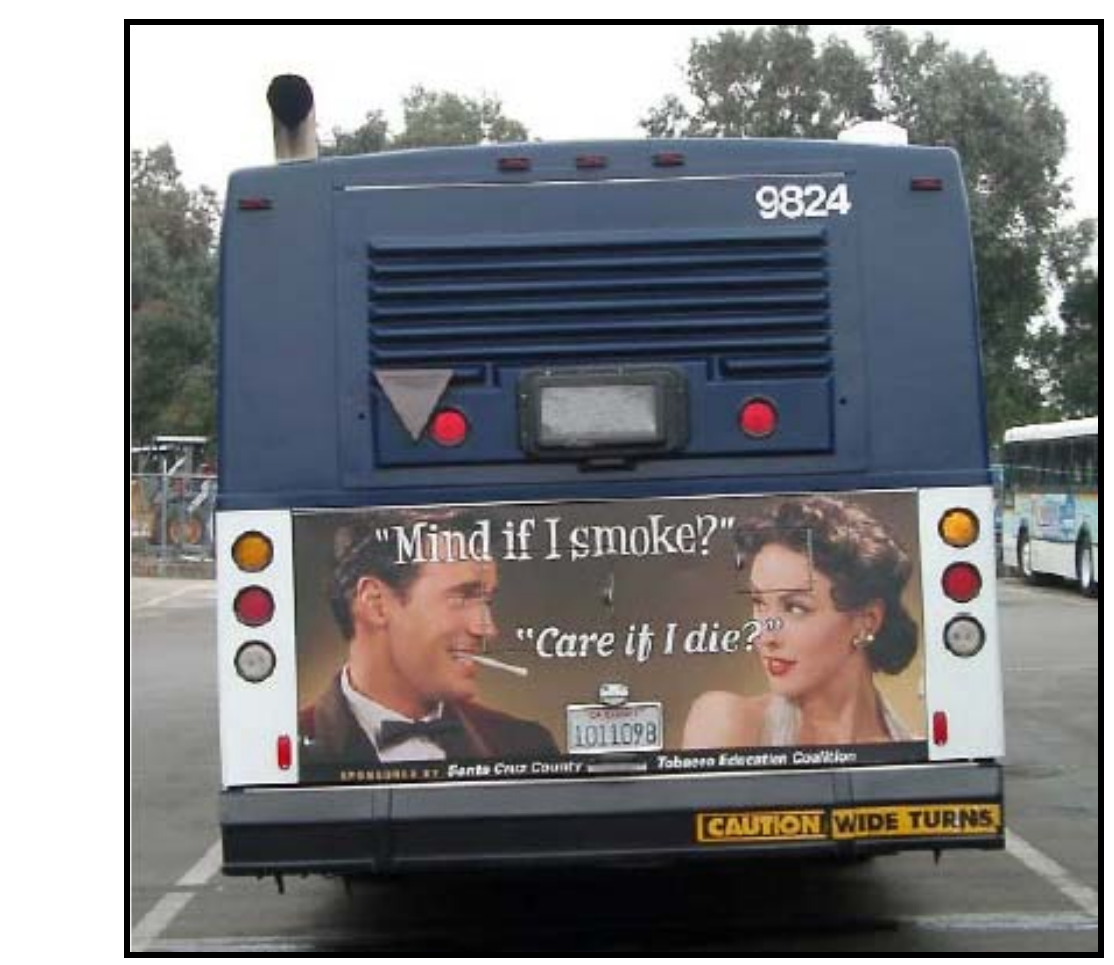

Figure 23 Santa Cruz Metropolitan Transit Bus with Yield LED Sign

(Source: TCRP Synthesis 49)

One of the survey questions for bus operators in TCRP Synthesis 49 was for the operators' perception of drivers' yield behavior with and without the use of the flashing yield signal. Bus operators at VTA had a more positive perception of drivers' yield behavior when using the flashing decal (Figure 24). The majority of bus operators also had a positive perception on the helpfulness of the yield signal in their bus operation (Figure 25). 


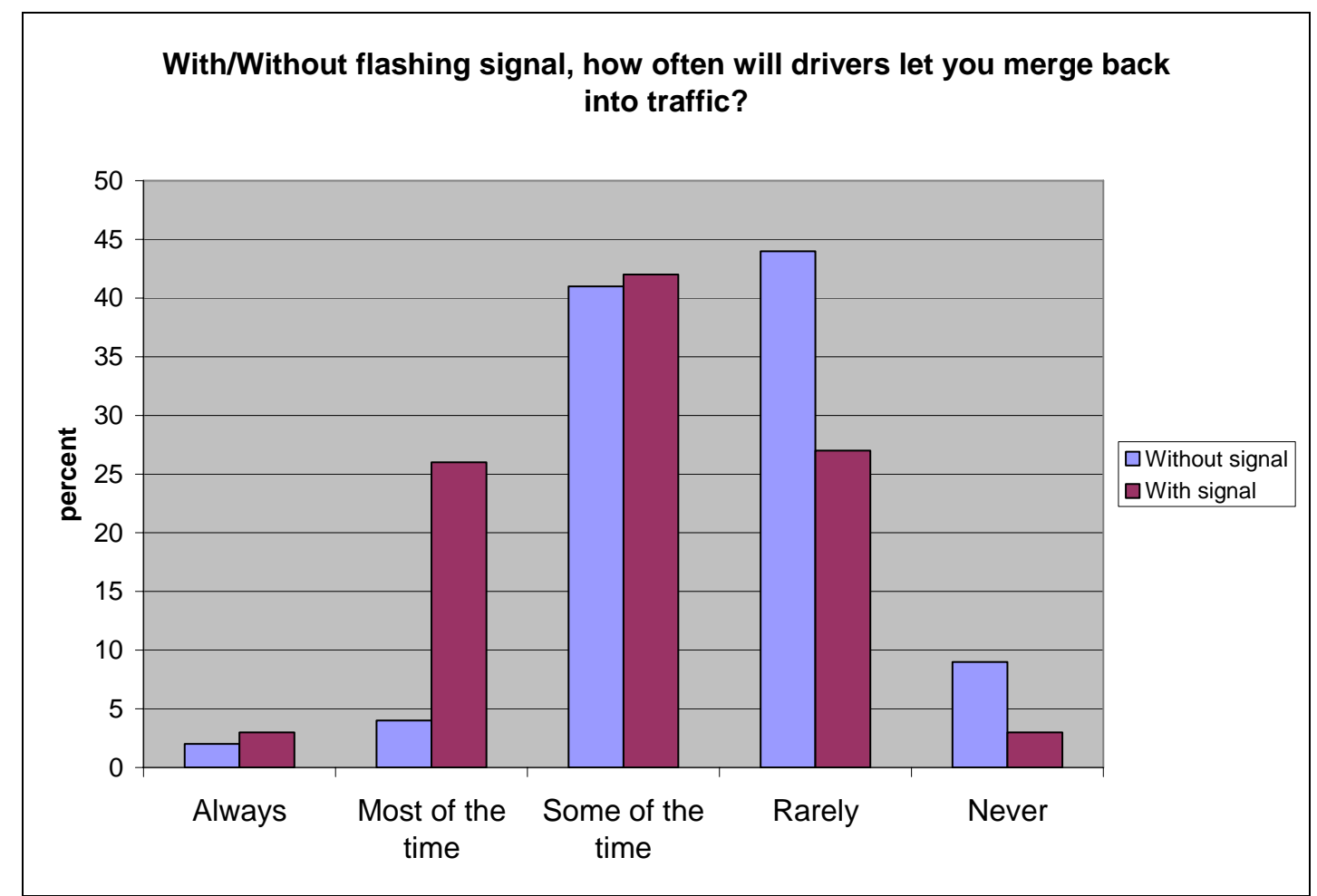

Figure 24 VTA Bus Operators' Perception of Yield Behavior

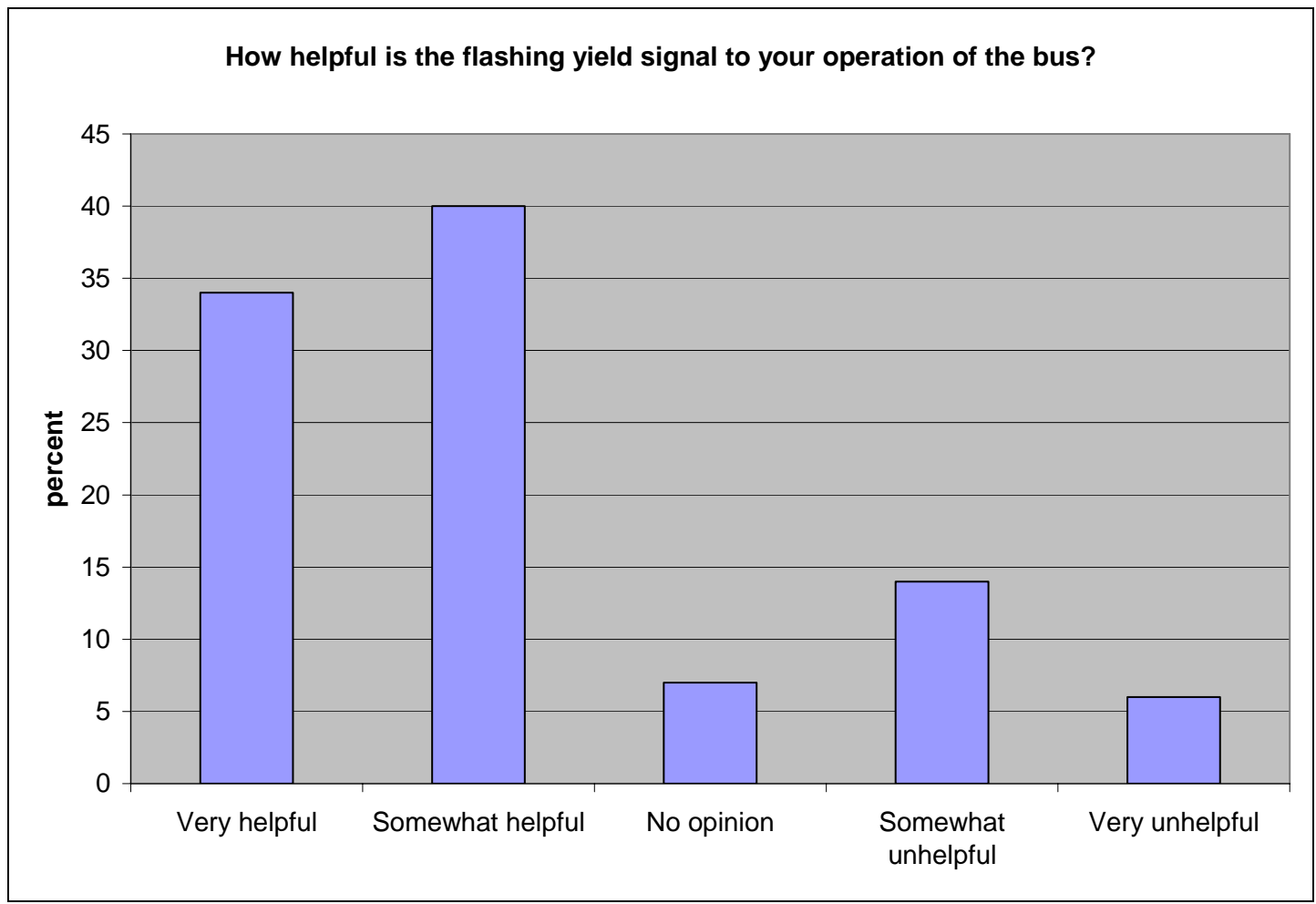

Figure 25 VTA Bus Operators' Perception of Flashing Yield Signal 


\section{Metro Transit, Minnesota}

The Metro Transit decals feature a red yield sign along with a reference to the Minnesota statute that gives buses priority as shown in Figure 26. The decals are being positioned on the left side and above the brake lights for maximum visibility. These decals have only recently been developed even though the law requiring motorists to the yield to the bus has been around for many years.

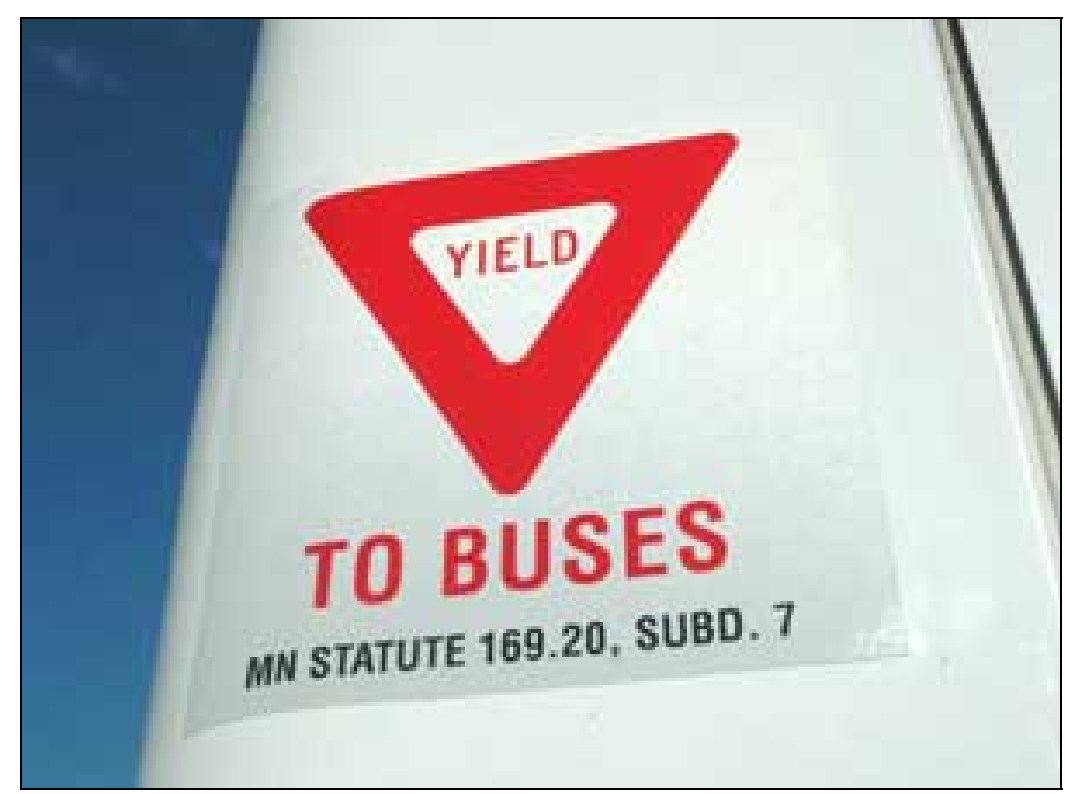

Figure 26 Metro Transit Decal

(Source: http://www.metrocouncil.org/Directions/transit/transit2006/yield.htm)

\section{Transit Agency Practice Comparisons}

Of the five transit agencies that were highlighted in TRCP Synthesis 49, two of these used a similar YTB decal. Coast Mountain Bus Company (CMBC) and Broward County (BC) Transit both use a similar decal, but the CMBC decal is placed higher than the BC Transit decal. CMBC also has additional decals above the bumper. In the perception of safety, the CMBC operators have a more positive response compared to BC Transit operators. CMBC operators also perceive higher motorist yield rates than the $\mathrm{BC}$ Transit operators. Tri-Met uses a red LED flashing yield sign, and the operator's perception of safety for this sign is higher than that of the CMBC decal. 


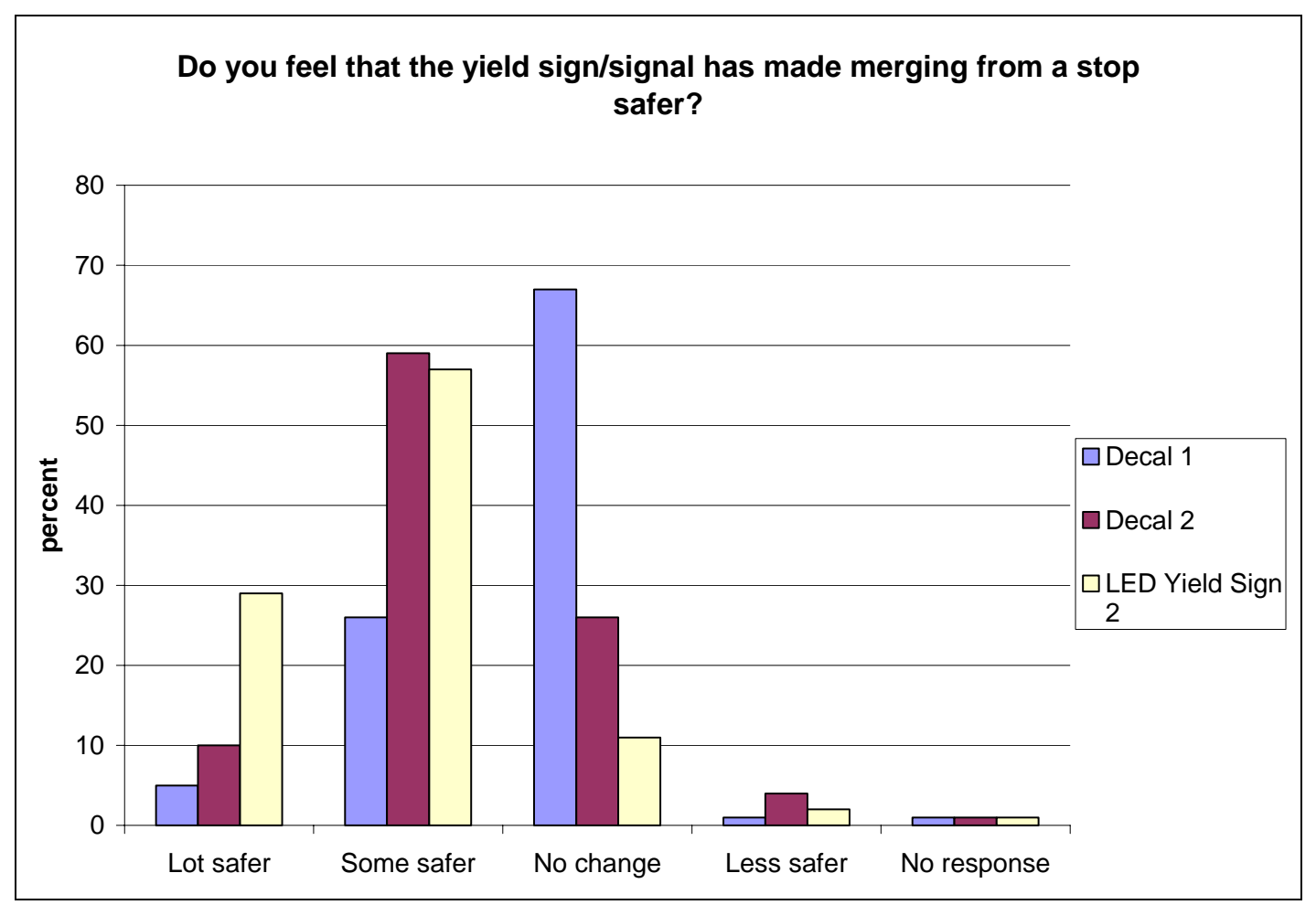

Figure 27 Comparison of Three Transit Agencies on the Perception of Safety With Yield Decal or Signal

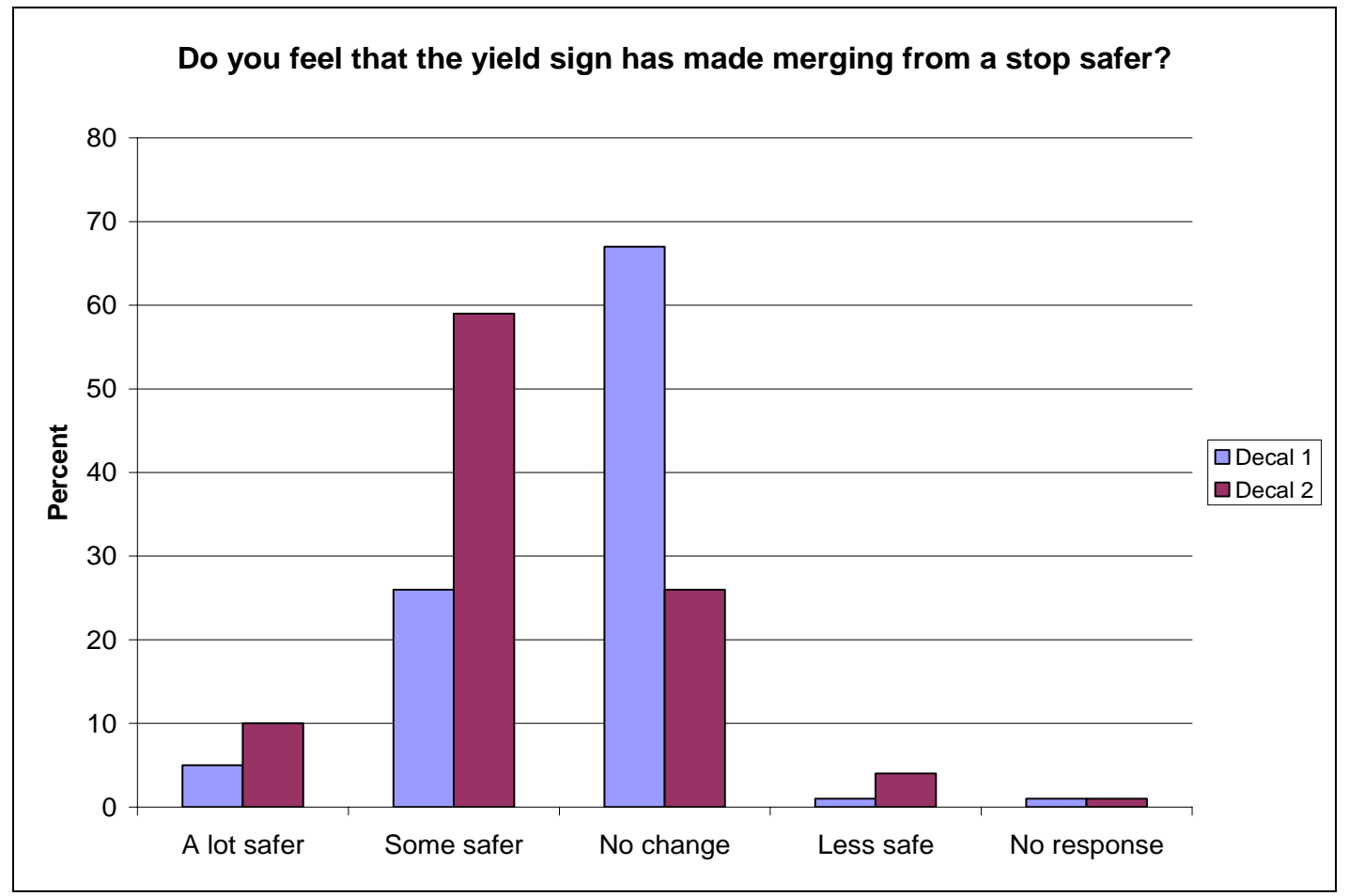

Figure 28 Comparison of Bus Operators' Perception of Yield Behavior for Decal 1 (BCT) and Decal 2(CMBC) 
In TCRP Synthesis 49, Tri-Met bus operators were asked what percentage of motorists stop and allow them to merge into the traffic lane when they use the yield signal. Similarly, Santa Clara Valley Transportation Authority (VTA) bus operators were asked how often drivers let them merge back into traffic. LED Yield Sign 3 (VTA) had a slightly more positive response than LED Yield sign 2 (Tri-Met) when the operators were asked about their perception of driver yield behavior (Figure 29).

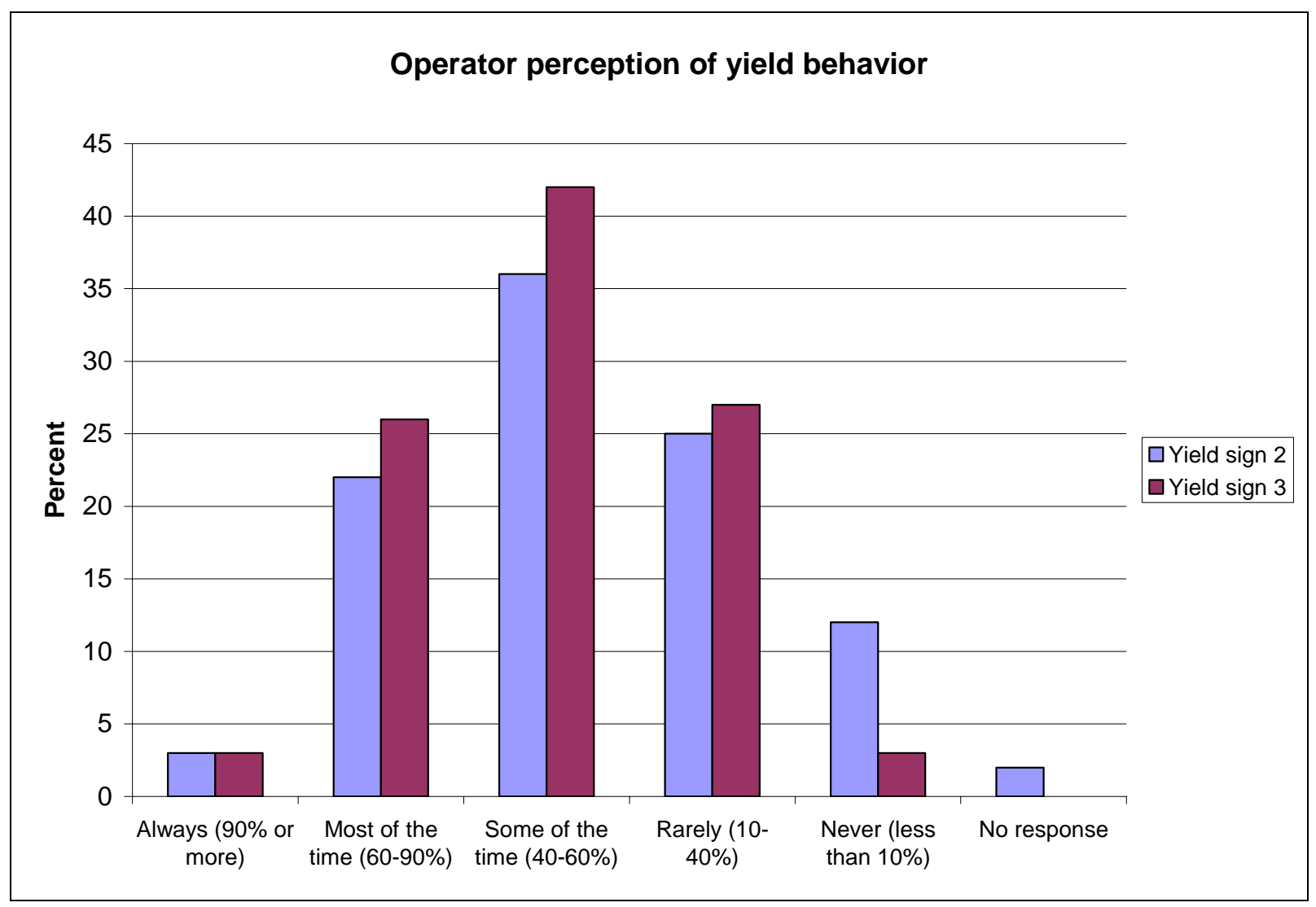

Figure 29 Comparison of LED Yield Sign 2 and LED Yield Sign 3 Perception of Driver Yield Behavior

\section{School Buses}

One thing of particular concern to school bus safety is the unloading and loading of children on the bus. Children are at greater risk in school bus loading or unloading zones since many accidents occur as children attempt to cross the road around a school bus. School bus passing laws and different technologies have therefore been employed to prevent other motorists from passing stopped school buses. Devices intended to enhance the visibility of school buses and to inform drivers of their responsibility to stop during loading and unloading operations are being implemented.

Along with the stop arm, school buses are equipped with flashing amber lights to indicate that the bus is preparing to stop, flashing red lights that extend from the left side of the bus, flashing red lights indicating that the bus has stopped and students are preparing to 
board or leave the bus, and other warning lights to increase the visibility of the bus. Decals are placed on the bus to inform the motorists of the meaning of the flashing lights. The "School Bus Stop Ahead" sign can be used to provide additional advance warning. A static sign, which is only applicable on the occasion that a school bus stops, may become ineffective due to rapid motorist desensitization to the risk and a subsequent degradation in safety at school bus loading/unloading zones (Carson et al. 2005). One remedy for this situation is to add flashing beacons that are activated when a school bus is in the loading/unloading zone.

Video enforcement for stop-arm violations has been attempted. In North Carolina, school bus drivers are trained to activate the vehicle's amber warning lights 300 feet before the stop, stop the bus 15 feet short of the closest waiting passenger, come to a complete stop, check the traffic, and then open the door. Opening the door activates the red warning lights and the stop arm. The North Carolina Department of Public Instruction and the Institute for Transportation Research and Education at North Carolina State University set out to find ways to reduce the illegal passing of stopped school buses. The study focused on three coastal school districts: Onslow, Pender, and New Hanover counties. In Onslow County, bus-mounted video cameras were used. The Onslow County project team mounted weatherproof video cameras outside the bus near the stop arm of selected school buses operated by drivers who had reported frequent illegal passing. The video cameras recorded the date, time, speed of the bus, activation of the amber warning lights, and the deployment of the stop arm. The initial use of the video cameras was to perform a time and motion study of how bus drivers were operating the traffic control devices-the amber warning lights, the red warning lights, and the stop arm. The videos showed that bus drivers sometimes failed to come to a complete stop before activating the red warning lights and stop arm (Tai and Graham 2005).

The time and motion study revealed that school bus drivers did not keep to the 300-foot warning stage and sometimes deployed the stop arm before the bus came to a complete stop. Some violation reports filed by bus drivers had been dismissed and were not pursued through the judicial system because bus drivers sometimes deployed the stop arm before coming to a complete stop. The study also showed at least one or two vehicles illegally passing while the stopped bus was loading and unloading school children. A training videotape was developed for school bus drivers emphasizing that the only way to communicate with motorists are through the vehicle's amber warning lights and red flashing lights.

After reinforcement training for school bus drivers in Onslow County, the average daily number of reported violations of the no-passing law filed by the 203 bus drivers dropped. More cameras were installed on the school buses to capture violations to assist in issuing citations. Video footage from stop arm violations was then highlighted on the news in Onslow County. All these measures further decreased stop arm violations (Tai and Graham 2005).

The Center for Urban Transportation Research conducted a study to determine drivers' understanding of Florida's school bus stop law and school bus signalization devices. A 
survey was developed and issued at 30 driver license examining offices throughout Florida. The finding suggested that, while many motorists do not understand the school bus stop law contained in one scenario, many more motorists are, in fact, intentionally violating the school bus stop law. According to the study, in general, the knowledge of drivers in Florida regarding their responsibilities as defined in the school bus stop law is significantly lacking (Center for Urban Transportation Research 1997).

Other signage directly related to YTB programs includes light emitting diode (LED) signs. These LED signs generally consist of a flashing "YIELD" sign activated by the bus operator when he or she attempts to re-enter the traffic lane. In 2006, Transpec Worldwide introduced a new LED flashing sign for the YTB programs. The new Transpec Merge Alert motorist warning device has been developed to assist with motorist education of YTB laws. The merge Alert delivers a highly-visible, high-brightness LED message that the bus is merging back into traffic. The device flashes a "Yield" sign, along with the word "MERGING," and then alternates to a flashing, left pointing "ARROW" along with a second "MERGING" text (Figure 30). In transit operations tests, the Merge Alert significantly reduces difficulty in the bus reentering traffic and reducing rear-end collisions.

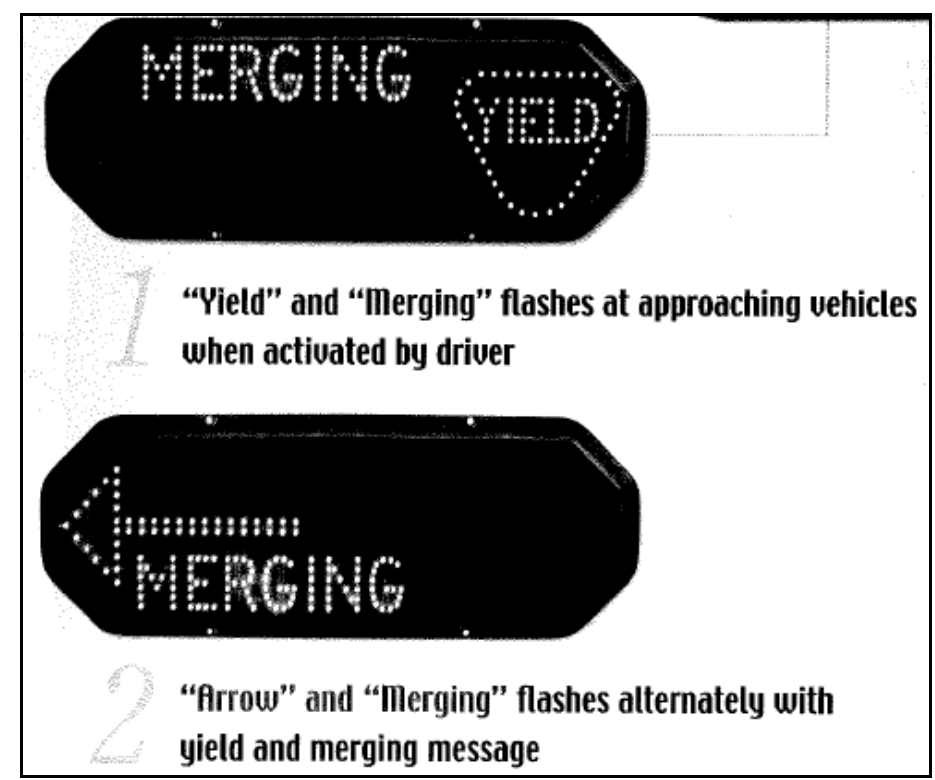

Figure 30 Transpec Merge Alert LED Sign

Another company developed a merge alert and wide-turn alert system. The Advance Safety Wheel and Hubs, LLC company has developed a system to prevent accidents from wide right turns and assisting the operator to re-enter traffic from a stop. For this concept, two safety control boards are placed on the back of transit buses, parallel to each other (Figure 31). On the left rear end of the bus, the control board is activated by the left turn signal. The message "Merging Left" flashes, then strolling arrows pointing left, and then the message "Thank You" when the turn signal is turned off. On the right side rear end of the bus, the control board is activated by the right turn signal activating the message 
“Wide-Right Turn”, then strolling arrows pointing right. A “Thank You” message appears when the turn signal is turned off.

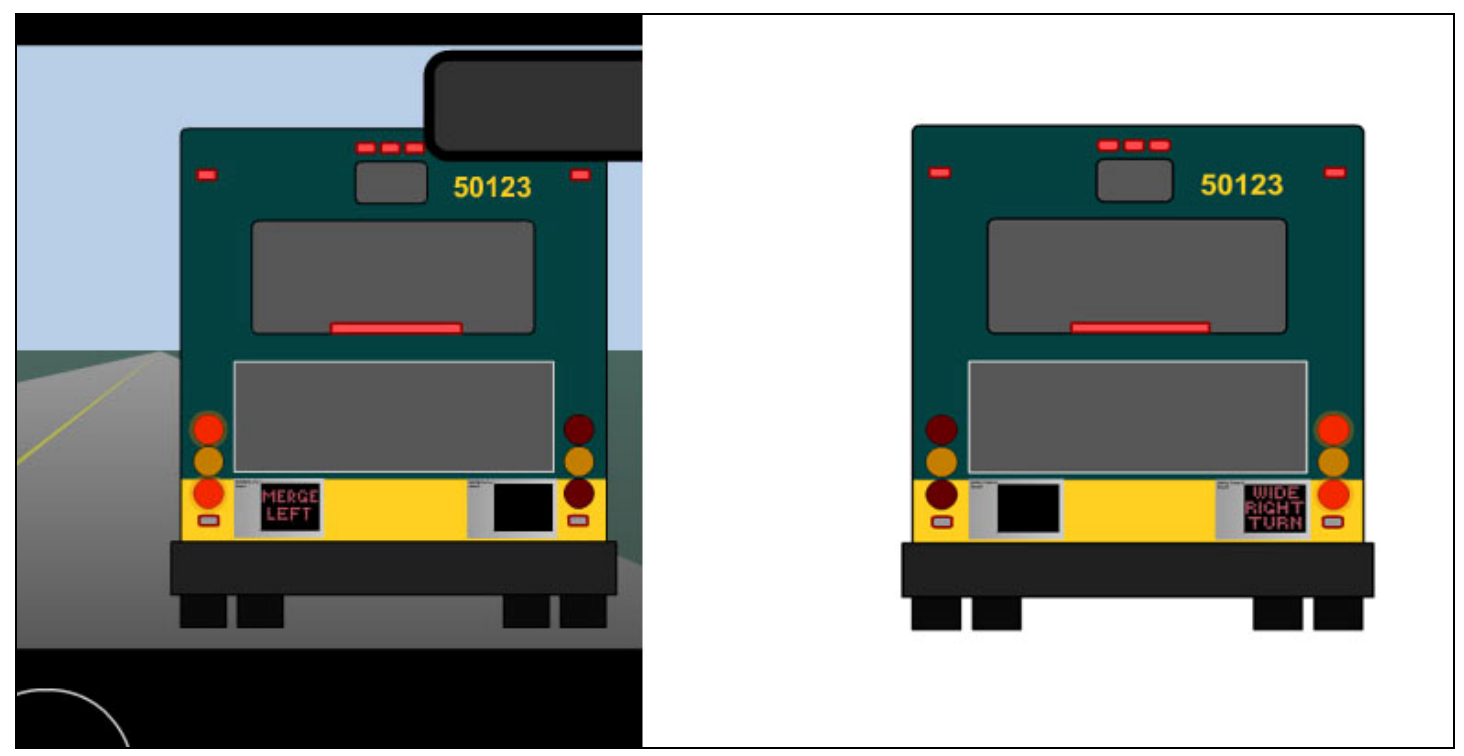

Figure 31 Advanced Safety Wheel and Hubs Alert System

The University of California Transportation Center initiated a study to create a device that would warn motorists approaching a stopped bus. Radar would be attached to the back of the bus, which will survey traffic behind the bus and report its location and the rate at which the gap between the bus and any approaching vehicle is decreasing (Cohn 2002). Other collisions avoidance systems are being researched by different entities (Moffa et al. 1996).

Since the Florida Yield-to-Bus law does not give guidance as to how to implement the law, there is no set signage and lighting uniformly used in Florida. A Yield-to-Bus decal mounted on the back of the bus is widely used; however, there are two agencies in Florida that use a flashing yield sign and others that use no special decals or signs. The common signs associated with the YTB laws in the North America are LED signs and decals. Transit Agencies in California and Oregon use a flashing red triangle with the word "yield" in the center of the triangle. Votran in Florida has recently implemented a similar flashing yield signs on eight new buses in their fleet. Leetran in Florida has also put flashing yield signs on a few of their buses. In British Columbia, a flashing sign with the word "yield" is used along with a decal. The decals range in size, location, and colors.

\section{Hazard Analysis}

\section{Traffic Control Devices}

The purpose of uniform traffic control devices is to promote highway safety and efficiency. Larger, brighter roadway signs have been said to be beneficial in controlling traffic. In a study done by Preston and Storm (2003), increasing the conspicuity of traffic control devices by using bigger, brighter, or additional signs and markings appeared to lower the frequency of "Ran the STOP” crashes. 
According to the Institute of Transportation Engineers Traffic Control Devices Handbook, potential problems with traffic control devices include:

- small print on word signs;

- confusing word messages;

- incomprehensible symbols;

- poorly placed or obscured signs;

- low contrast between sign and background;

- confusing signal combination; and

- information overload

Guide signs are the most frequently cited for information overload; however, warning and regulatory signs can be a problem if the roadway geometrics require multiple regulatory and warning signs, and warning signs are placed close to each other (Hanscom and Dewar 2001).

Device characteristics include sign legibility, legibility distance, and glance legibility. Test legibility is measured in legibility index (LI). MUTCD legibility is based on a LI of $40 \mathrm{ft}$./in. Glance legibility is the capability of a traffic control device that allows motorists to derive information when viewing a traffic control device from a very limited time (Hanscom and Dewar 2001).

According to one study done on driver's understanding of regulatory versus warning speed signs, only about half of the participants thought that speeds on warning signs were legal (Katz et al.).

\section{Rear Lighting Configurations}

Deceleration lightings are amber lights mounted in horizontal alignment on the rear of the vehicle at or near the vertical centerline of the vehicle. These lights are permitted to light and flash during deceleration, braking, or standing and idling of the bus. Vehicular hazard warning flashers may be used in conjunction with or in lieu of a rear-mounted deceleration lighting system. Several letters were written to NHTSA about the use of flashing deceleration lights. According to a letter issued by NHTSA, the simultaneous use of flashing (amber) and steady-burning (red) lamps have the potential for creating confusion in vehicles to the rear of the bus and impairing the effectiveness of the required stop lamps (Womack 1993). 


\section{Roadside Signs and Pavement Markings}

\section{Bus Stop Location and Design}

Since Florida statutes indicated that vehicles must yield the right-of-way to a publicly owned transit bus from a specifically designated pull-out bay, it would be helpful to understand the detailed information regarding the bus pull-out design. There are various types of bus stops that are dependent on location, ridership, and adjacent land uses. Pasco County Public Transportation (PCPT) identifies three types of bus stops used: standard local stops, major local stops, and superstops. These designs range from a single signpost to a full bus bay with other special facilities. Bus bays are typically constructed on highvolume or high-speed roadways (KRW, Inc 1996). Other types of bus stops are curb-side, open bus bay, queue jumper bus bay, bus bulbs, and nub stops.

TCRP Report 19: Guidelines for the Location and Design of Bus Stops contains information about the factors that would lead to the construction of bus bays. Bus bays should be considered on roads where curb lane traffic exceeds 250 vehicles during the peak hour, but bus drivers should not use bus bays when traffic volumes exceed 1000 vehicles per hour per lane (Texas Transportation Institute 1996). Heavy volumes make it very difficult for buses to merge back into the flow of traffic. Acceleration lanes, signal priority, or far-side placements are potential solutions for this. Bus bays are ideal where traffic speeds exceed 40 miles per hour, where vehicles are prone to collide with the rearend of a stopped bus and locations with high passenger volumes or where the dwell time exceeds 30-seconds during peak hours. Areas where there are extended layover times and high volumes of buses at peak hours are also ideal for bus bays. Bus bays should be designed to reduce automobile-bus conflict, provide greater separation between traffic and pedestrians waiting for the bus, and allow the bus to quickly regain its travel speed upon re-entry into the traffic (Florida Planning and Development Lab 2004). As shown in Figure 32, the total length of a bus bay consists of an entrance taper, deceleration length, stopping area, acceleration length, and an exit taper. 


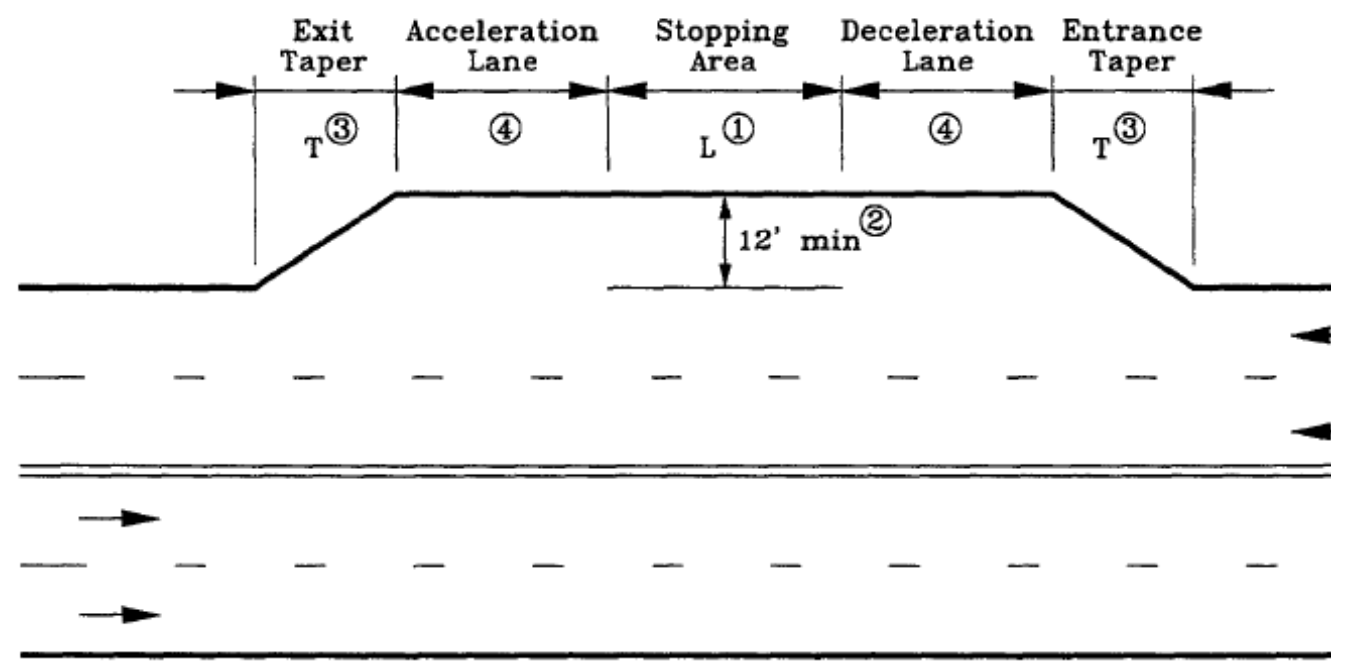

\begin{tabular}{||c|c|c|c|c||}
\hline $\begin{array}{c}\text { Through Speed } \\
\text { (mph) }\end{array}$ & $\begin{array}{c}\text { Entering Speed } \\
\text { (mph) }\end{array}$ & $\begin{array}{c}\text { Length of } \\
\text { Acceleration Lane } \\
\text { (Feet) }\end{array}$ & $\begin{array}{c}\text { Length of } \\
\text { Deceleration Lane } \\
\text { (Feet) }\end{array}$ & $\begin{array}{c}\text { Length of Taper } \\
\text { (Feet) }\end{array}$ \\
\hline 35 & 25 & 250 & 184 & 170 \\
40 & 30 & 400 & 265 & 190 \\
45 & 35 & 700 & 360 & 210 \\
50 & 40 & 975 & 470 & 230 \\
55 & 45 & 1400 & 595 & 250 \\
60 & 50 & 1900 & 735 & 270 \\
\hline
\end{tabular}

Figure 32 Bus Bay Configuration

(Source: TCRP Report 19)

Another bus bay configuration is the queue jumper bus bay as shown in Figure 33. The queue jumper bus bay can be used in combination with a right-turn-only lane or at traffic signals that allow buses to move ahead of other vehicles. The queue jumper bus bay; however, may cause delays to right-turning vehicles. When designed with a right-turn lane, buses are allowed to use the right turn lane at the near-side of the intersection to bypass traffic congestion and move ahead to the bus stop located at the far-side of the intersection. 


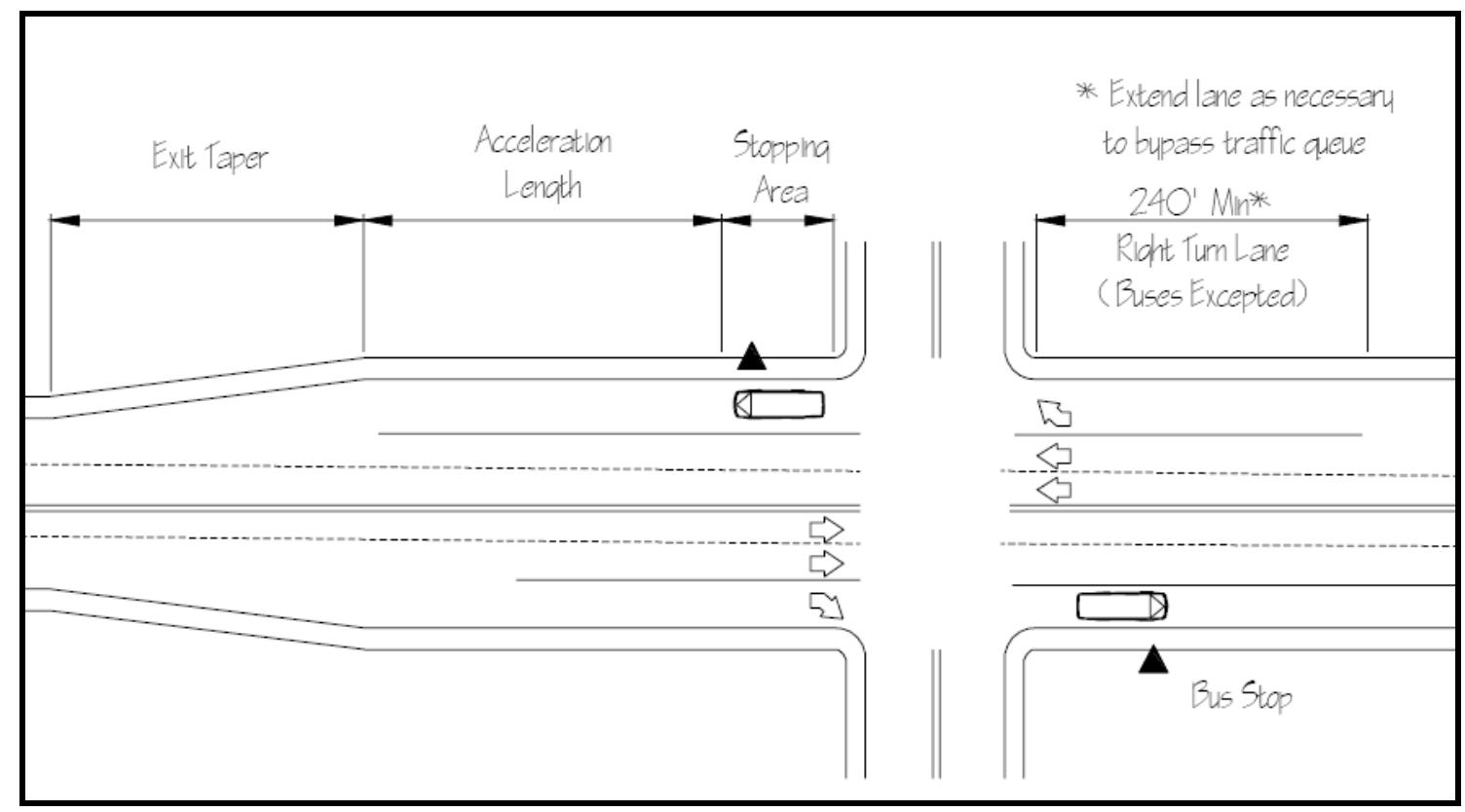

Figure 33 Queue Jumper Bus Bay Configuration

(Source: FDOT Accessing Transit Handbook)

There are three options for bus stop locations: far-side, near-side, and mid-block. The farside bus stop is located downstream of the intersection, the near-side bus stop is located upstream of the intersection, and the mid-block bus stop is located half-way between intersections. Mid-block stops should be avoided unless route alignment requires a right turn and the curb radius is short, the distance between intersections is unusually long, or major transit generators are located mid-block and cannot be served at the nearest intersection, or marked mid-block pedestrian crossing is present. Bus stops are spaced as much as 2,640 feet apart in rural areas to a minimum of only 300 feet in core areas of central business districts. Another procedure for the placement of bus stops is to put them at major trip generators but the final decision on bus stop location is dependent on several safety and operating elements that require on-site evaluation. TCRP Report 19 recommends that bus bays be placed at the far-side of the intersection and mid-block bus bay locations are only desirable when associated with key pedestrian access to major transit-oriented activity centers. The dimensions of the bus bay are dependent on through speed or entering speed.

The current practices in YTB programs do not include additional roadside signage. The Manual on Uniform Traffic Control Devices otherwise has recommendations for "Yield" signs and also "Yield to Pedestrians" and "Yield to Bikes."

\section{Manual on Uniform Traffic Control Devices}

The Manual on Uniform Traffic Control Devices (MUTCD) does not have standard yield-to-bus signs.

According to section 2B.08 of the MUTCD, the yield sign should be a downwardpointing equilateral triangle with a wide red border and the legend "Yield" in red on a 
white background (Figure 34). Yield lines must be white and if used, yield lines shall consist of a row of solid white isosceles triangles pointing toward approaching vehicles extending across approach lanes to indicate the point at which the yield is intended or required to be made.

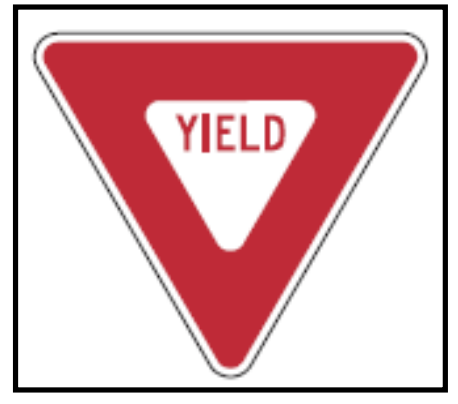

Figure 34 Yield Sign

(Source: MUTCD, 2B.09)

Vehicles controlled by a yield sign need to slow down or stop when necessary to avoid interfering with conflicting traffic. The MUTCD states that the yield sign assigns rightof-way to traffic on certain approaches to an intersection. It makes no mention of using yield-to-bus signs, but they do have special yield signs for yielding to pedestrians. If yield lines are used in advance of an unsignalized, marked midblock crosswalk, "Yield Here to Pedestrians" signs should be placed 6.1 to $15 \mathrm{~m}$ (20 to $50 \mathrm{ft}$ ) in advance of the nearest crosswalk line. The "In-Street Pedestrian Crossing" sign may be used to remind road users of laws regarding right of way at an unsignalized pedestrian crossing. The legend "State Law" may be shown at the top of the sign if applicable. The legends "Stop for" or "Yield to" may be used in conjunction with the appropriate symbol. Yield lines may be used to indicate the point behind which vehicles are required to yield in compliance with a "Yield" sign or a "Yield Here to Pedestrians" sign as shown in Figure 35.

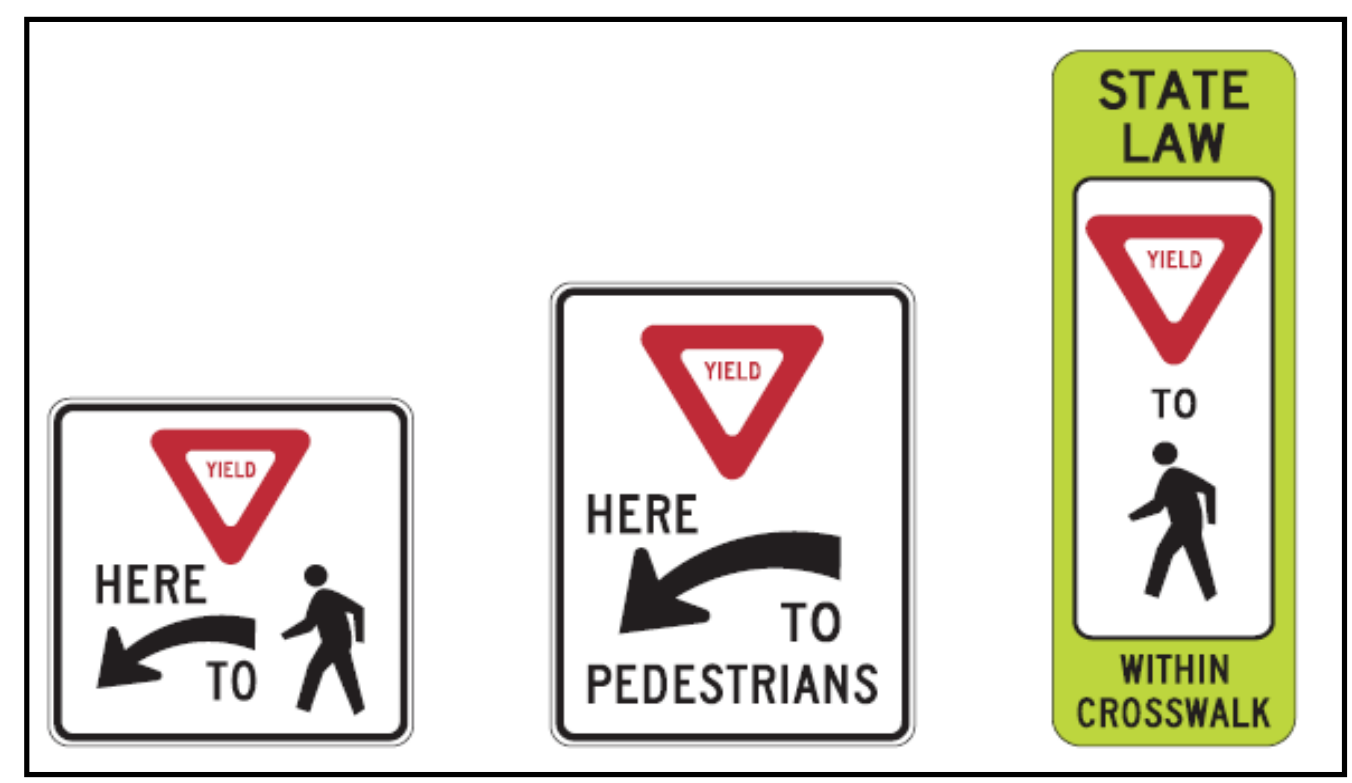

Figure 35 Yield to Pedestrians Signs (Source: MUTCD, 2B.13) 
The yield line consists of individual triangles with a base of 300 to $600 \mathrm{~mm}$ (12 to $24 \mathrm{in}$ ) wide and a height equal to 1.5 times the base. The space between the triangles should be 75 to $300 \mathrm{~mm}$ (3 to $12 \mathrm{in}$ ). Yield lines may be used to indicate the point behind which vehicles are required to yield in compliance with a yield sign (Figure 34) or a "Yield Here to Pedestrians" (Figure 35) sign. Yield lines are placed a minimum of $1.2 \mathrm{~m}(4 \mathrm{ft}$ ) in advance of the nearest crosswalk line at controlled intersections, except for yield lines at roundabout intersections and at midblock crosswalks. In the absence of a marked crosswalk, the stop line or yield line is placed at the desired stopping or yielding point, but should be placed no more than $9 \mathrm{~m}(30 \mathrm{ft})$ nor less than $1.2 \mathrm{~m}(4 \mathrm{ft})$ from the nearest edge of the intersecting traveled way. If used at an unsignalized midblock crosswalk, yield lines are placed adjacent to the "Yield Here to Pedestrians" sign located 6.1 to $15 \mathrm{~m}$ (20 to $50 \mathrm{ft}$ ) in advance of the nearest crosswalk line, and parking should be prohibited in the area between the yield line and the crosswalk as shown in Figures 36 and 37. Drivers who yield too close to crosswalks on multi-lane approaches place pedestrians at risk by blocking other drivers' views of pedestrians.

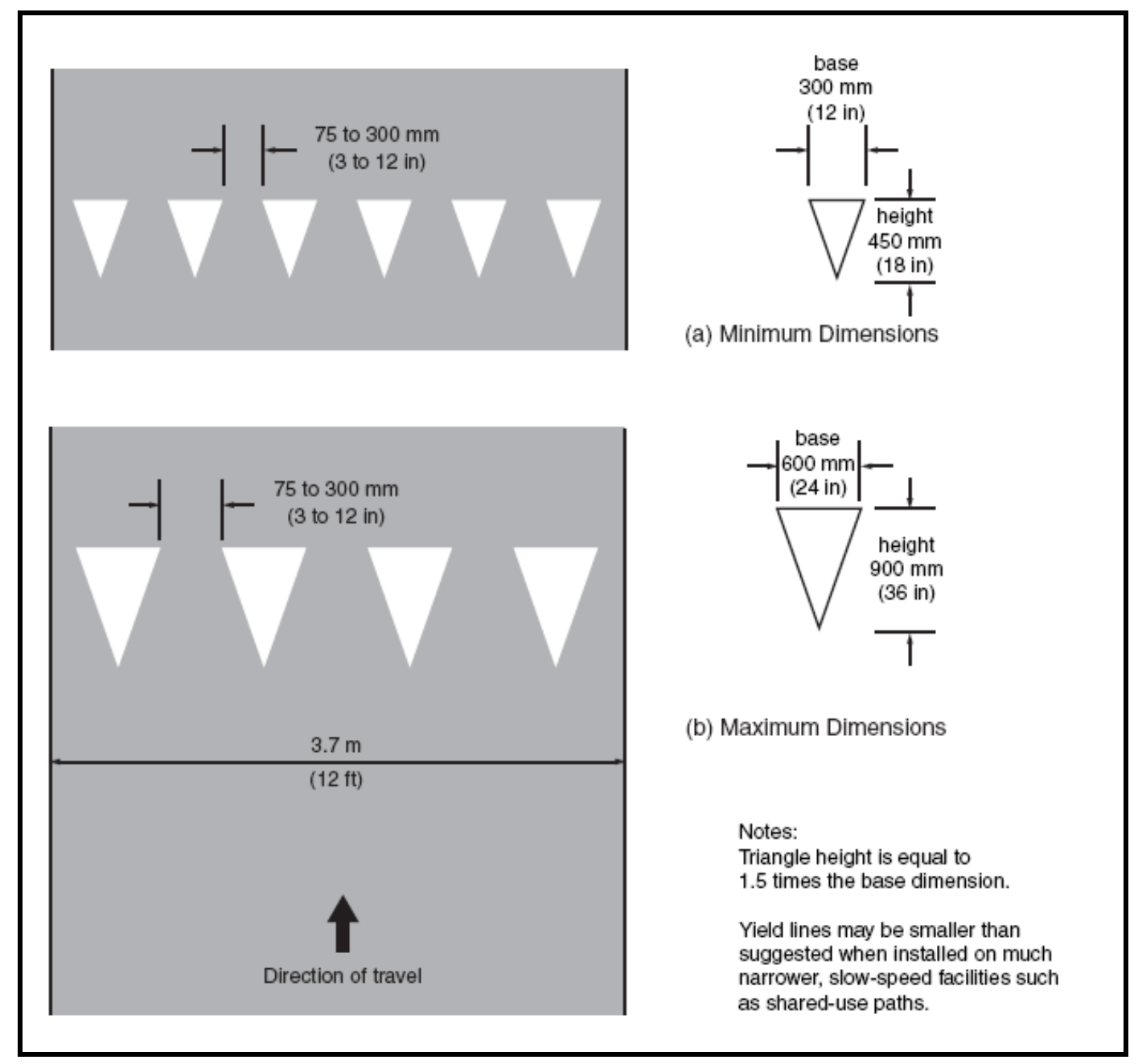

Figure 36 Yield Pavement Markings

(Source: MUTCD, 3B.16) 


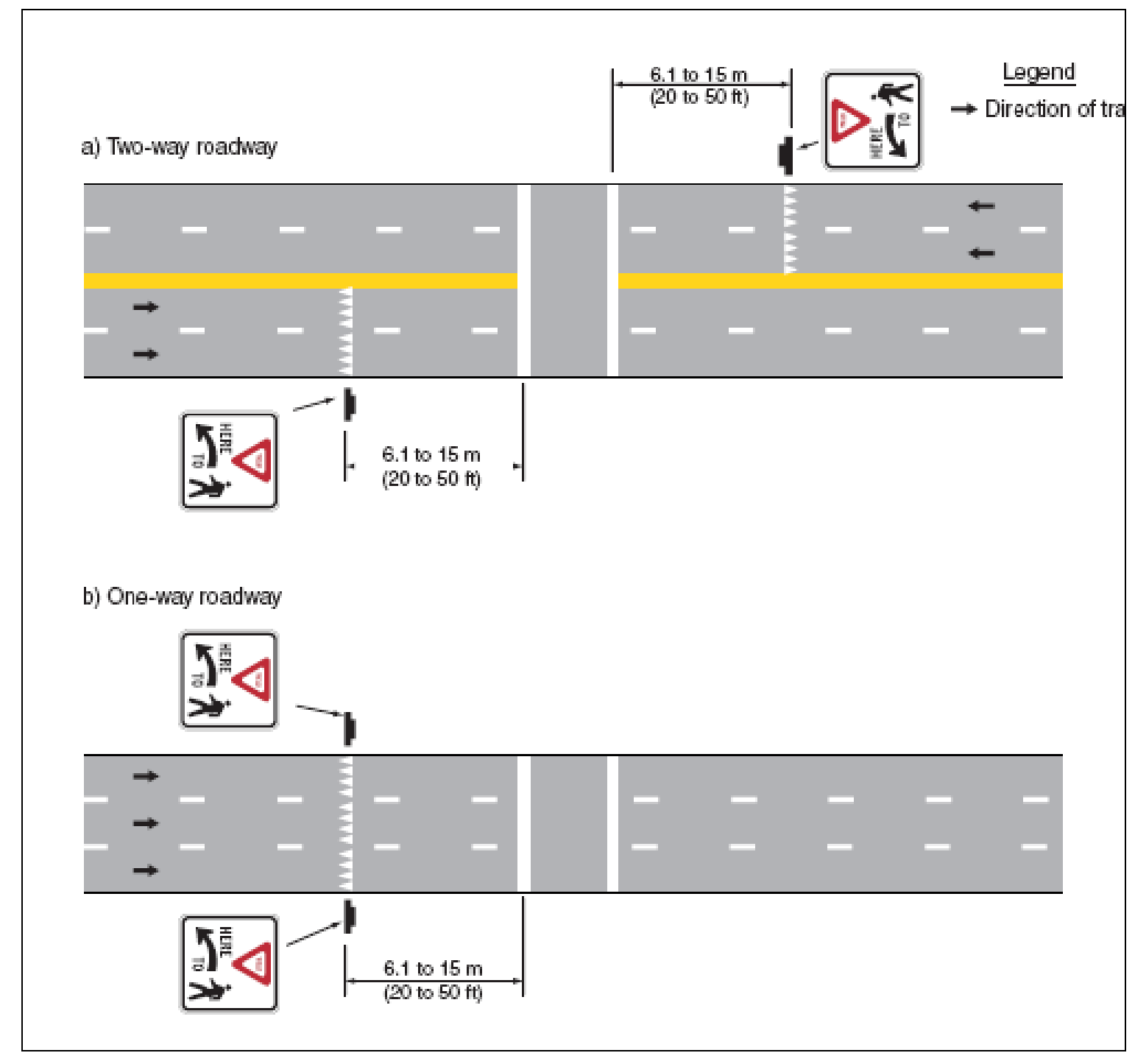

Figure 37 Placement of Yield Markings

(Source: MUTCD Section 3B)

At roundabout intersections, a yield line (Figure 38) may be used to indicate the point behind which vehicles are required to yield at the entrance to a roundabout intersection. 


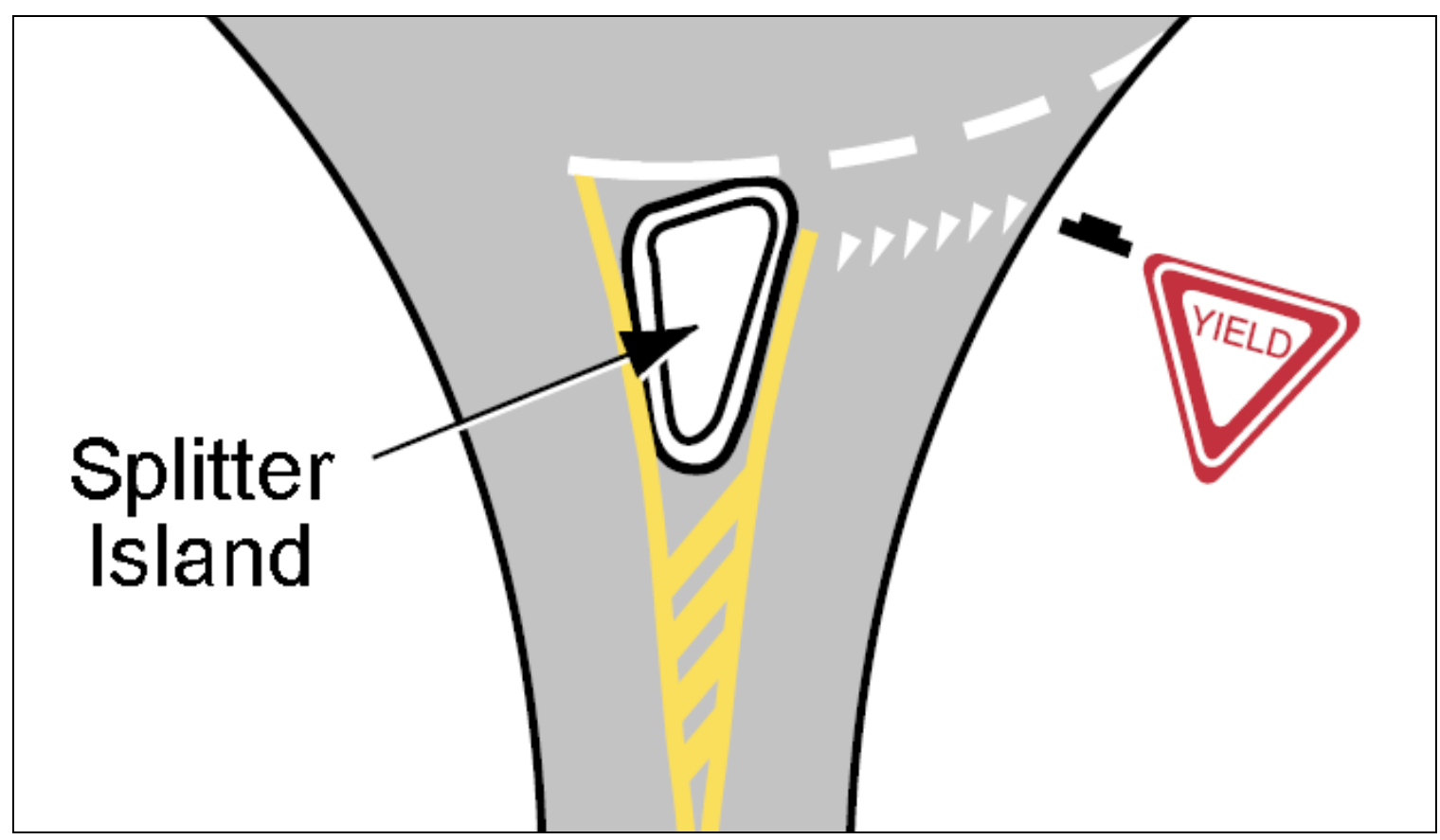

Figure 38 Yield Marking for Roundabout

(Source: US Department of Transportation Federal Highway Administration, Office of Transportation Operations, FHWA-OP-02-090)

A yield-ahead triangle symbol (Figure 39) or "Yield Ahead" word pavement marking may be used on approaches to intersections where the approaching traffic will encounter a yield sign at the intersection. The yield-ahead triangle symbol or "Yield Ahead" word pavement marking cannot be used unless a yield sign is in place at the intersection. The yield-ahead symbol marking shall be as shown in Figure 39.

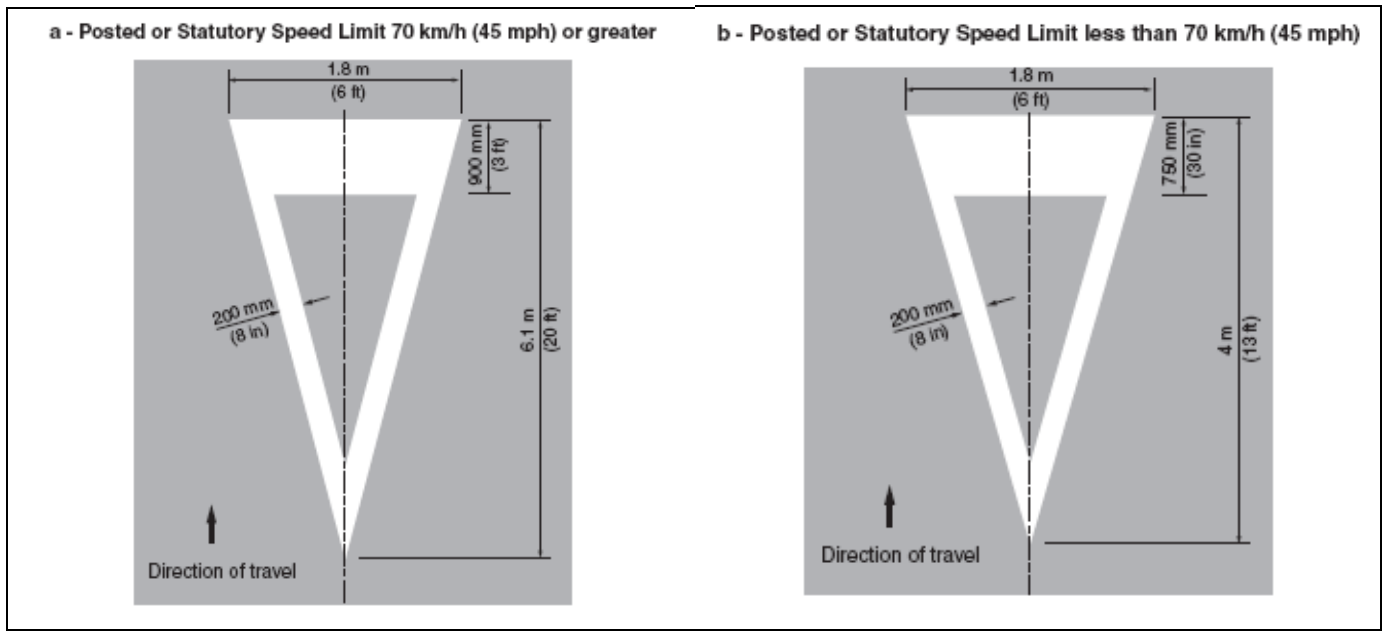

Figure 39 Yield Ahead Triangle

(Source: MUTCD, Section 3B) 
Al-Masaeid and Sinha (1994) suggest that studies on the effectiveness of pavement markings are not consistent. Derived accident reduction factors due to pavement markings for all average daily traffic volumes on rural roads and for all lane widths varied from -13 percent to +35 percent. For a specific countermeasure, there is no exact estimate of accident reduction factor. Regardless of the method of estimation, nature of the environment, or accident experiences, the estimation of accident reduction factor is uncertain (Al-Masaeid and Sinha 1994). However, safety studies on pavement marking tend to be mostly focused on visibility; therefore, it is hard to say that this may apply to a safety study of whether pavement marking changes yield behavior of motorists.

Yan, Radwan, Birriel and Guo (2006) conducted a study on the pavement marking with word message "Signal Ahead." The study investigated the effect of this pavement marking on signalized intersections and safety. The "Signal Ahead" pavement marking is intended to encourage drivers located upstream of the marking to stop at the intersection at the onset of the yellow phase. In their experimental design, the pavement marking position is related to the speed limit and vehicle's deceleration rate. The study showed a significantly positive effect on signalized-intersection safety (Yan, Radwan, Birriel, Dahai 2006).

Other yield signs available are for yielding to bicyclists. The sign is $900 \mathrm{~mm}$ by $750 \mathrm{~mm}$. The sign is used where motor vehicles entering an exclusive right-turn lane must weave across bicycle lanes; the "Begin Right Turn Lane Yield to Bikes” (R4-4) sign (Figure 40) may be used to inform both the motorist and the bicyclist of this weaving maneuver.

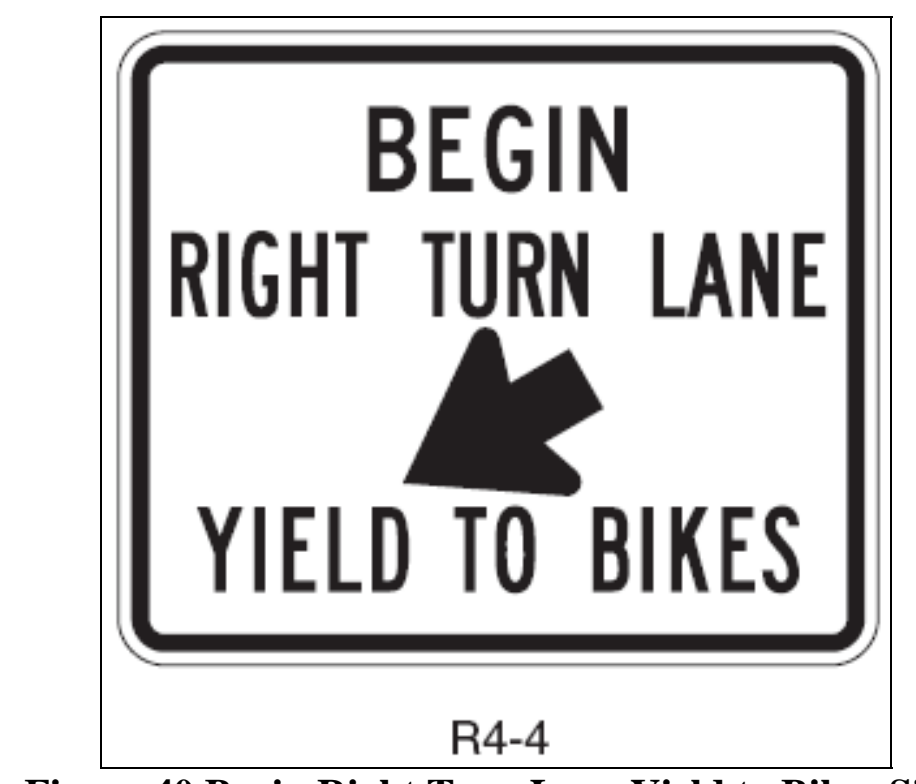

Figure 40 Begin Right Turn Lane Yield to Bikes Sign

(Source: MUTCD)

The MUTCD also does not have any standard signs to warn road users of the possibility of vehicles unexpectedly stopped in the travel lane but they do have general guidelines for signs governing the parking, stopping, and standing of vehicles. Discussions of 
parking signs and parking regulations in Section 2B.40 of the MUTCD apply to parking and stopping. Prohibitive signs should have a red legend and border on a white background while permissive signs should have a green legend and border on a white background. Alternate designs may include, on a single panel, a transit logo, an approved bus symbol, the words "Bus Stop", and an arrow. The preferred bus symbol color is black, but other dark colors may be used. Additionally, the transit logo may be shown on the bus face in the appropriate colors instead of placing the logo separately. The reverse side of the sign may contain bus routing information. Parking prohibition signs around bus stops are illustrated in this section of the MUTCD (Figure 41).

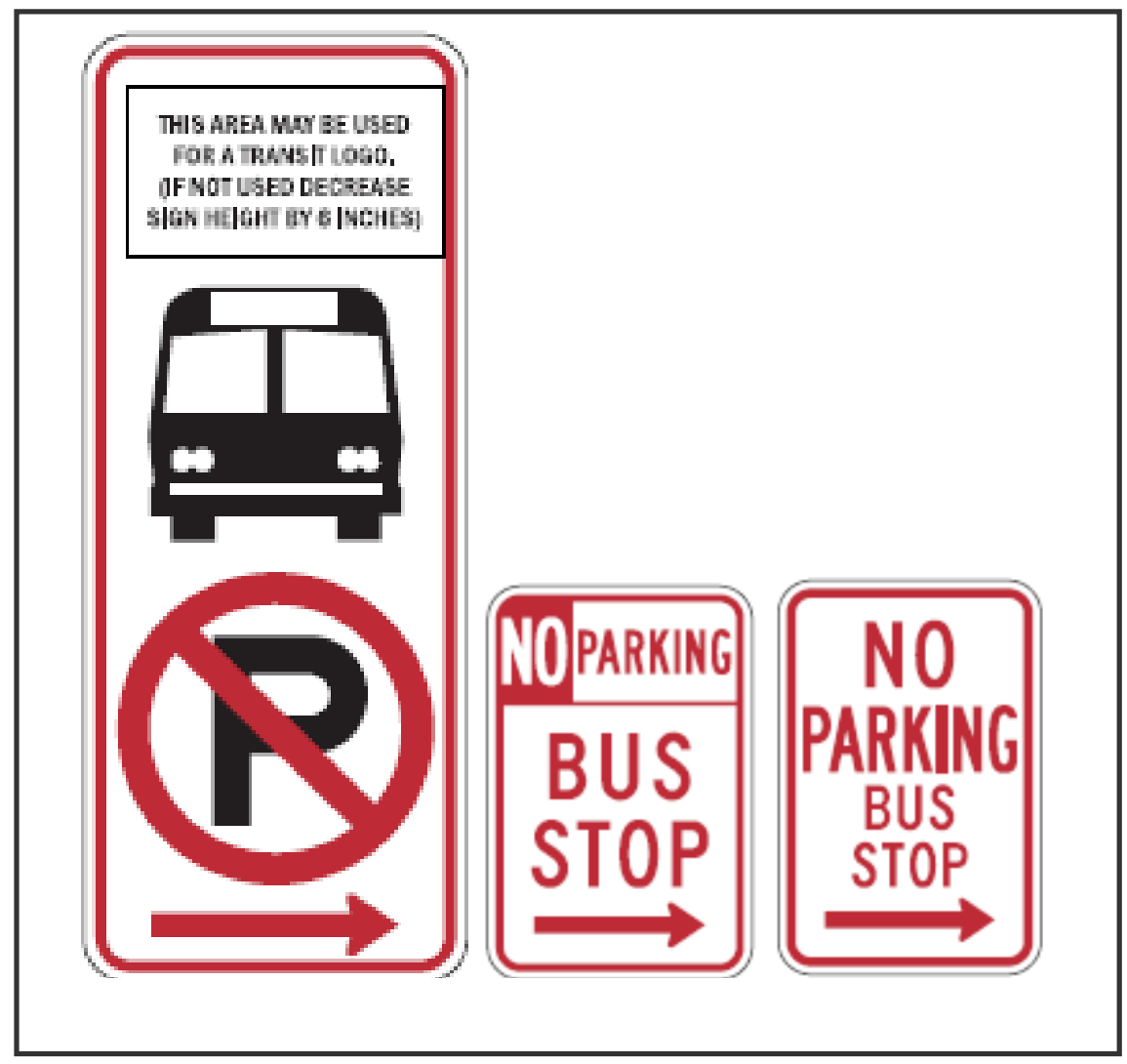

Figure 41 No Parking Signs Related to Transit Stops

(Source: MUTCD, 2B.40)

Roadside signage could provide additional information to motorist to warn them of the potential of buses merging into traffic. In the event that a sign on the back of the bus is not seen, the roadside sign may serve to inform the motorist that they must yield to the bus at these bus bay locations. A roadside sign may not be necessary for all bus bay locations, but they could be helpful at specific locations where rear-end collision are observed to be high due to non-compliance with the YTB laws. Also, in high crash locations, additional pavement markings can be used to remind motorists to yield. 


\section{Yield-to-Bus Legislation}

In the United States, six states have passed laws requiring motorists to yield to buses attempting to merge back into traffic. The laws vary in requirements for transit agencies and under what circumstances motorists are required to yield. The following are excerpts from different states pertaining to YTB laws. Details of these laws are presented in Appendix A.

\section{Florida}

Florida Statute 316.0815 states that "vehicles must yield the right-of-way to a publicly owned transit bus traveling in the same direction which has signaled and is reentering the traffic flow from a specifically designated pullout bay. The operator of the bus must also drive with due regard for the safety of all persons using the roadway." This law is concise and makes no mention of specific signs, lights, fines or implementation.

The Florida Driver's Handbook 2007 was checked to see if there was any mention of requirements to yield to the bus. Under the heading of "Right-of-Way", the handbook says, "Who has the right-of-way in Florida? The answer is no one! The law only says who must yield (give up) the right-of-way." Under this is the subheading "Public Transit" where it does mention the yield-to-bus law. It says, "All drivers should yield the right-ofway to public transit buses traveling in the same direction which have signaled and are reentering the traffic flow from a specifically designated pullout bay."

There are special sections for sharing the road with trucks, bicyclists and motorcyclists. In the part for trucks they say, "Whether you are sharing the road with a car, truck, bus, or other large vehicle, it's important for safety's sake to obey traffic laws, abide by the rules of the road, and drive defensively." This section continues to point out different issues when sharing a road with trucks and mentions that buses have the same issues. It includes blind spots, methods for passing a truck or bus, wide right turns, following a truck and unsafe passing. There is also a section on defensive driving which addresses how to avoid rear-end collisions. This section recommends that drivers check their brake lights often, know what is going on around then, use rearview mirrors, signal in advance for turns, stops and lane changes, slow down gradually and avoid any sudden actions, drive with the flow of traffic (within the speed limit), and keep at least two seconds following distance.

\section{Washington}

The Revised Code of Washington (RCW) 46.61.220 is very similar to the Florida statute 316.0815. RCW 46.61.220 states that "the driver of a vehicle shall yield the right of way to a transit vehicle traveling in the same direction that has signaled and is reentering the traffic flow." It differs from the Florida statute in that it does not specify the type of bus stop; it does, however, go on to state that the driver of a transit vehicle shall drive with due regard for the safety of all persons using the roadway. Washington Administrative Code (WAC) 204-10-020 specifies the required lighting for motor vehicles and buses. Municipal transit vehicles may be equipped with a single additional hazard strobe lamp. This strobe lamp is activated by an independent switch and used in situations where sight 
is obscured, or to improve the visibility of the bus when stopping, standing, or starting onto a highway.

\section{Oregon}

Oregon Revised Statute 811.167 states that a person commits the offense of failure to yield the right-of-way to a transit bus entering traffic if they do not yield the right-of-way to a bus bearing a yield sign as described in that subsection displayed on the back of the transit bus. They also commit an offense if the person is operating a vehicle that is overtaking the transit bus from the rear of the transit bus; and the transit bus, after stopping to receive or discharge passengers, is signaling an intention to enter the traffic lane occupied by the person. The section describes the type of YTB decal to be used as well as a fine.

\section{California}

California Vehicle Code 21810 states that the driver of a vehicle overtaking a transit bus shall yield the right-of-way to the bus if all of the following conditions are present:

1. "The transit bus has entirely exited an active traffic lane to board or drop off passengers at a designated bus stop, and is attempting to reenter the lane from which it exited.

2. Directional signals on the transit bus are flashing to indicate that the bus is preparing to merge with traffic.

3. The transit bus is equipped with a yield right-of-way sign on the left rear of the bus."

The code goes on to specify how the YTB sign is to be used and how the law is to be implemented. It also requires transit agencies to conduct a public awareness campaign.

\section{New Jersey}

The New Jersey statutes say that the driver of a non-emergency vehicle shall yield the right of way to any bus provided that:

1. "The driver is operating a vehicle that is in a position to overtake the bus from its rear; and

2. The bus, after exiting an active traffic lane for the purpose of stopping to receive or discharge passengers is attempting to reenter the lane from which it exited and to enter the traffic lane occupied by the driver by signaling its intention to do so. No other lane changes shall be applicable.”

The original bill included specifications for a right-of-way yield sign to be placed on the left rear of the bus, illuminated by a flashing light when the bus driver signals intention to enter an active traffic lane. It also stated that the Director of the Division of Motor Vehicles shall adopt rules and regulations governing the message or messages on the yield sign, specifications for the size, color, shape, lettering and illumination of the sign and specifications for the placement of the sign on the bus. These details, however, were not enacted and were omitted from the law when it was passed in 2004. 


\section{Minnesota}

Minnesota Statute 169.20 Subdivision 7 for Transit bus states that:

"The driver of a vehicle traveling in the right-hand lane of traffic shall yield the right-ofway to any transit bus attempting to enter that lane from a bus stop or shoulder, as indicated by a flashing left turn signal.”

Oregon, Washington, Minnesota, and Florida share the basic elements of the law by stating that motor vehicles should yield to publicly owned transit buses. Oregon, Washington, and Florida also state that the driver should operate with due regard for the safety of all persons using the roadway. Oregon and California; however, are more specific by defining the yield signal. They also mention overtaking a bus as failure to yield the right-of-way under certain conditions. Originally, the New Jersey bill for the new Yield-to-Bus law specified a yield sign but this was omitted from the law in 2004.

A clearer, more defined law seems to be best for compliance. In the bus operators survey in TCRP Synthesis 49, bus operators in Florida and Washington felt that most people were unaware of the Yield-to-Bus law (Figure 42).

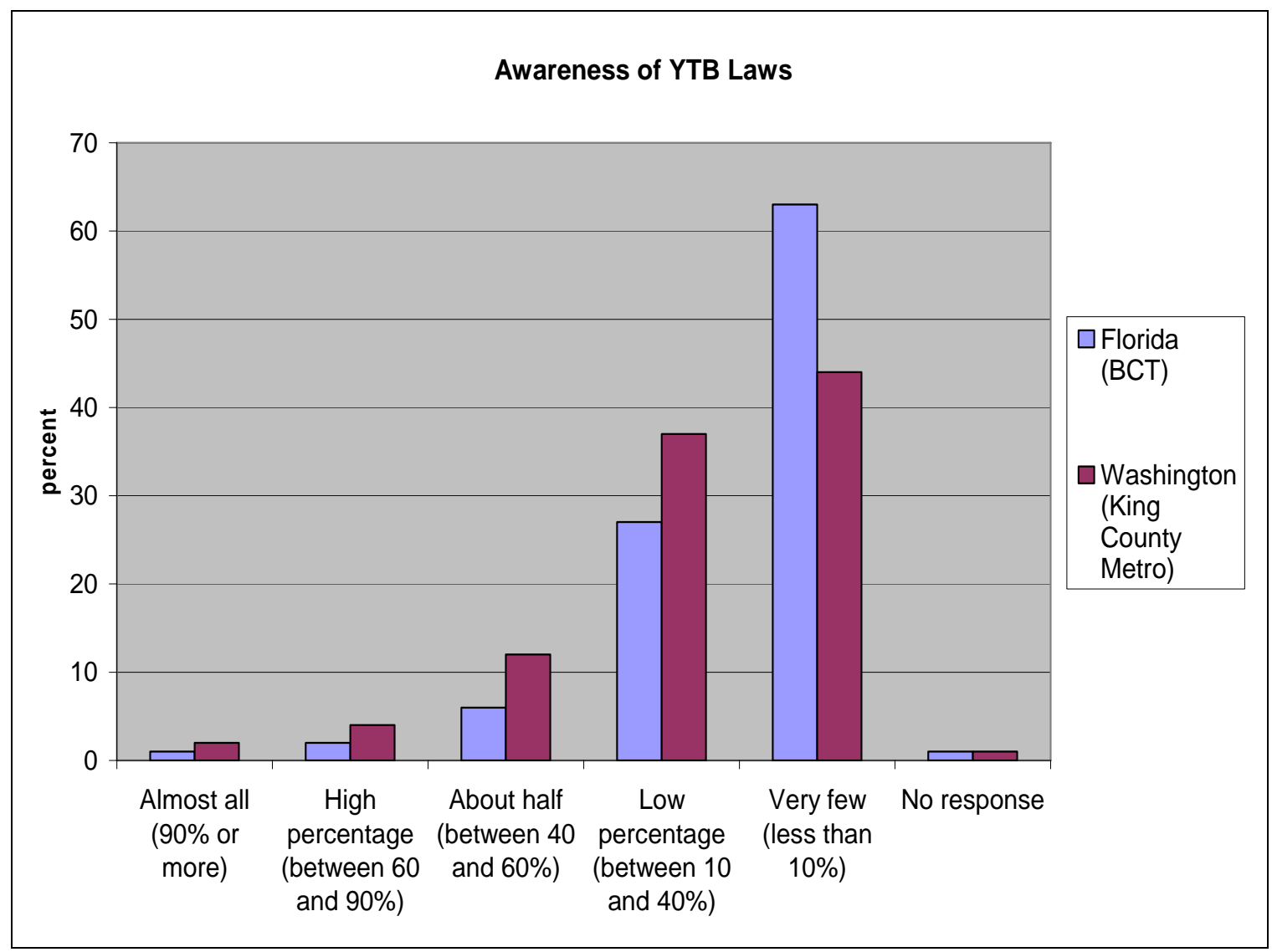

Figure 42 Operators Perception of Motorists’ Awareness of YTB Laws 


\section{Europe}

There is not much information on the YTB legislation in Europe because of a strong push for the exclusive bus lanes and other priority measures. In England and Germany, bus bays have been filled, and these stops have been turned into regular curbside stops so that buses do not have the problem of re-entering the traffic. There seems to be more concern about the delay of buses than those of cars, so they allow cars to queue behind the bus. Implementation of the exclusive bus lanes also prevents bus merging problems.

\section{Summary}

Based on the literature review, the most effective technology used to supplement the YTB laws in North America is the flashing yield sign. However, different states may have different laws regarding the implementation of additional flashing lights on the back of the bus. The Florida YTB law is one of the least comprehensive laws and does not specify how the law is to be implemented. The awareness of the law also seems to be lacking even though it is mentioned in the Florida Driver's Handbook.

The Manual on Uniform Traffic Control Devices (MUTCD) does not address traffic control devices for the YTB law; however, it does specify pavement markings and signs for general yielding at intersections, and yielding for pedestrians and bicyclists. The bus activated flashing beacon seems to be a promising technology for school buses; however, the flashing beacon, due to restrictions on use in the MUTCD, may have limited use in YTB applications. Warning beacons are used as supplemental emphasis to regulatory signs, except STOP, YIELD, DO NOT ENTER, and SPEED LIMIT signs. Other types of flashing beacons mentioned in the MUTCD include intersection control beacons, speed limit sign beacons, and stop beacons. Installing video cameras on school buses to capture people illegally passing the school bus seems to have a significant effect on compliance with school bus laws.

Roadside signage could provide additional information to motorist to warn them of the potential of buses merging into traffic. In the event that a sign on the back of the bus is not seen, the roadside sign may serve to inform the motorist that they must yield to the bus at bus bay locations. A roadside sign may not be necessary for all bus bay locations, but at specific locations where rear-end collisions are observed to be high due to noncompliance with the YTB laws. Also, in high crash locations, additional pavement markings can be used to remind motorists to yield. 


\section{CHAPTER 3 - METHODOLOGY}

The results of the literature review summarized the current YTB laws, YTB decals and signage, and roadside signage and pavement marking applied to YTB. In order to determine the best practices in signs and lighting for Florida's public transit buses, bus operator surveys and field studies were conducted in addition to the comprehensive overview of YTB lighting configurations and signage. A preliminary crash data analysis was conducted to supplement the results from survey and field studies.

\section{Bus Operator Survey}

Bus operators have first hand experience with the difficulty of moving in traffic safely; therefore, it was important to document their experiences. A bus operator questionnaire was developed to aid in preparing recommendations for the project objectives. The questionnaire was formatted in three sections. The first section asked questions about bus operations and perceived motorist yield behavior. There were questions on their use of bus pull-out bays, right-turn lanes and wide shoulders for loading and unloading passengers. The second section pertained to different technologies available on the back of the bus for moving the bus back into traffic safely. The third section pertained to the current Florida laws and any additional safety concerns. At the end of the questionnaire was a narrative portion where bus operators were able to make recommendations for their own bus safety program as well as any additional comments and concerns. A copy of the questionnaire developed is shown in Appendix B.

\section{Field Observations}

To supplement bus operator surveys, observations in the field can provide valuable information on current conditions and driver behavior. Three variables that can be recorded in the field are clearance times, yield behavior, and conflicts.

\section{Clearance Time and Re-entry Delay}

The clearance time is defined in the Transit Capacity and Quality of Service Manual as the minimum time required for one bus to accelerate out of and clear the loading area and the next bus to pull into the loading area, including any time spent waiting for a gap in traffic (Kittelson and Associates 2003). Part of the clearance time is fixed and consists of the time it takes the bus to start up and travel its own length. The variable part of clearance time is only apparent for off-line stops when a bus must wait for a suitable gap in traffic. This variable portion of the clearance time is known as the re-entry delay. The Transit Capacity and Quality of Service Manual suggests that in states with yield-to-bus laws, the re-entry delay can be minimized or eliminated depending on how well motorists comply with the laws. Table 2 shows the average re-entry delay for adjacent lane of different mixed traffic volumes. These values were computed using the HCM 2000 unsignalized intersection methodology, thus can only be applied to off-line stops where buses must yield to other traffic when re-entering, and the stop cannot be influenced by a signalized intersection. 
Table 2 Average Bus Re-entry Delay

\begin{tabular}{cc}
\hline $\begin{array}{c}\text { Adjacent Lane } \\
\text { Mixed Traffic Volume (veh/h) }\end{array}$ & $\begin{array}{c}\text { Average Re-entry } \\
\text { Delay (sec) }\end{array}$ \\
\hline 100 & 1 \\
200 & 2 \\
300 & 3 \\
400 & 4 \\
500 & 5 \\
600 & 6 \\
700 & 8 \\
800 & 10 \\
900 & 12 \\
1,000 & 15 \\
\hline
\end{tabular}

(Source: Transit Capacity and Quality of Service Manual)

Off-line bus stops are subject to re-entry delay which is dependent on traffic volumes and the platooning effect from upstream traffic signals (Gan et al 2002). According to TCRP Report 26, one element that affects bus capacity is the clearance time. In order to remedy the negative effects of clearance time, the report suggests using on-line stops and enacting and enforcing laws that require cars to yield to buses re-entering traffic (Jacques and Levinson 1997).

\section{Conflict Study and Yield Behavior}

A conflict study can be used to determine hazardous locations and situations. A traffic conflict is a situation in which a collision would have occurred if road users had continued with unchanged speeds and directions. Counting the number of serious conflicts that occur at a location can be used to determine the level of traffic hazard (De Langen and Tembele 1994). Traffic Conflict Techniques (TCTs) have been developed in a number of European and North American countries to add relevant information to existing accident data, or to replace missing accident data (Muhlrad 1993). A conflict is often determined by an abrupt braking maneuver; therefore, vehicle tail-lights are watched and the drivers' speed and rapid deceleration are noted.

Yield behavior is determined by inspection of videos taken in the field. Like a conflict study, yield behavior is determined by the observer and is a subjective measure of traffic safety. Yield behavior varies by location since an intersection affects driver behavior, so yield behavior at mid-block locations are expected to be different from that at far-side and near-side bus stops. 


\section{CHAPTER 4 - DATA COLLECTION}

\section{Bus Operator Survey}

Preliminary bus operator questionnaires were conducted at the State Bus Rodeo in Jacksonville, Florida in March 2007. Twelve bus operators from several different transit agencies across Florida participated in the Rodeo, which is an event where bus operators and maintenance staff compete in various competitions. Questionnaires were handed to each bus operator on the first day of the Rodeo and were collected on the following day. Additional surveys were administered aurally for the operators that did not complete the survey prior to the second day of the Rodeo. A total of ten questionnaires were received from operators representing ten different transit agencies. While in Jacksonville a visit was made to the bus operator lounge of the Jacksonville Transit Authority (JTA) during the bus operator practice day for the Rodeo. Most of the questionnaires were administered by reading the questions to bus operators and filling in their responses. A few operators took questionnaires and filled them out and returned them by the end of the visit.

Additional surveys were done at the bus operator facilities for Lynx in Orange County and Hillsborough Area Regional Transit (HART) in Hillsborough County, Florida. In these areas, it was an opportune time for questionnaires to be completed because bus operators were waiting on their shifts. At these locations questionnaires were also completed in two different ways; questions were read directly to the bus operator while the responses were filled out by the person administering the survey; other surveys were handed directly to the bus operator to be filled out. Surveys were conducted at Lynx on Wednesday, March 28, 2007 between 12 noon and 2 PM. HART surveys were conducted on Thursday, April 26, 2007 between 2 PM and 4 PM. Data collection dates and times were suggested by transit agency supervisory staff. The method of survey administration was also dependent on the preference of transit agency staff. Additional questionnaires were left at the Lynx and HART facilities for operators who were not present at the time of the survey but wished to participate. The additional Lynx questionnaires were mailed back, while the HART questionnaires were collected at a later date.

Additional questionnaires were mailed and e-mailed to transit agencies for responses to be mailed back when completed by the bus operators. Mailed questionnaires were received from Lee County Transit (Leetran), Volusia County Transit (Votran), Pinellas Suncoast Transit Authority (PSTA) in Pinellas County and StarMetro in Leon County. Surveys from Lee County and Volusia County were completed between March and April 2007. Surveys from Pinellas County were completed in May 2007 and surveys from Leon County were completed between May and June 2007.

The transit agencies chosen for the survey represented a range of practices in Florida. JTA in Duval County did not have any YTB decals or LED lights; therefore, their responses represented operators who were not using any YTB technologies. Pinellas Suncoast Transit Authority (PSTA) in Pinellas County and HART both had YTB decals on their entire fleet; therefore their responses represented agencies with a widely used YTB technology. Lynx in Orange County had three different YTB decals, but they were 
not installed on all buses. Operators from Lynx were able to compare the different YTB decals and comment on their effectiveness. Leetran used both YTB decals and "Yield" LED signs but not on their entire bus fleet. Votran never had any YTB decals, but they did have "Yield" LED lights on a few of their buses. Leetran and Votran represented the only agencies in Florida that employed a technology other than the decal for YTB laws.

Reading out questions directly ensured that surveys were filled out completely and questions were understood properly. Questionnaires that were handed out had more sources of error since questions could be misunderstood and questionnaires could be filled out incorrectly.

A total of 277 bus operator questionnaires representing 12 counties were obtained. Only one questionnaire was received from Polk, Manatee, Broward, Brevard and Alachua counties during the preliminary survey in March 2007; therefore, information from these counties were not greatly represented. Figure 43 shows the composition of the bus operator survey. The responses from the bus operators are available in Appendix C.

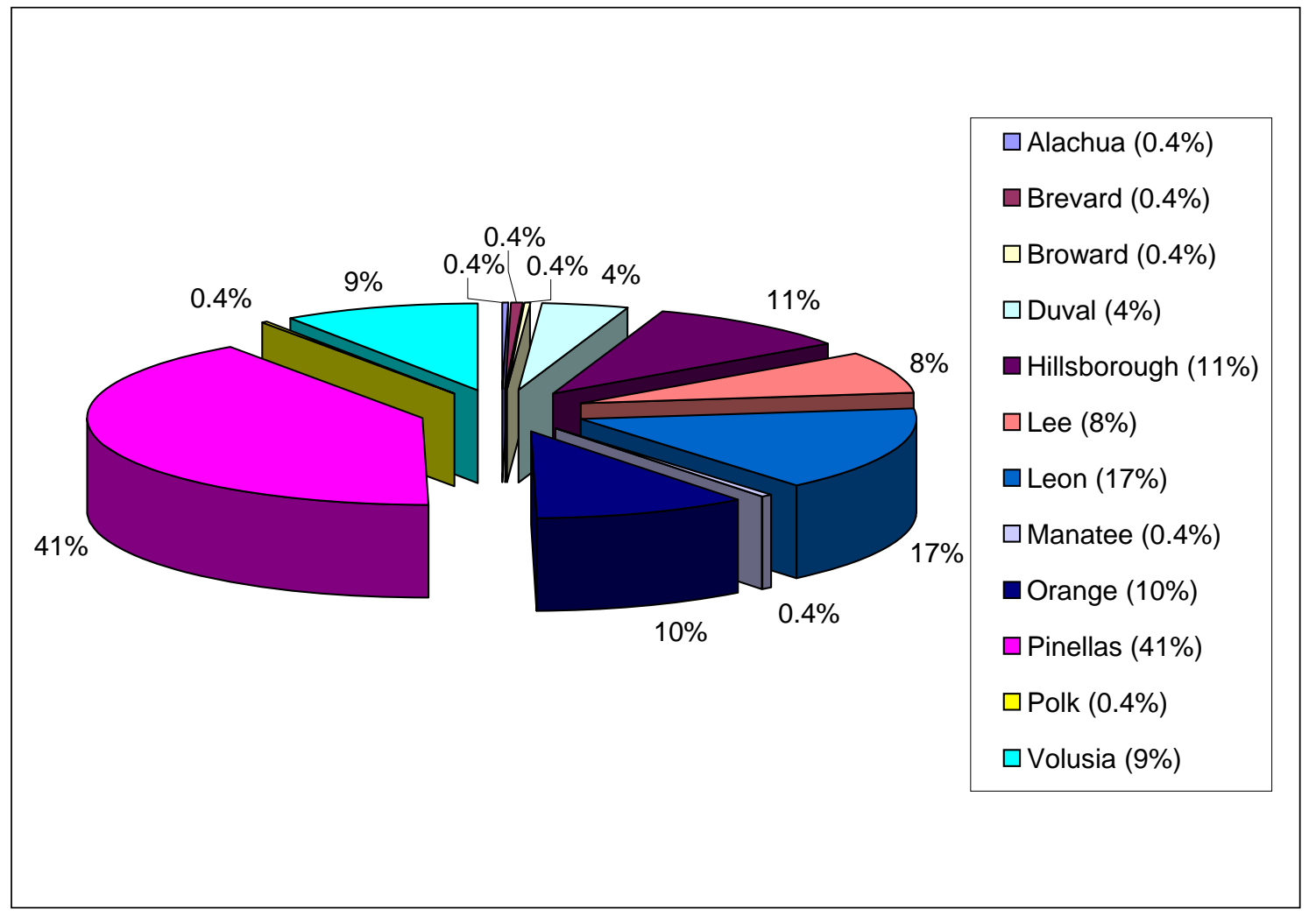

Figure 43 Counties Involved in Survey 
One problem with the questionnaire responses was the possibility for other operators and transit agency employees to influence the bus operators' perception of a new technology. Constant negative or positive feedback can influence the bus operators' views of a certain practice.

The number of surveys received from each transit agency can also impact the survey results. As shown in Figure 33, survey results from Pinellas County accounted for 41 percent of the bus operator survey. Weights could possibly be added to the transit agency responses; however, the results were very similar across counties with YTB decals and weights would not significantly impact the final results. Leetran and Votran responses only accounted for 8 and 9 percent of responses respectively, and this was another challenge since they are the only agencies that employed flashing yield signs in Florida, compounding the already existing issue of only a few buses in the fleet having this technology. JTA was the only agency in the study that employed no signs or lighting for the YTB law.

\section{Field Observation}

Field studies were conducted using a video camera mounted on a tripod. The camera was positioned at an adequate distance to capture buses moving in and out of bus pull-out bays. Locations had to be selected where a camera could be mounted and positioned with a clear view of the buses and cars. Far-side bus stop locations posed a particular challenge since the camera had to be located across the intersection. At certain times, the cross street traffic would block the view of the buses at far-side stops.

\section{Site Selection}

Three locations were chosen in Hillsborough County for field studies of HART buses, and three locations were also chosen in Orange County for field studies of LYNX buses. In each county one far-side, one mid-block, and one near-side bus stop were selected. The locations were chosen based on the traffic conditions and the existence of a bus pullout bay. For there to be any significant data, these locations had to have enough passenger volumes to observe the bus moving in and out of traffic to load and unload passengers. The locations also had to have high traffic volumes, otherwise there would be no difficulty in merging back into traffic. At least three hours were spent at each location. The locations chosen in Orange County were based on recommendations by Lynx staff. Field studies in Hillsborough County were conducted during the afternoon peak hours in

December 2006. Field studies in Orange County were conducted during morning and afternoon peak hours. Details of these field observations are shown in Table 3. 
Table 3 Hillsborough and Orange County Field Data Locations

\begin{tabular}{|c|c|c|c|c|}
\hline County & Location & Date & Start Time & 2006 AADT \\
\hline Hillsborough & $\begin{array}{l}\text { Fletcher Ave and Bruce B } \\
\text { Downs Blvd }\end{array}$ & 12-Dec-06 & 1:00 PM & 23500 \\
\hline Hillsborough & $\begin{array}{l}\text { Hillsborough Ave and } \\
\text { Florida Ave }\end{array}$ & 13-Dec-06 & $2: 20 \mathrm{PM}$ & 29500 \\
\hline Hillsborough & $\begin{array}{l}\text { Fletcher Ave and Dale } \\
\text { Mabry Blvd }\end{array}$ & 14-Dec-06 & 12:37 PM & 21000 \\
\hline Orange & $\begin{array}{l}\text { Kirkman Road and Conroy } \\
\text { Road } 1\end{array}$ & 24-Apr-07 & 6:44 AM & 30000 \\
\hline Orange & $\begin{array}{l}\text { Kirkman Road and Conroy } \\
\text { Road } 2\end{array}$ & 24-Apr-07 & 7:56 AM & 30000 \\
\hline Orange & $\begin{array}{l}\text { Orange Blossom Trail and } \\
\text { Holden Ave }\end{array}$ & 24-Apr-07 & 1:09 PM & 33500 \\
\hline
\end{tabular}

Basic geometrical information at Orange County locations was taken, which includes the distance from the bus stop to the nearest intersection and the geometry of the bus pull-out bay. The Average Annual Daily Traffic (AADT) for these locations was obtained from the Florida Department of Transportation to compare relative traffic conditions. Details of these field locations are presented in Appendix E.

Site visits were also made to Volusia County and Lee County in January 2007. Pictures were taken of potential data collection locations and YTB signage practices. Some of the pictures collected from Volusia and Lee County are presented in Appendix F along with pictures from Hillsborough County and Orange County.

During field visits to Volusia County, drivers were not observed to be using the flashing yield signs and the flashing yield signs in Lee County were not yet implemented therefore further video data was not collected in these counties.

\section{New Test Decal}

Based on the results of the literature review and preliminary bus operator surveys, a new YTB decal was designed by the project team and produced by Next Day Signs to be tested on StarMetro buses in Tallahassee. The new decal was made larger than the average decal in Florida to see if the larger sign has any effect on a transit system that previously never employed any YTB signage or lighting. Ten decals were made using reflective vinyl. The decal was made as an 18 inch square with the Florida Statute listed (Figure 44). The design of the new decal was based on results from the literature review, bus operator survey and the MUTCD yield sign. In the narrative portion of the questionnaire, some bus operators recommended a larger YTB decal; therefore, the new 
test decal was made larger than the typical decals seen in Florida. The red triangle, which is the sign used in the MUTCD was also made brighter and more like the MUTCD yield sign. The basic elements of the YTB decal were made similar to other YTB decals used in Florida. Initially, a large 69 inch decal, similar to the one used by Lynx in Orlando was considered but StarMetro did not want this larger decal to conflict with advertising on the back of the bus.

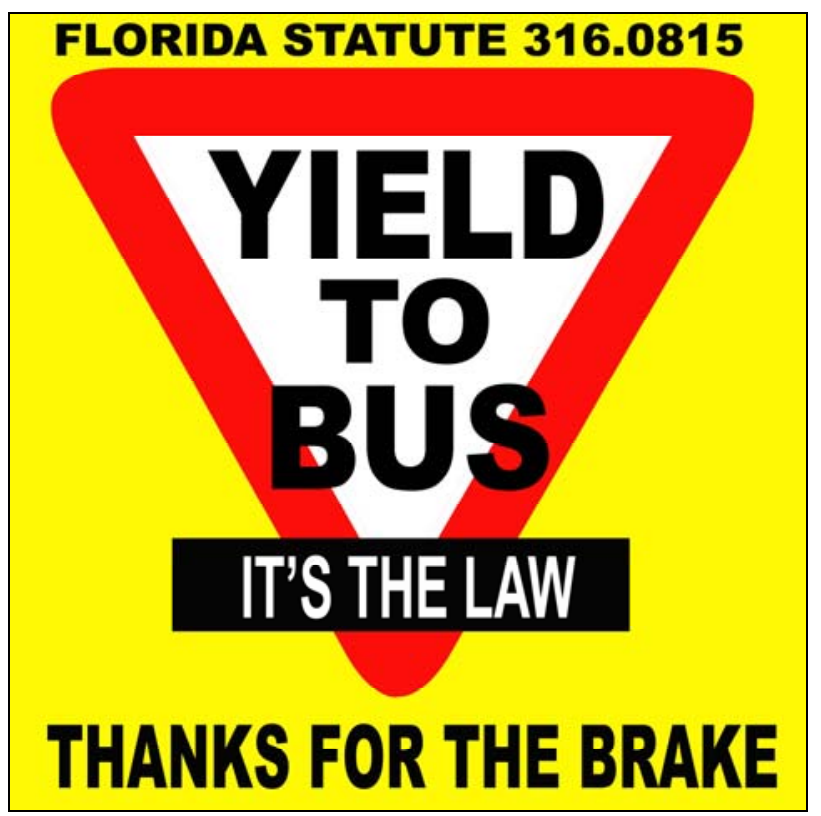

Figure 44 New YTB Decal for StarMetro

The StarMetro bus fleet consisted of 68 buses and the maintenance personnel were instructed to put the decals in the upper-left corner of the rear door panel of 10 buses.

The site locations chosen for the new test decal were based on suggestions from the StarMetro bus operators. Bus pull-out bays are not common in Tallahassee, therefore one of the locations chosen was a bus stop located in a right-turn lane where the bus needed to exit and go straight after loading and unloading passengers. The bus operators have to merge into traffic from the right-turn lane. The locations chosen are presented in Table 4.

Table 4 Leon County Field Data Locations

\begin{tabular}{llll}
\hline Location & Date & Start Time & 2006 AADT \\
\hline Macomb St and Georgia St & 16-May-07 & $7: 26$ AM & 8800 \\
Monroe St and John Knox Rd & 16-May-07 & 9:18 AM & 21500 \\
\hline
\end{tabular}

\section{Yield Behavior, Re-entry Delay, and Conflict Study}

From videos taken in the field, the re-entry delay, conflicts, and yield behavior of motorists were recorded. Different types of conflicts were observed in the field. Hard breaking maneuvers, weaving into oncoming traffic, and changing lanes abruptly behind the bus into a clear lane were considered conflicts. Secondary conflicts were created when motorists weaved into another lane causing drivers in that lane to abruptly apply the brakes. Yield behavior was determined by cars slowing down to allow the bus back into traffic. The purpose of the YTB law is to make motorists yield to the bus when it attempts 
to re-enter traffic from a specifically designated bus pull-out bay. The number of cars that would pass a bus attempting to merge back into traffic was also used as a measure of yield behavior. The number of motorists that would pass a bus attempting to merge is dependent on several variables including the traffic volume, road geometry and general visibility of the bus. The speed of the road and awareness of the YTB law also influences the motorists' yield behavior.

The motorists' yield behavior has a significant impact on the re-entry delay of buses. The re-entry delay for this study was used to evaluate the difficulty of bus operations in traffic. The re-entry delay of buses with different YTB technologies were compared to ascertain whether there was any noticeable difference in motorists' reaction to merging buses with and without YTB decals.

\section{Crash Data}

FDOT District 7 crash data, which includes Pinellas and Hillsborough counties, was used to look at bus crash trends between 2001 and 2005 for the Hillsborough Regional Area Transit (HART) and Pinellas Suncoast Transit Authority (PSTA) buses. The crash data is based on police crash reports. Bus crashes were separated in the database by vehicle type and vehicle use. Crashes where the bus was not at fault and the cause was rear-end or side-swipe were then separated. As buses move in and out of bus pull-out bays, they are prone to rear-end and side-swipe collisions. A total of 65 crashes in this category were obtained for Hillsborough County and 120 for Pinellas County. 


\section{CHAPTER 5 - DATA ANALYSIS}

\section{Survey Results}

Based on the literature review, electronic signs on the back of the bus are favored more than the decals. The bus operator questionnaires conducted produced these same results. When asked which technology they preferred, the majority (73 percent) chose the LED merging sign. The bus operators perceive the electronic sign to be more helpful in bus operations and they also perceive it to help with safety more than the decal. The only positive responses for the decals were in mentions of the large 69 inch decal present on some of the LYNX buses in Orlando. When asked if there was a noticeable difference in motorist yield behavior compared to before the implementation of the YTB technology, the bus operators with experience using the decal were more inclined to answer negatively. Figure 45 shows the results from question 9 of the survey which asked whether there was a noticeable difference in yield behavior after the implementation of the YTB technology. Figure 46 shows the bus operators' perception of the safety effects for different YTB technologies. Figure 47 shows the bus operators' response to question 8 on the questionnaire, which asked how helpful the YTB signs were.

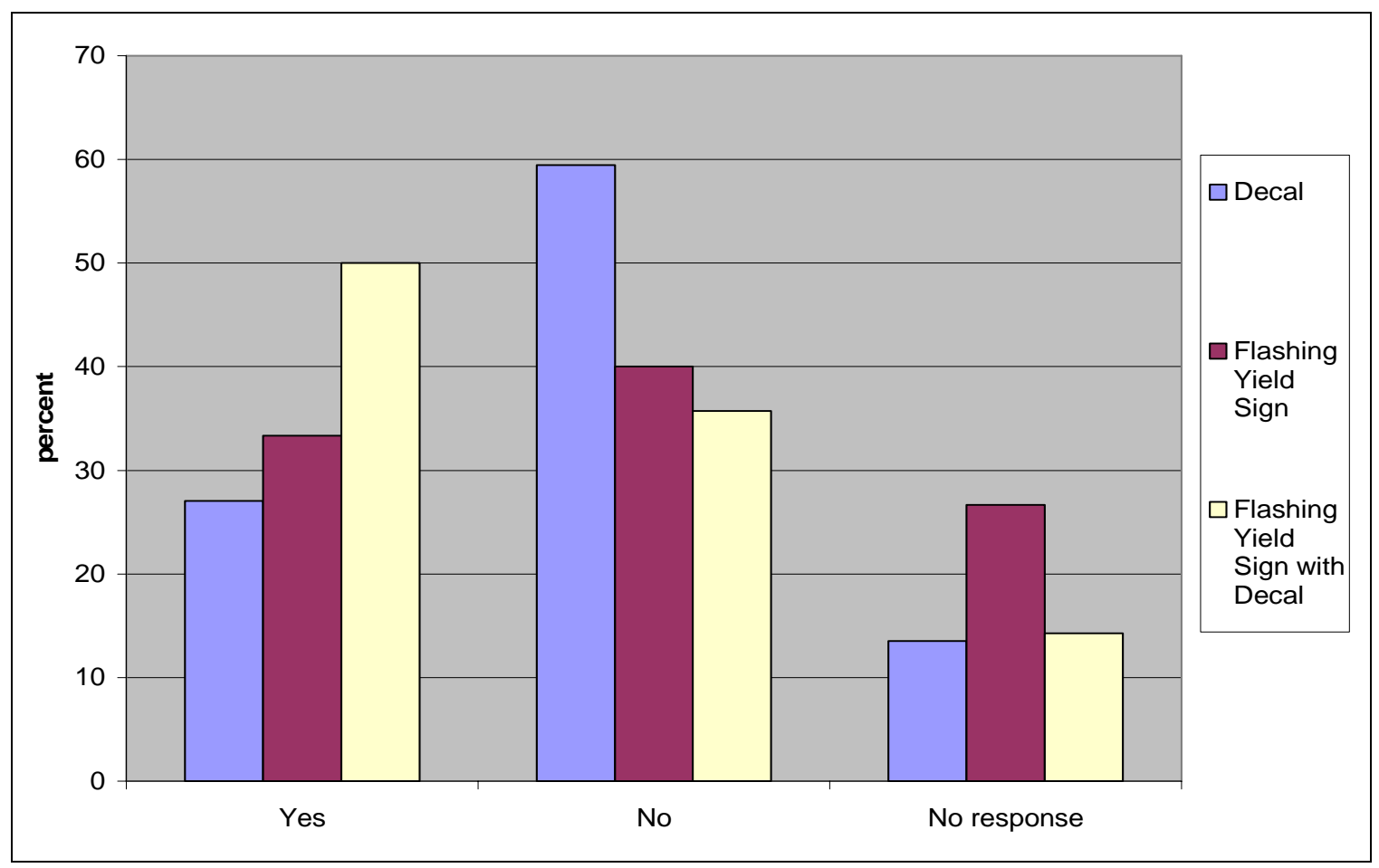

Figure 45 Differences in Yield Behavior Reported by Bus Operators 


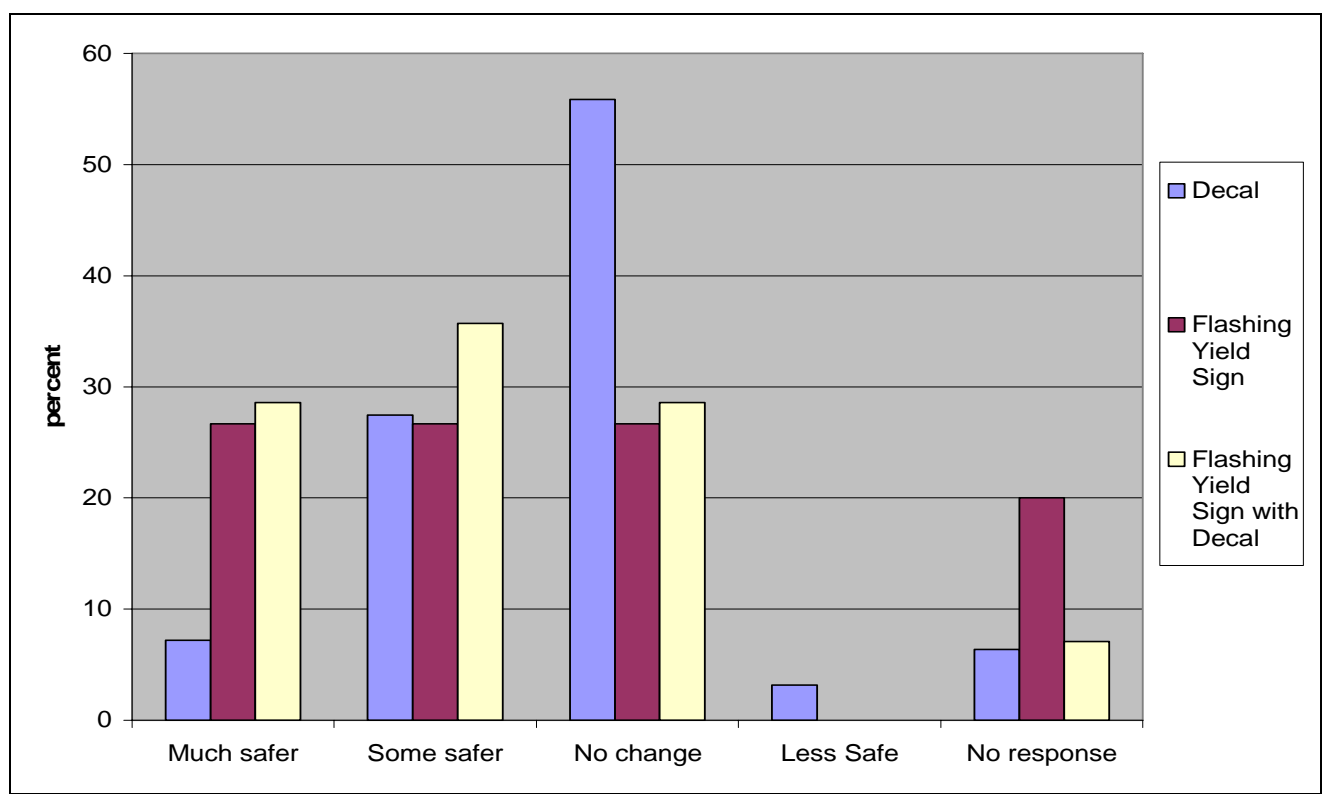

Figure 46 Bus Operators' Perception of Safety Effects

In the narrative portion of the questionnaire, the most common recommendation for a bus safety program was better police enforcement of the laws and more public service announcements about the presence of the YTB laws. Other recommendations made by the bus operators were to install stop arms like school buses and improve the existing lighting and signs. Bus operator narrative responses are available in Appendix D. When asked about the current Florida laws, 50 percent of bus operators felt that the current laws are insufficient and 5 percent had no response. When asked about the conditions where motorists should yield to the bus, 76 percent of operators felt that there are other conditions in which motorists should yield.

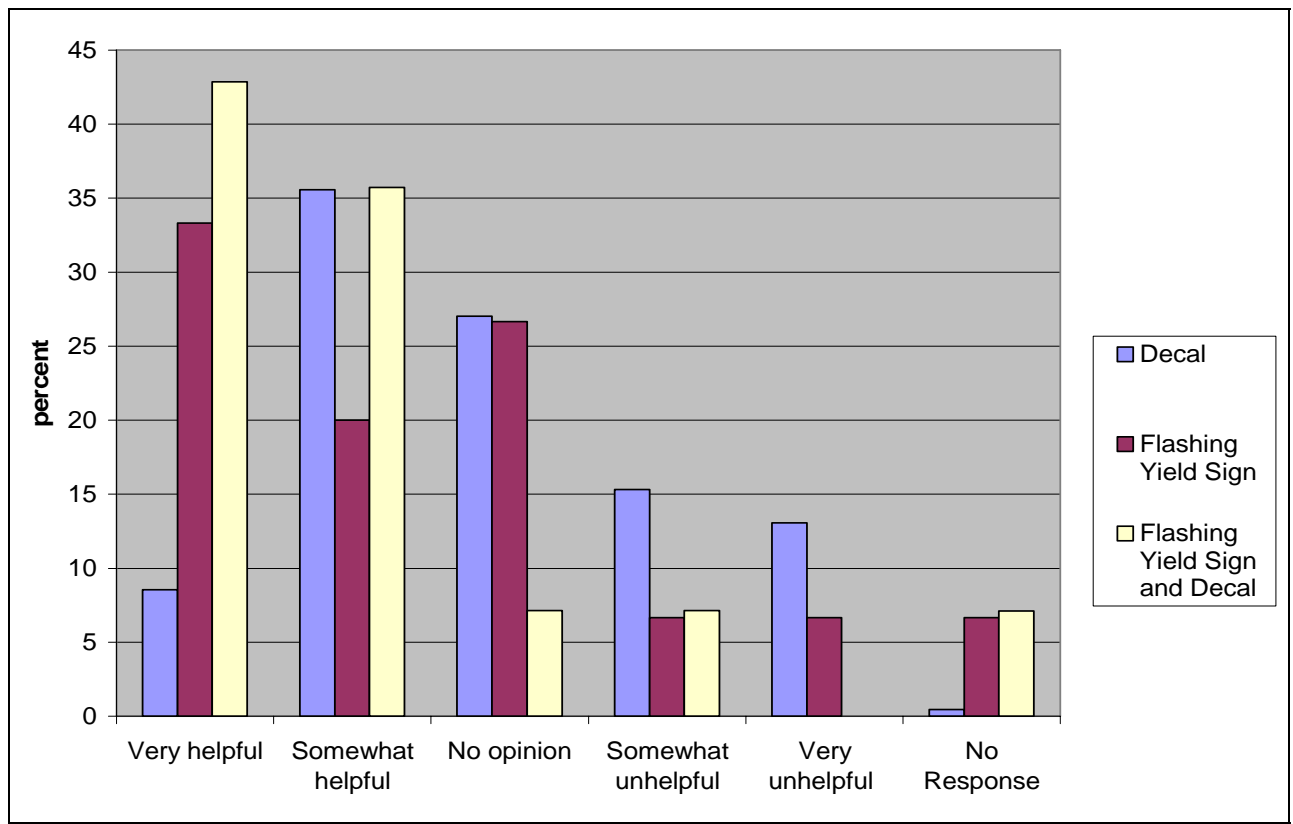

Figure 47 Bus Operators' Perception of the Helpfulness of YTB Signs 
In order to evaluate whether there should be consideration for expanding the current Florida statute to include yielding to a bus merging back from any offline stop, the operators were asked if they have any bus pull-out bays on their route. Although 74 percent of operators responded that there were bus pull-out bays on their routes, many of them also responded that they use right-turn lanes or wide shoulder lanes to load and unload passengers as seen in Figure 48, which shows how often bus operators use these other offline stops. Some operators also commented that they do not use designated bus pull-out bays because it makes pulling into traffic more difficult.

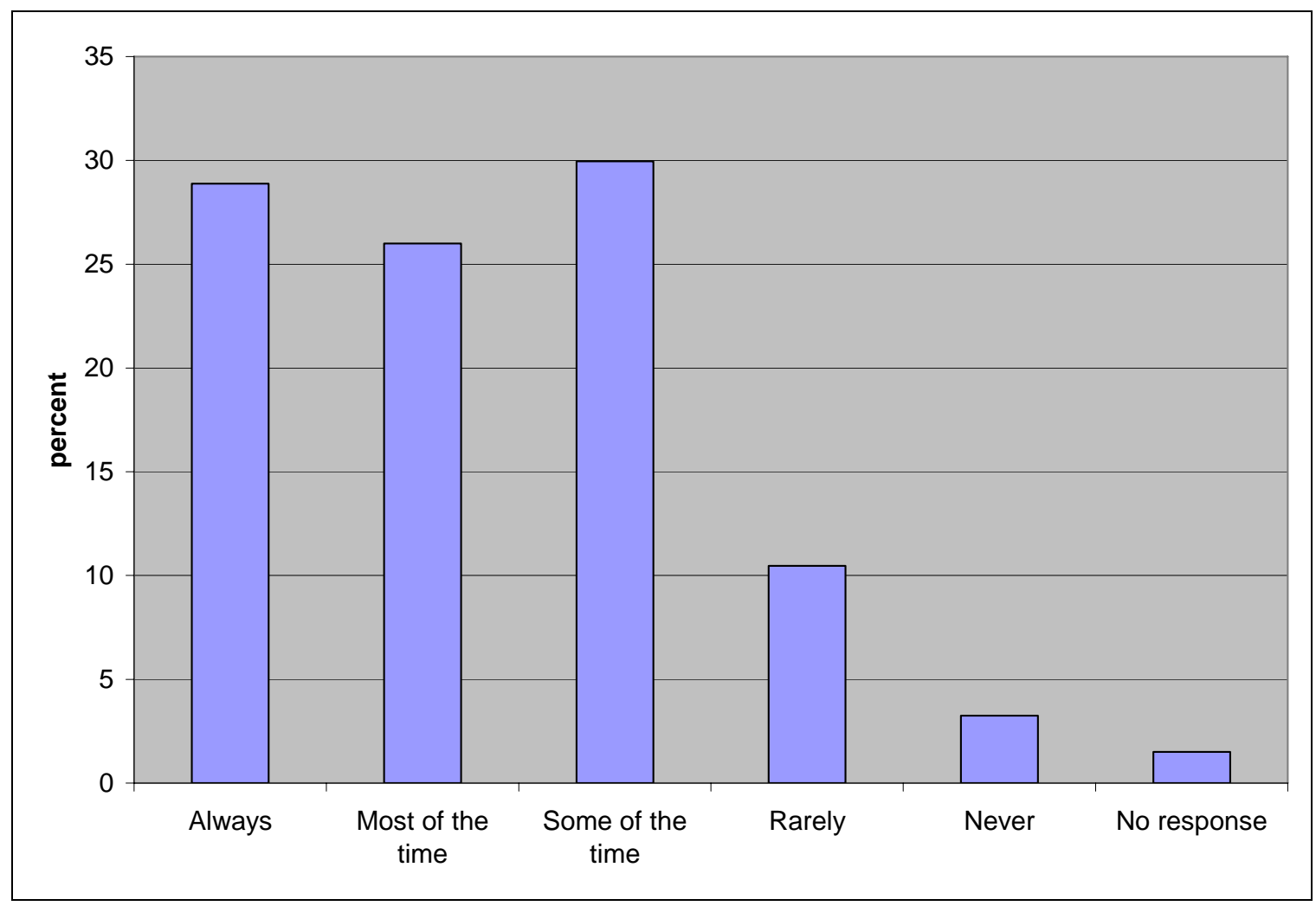

Figure 48 Bus Operators' Use of Right-turn Lane or Shoulder

\section{Field Observations}

From the field data collected, it was obvious that the location of the bus pull-out bay and the traffic volume affected the yield behavior of other motorists. Far-side bus stop locations had the unique problem of being located where drivers would have to yield in the physical area of the intersection to allow buses to enter. Therefore, motorists never yielded to the bus at a far-side stop unless the bus did not use the pull-out bay, forcing traffic to accumulate behind the bus. This location may be a dangerous place to attempt to yield since following motorists do not expect another motorist to slow down in the middle of the intersection. The average re-entry delays for the hours recorded ranged from 13 to 36 seconds as shown in Table 5 . 
Table 5 Average Re-entry Delay by Location and AADT

\begin{tabular}{|c|c|c|c|c|}
\hline County & Location & $\begin{array}{l}\text { Location } \\
\text { type }\end{array}$ & 2006 AADT & $\begin{array}{l}\text { Average } \\
\text { Re-entry } \\
\text { Delay (s) }\end{array}$ \\
\hline Hillsborough & $\begin{array}{l}\text { Fletcher Ave and Bruce B } \\
\text { Downs Blvd }\end{array}$ & Near-side & 23500 & 13 \\
\hline Hillsborough & $\begin{array}{l}\text { Hillsborough Ave and } \\
\text { Florida Ave }\end{array}$ & Far-side & 29500 & 32 \\
\hline Hillsborough & $\begin{array}{l}\text { Fletcher Ave and Dale } \\
\text { Mabry Blvd }\end{array}$ & Mid-block & 21000 & 15 \\
\hline Orange & $\begin{array}{l}\text { Kirkman Road and Conroy } \\
\text { Road } 1\end{array}$ & Near-side & 30000 & 13 \\
\hline Orange & $\begin{array}{l}\text { Kirkman Road and Conroy } \\
\text { Road } 2\end{array}$ & Far-side & 30000 & 13 \\
\hline Orange & $\begin{array}{l}\text { Orange Blossom Trail and } \\
\text { Holden Ave }\end{array}$ & Mid-block & 33500 & 36 \\
\hline
\end{tabular}

The delay of buses is dependent on several variables, including the number of lanes, location of bus stop, hourly traffic volumes, and the attitude towards buses in that specific location.

Dangerous weaving and conflicts were observed as cars attempted to move out of the lane that the bus was merging into. There seems to be no difference in motorist yield behavior with the presence of a decal. The weaving observed caused conflicts with other vehicles on the road, not just the buses, so the crash data consisting of only bus accidents may not accurately reflect the accidents caused as buses merge into traffic. Some accidents may occur between the weaving automobile and the automobile in the lane in which the weaving motorist is trying to merge. The number of conflicts observed during a specific time period was dependent on the traffic conditions and headway of the bus. Higher traffic volumes and smaller headways will increase the number of conflicts.

In these studies there were no occurrences observed of drivers yielding to the bus, therefore the number of vehicles that would pass the bus as it attempted to merge into traffic was the only variable recorded for yield behavior. The only time drivers were seen slowing down while approaching a bus operator that had signaled his or her intent to merge into traffic was when traffic was backed up to the bus pull-out bay, allowing the bus operator to merge in-between two stopped cars. In this scenario there were no conflicts recorded, which was the situation often at the Florida Avenue and Hillsborough Avenue location in Hillsborough County. 
Table 6 shows the conflict rate expressed in conflicts per 100 buses obtained at each site location as well as the average headway of the buses that stopped and the average number of cars that passed the bus after the bus operator signaled his or her intent to merge back into the travel lane. Appendix $\mathrm{G}$ includes the field observations for all these locations.

Table 6 Average Headway, Conflict rate and Yield Behavior from Field Data

\begin{tabular}{llccc}
\hline County & Location & $\begin{array}{c}\text { Average } \\
\text { Headway } \\
\text { (minutes) }\end{array}$ & $\begin{array}{c}\text { Conflicts } \\
\text { per 100 } \\
\text { buses }\end{array}$ & $\begin{array}{c}\text { Average } \\
\text { number of } \\
\text { cars that } \\
\text { pass after } \\
\text { left signal }\end{array}$ \\
\hline Hillsborough & $\begin{array}{l}\text { Fletcher Ave and Bruce B Downs } \\
\text { Blvd }\end{array}$ & 22 & 18 & 9 \\
Hillsborough & Hillsborough Ave and Florida Ave & 30 & 0 & 6 \\
Hillsborough & Fletcher Ave and Dale Mabry Blvd & 34 & 51 & 3 \\
Orange & Kirkman Road and Conroy Road 1 & 24 & 8 & 10 \\
Orange & Kirkman Road and Conroy Road 2 & 25 & 33 & 0 \\
Orange & $\begin{array}{l}\text { Orange Blossom Trail and Holden } \\
\text { Ave }\end{array}$ & 9 & 34 & 9 \\
\hline
\end{tabular}

\section{New Test Decal}

No significant findings were obtained from video data of the new decal used at StarMetro possibly because the video was taken the same day the new decals were implemented. During the hours of data collection there was no significant difference in motorists' behavior around buses with and without the new decal. Video data was collected the morning after the new decals were implemented, so perhaps the motorists did not have a chance to react to the new signs. Operator questionnaires were then distributed 2 weeks after the new decals were implemented to see if they noticed any difference in motorists' behavior after 2 weeks. Forty-one percent of operators said there was a noticeable difference in yield behavior, but a few operators commented in the narrative section that motorists are still not used to the new decals.

The decals were restricted to buses that did not have advertising on the back and also to the newer Gillig buses since the older RTS models did not have adequate space to accommodate an 18 inch decal. The lighting configuration on the back of the buses constrained the exact location of the decal. On the older Gillig buses, the decal could be placed in the corner of the rear door panel. On the newer Gillig models, the decal had to be placed closer to the center to avoid the rear lights. Figure 49 shows the locations where the new test decals were placed on the StarMetro Gillig buses. 


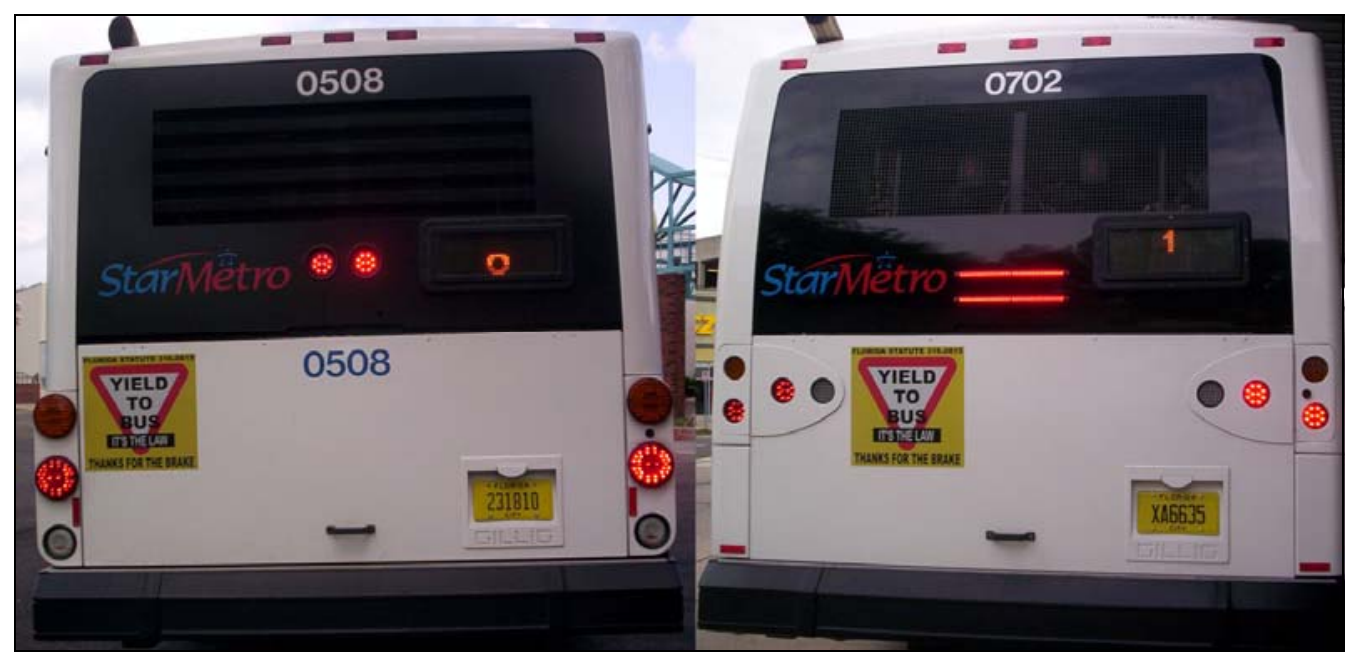

Figure 49 StarMetro Decal Placements

\section{Crash Analysis}

The Pinellas county crash data suggests that bus crashes between 2001 and 2005 remained constant. The YTB decals were installed on all PSTA buses in 2005 but no noticeable trend was seen in the bus crashes from January 2005 to December 2005. These results are inconclusive because the exact date of the installation of YTB decals was not ascertained.

The bus crash trends from 2003 to 2005 in Pinellas County, using crash data, shows that for crashes involving at least one vehicle defined as a public transit bus, the bus was only at fault in 31 percent of cases. In these cases where the bus was not at fault, 48 percent of accidents occurred at an intersection, 10 percent were influenced by an intersection, and 9 percent were in a public bus stop zone. In these cases where the bus was not at fault, 51 percent of the cases involved a bus slowing/stopped or stalled and 38 percent involved a bus traveling straight ahead (not merging or turning). These findings are consistent with previous research and the field observations.

The 2003 to 2005 Hillsborough crash data shows that 34 percent of bus crashes were rear-end collisions, 23 percent were angle collisions and 24 percent were side-swipe collisions. There was an increase in bus accidents between 2001 and 2005. The HART decals were installed between 2001 and 2002; therefore they do not appear to have any effect on bus crashes. The number of crashes fluctuated yearly with an increase from 8 to 12 crashes between 2001 and 2002 and a decrease from 12 to 8 between 2002 and 2003 . The number of crashes rose again to 16 in 2004.

This preliminary crash analysis indicated that yield to bus decals currently on most of public transit buses had no any effects on the bus related crashes. A further and more detailed analysis needs to find out what are the crash patterns and crash rates near bus stops, especially near bus pull-out bays. 


\section{CHAPTER 6 - CONCLUSIONS AND RECOMMENDATIONS}

\section{Conclusions}

Signs and bus exterior lighting can be used to improve bus safety and operations but proper law enforcement must be in place for the technology to be effective. Exterior bus lights can warn motorist that the bus is merging into traffic but they must be able to understand the meaning of these signals. There needs to be a standard procedure for buses merging into traffic because many different lights of different colors can be confusing to the motorist. There is also a stigma attached to driving behind slow moving buses, which causes motorists to find ways around them regardless of the laws and warning lights. Therefore, law enforcement is needed to change the drivers' yield behavior. There are some questions pertaining to the extent which the public is being educated about the law. Currently, in the 2007 Florida Driver's Handbook, there is mention of the law requiring motorists to yield to the bus, but this is just a small section of the handbook and could easily be overlooked unless it is being tested in driver exams. Further research can be done to evaluate both the public's understanding of bus rear lighting and their knowledge of the laws. This awareness can be compared to other states in which the laws are present to see if a different environment and attitude towards transit will also affect yield behavior. Additionally, a look into citations issued would be a good measure of law compliance and enforcement.

Decals, although they do not get favorable responses from bus operators, nor appear to change driver yield behavior, can be used as public announcements acting as small advertisements on the back of the buses, provided motorist get the time to read it. The dilemma with bus decals is that the lighting configuration on the back of buses does not always allow for larger decals, and small decals cannot easily be read by other motorists. Standardizing a yield decal for Florida buses may be a difficult feat since the lighting layout on the back of the bus constrains the size and location of the decals. Larger decals have a more favorable response from bus operators; however, these decals cannot be accommodated on all buses due to conflicts with advertising and lighting configurations. The flashing yield sign or one of the more recent technologies that are not yet on the market may be more beneficial for bus operations and safety. However, there needs to be a standardized way to use the flashing warning signs so that motorists can understand what the sign means. NHTSA recognizes that adding more lights will not necessarily improve bus safety. There must be further research into these new LED lights with dynamic messages that are favored by bus operators. Public awareness of the dangers of hastily weaving behind a bus and awareness of the existence of yield-to-bus laws is vital for supporting any new technology employed to improve bus safety and operations.

Bus pull-out bays are sometimes needed in certain locations. In places where dwell times are long, the buses should be out of the travel lane in order to increase the capacity of the road. This can reduce queuing delays for motorists, unfortunately, buses using the pullout bays will lose some time when trying to merge back into traffic. While yield-to-bus laws were created to alleviate this problem, it is not safe to apply it to all off-line bus stops. At far-side bus stops, it is not safe for motorists to yield to a bus if they are in an intersection. More in-depth research can be conducted to justify the use of pull-out bays 
and delay savings to the transit agency when there is compliance with the law. The figures presented in this research for re-entry delay could be explored to see the impact these small delays will have on the entire route. Future research can be done to explore re-entry delay, delay propagation, and schedule adherence. A model can be developed to predict the delay a bus will have based on variables such as the number of lanes, location of bus stop, distance to the nearest intersection, hourly volumes, speed limit, and bus headway.

Additionally, research needs to be done on the dynamic LED signs mentioned in this research. If implemented, they do not appear to cause any conflicts with other rear lighting, and since they display a clear message, they do not appear to have any ambiguous meanings. However, this would have to be tested in the field to make sure drivers understand the meaning of the word messages.

\section{Recommendations}

\section{Bus Rear Lighting and Signage}

Based on field observations of the rear-lighting on Florida buses, there is no set lighting configuration used. Although a basic configuration is observed based on NHTSA standards, the colors and types of lights vary greatly within the limits of NHTSA. The amber strobes lights can be confused with turning signals if only half of the bus rear is visible, which is the situation at some bus bay locations. In this situation it is difficult to tell if a bus is stopped and picking up passengers or trying to merge into traffic. The typical motorist does not have the time to decipher the bus actions, so there needs to be some guidelines for the placement of optional lights on the back of the bus. The Federal Motor Vehicle Safety Standards and Regulations (FMVSS) allow for stop lamps that are activated by the braking system to be red or amber and the turn signals can also be red or amber. To standardize the lighting on the back of the bus, a set color should be chosen.

The majority of bus operators prefer the flashing Merge Alert sign, which is currently not being used by any transit agencies. Further tests can be done on this LED sign to see if it is worth applying. If it is implemented, there needs to be clear guidelines as to what other optional lighting is added to the bus. If a dynamic LED sign is placed on the back of the bus, it probably should not be used simultaneously with flashing hazard lights or deceleration lights.

\section{Roadside Signs and Pavement Marking}

Since the MUTCD currently has no signage or pavement markings for the YTB law, new signage and pavement markings can be developed based on the existing practices for yielding to pedestrians and bicyclists. One concern would be that adding more to the MUTCD may only add to driver confusion. Many roads are already congested with roadway signs and pavement markings that give drivers more information than they are able to digest. Therefore, additional signs and pavement marking for the YTB law would have to be used under strict engineering judgment in areas where many conflicts are observed. Figure 50 shows possible YTB roadway signs that can be added to the MUTCD. 


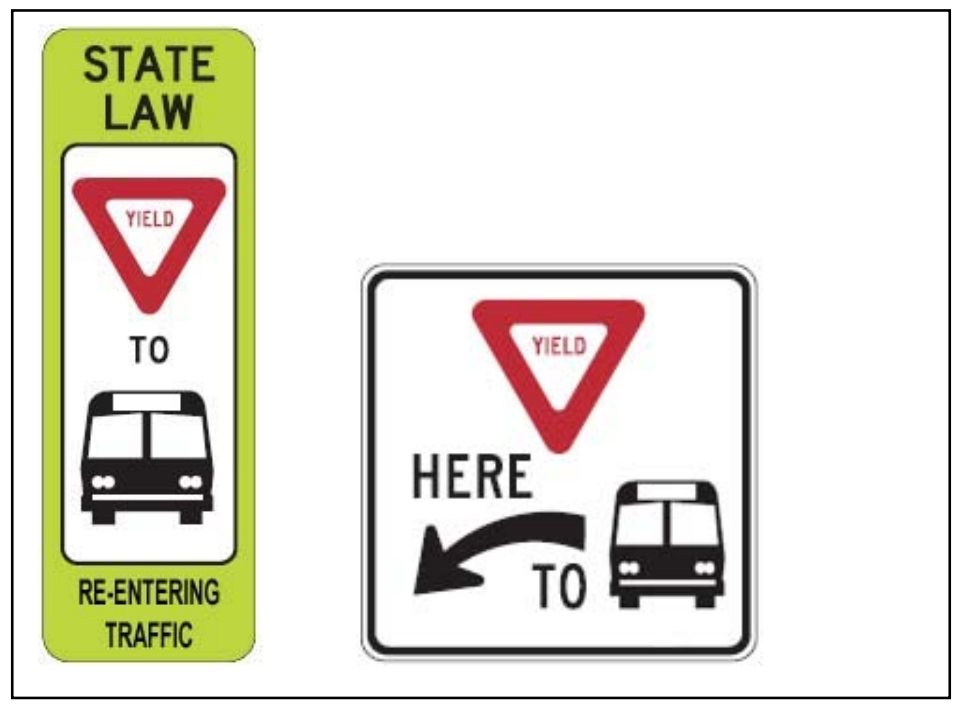

Figure 50 Yield-to-Bus Roadway Signs

Additionally, roadside flashing beacons that are activated by a bus in a bus pull-out bay can be explored. The location of these beacons would be very strict since it may conflict with intersection lights at near-side and far-side bus stop locations.

\section{Legislation}

The current Florida statutes make no mention of how the YTB law is to be implemented and this possibly contributes to the lack of law enforcement. Taking the example of other states, the Florida Statute can be expanded to include a penalty for not yielding to the bus or a classification for the type of offence committed. The viability of the law is partially dependent on how well it can be enforced, so adding more information on the implementation and penalties should be beneficial.

Other States require a public awareness campaign to let motorists know about the yield-to bus laws and this is something that needs to be done in Florida. Like in other states, a system should be set up to evaluate the necessity of the law based on the total number of traffic collisions, traffic congestion issues, public opinion, and the efficiency of transit operations.

According to the bus operator survey, the majority of operators believe that there are other conditions in which motorists should yield to a public transit bus. The bus operators also reported that they use shoulders and right-turn lanes to pull out of traffic, not just a specifically designated bus pull-out bay. A detailed look into Florida bus crashes and delay problems can be used to determine whether it is necessary for motorists to yield under other conditions. Other states have not specified that motorists should yield only at specifically designated bus pull-out bays; therefore, buses that pull over in any off-line stop would be covered under the laws. Removing the requirement of only yielding to buses from a designated bus bay should be considered especially since some counties do not have many bus bays, yet buses still have difficulty merging into traffic after loading and unloading passengers. 


\section{Further Research}

\section{Development of Roadside Signage to Help Bus Merge Back into Traffic Safely}

Results from this NCTR research project (Phase I) indicated that MUTCD currently has no signage or pavement markings for the YTB law. One of three recommendations based on this research is to develop new roadside YTB signage or advanced warning flashing beacons that can be activated by a bus in a bus pull-out bay.

Further research needs to develop new roadside signage to facilitate the YTB law, and evaluate the operations and safety effects of the developed signage on public transit and traffic. A concept developed based on previous research is to use an advanced warning flashing beacon that indicates that a bus is pulling out of a bay. This system involves an underground detector that is installed at the front of the bus pull-out bay. Once a bus is detected at the bay, the advanced warning yellow signal will start to flash (similar to school zone flashing beacons). The intent is to slow traffic down, creating a safer condition for buses to reenter traffic. Some considerations should be given to posting a lower speed limit when light is flashing. Figure 51 shows a YTB flashing beacons installed in Tampa downtown area.

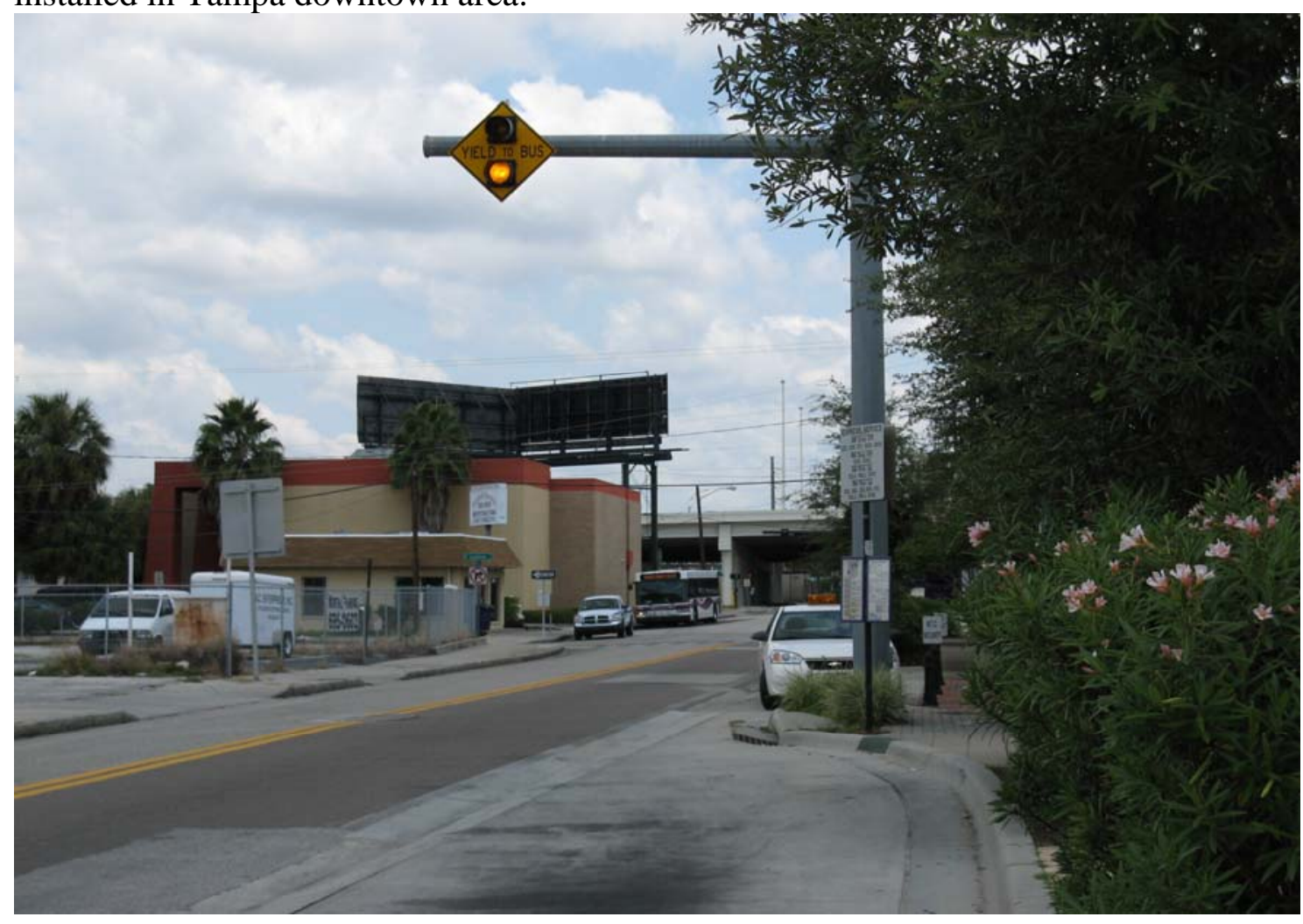

Figure 51 Yield-to-Bus Roadway Flashing Beacons 
The results of phase I of this NCTR project clearly showed that merging into traffic has been a great concern for transit agencies and bus operators. Field observations and conflict studies showed that additional delays to the buses and many traffic conflicts were caused when buses attempted to move back into traffic from a pull-out bay. This further research will give a clear definition of when motorists should yield to buses based on the roadside signage. The implementation of new roadside signage will directly result in significant improvements to bus operations and safety, and enforcement of YTB laws.

\section{Evaluation of the Latest Yield-to-Bus LED Flashing Signs}

This project concluded that the decal currently implemented in Florida is not effective. LED flashing yield signs have recently been implemented for two Florida transit agencies, and some new technologies such as "Merging" electronic arrows and others are on the market. The real effects of this sign on safety and operations are not clear. Further research needs to be done to evaluate the operational and safety impacts of the latest LED Yield to Bus Signage. It should also be determined whether these new technologies should be included in the YTB statues. A further look into the procedures for pulling in and out of bus pull-out bays would have to be done before adding additional lights. It was observed that different bus operators had varying methods for moving in and out of traffic. Some kept on their hazard lights while the bus was stopped, while others did not. Bus operators also turned on their left signals at different times when attempting to merge into traffic. With the addition of a new LED sign, there would need to be a set procedure for what other lights can be used at the same time and the order in which these lights should be used.

\section{Development of a Program to Increase Public Awareness of YTB laws}

According to a study done for Transit Cooperative Research Program (TCRP) Synthesis 49 , over $60 \%$ of bus operators surveyed in Broward County felt that less than $10 \%$ of the driver population was aware of the yield-to-bus laws. Currently in the 2007 Florida Driver's Handbook, there is mention of the law requiring motorists to yield to the bus, but this is just a small section of the handbook and therefore it could easily be overlooked unless it is being tested in driver exams. Further research can be done to evaluate both the public's understanding of bus rear lighting and their knowledge of the laws. This awareness can be compared to other states in which the laws are present to see if a different environment and attitude towards transit will also affect yield behavior. Additionally, a look into citations issued would be a good measure of law compliance and enforcement. Public awareness of the dangers of hastily weaving behind a bus and awareness of the existence of yield-to-bus laws is vital for supporting any new technology employed to improve bus safety and operations.

\section{Development of a Model to Estimate Re-entry Delays}

More in-depth research can be conducted to justify the use of pull-out bays and delay savings to the transit agency when there is compliance with the law. Re-entry delay could be explored to see the impact these small delays will have on the entire bus route. Future research can be done to explore re-entry delay, delay propagation and schedule adherence. A model can be developed to predict the delay a bus will have based on 
variables such as the number of lanes, location of bus stop, distance to the nearest intersection, hourly volumes, speed limit, and bus headway. Computer simulation can be used to develop the re-entry delay models for a bus moving back into traffic from a pullout bay. These delay statistics will be of special interest to transit agencies and planning professionals. Research should also be conducted to determine the total person-minutes delays of both bus passengers and other vehicle passengers that result from the use of bus pull-out bays.

\section{Safety Effects of Bus Merging Back Into Traffic from a Pull-Out Bay}

Based on videos in the field, crash records showing only bus accidents may only be a portion of the accidents caused by buses attempting to merge into traffic. The weaving observed caused conflicts with other vehicles on the road, not just the buses; therefore, the crash data consisting of bus accidents only may not accurately predict the accidents caused as buses merge into traffic. Some accidents may occur between the weaving automobile and the automobile in the lane in which the weaving motorist is trying to merge. Further research can be done to investigate these other incidents around off-line bus stops. The traffic conflicts study can be used to supplement the crash analysis. 


\section{REFERENCES}

46.61.220 Transit Vehicles, Revised Code of Washington (RCW) Chapter 46.61, Rules of the Road.

39:4-87.1 Right of way of certain buses reentering traffic, Title 39 Motor Vehicles and Traffic Regulations, New Jersey Public Law 2003.

169.20 RIGHT-OF-WAY, Chapter 169, Traffic Regulations, Minnesota Statutes 2006.

316.0815 Duty to Yield to Public Transit Vehicles, Chapter 316, Florida Statute, Florida State Uniform Traffic Control, Tallahassee, July 1999.

811.167-Failure to Yield Right-of Way to Transit Buses; Rules; Penalty, Rules of the Road, Oregon Revised Statutes, Oregon State Legislature, Salem, July 10, 1997.

21810 Right of Way: Yielding to Buses, California Vehicle Code (CVC), Section 21810, Department of Motor Vehicles, Sacramento, September 27, 1999.

2006 Florida Transit Handbook, Florida Department of Transportation, Center for Urban Transportation Research, Tampa FL.

2007 Florida Driver's Handbook, Department of Highway Safety and Motor Vehicles Tallahassee, FL.

Al-Masaeid, H., and Sinha, K. (1994). “Analysis of Accident Reduction Potentials of Pavement Markings” Journal of Transportation Engineering, 120(5) 723-736.

Brilon, W. and Laubert, W. (1994). “Priority for Public Transit in Germany.” Journal of Advanced Transportation. Vol. 23, no. 3. p. 313.

Carson, J., Holick, A., Park E., Woodridge, M., and Zimmer, R. (2005). Development And Evaluation Of An Active Warning Device For School Bus Loading And Unloading Points In Areas Of Limited Visibility. FHWA/TxDOT Report 0-4749-1.

Center for Urban Transportation Research (1997). Motorist Comprehension of Florida's School Bus Stop Law and School Bus Signalization Devices. Florida Department of Education Final Report. 
City of Ottawa Home page (2006). Media Advisories, News Releases and Public Service Announcements. Available at http://www.ottawa.ca/cgi-

bin/pressco.pl?\&Elist=1462\&lang=en Accessed October 24, 2006.

Cohn, T. "On the Back of the Bus.” Access Fall 2002, 17-21, Available online at http://www.uctc.net/access/access21.pdf Accessed July 26, 2006.

De Langen M., Tembele R. (1994). Guidelines for Pedestrian and Bicycle Traffic in African Cities. SSATP Urban NMT studies. E \& S. Africa. Report 2.

Florida Planning and Development Lab (2004). Accessing Transit: Design Guidelines for Florida Bus Passenger Facilities. Florida Department of Transportation.

Gan, A., Yue, A., Joan, S., Zhao, F. (2002). Development of Operational Performance Models for Bus Lane Preferential Treatments, Final Report, Florida Department of Transportation, BC-792.

Hanscom, F., Dewar, R. (2001).Human Factors. Traffic Control Devices Handbook edited by James L. Pline. Institute of Transportation Engineers, Washington D.C.

Jacques, K., and Levinson, H. (1997). Operational Analysis of Bus Lanes on Arterials. TCRP Report 26, Transit Cooperative Research Program, Transportation Research Board, National Research Council, National Academy Press, Washington D.C.

Katz, B., Rousseau, G., Warren, D. (2003). Comprehension of Warning and Regulatory Signs for Speed. ITE 2003 Annual Meeting and Exhibit held in conjunction with the ITE District 6 Annual Meeting, Seattle, WA

King, R.D., (2003). TCRP Synthesis 49: Yield-to-Bus - State of the Practice. Transportation Research Board, Washington D.C.

Kittelson \& Associates, Inc., et. al., (2003). Transit Capacity Quality of Service Manual, $2^{\text {nd }}$ Ed., TCRP Report 100, Transit Cooperative Research Program, Transportation Research Board, Washington, D.C.

KRW, Inc. (1996). TCRP Report 12: Guidelines for Transit Facility Signing and Graphics. National Academic Press, Washington D.C.

Lee, S., Wierwille, W., Klauer, S. (2002). Enhanced Rear Lighting And Signaling Systems: Literature Review and Analyses of Alternative System Concepts. USDOT Technical Report DOT HS 809425.

Lehman Center for Transportation Research (2002). "Development of Operational Performance Models for Bus Lane Preferential Treatments”. Florida Department of Transportation. 
Luke Transportation Engineering Consultants (2004). "Florida State Highway System Transit Safety Study.” Available online at http://www.dot.state.fl.us/transit/Pages/FDOTTransitSafetyStudyReport.doc. Accessed July 19, 2006.

McGehee, D., Dingus, T. A., \& Mollenhauer, M. (1994). IVHS countermeasures for rearend collisions, Task 2. U.S. Department of Transportation NHTSA Technical Report DTNH22-93-C-07326. Washington, DC.

Metropolitan Council Homepage (2006). New bus decals remind automobile drivers to yield. Available at http://www.metrocouncil.org/Directions/transit/transit2006/yield.htm. Accessed October 16, 2006.

Misener. J. A., Tsao, H.-S. J., Song, B., \& Steinfeld, A. (2000). The emergence of a cognitive car following driver model with applications to rear-end crashes with a stopped lead vehicle. Presented at the 79th Annual Meeting of the Transportation Research Board. Washington, D.C.: Transportation Research Board.

Moffa, P., Austin, J., Dow, G.S., Ikizyan, I., and Hibben, M. (1996). Development of Performance Specifications for Collision Avoidance Systems for Lane Change, Merging, and Backing. Task 5 Interim Report: Crash Countermeasure Technology Investigation. (DOT-HS 808506). National Highway Traffic Safety Administration (NHTSA), Washington, D.C.

Muhlrad, N. (1993). Traffic Conflict Techniques and Other Forms of Behavioural Analysis: Application to Safety Diagnoses. 6th ICTCT workshop Salzburg Proceedings. Available online at http://www.ictct.org/workshops/93-Salzburg/Muhlrad.pdf. Accessed July 1, 2007.

National Center for Statistics and Analysis (2006). Traffic Safety Facts 2005: A Compilation of Motor Vehicle Crash Data from the Fatality Analysis Reporting System and the General Estimates System, National Highway Traffic Safety Administration, National Center for Statistics and Analysis, U.S. Department of Transportation, Washington DC 20590.

National Institute for Aviation Research (2005). Mass Transit Crashworthiness Statistical Data Analysis. Report No. FTA-002.

National Research Council (2001). "Making Transit Work: Insight from Western Europe, Canada, and the United States - Special Report 257." National Academics Press. Washington D.C.

Preston, H. and Storm, R. (2003). Reducing Crashes at Rural Thru-STOP Controlled Intersections. Mid-Continent Transportation Research Symposium. August 21-22, 2003, Ames, Iowa 
Recht P. [Letter to Jeffrey Echt, 1995]. NHTSA's Interpretation Files.

Tsai J., Graham D. (2005). Reducing the Illegal Passing of School Buses: Video Footage Assists in Documentation, Training, and Raising Public Awareness. TR NEWS 237.

Technology and Management Systems, Inc. (2001). TCRP Report 66: Effective Practices to Reduce Bus Accidents. National Academic Press, Washington D.C.

Texas Transportation Institute (1996). Report 19: Guidelines for the Location and Design of Bus Stops. National Academic Press, Washington D.C.

U. S. Department of Transportation, Federal Highway Administration (2003). Manual on Uniform Traffic Control Devices for Streets and Highways 2003 Edition. Washington, D.C.

US Department of Transportation Federal Highway Administration (2002). US Pavement Markings. Office of Transportation Operations, FHWA-OP-02-090, Washington D.C.

United Kingdom Department of Transportation (2003). Bus Priority: The Way Ahead. Available online at http://www.buspriority.org.uk. Accessed November 13, 2006.

United Kingdom Department of Transportation (2004). The Highway Code. Available online at http://www.highwaycode.gov.uk. Accessed November 13, 2006.

USDOT IVI (February 2006). Intelligent Vehicle Initiative Website. Available online at http://www.its.dot.gov/ivi/ivi.htm. Accessed November 13, 2006.

Wiacek, C., Najm, W. (1999). Driver/vehicle characteristics in rear-end pre-crash scenarios based on the General Estimates System (GES). Society of Automotive Engineers Technical Paper 1999-01-0817. Warrendale, PA.

Womack, J. [Letter to Wayne Ferguson, Research Manager, Transportation Research Council Department of Transportation, 1993]. ref:108\#VSA NHTSA Interpretation Files Available at http://isearch.nhtsa.gov/files/8602.html

Yan, X., Radwan, E., Birriel, E., Dahai, G. (2006). "Effect of the Pavement-Marking Countermeasure to Improve Signalized-Intersection Safety" TRB $85^{\text {th }}$ Annual Meeting, January 2006, Washington D.C. 
APPENDICES 


\section{Appendix A: Yield to Bus Laws}

California Vehicle Code (CVC) Section 21810

\section{Right-of-Way: Yielding to Buses}

a) The driver of a vehicle overtaking a transit bus shall yield the right-of-way to the bus if all of the following conditions are present:

1) The transit bus has entirely exited an active traffic lane to board or deboard passengers at a designated bus stop, and is attempting to reenter the lane from which it exited.

2) Directional signals on the transit bus are flashing to indicate that the bus is preparing to merge with traffic.

3) The transit bus is equipped with a yield right-of-way sign on the left rear of the bus. The sign shall be both of the following:

A. Designed to warn a person operating a motor vehicle approaching the rear of the bus that the person is required to yield the right-of-way to the bus when the bus is entering traffic.

B. Illuminated by a flashing light when the bus is signaling in preparation for entering a traffic lane after having stopped to receive or discharge passengers.

b) Nothing in this section requires a transit agency to install the yield right-of-way sign described in paragraph (3) of subdivision (a).

c) This section does not relieve the driver of a transit bus from the duty to drive the bus with due regard for the safety of all persons and property. Nothing in this section relieves the transit agency from complying with the standard of care for its passengers established by Section 2100 of the Civil Code.

d) The provisions of this section are applicable to the Santa Cruz Metropolitan Transit District, the Orange County Transportation Authority, the AlamedaContra Costa Transit District, and the Santa Clara County Transit District, if the governing board of the district approves a resolution, after a public hearing on the issue, requesting that this section be made applicable to it, and transmits a copy of the resolution to the commissioner.

e) (1) Notwithstanding Section 7055.5 of the Government Code, on or before December 31, 2002, the commissioner, after consultation with the participating transit agencies, participating law enforcement, and the advisory committee established pursuant to paragraph (3) of subdivision (a) of Section 34501 of the Vehicle Code, shall report to the Legislature on the effectiveness of the right-ofway for transit vehicles established by this section, including, but not limited to, any impact on the highway and local road safety and the efficiency of transit operations. The report shall recommend whether or not the right-of-way established by this section should be made permanent on a local basis, and whether it would be effective if implemented on a statewide basis. (2) The commissioner, in consultation with the participating transit agencies, the California Transit Association, the advisory committee, and the participating local 


\section{Appendix A: (Continued)}

law enforcement agencies, shall identify the information required for preparation of the report required under paragraph (1).

This information may include, but need not be limited to, all of the following:

(A)The total number of traffic collisions causing fatalities or injuries, and the number causing only property damage.

(B) Traffic congestion issues.

(C) Public opinion issues.

(D)Efficiency of transit operations.

(E) The public education program required under subdivision (i).

(3) The commissioner may develop a format and schedule for reporting the information identified under paragraph (2), and the local law enforcement agencies, transit agencies, and the California Transit Association shall provide the commissioner with the information by using that format and in compliance with that schedule.

f) Each transit agency participating in the program shall undertake a public education program to inform motorists of the requirements imposed by this section.

g) The base fine for a violation of subdivision (a) is thirty-five dollars (\$35).

h) This section shall remain in effect only until January 1, 2004, and as of that date is repealed, unless a later enacted statute, that is enacted before January 1, 2004, deletes or extends that date.”

Florida Statutes, Title XXIII, MOTOR VEHCILES Chapter 316

316.815 Duty to yield to public transit vehicles

(1) The driver of a vehicle shall yield the right-of-way to a publicly owned transit bus traveling in the same direction that has signaled and is reentering the traffic flow from a specifically designated pullout bay.

(2) This section does not relieve the driver of the public transit bus from the duty to drive with due regard for the safety of all persons using the roadway.

Minnesota Statutes 2006, Chapter 169, Traffic Regulations

\subsection{RIGHT-OF-WAY}

Subdivision 7 Transit bus. The driver of a vehicle traveling in the right-hand lane of traffic shall yield the right-of-way to any transit bus attempting to enter that lane from a bus stop or shoulder, as indicated by a flashing left turn signal

New Jersey Public Law 2003, Title 39 Motor Vehicles and Traffic Regulations

39:4-87.1 Right of way of certain buses reentering traffic c.226

1. a. The driver of a non-emergency vehicle upon a highway shall yield the right of way to any bus, provided that: 
1) The driver is operating a vehicle that is in a position to overtake the bus from its rear; and

2) The bus, after exiting an active traffic lane for the purpose of stopping to receive or discharge passengers is attempting to reenter the lane from which it exited and to enter the traffic lane occupied by the driver by signaling its intention to do so. No other lane changes shall be applicable.

As used in this act, "bus" means a bus as defined in section 3 of P.L. 1995, c.225 (C. 48:4-2.1e), in regular scheduled service, and a motorbus operated in regular route service pursuant to P.L. 1979, c.150 (C. 27:25 -1 et seq.).

b. The New Jersey Transit Corporation shall conduct a public education program to inform motorists of the requirements imposed by this section relating to bus rights-of-way.

c. The Commissioner of Transportation shall study the need for further action to effectuate the purposes of this 2002 amendatory act and shall, no later than 18 months after the effective date of this 2002 amendatory act, report to the Governor and the Legislature.

d. This section shall not relieve the driver of any bus from the duty to drive with due regard for the safety of all persons, nor shall it protect the driver from the consequences of his reckless disregard for the safety of others. Nothing in this section shall be construed to limit any immunity or defense otherwise provided by law.

\section{Oregon Revised Statutes (ORS) Chapter 811, Rules of the Road for Drivers}

811.167 Failure to yield right-of-way to transit buses, rules, penalty

1) A person commits the offense of failure to yield the right of way to a transit bus entering traffic if the person does not yield the right of way to a transit bus when:

a. A yield sign as described in subsection (2) of this section is displayed on the back of the transit bus;

b. The person is operating a vehicle that is overtaking the transit bus from the rear of the transit bus; and

c. The transit bus, after stopping to receive or discharge passengers, is signaling an intention to enter the traffic lane occupied by the person.

2) The yield sign referred to in subsection (1)(a) of this section shall warn a person operating a motor vehicle approaching the rear of a transit bus that the person must yield when the transit bus is entering traffic. The yield sign shall be illuminated by a flashing light when the bus is signaling an intention to enter a traffic lane after stopping to receive or discharge passengers. The Oregon Transportation Commission shall adopt by rule the message on the yield sign, specifications for the size, shape, color, lettering and illumination of the sign and specifications for the placement of the sign on a transit bus.

3) This section does not relieve a driver of a transit bus from the duty to drive with due regard for the safety of all persons using the roadway. 
4) As used in this section, "transit bus" means a commercial bus operated by a city, a mass transit district established under ORS 267.010 to 267.390 or a transportation district established under ORS 267.510 to 267.650 .

5) The offense described in this section, failure to yield the right of way to a transit bus entering traffic, is a Class D traffic violation.

Revised Code of Washington (RCW) Chapter 46.61, Rules of the Road

RCW 46.61.220 Transit Vehicles

(1) The driver of a vehicle shall yield the right-of-way to a transit vehicle traveling in the same direction that has signaled and is reentering the traffic flow.

(2) Nothing in this section shall operate to relieve the driver of a transit vehicle from the duty to drive with due regard for the safety of all persons using the roadway. 


\section{Appendix B: Bus Operator Questionnaire}

\section{Center for Urban Transportation Research \\ National Center for Transit Research}

FDOT Project: BD 549-34

\section{Moving Bus Back into Traffic Safely - Signage and Lighting \\ Bus Operator Questionnaire}

The purpose of this survey is to evaluate bus operators' perception of driver behavior and Florida yield-to-bus programs. The project team will use this information to evaluate existing signs and lights on the back of the bus as well as current problems drivers may face with off-line bus stops.

Your participation in this survey is greatly appreciated.

County: Years of experience as a bus operator:

\section{Section 1: Bus Operations}

1 Are there any bus pull-out bays (figure 1.1) on any of the bus routes you have been assigned?

$\square$ Yes

$\square$ No

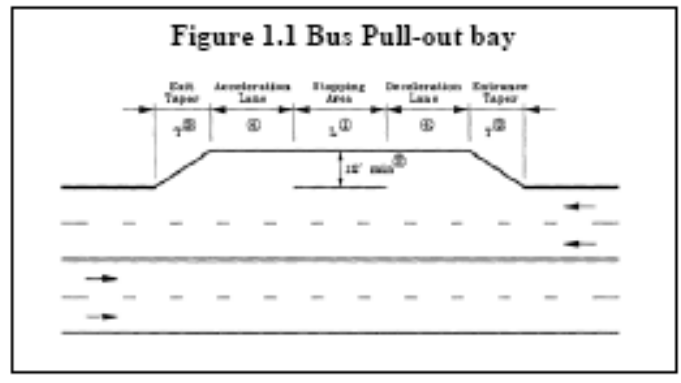

2 Do you use the shoulder or right turn lane to pull out of traffic at bus stops?

$\square$ Always

$\square$ Most of the time

$\square$ Some of the time

$\square$ Rarely

$\square$ Never

3 Do you ever have difficulty while attempting to merge back into traffic when the bus is out of the traffic lane?
$\square$ Always
Most of the time
Some of the time
Rarely
Never 


\section{Appendix B: (Continued)}

\section{Center for Urban Transportation Research \\ National Center for Transit Research}

FDOT Project: BD 549-34

Moving Bus Back into Traffic Safely - Signage and Lighting

Bus Operator Questionnaire

4 From your experiences, what percentage of motorists yields when you signal your intent to merge into the traffic lane?

$\square$ Almost all ( $90 \%$ or more)

A high percentage (between 60 and 90\%)

About half (between 40 and $60 \%$ )

$\square$ A low percentage (between 10 and $40 \%$ )

$\square$ Very few (Less than $10 \%$ )

Section 2: Yield-to-bus technology

5 Does your agency have a yield-to-bus decal (figure 2.1) or flashing yield sign (figure 2.2) on the back of the bus?

$\triangle$ Yes

No (If no, skip to question 12)
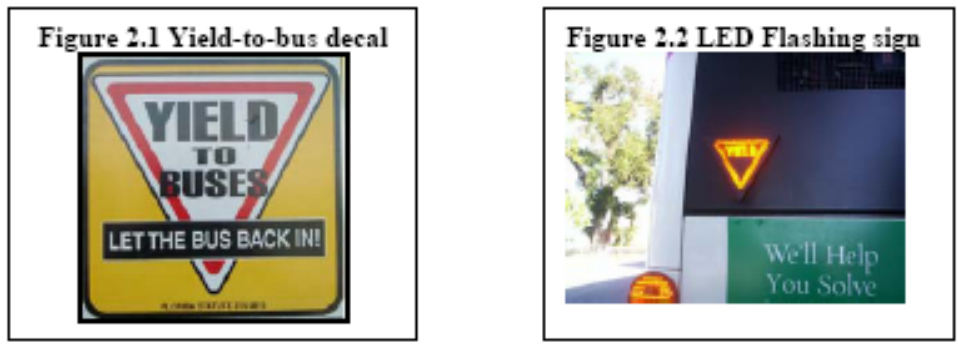

6 What type of yield-to-bus signage or lighting configuration does your agency have on the back of the bus?
$\otimes$ Decal
Flashing yield sign
Other

7 Do you feel that the Yield-to-bus signage (decal or LED yield sign) has made merging from a stop safer?

$\square$ Much safer

Some safer

$\square$ No change

$\square$ Less safe

$\square$ No response 


\section{Appendix B: (Continued)}

\section{Center for Urban Transportation Research \\ National Center for Transit Research}

FDOT Project: BD 549-34

Moving Bus Back into Traffic Safely - Signage and Lighting

Bus Operator Questionnaire

8 How helpful has the decal been in bus operations?

$\square$ Very helpful

Somewhat helpful

No opinion

Somewhat unhelpful

$\square$ Very unhelpful

9 Is there a noticeable difference in the percentage of motorist who would yield to the bus as it attempts to merge before the implementation of the decal?

$$
\square \text { Yes }
$$

$\square$ No

\section{If your transit agency has electronic signs, please answer question 10 and 11}

10 When you are NOT using the flashing yield signal, how often will other drivers let youmerge into traffic?

$\square$ Always

Most of the time

Some of the time

$\square$ Rarely

Never

11 When you DO use the flashing yield sigtal how often will other drivers let you merge into traffic?

$\square$ Always

$\square$ Most of the time

$\square$ Some of the time

$\square$ Rarely

$\square$ Never

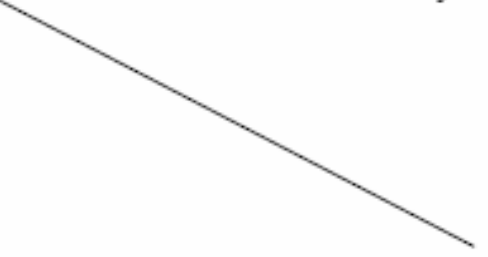

12 Does your agency employ any other technologies (signs, alternative lighting, etc.) to improve bus safety?

$\square$ Yes

$\square$ No

If yes, specify 


\title{
Appendix B: (Continued)
}

\author{
Center for Urban Transportation Research \\ National Center for Transit Research \\ FDOT Project: BD 549-34 \\ Moving Bus Back into Traffic Safely - Signage and Lighting \\ Bus Operator Questionnaire
}

13 Which of these yield-to-bus signs do you think would be most effective for bus operations and improved safety?
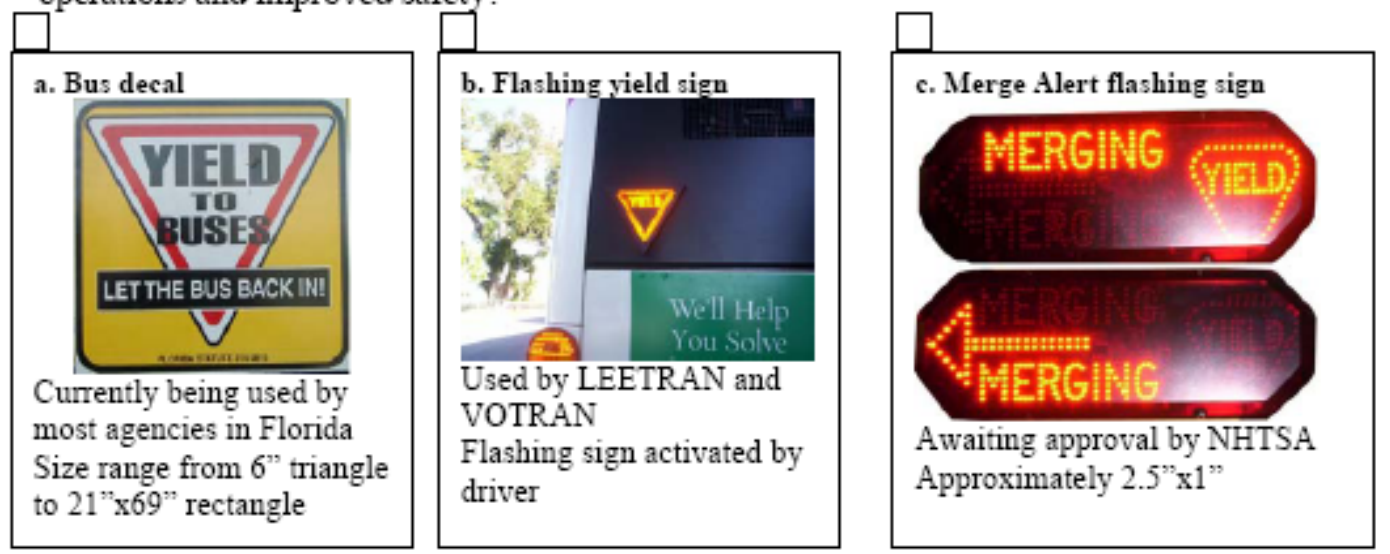

\section{Section 3: Florida Statute}

The current Florida Statute 316.0815 states:

"The driver of a vehicle must yield the right-of-way to a publicly owned transit bus traveling in the same direction which has signaled and is reentering the traffic flow from a specifically designated pullout bay. The operator of the bus must also drive with due regard for the safety of all persons using the roadway."

14 Do you think that the current Florida Statutes are sufficient for increasing the safety of bus operations?

$\square$ Yes

15 Do you think there may be other conditions in which motorists should yield to a public transit bus apart from when the bus is re-entering from a specially designed pull-out bay?

$\square$ Yes

16 If you could design a safety program for the operation of buses in traffic what would you like to see implemented? 


\section{Appendix C: Bus Operator Questionnaire Responses}

Table 7 Bus Operator Responses for All Counties in Survey

\begin{tabular}{lcc}
\hline Response & Frequency & Percent \\
\hline County & & \\
Alachua & 1 & 0.4 \\
Brevard & 1 & 0.4 \\
Broward & 1 & 0.4 \\
Duval & 12 & 4.3 \\
Hillsborough & 27 & 9.7 \\
Lee & 22 & 7.9 \\
Leon & 44 & 15.9 \\
Manatee & 1 & 0.4 \\
Orange & 29 & 10.5 \\
Pinellas & 112 & 40.4 \\
Polk & 1 & 0.4 \\
Volusia & 26 & 9.4 \\
Total & 277 & 100.0
\end{tabular}

Question 1: Are there any bus pull-out bays on any of the bus routes you have been assigned?

$\begin{array}{lcc}\text { Yes } & 206 & 74.4 \\ \text { No } & 58 & 20.9 \\ \text { No response } & 13 & 4.7 \\ \text { Total } & 277 & 100.0\end{array}$

Question 2: Do you use the shoulder or right turn lane to pull out of traffic at bus stops?

$\begin{array}{lcc}\text { Always } & 80 & 28.9 \\ \text { Most of the time } & 72 & 26.0 \\ \text { Some of the time } & 83 & 30.0 \\ \text { Rarely } & 29 & 10.5 \\ \text { Never } & 9 & 3.2 \\ \text { No response } & 4 & 1.5 \\ \text { Total } & 277 & 100.0\end{array}$




\section{Appendix C: Continued}

Table 7 Continued

\begin{tabular}{lcc}
\hline Response & Frequency & Percen \\
\hline $\begin{array}{l}\text { Question 3: Do you ever have difficulty while attempting to merge back into traffic } \\
\text { when the bus is out of the traffic lane? }\end{array}$ & 109 & 39.4 \\
Always & 85 & 30.7 \\
Most of the time & 67 & 24.2 \\
Some of the time & 9 & 3.2 \\
Rarely & 2 & 0.7 \\
Never & 5 & 1.8 \\
No response & 277 & 100.0 \\
Total &
\end{tabular}

Question 4: From your experiences, what percentage of motorists yields when you signal your intent to merge into the traffic lane?

Almost all (90\% or more)

A high percentage (between 60 and 90\%)

6

15

2.2

About half (between 40 and 60\%)

49

5.4

A low percentage (between 10 and 40\%)

73

17.7

Very few (Less than 10\%)

129

26.4

No response

5

46.6

Total

277

1.8

100.0

Question 5: Does your agency have a yield-to-bus decal or flashing yield sign on the back of the bus?

$\begin{array}{lcc}\text { Yes } & 252 & 91.0 \\ \text { No } & 24 & 8.7 \\ \text { No response } & 1 & 0.4 \\ \text { Total } & 277 & 100.0\end{array}$

Question 6: What type of yield-to-bus signage or lighting configuration does your agency have on the back of the bus?

No signage or Decal 22

7.9

Decal

222

80.1

Flashing yield

15

5.4

Other

3

1.1

Decal and flashing yield

14

5.1

No response

1

0.4

Total

277

100.0 


\section{Appendix C: Continued}

Table 7 Continued

\begin{tabular}{lcc}
\hline Response & Frequency & Percent \\
\hline Question 7: Do you feel that the Yield-to-bus signage (decal or LED yield sign) has ma \\
merging from a stop safer? & 21 & 7.6 \\
No signage or Decal & 25 & 9.0 \\
Much safer & 70 & 25.3 \\
Some safer & 133 & 48.0 \\
No change & 7 & 2.5 \\
Less safe & 21 & 7.6 \\
No response & 277 & 100.0 \\
Total & &
\end{tabular}

Question 8: How helpful has the decal been in bus operations?

No decal

Very helpful

Somewhat helpful

No opinion

Somewhat unhelpful

Very unhelpful

No Response

Total

Question 9: Is there a noticeable difference in the percentage of motorist who would yield to the bus as it attempts to merge before the implementation of the decal?

No decal

22

Yes

74

26.7

No

145

No response

36

Total

Question 10: When you are NOT using the flashing yield signal, how often will other drivers let you merge into traffic?

No flashing yield

Most of the time

Some of the time

Rarely

Never

No response 


\section{Appendix C: Continued}

Table 7 Continued

Response Frequency

Percent

Question 11: When you DO use the flashing yield signal, how often will other drivers let you merge into traffic?

No flashing yield

Always

Most of the time

12

4.3

Some of the time

13

4.7

Rarely

6

2.2

No response

5

Total

277

1.8

100.0

Question 12: Does your agency employ any other technologies (signs, alternative lighting, etc.) to improve bus safety?

Yes

No

No response

Total
81

120

76

277
29.2

43.4

27.4

100.0

Question 13: Which of these yield-to-bus signs do you think would be most effective for bus operations and improved safety?

$\begin{array}{lcc}\text { Decal } & 25 & 9.0 \\ \text { Flashing yield sign } & 20 & 7.2 \\ \text { Merge alert } & 203 & 73.3 \\ \text { Two technologies } & 13 & 4.7 \\ \text { No response } & 16 & 5.8 \\ \text { Total } & 277 & 100.0\end{array}$

Question 14: Do you think that the current Florida Statutes are sufficient for increasing the safety of bus operations?

Yes

No

No response

Total
126

137

14

277
45.5

49.5

5.1

100.0 


\section{Appendix C: Continued}

Table 7 Continued

Response

Frequency

Percent

Question 15: Do you think there may be other conditions in which motorists should yield to a public transit bus apart from when the bus is re-entering from a specially designed pull-out bay?

Yes

No

No response

Total
209

51

17

277
75.5

18.5

6.1

100.0

\section{Table 8 Duval County Bus Operator Responses}

Response Frequency

Percent

Question 1: Are there any bus pull-out bays on any of the bus routes you have been assigned?

Yes

11

91.7

No

8.3

Total

12

100.0

Question 2: Do you use the shoulder or right turn lane to pull out of traffic at bus stops?

Most of the time

4

4

Some of the time

Rarely

Never

No response

Total
1

2

1

12
33.3

33.3

8.3

16.7

8.3

100.0

Question 3: Do you ever have difficulty while attempting to merge back into traffic when the bus is out of the traffic lane?
Always
3
25.0
Most of the time
4
33.3
Some of the time
3
25.0
No response
2
16.6
Total 


\section{Appendix C: Continued}

Table 8 Continued

\begin{tabular}{lcr}
\hline Response & Frequency & Percent \\
\hline Question 4: From your experiences, what percentage of motorists yields when you sign \\
your intent to merge into the traffic lane? \\
About half (between 40 and 60\%) & 3 & 25.0 \\
A low percentage (between 10 and 40\%) & 3 & 25.0 \\
Very few (Less than 10\%) & 4 & 33.3 \\
No response & 2 & 16.6 \\
Total & 12 & 100.0
\end{tabular}

Question 5: Does your agency have a yield-to-bus decal or flashing yield sign on the back of the bus?
Yes
2
16.7
No
10
83.3
Total
12
100.0

Question 6: What type of yield-to-bus signage or lighting configuration does your agency have on the back of the bus?
No signage or lighting
10
83.3
Decal
2
16.7
Total
12
100.0

Question 13: Which of these yield-to-bus signs do you think would be most effective for bus operations and improved safety?

Decal 2

16.7

Flashing yield sign

16.7

Merge alert

2

58.3

No technologies

7

8.3

Total

12

100.0

Question 14: Do you think that the current Florida Statutes are sufficient for increasing the safety of bus operations?
Yes
8
66.7
No
2
16.7
No response
2
16.7
Total 


\section{Appendix C: Continued}

Table 8 Continued

\begin{tabular}{lcc}
\hline Response & Frequency & Percent \\
\hline Question 15: Do you think there may be other conditions in which motorists should yield \\
to a public transit bus apart from when the bus is re-entering from a specially designed \\
pull-out bay? \\
Yes & 8 & 66.7 \\
No & 3 & 25.0 \\
No response & 1 & 8.3 \\
Total & 12 & 100.0 \\
\hline
\end{tabular}

Table 9 Hillsborough County Bus Operator Survey Responses

\begin{tabular}{lcc}
\hline Response & Frequency & Percent \\
\hline Question 1: Are there any bus pull-out bays on any of the bus routes you have been \\
assigned? & 23 & 85.2 \\
Yes & 4 & 14.8 \\
No & 27 & 100.0 \\
Total & & \\
& & \\
Question 2: Do you use the shoulder or right turn lane to pull out of traffic at bus stops? & Frequency & 29.6 \\
& 8 & 29.6 \\
Always & 8 & 25.9 \\
Most of the time & 7 & 11.1 \\
Some of the time & 3 & 3.7 \\
Rarely & 1 & 100.0 \\
Never & 27 &
\end{tabular}

Question 3: Do you ever have difficulty while attempting to merge back into traffic when the bus is out of the traffic lane?

Always

$\begin{array}{cc}\text { Frequency } & \text { Percent } \\ 15 & 55.6 \\ 5 & 18.5 \\ 5 & 18.5 \\ 1 & 3.7 \\ 1 & 3.7 \\ 27 & 100.0\end{array}$




\section{Appendix C: Continued}

Table 9 Continued

\begin{tabular}{lcc}
\hline Response & Frequency & Percent \\
\hline Question 8: How helpful has the decal been in bus operations? & \\
Very helpful & 1 & 3.7 \\
Somewhat helpful & 12 & 44.4 \\
No opinion & 10 & 37.0 \\
Somewhat unhelpful & 1 & 3.7 \\
Very unhelpful & 3 & 11.1 \\
Total & 27 & 100.0
\end{tabular}

Question 9: Is there a noticeable difference in the percentage of motorist who would yield to the bus as it attempts to merge before the implementation of the decal?

Yes

No

No response

Total
6

20

1

27
22.2

74.1

3.7

100.0

Question 13: Which of these yield-to-bus signs do you think would be most effective for bus operations and improved safety?
Flashing yield sign
4
14.8
Merge alert
23
85.2
Total
27
100.0

Question 14: Do you think that the current Florida Statutes are sufficient for increasing the safety of bus operations?
Yes
15
55.6
No
11
40.7
No response
1
3.7
Total
27
100.0

Question 15: Do you think there may be other conditions in which motorists should yield to a public transit bus apart from when the bus is re-entering from a specially designed pull-out bay?

Yes

20

74.1

No

7

25.9

Total

27

100.0 


\section{Appendix C: Continued}

Table 10 Lee County Bus Operator Responses

\begin{tabular}{lcc}
\hline Response & Frequency & Percent \\
\hline Question 1: Are there any bus pull-out bays on any of the bus routes you have been \\
assigned? & 14 & 63.6 \\
Yes & 7 & 31.8 \\
No & 1 & 4.5 \\
No response & 22 & 100.0 \\
Total & \\
& \\
Question 2: Do you use the shoulder or right turn lane to pull out of traffic at bus stop & 10 & 45.5 \\
Always & 3 & 13.6 \\
Most of the time & 8 & 36.4 \\
Some of the time & 1 & 4.5 \\
No response & 22 & 100.0 \\
Total & & \\
& & \\
Question 3: Do you ever have difficulty while attempting to merge back into traffic whe & & \\
the bus is out of the traffic lane? & 8 & 36.4 \\
Always & 7 & 31.8 \\
Most of the time & 6 & 27.3 \\
Some of the time & 1 & 4.5 \\
No response & 22 & 100.0 \\
Total &
\end{tabular}

Question 4: From your experiences, what percentage of motorists yields when you signal your intent to merge into the traffic lane?
Almost all (90\% or more)
1
4.5
About half (between 40 and 60\%)
22.7
A low percentage (between 10 and 40\%)
36.4
Very few (Less than 10\%)
31.8
No response
4.5
Total

Question 5: Does your agency have a yield-to-bus decal or flashing yield sign on the back of the bus?
Yes
21
95.5
No
Total
22
100.0 


\section{Appendix C: Continued}

Table 10 Continued

\begin{tabular}{lcc}
\hline Response & Frequency & Percent \\
\hline Question 6: What type of yield-to-bus signage or lighting configuration does your agency \\
have on the back of the bus? & 7 & 31.8 \\
Decal & 1 & 4.5 \\
Flashing yield sign & 14 & 63.6 \\
Decal and Flashing yield sign & 22 & 100.0
\end{tabular}

Question 7: Do you feel that the Yield-to-bus signage (decal or LED yield sign) has made merging from a stop safer?

$\begin{array}{lcc}\text { Much safer } & 5 & 22.7 \\ \text { Some safer } & 7 & 31.8 \\ \text { No change } & 8 & 36.4 \\ \text { No response } & 2 & 9.1 \\ \text { Total } & 22 & 100.0\end{array}$

Question 8: How helpful has the decal been in bus operations

Very helpful

Somewhat helpful

31.8

No opinion

Somewhat unhelpful

3

9.1

No Response

2

4.5

Total

Question 9: Is there a noticeable difference in the percentage of motorist who would yield to the bus as it attempts to merge before the implementation of the decal?

Yes 9

No

9

40.9

No response

4

18.2

Total

22

100.0

Question 10: When you are NOT using the flashing yield signal, how often will other drivers let you merge into traffic?

No flashing yield

Most of the time

13.6

Some of the time

2

9.1

Rarely

9

40.9

No response

Total 


\section{Appendix C: Continued}

Table 10 Continued

\begin{tabular}{lcc}
\hline Response & Frequency & Percent \\
\hline Question 11: When you DO use the flashing yield signal, how often will other drivers let \\
you merge into traffic? & 3 & 13.6 \\
No flashing yield & 4 & 18.2 \\
Always & 6 & 27.3 \\
Most of the time & 7 & 31.8 \\
Some of the time & 1 & 4.5 \\
Rarely & 1 & 4.5 \\
No response & 22 & 100.0 \\
Total & &
\end{tabular}

Question 12: Does your agency employ any other technologies (signs, alternative lighting, etc.) to improve bus safety?

$\begin{array}{lcc}\text { Yes } & 5 & 22.7 \\ \text { No } & 13 & 59.0 \\ \text { No response } & 4 & 18.2 \\ \text { Total } & 22 & 100.0\end{array}$

Question 13: Which of these yield-to-bus signs do you think would be most effective for bus operations and improved safety?
Flashing yield sign
2
9.1
Merge alert
16
72.7
Two technologies
3
13.6
No response
1
4.5
Total
22
100.0

Question 14: Do you think that the current Florida Statutes are sufficient for increasing the safety of bus operations?
Yes
10
45.5
No
12
54.5
Total
22
100.0

Question 15: Do you think there may be other conditions in which motorists should yield to a public transit bus apart from when the bus is re-entering from a specially designed pull-out bay?

Yes 15

68.2

No

27.2

No response 


\section{Appendix C: Continued}

Table 11 Leon County Bus Operator Responses

\begin{tabular}{lcc}
\hline Response & Frequency & Percent \\
\hline $\begin{array}{l}\text { Question 1: Are there any bus pull-out bays on any of the bus routes you have been } \\
\text { assigned? }\end{array}$ & 27 & 61.4 \\
Yes & 13 & 29.5 \\
No & 4 & 9.1 \\
No response & 44 & 100.0
\end{tabular}

Question 2: Do you use the shoulder or right turn lane to pull out of traffic at bus stops?

$\begin{array}{lcc}\text { Always } & 11 & 25.0 \\ \text { Most of the time } & 11 & 25.0 \\ \text { Some of the time } & 12 & 27.3 \\ \text { Rarely } & 6 & 13.6 \\ \text { Never } & 2 & 4.5 \\ \text { No response } & 2 & 4.6 \\ \text { Total } & 44 & 100.0\end{array}$

Question 3: Do you ever have difficulty while attempting to merge back into traffic when the bus is out of the traffic lane?
Always
11
25.0
Most of the time
16
36.4
Some of the time
15
34.1
Rarely
1
2.3
No response
12.3
Total
44
100.0

Question 4: From your experiences, what percentage of motorists yields when you signal your intent to merge into the traffic lane?
A high percentage (between 60 and 90\%)
About half (between 40 and 60\%)
$12 \quad 27.3$
A low percentage (between 10 and 40\%)
8
18.2
Very few (Less than 10\%)
No response
Total
44
100.0 


\section{Appendix C: Continued}

Table 11 Continued

\begin{tabular}{lcc}
\hline Response & Frequency & Percent \\
\hline Question 5: Does your agency have a yield-to-bus decal or flashing yield sign on the \\
back of the bus? & 43 & 97.7 \\
Yes & 1 & 2.3 \\
No response & 44 & 100.0 \\
Total &
\end{tabular}

Question 6: What type of yield-to-bus signage or lighting configuration does your agency have on the back of the bus?
Decal
43
97.7
No response
1
2.3
Total
44
100.0

Question 7: Do you feel that the Yield-to-bus signage (decal or LED yield sign) has made merging from a stop safer?

$\begin{array}{lcc}\text { Much safer } & 6 & 13.6 \\ \text { Some safer } & 19 & 43.2 \\ \text { No change } & 14 & 31.8 \\ \text { Less safe } & 1 & 2.3 \\ \text { No response } & 4 & 9.1 \\ \text { Total } & 44 & 100.0\end{array}$

Question 8: How helpful has the decal been in bus operations

Very helpful

Somewhat helpful

38.6

No opinion

Somewhat unhelpful

Very unhelpful

No Response

Total

2

100.0

Question 9: Is there a noticeable difference in the percentage of motorist who would yield to the bus as it attempts to merge before the implementation of the decal?

Yes

18

40.9

No

18

40.9

No response

8

18.2

Total

44

100.0 


\section{Appendix C: Continued}

\section{Table 11 Continued}

\begin{tabular}{lcc}
\hline Response & Frequency & Percent \\
\hline Question 12: Does your agency employ any other technologies (signs, alternative \\
lighting, etc.) to improve bus safety? \\
Yes & 8 & 18.2 \\
No & 11 & 25.0 \\
No response & 25 & 56.8 \\
Total & 44 & 100.0
\end{tabular}

Question 13: Which of these yield-to-bus signs do you think would be most effective for bus operations and improved safety?

Decal

920.5

Flashing yield sign $\quad 2 \quad 4.5$

$\begin{array}{lcc}\text { Merge alert } & 28 & 63.6\end{array}$

No response $\quad 5 \quad 11.4$

$\begin{array}{lll}\text { Total } & 44 & 100.0\end{array}$

Question 14: Do you think that the current Florida Statutes are sufficient for increasing the safety of bus operations?
Yes
24
54.5
No
$15 \quad 34.1$
No response
5
11.4
Total
44
100.0

Question 15: Do you think there may be other conditions in which motorists should yield to a public transit bus apart from when the bus is re-entering from a specially designed pull-out bay?

Yes

37

84.1

No

4

9.1

No response

3

6.8

Total

44

100.0 


\section{Appendix C: (Continued)}

\section{Table 12 Orange County Bus Operator Responses}

\begin{tabular}{lcc}
\hline Response & Frequency & Percent \\
\hline $\begin{array}{l}\text { Question 1: Are there any bus pull-out bays on any of the bus routes you have been } \\
\text { assigned? }\end{array}$ & 26 & 89.7 \\
Yes & 2 & 6.9 \\
No & 1 & 3.4 \\
No response & 29 & 100.0 \\
Total &
\end{tabular}

Question 2: Do you use the shoulder or right turn lane to pull out of traffic at bus stops?

$\begin{array}{lcc}\text { Always } & 6 & 20.7 \\ \text { Most of the time } & 10 & 34.5 \\ \text { Some of the time } & 10 & 34.5 \\ \text { Rarely } & 3 & 10.3 \\ \text { Total } & 29 & 100.0\end{array}$

Question 3: Do you ever have difficulty while attempting to merge back into traffic when the bus is out of the traffic lane?

$\begin{array}{lcc}\text { Always } & 17 & 58.6 \\ \text { Most of the time } & 9 & 31.0 \\ \text { Some of the time } & 3 & 10.3 \\ \text { Total } & 29 & 100.0\end{array}$

Question 4: From your experiences, what percentage of motorists yields when you signal your intent to merge into the traffic lane?

$\begin{array}{lll}\text { A high percentage (between } 60 \text { and 90\%) } & 2\end{array}$

About half (between 40 and 60\%) $\quad 4 \quad 13.8$

A low percentage (between 10 and 40\%) $\quad 10 \quad 34.5$

Very few (Less than 10\%) 13

Total $\quad 29 \quad 100.0$

Question 5: Does your agency have a yield-to-bus decal or flashing yield sign on the back of the bus?

Yes

No

Total
28

1

29
96.6

3.4

100.0 


\section{Appendix C: (Continued)}

Table 12 (Continued)

\begin{tabular}{lcc}
\hline Response & Frequency & Percent \\
\hline Question 6: What type of yield-to-bus signage or lighting configuration does your \\
agency have on the back of the bus? & 1 & 3.4 \\
No signage or decal & 28 & 96.6 \\
Decal & 29 & 100.0 \\
Total &
\end{tabular}

Question 7: Do you feel that the Yield-to-bus signage (decal or LED yield sign) has made merging from a stop safer?

No signage or Decal

1

6

10

12

29
Much safer

Some safer

No change

Total
3.4

20.7

34.5

41.4

100.0

Question 8: How helpful has the decal been in bus operations

No decal

Very helpful

Somewhat helpful

41.4

No opinion

Somewhat unhelpful

Very unhelpful

Total

29

100.0

Question 9: Is there a noticeable difference in the percentage of motorist who would yield to the bus as it attempts to merge before the implementation of the decal?

No decal

Yes

No

Total
1

13

15

29
3.4

44.8

51.7

100.0

Question 12: Does your agency employ any other technologies (signs, alternative lighting, etc.) to improve bus safety?
Yes
2
6.9
No
Total
29
100.0 


\section{Appendix C: (Continued)}

Table 12 (Continued)

\begin{tabular}{lcc} 
Response & Frequency & Percent \\
\hline Question 13: Which of these yield-to-bus signs do you think would be most effectiv \\
for bus operations and improved safety? \\
Decal & 3 & 10.3 \\
Flashing yield sign & 1 & 3.4 \\
Merge alert & 24 & 82.8 \\
No response & 1 & 3.4 \\
Total & 29 & 100.0
\end{tabular}

Question 14: Do you think that the current Florida Statutes are sufficient for increasing the safety of bus operations?

$\begin{array}{lcc}\text { Yes } & 17 & 58.6 \\ \text { No } & 12 & 41.4 \\ \text { Total } & 29 & 100.0\end{array}$

Question 15: Do you think there may be other conditions in which motorists should yield to a public transit bus apart from when the bus is re-entering from a specially designed pull-out bay?
Yes
22
75.9
No
7
24.1
Total
29
100.0

\section{Table 13 Pinellas County Bus Operator Responses}

\begin{tabular}{lcc}
\hline Response & Frequency & Percent \\
\hline Question 1: Are there any bus pull-out bays on any of the bus routes you have been \\
assigned? & 89 & 79.5 \\
Yes & 18 & 16.1 \\
No & 5 & 4.5 \\
No response & 112 & 100.0 \\
Total &
\end{tabular}

Question 2: Do you use the shoulder or right turn lane to pull out of traffic at bus stops?

$\begin{array}{lcc}\text { Always } & 37 & 33.0 \\ \text { Most of the time } & 30 & 26.8 \\ \text { Some of the time } & 32 & 28.6 \\ \text { Rarely } & 11 & 9.8 \\ \text { Never } & 2 & 1.8 \\ \text { Total } & 112 & 100.0\end{array}$




\section{Appendix C: (Continued)}

Table 13 (Continued)

\begin{tabular}{lcc}
\hline Response & Frequency & Percent \\
\hline $\begin{array}{l}\text { Question 3: Do you ever have difficulty while attempting to merge back into traffic } \\
\text { when the bus is out of the traffic lane? }\end{array}$ & 47 & 42.0 \\
Always & 34 & 30.4 \\
Most of the time & 23 & 20.5 \\
Some of the time & 6 & 5.4 \\
Rarely & 2 & 1.8 \\
Never & 112 & 100.0 \\
Total & &
\end{tabular}

Question 4: From your experiences, what percentage of motorists yields when you signal your intent to merge into the traffic lane?

$\begin{array}{lcc}\text { Almost all (90\% or more) } & 4 & 3.6 \\ \text { A high percentage (between } 60 \text { and } 90 \%) & 4 & 3.6 \\ \text { About half (between } 40 \text { and } 60 \%) & 14 & 12.5 \\ \text { A low percentage (between } 10 \text { and 40\%) } & 33 & 29.5 \\ \text { Very few (Less than 10\%) } & 57 & 50.9 \\ \text { Total } & 112 & 100.0\end{array}$

Question 7: Do you feel that the Yield-to-bus signage (decal or LED yield sign) has made merging from a stop safer?

$\begin{array}{lcc}\text { Much safer } & 4 & 3.6 \\ \text { Some safer } & 25 & 22.3 \\ \text { No change } & 68 & 60.7 \\ \text { Less safe } & 6 & 5.4 \\ \text { No response } & 9 & 8.0 \\ \text { Total } & 112 & 100.0\end{array}$

Question 8: How helpful has the decal been in bus operations?

Very helpful

Somewhat helpful

No opinion

Somewhat unhelpful

Very unhelpful

Total

23

100.0 


\section{Appendix C: (Continued)}

Table 13 (Continued)

\begin{tabular}{lcr}
\hline Response & Frequency & Percent \\
\hline Question 9: Is there a noticeable difference in the percentage of motorist who would \\
yield to the bus as it attempts to merge before the implementation of the decal? \\
Yes & 21 & 18.8 \\
No & 73 & 65.2 \\
No response & 18 & 16.1 \\
Total & 112 & 100.0
\end{tabular}

Question 12: Does your agency employ any other technologies (signs, alternative lighting, etc.) to improve bus safety?

$\begin{array}{lcc}\text { Yes } & 36 & 32.1 \\ \text { No } & 32 & 28.6 \\ \text { No response } & 44 & 39.3 \\ \text { Total } & 112 & 100.0\end{array}$

Question 13: Which of these yield-to-bus signs do you think would be most effective for bus operations and improved safety?

Decal

$\begin{array}{cc}8 & 7.1 \\ 3 & 2.7 \\ 87 & 77.7 \\ 10 & 8.9 \\ 4 & 3.6 \\ 112 & 100.0\end{array}$

Flashing yield sign

100.0

Question 14: Do you think that the current Florida Statutes are sufficient for increasing the safety of bus operations?

$\begin{array}{lcc}\text { Yes } & 41 & 36.6 \\ \text { No } & 69 & 61.6 \\ \text { No response } & 2 & 1.8 \\ \text { Total } & 112 & 100.0\end{array}$

Question 15: Do you think there may be other conditions in which motorists should yield to a public transit bus apart from when the bus is re-entering from a specially designed pull-out bay?

Yes

No

18

16.1

No response

7

6.3

Total

112

100.0 


\section{Appendix C: (Continued)}

Table 14 Volusia County Bus Operator Responses

\begin{tabular}{lcc}
\hline Response & Frequency & Percent \\
\hline $\begin{array}{l}\text { Question 1: Are there any bus pull-out bays on any of the bus routes you have been } \\
\text { assigned? }\end{array}$ & 13 & 50.0 \\
Yes & 11 & 42.3 \\
No & 2 & 7.7 \\
No response & 26 & 100.0 \\
Total &
\end{tabular}

Question 2: Do you use the shoulder or right turn lane to pull out of traffic at bus stops?

Always

6

23.1

Most of the time

5

19.2

Some of the time

34.6

Rarely

9

15.4

Never

4

7.7

Total

100.0

Question 3: Do you ever have difficulty while attempting to merge back into traffic when the bus is out of the traffic lane?

$\begin{array}{lcc}\text { Always } & 7 & 26.9 \\ \text { Most of the time } & 9 & 34.6 \\ \text { Some of the time } & 9 & 34.6 \\ \text { Rarely } & 1 & 3.8 \\ \text { Total } & 26 & 100.0\end{array}$

Question 4: From your experiences, what percentage of motorists yields when you signal your intent to merge into the traffic lane?

Almost all (90\% or more) $\quad 1 \quad 3.8$

A high percentage (between 60 and 90\%) $\quad 1 \quad 3.8$

About half (between 40 and 60\%) $\quad 8 \quad 30.8$

A low percentage (between 10 and 40\%) $\quad 3 \quad 11.5$

Very few (Less than 10\%) $\quad 13 \quad 50.0$

$\begin{array}{lll}\text { Total } & 26 & 100.0\end{array}$




\section{Appendix C: (Continued)}

Table 14 (Continued)

\begin{tabular}{lcr}
\hline Response & Frequency & Percent \\
\hline Question 5: Does your agency have a yield-to-bus decal or flashing yield sign on the \\
back of the bus? \\
Yes & 15 & 57.7 \\
No & 11 & 42.3 \\
Total & 26 & 100.0
\end{tabular}

Question 6: What type of yield-to-bus signage or lighting configuration does your agency have on the back of the bus?

$\begin{array}{lcc}\text { No signage or Decal } & 9 & 34.6 \\ \text { Flashing yield } & 14 & 53.8 \\ \text { Other } & 3 & 11.5 \\ \text { Total } & 26 & 100.0\end{array}$

Question 7: Do you feel that the Yield-to-bus signage (decal or LED yield sign) has made merging from a stop safer?

$\begin{array}{lcc}\text { No sign or decal } & 9 & 34.6 \\ \text { Much safer } & 4 & 15.4 \\ \text { Some safer } & 4 & 15.4 \\ \text { No change } & 5 & 19.2 \\ \text { No response } & 4 & 15.4 \\ \text { Total } & 26 & 100.0\end{array}$

Question 8: How helpful has the decal been in bus operations

No signage or Decal 9

Very helpful 4

34.6

Somewhat helpful

15.4

No opinion

11.5

Somewhat unhelpful

23.1

Very unhelpful

3.8

No Response

7.7

Total

13.8

26

100.0 


\section{Appendix C: (Continued)}

Table 14 (Continued)

\begin{tabular}{lcr}
\hline Response & Frequency & Percent \\
\hline Question 9: Is there a noticeable difference in the percentage of motorist who would \\
yield to the bus as it attempts to merge before the implementation of the decal? \\
No decal & 9 & 34.6 \\
Yes & 7 & 26.9 \\
No & 6 & 23.1 \\
No response & 4 & 15.4 \\
Total & 26 & 100.0 \\
& & \\
Question 10: When you are NOT using the flashing yield signal, how often will other \\
drivers let you merge into traffic? & & \\
No flashing yield & 9 & 34.6 \\
Most of the time & 3 & 11.5 \\
Some of the time & 3 & 11.5 \\
Rarely & 8 & 30.8 \\
Never & 1 & 3.8 \\
No response & 2 & 7.7 \\
Total & 26 & 100.0
\end{tabular}

Question 11: When you DO use the flashing yield signal, how often will other drivers let you merge into traffic?

No flashing yield

9

34.6

Always

2

7.7

Most of the time

5

19.2

Some of the time

2

7.7

Rarely

19.2

No response

5

11.5

Total

100.0

Question 12: Does your agency employ any other technologies (signs, alternative lighting, etc.) to improve bus safety?

Yes

No

No response

Total
3

21

2

26
11.5

80.8

7.7

100.0 


\section{Appendix C: (Continued)}

Table 14 (Continued)

\begin{tabular}{lcr} 
Response & Frequency & Percent \\
\hline $\begin{array}{l}\text { Question 13: Which of these yield-to-bus signs do you think would be most effectiv } \\
\text { for bus operations and improved safety? }\end{array}$ & 3 & 11.5 \\
Decal & 5 & 19.2 \\
Flashing yield sign & 14 & 53.8 \\
Merge alert & 4 & 15.4 \\
No response & 26 & 100.0 \\
Total & &
\end{tabular}

Question 14: Do you think that the current Florida Statutes are sufficient for increasing the safety of bus operations?

$\begin{array}{lcc}\text { Yes } & 8 & 30.8 \\ \text { No } & 14 & 53.8 \\ \text { No response } & 4 & 15.4 \\ \text { Total } & 26 & 100.0\end{array}$

Question 15: Do you think there may be other conditions in which motorists should yield to a public transit bus apart from when the bus is re-entering from a specially designed pull-out bay?

Yes

16

61.5

No

7

26.9

No response

3

11.5

Total

26

100.0 


\section{Appendix D: Bus Operator Survey Narrative Responses}

\section{Orange County}

Question 16: If you could design a safety program for the operation of buses in traffic what would you like to see implemented?

Time and Schedule improvements - always rushing

Police guarding and ticketing

Designated no parking at bus stops because this can cause rear-end collisions

Better buses

Take out left turns

Eliminate having to traverse over 3 lanes of traffic in a short distance

Ask motorists to give buses more space

Lights needed on rear-right side to see the person getting off the bus

Motorists should yield when buses are merging in and out and at train tracks

There needs to be a big enough sign and public awareness to let people know it is against the law

Florida statutes need to be implemented and the public needs to be educated

There needs to be education on how to catch a bus at night and getting operators attention at night

Proper lighting around bus stops

Implement a stop arm like on school buses

Give moving violations and tickets of $\$ 2501^{\text {st }}$ offense, $\$ 5002^{\text {nd }}$ offence and $\$ 1000$ for the $3^{\text {rd }}$ offence. Install cameras that issue tickets to cars.

A course which reviews the transit operators' right of way responsibilities in heavy traffic situation with respect to 316.0815

Yield to bus program

Bus lanes

More police officers catching the motorists that abuse our rights

More flashing lights in the middle of the bus

Florida Statute regarding right of way with a city bus; is not enforced. As with any other law that is not enforced, it is useless. Public service announcements/commercials should also be utilized in all mediums , ex. TV, radio, newspapers, cable; informing the public in the above stature

Make law, no right turn in front of bus

Make all buses the same on the back of bus, signs and lights; Also keep rear of bus for safety messages only; make all buses the same statewide

More PSAs about the law

[For a safety program] How to use mirrors; more on the ADA laws

Vehicles must yield when bus is pulling away from shoulders also Larger bus yield sign and public announcements to educate the public

TV announcements, larger bus sign, law enforcement doing a better job in assisting the public bus system!

Put the fine amount on decal 


\section{Appendix D: (Continued)}

\section{Other Comments/Safety Concerns}

Some traffic lights are too short

I do not like the pullout lane because the public does not know that the bus has the right of way and signs are not big enough

Fl statutes not enforced

[Yield to bus sign most effective] big sign across back of bus

The buses that have a sign across the whole back side of bus helps a lot all of our [buses] should have the large signs on the back

Yield to bus decal needs to be bigger

Yield sign is too small

Bigger the better (concerning signage)

Do not construct pull-ins or pull out bays

The decal protects you in the event of an accident

Passengers being in the way Remaining seated while the bus stops

I think the above electronic sign [merge alert] would be a very good idea

Vehicles should yield to bus at any service stop

Bus stop locations

Driving through parking lots

Stops too close to lights where you need to make a left turn

Tourists

Impatient people blowing their horn at stops

Stops in turning lanes

Far-side bus stops that cause rear-end collisions

Vehicles crossing on double yellow line while passengers are attempting to cross the road

Bus stop locations

Motorists don't understand the turn signal

Dangerous when crossing lanes and making left turn

It is dangerous at railroads and bus stops when the bus stops

\section{Duval}

Question 16: If you could design a safety program for the operation of buses in traffic what would you like to see implemented?

Adequate mirrors

Mirrors with control knobs - they are currently manually fixed

General traffic safety - merging warning

Once the lights are off the driver should know the bus is about to move. Educate

passengers on crossing behind the bus and stay until the bus is clear

Tell passengers to stay stationary - passengers get bumped by mirrors

Put safety markers by bus stop where pedestrians stand behind

Motorists should yield at railroad tracks

Put stop arm like school bus

All buses should have a flashing stop sign 


\section{Appendix D: (Continued)}

Bus stops should be well lit, especially bus shelters

Add mirrors; spot mirrors

Install stop-arm

More laws to protect the driver

Enforce laws

Adjust the geometry in relation to the stop to protect safety

Brighten the back of the bus

Blinking/glowing bus sign

Bus lanes and HOV lanes

Going into left lane to let off passengers should not be allowed

Enforce laws

Educate and add more pull-ins

More stringent laws

Better lights on the back of the bus

Prohibit right turns in front of bus - cars overtake buses at intersection to make right turn

Other Comments/Safety Concerns

Do not overtake while merging

Bad sight distance, cannot see people in shelter

\section{Volusia}

Question 16: If you could design a safety program for the operation of buses in traffic what would you like to see implemented?

Motorists still drive around the bus when we are at a bus stop even with a double yellow line. There should be commercials on TV and radio letting motorists know the law i.e. Florida statutes

Stay back at least 150 feet back; sometimes you have to over shoot the bus stop because some car is on top of you

Anytime a bus makes a lane change it would be great if motorists would be accommodative

"Anytime" we need to have them yield to us

Make it illegal to pass a bus without pulling fully into the other lane (as it is they try to pass in the same lane as a bus which is close to the curb)

It seems that no one knows about the law, not even the Police

For passengers crossing streets once they deboard and elderly in wheelchairs or passengers with bikes

School zones and hospital zones drivers should not be allowed to pass a bus or go around a bus. Unfortunately, people ignore flashing signs the same way they ignore life threatening warnings

Other Comments/Safety Concerns 


\section{Appendix D: (Continued)}

People ignore flashing signs, some never yield-the-right of way

I have no idea what [the Florida Statutes] are, unless I know them without knowing, I know them

Having to move over a number of lanes to make left turns

We don't have pull-out bays, we drive into shopping centers which is very wrong. We should not be in parking lots with a 37 foot bus; not very safe

Right and Left turns [motorists should yield to the bus], We are slow moving into traffic; no passing at RR crossing

\section{Lee}

Question 16: If you could design a safety program for the operation of buses in traffic what would you like to see implemented?

Need more awareness of law (TV, radio)

More "Public Service" on TV and radio about driving habits, traffic signal triggers/merge for public bus and general defensive driving habits

Right turn lanes should be for buses and right turns only traveling on US 41

We should have a bus lane on US 41

\section{Other Comments/Safety Concerns}

Police and sheriff don't even let the bus or trolleys in

Law needs to be enforced

A lot of times drivers speed up when directionals are turned on as well as deliberately block the bus from re-entering

When merging from right turn or curb and have to cross over 3 lanes to get into left turn lane to make left turn

The flashing yield signs on the new buses provide a great increase in pulling back into traffic safely. I drove one for 4 plus hours and at least 8 out of every 10 times the flashing light stopped or slowed traffic for re-entry

Motorists should always yield to buses regardless of pull-out or not

[Motorists should yield] At all bus stops no matter where the bus stop is located

[Motorists should yield at] All lane changes

Police never enforce the yield sign

The flashing yield signs on the new buses provide a "great" increase in pulling back into traffic safely. I drove one for 4+ hours and at least 8 out of every 10 times the flashing light stopped or slowed traffic for re-entry

\section{Hillsborough}

Question 16: If you could design a safety program for the operation of buses in traffic what would you like to see implemented?

100 feet from rear - clear lane to return back to the flow of traffic

Flashing signs 


\section{Appendix D: (Continued)}

Bus only lanes; flashing lights can be distracting; drivers do not pay attention More TV commercials reminding people that they need to yield to the bus

Put TV commercial to inform the public that is the law and they will be fined if they don't obey

Police citations

Bigger and brighter sign that flashes

Yield at turn signal with no left arrow

Security from patrons

Better follow-up on enforcement

Bus route signs (Dover Road); letting drivers know when they need to turn; More instructions for new drivers showing them where to go (signs that light up)

Police citations

More TV commercials reminding people that they need to yield to the bus; Put TV commercial to inform the public that they will be fined if they don't obey

Bus only lanes - flashing lights can be distractions

People not paying attention is the biggest issue

Have more flashing signs on back of bus

The state of Florida needs to pass tougher laws on the use of cell phone while people are driving, too many accidents due to drivers not paying attention while driving No right turns around bus

Wheelchair lift in operation, yield to wheelchair

Flashing red instead of yellow

Well lit bus stop

Lit like street sign

Running red lights and stop signs at intersections

Have destination sign to help police for emergencies

Police support

Stop arm with flashing light; patrons ask for bus to block traffic for them; every bus should have a gadget that shows a light for traffic to stop; drivers need support from police

Distance between bus stop and left turns need to be enough for safe weaving

Bus has right of way all the time

Electronic sign should state "it's the law"

\section{Other Comments/Safety Concerns}

People not paying attention is the bigger issue

Bus should have right of way at all times

Yield to bus everytime the bus stops

Yield to bus under all conditions

Pulling back into traffic - biggest concern

Changing lanes in heavy traffic

Signal flashing too small, looks like flashers

Flashing signs 


\section{Appendix D: (Continued)}

People pulling in front of the bus

Safety of operators - defense for operators

Sometimes horns don't work

Current statutes sufficient if enforced

Pulling in front of the bus

Passengers crossing in front of bus

\section{Manatee}

Other Comments/Safety Concerns

Merging alert flashing sign would help

\section{Brevard}

Question 16: If you could design a safety program for the operation of buses in traffic what would you like to see implemented?

Passenger wheel chair technology - no steps

\section{Pinellas}

Question 16: If you could design a safety program for the operation of buses in traffic what would you like to see implemented?

School bus stop sign [on public transit buses]

Yield to bus changing lanes in addition to merging into traffic in 316.0815

Law enforcement giving a ticket on the spot to violators

Designated bus lanes for pick-up-drop-off only

I guess more public relations commercials in regards to letting buses back into traffic and that the buses travel in the right hand lanes to avoid being hazards and cutting buses off to enter shopping plazas. Stress to the public of working together to make things run smoother for all using the public roadways

Merge alert flashing sign

I don't think the average motorist knows to yield to buses. More signage and lighting! Public service announcements!

I feel the public does not know that they should yield to buses trying to merge. It is somewhat like the move over law, Florida should use public service spots on TV and Radio to better inform the public!

We would have stop signs like school buses

A new signage and lighting would benefit all on the roadway

Bus only lanes

More tickets given out to cars and signs on roadway saying to yield to buses

Cars will not yield to buses. I have even seen police not yield. People need to be educated to what they do when buses want back in. They even turn right in front of the bus from left lane 


\section{Appendix D: (Continued)}

Cars should not turn right on red when transit bus entering intersection on a green $90 \%$ of the time we have a bus stop on other side of intersection and enter slowly preparing to stop get abruptly cut off. Cars should not be permitted to cut in front of buses (safe distance).

Better mirrors to improve circle of safety around bus; larger turn signals

Wishing we had more lighted signs, lighted yield, stop, merging would help greatly because it catches attention

Enforce existing traffic laws

Put out a caution sign for "bus merging back into traffic" so that traffic will slow or stop

The construction of pull-out bays and bus lanes on specifically designated routes that make frequent stops in high traffic areas

I also think more active enforcement of the traffic laws pertaining to yielding to buses and pedestrians attempting to access buses and bus stop areas. Unfortunately, many motorists are very reckless when following and maneuvering around buses. Thank you for your time and attention to these important safety issues Bus lane only A system just like a school bus. But we have to be more discretionary in using the system and a lane specifically made for buses.

Enforcement of statute 316.0815

Better driver education and public awareness Enforce FS 316.0815

a. Directional traffic lights at all intersections where a bus must cross heavy traffic b. "buses only" lanes on major thoroughfares

1.Smith system 2.Cars must be 100' to the rear of bus 3.cars should know 4 blends of blender and we need to change lanes 4 . uniform system for stopping at stops 1.right turn signal 2.2 bus length 4 -way on 3.left turn signal upon leaving stop The decals in the back needs to be larger - the people don't see them anymore. A stay back 50'-100' decal should be placed near the deceleration lights. It's a game for the car drivers - to see how long they can pin you and keep you from changing lanes. When 1015 cars go by its not because they don't know what's right. It's a game they play to get at the big, slow bus.

Lane should be clean at all times when bus is in view

Educating the public on the current FL statute 316.0815

More law enforcement toward motorists who will not yield to buses. DOT enforces rules upon drivers... how about enforcing drivers who rudely do not give buses a "brake" Improve horn system

Yield "flashing" lights

Instead of flashing yellow lights when stopping, flashing red sign that reads stopping!

A button for drivers to push to hold green lights longer would help keep buses on time

Enforcement of FL statute 316.0815

If motorists see it [the decal], read it, and understand it, then it can be very helpful Keep a distance of at least 50' from the rear of a transit bus. Do not pass bus on left in a single lane (even if enough space is provided) 


\section{Appendix D: (Continued)}

I believe that all drivers of motor vehicles with a valid license should relieve an annual or semi-annual update on rules of the road and be required to answer a questionnaire when their renewal time is present along with an eye test Statute should be enforced

Bus stops should be just like handicapped parking Stopped for wheel chair sign, merging multiple lanes

16 If you could design a safety program for the operation of buses in traffic what would you like to see implemented?

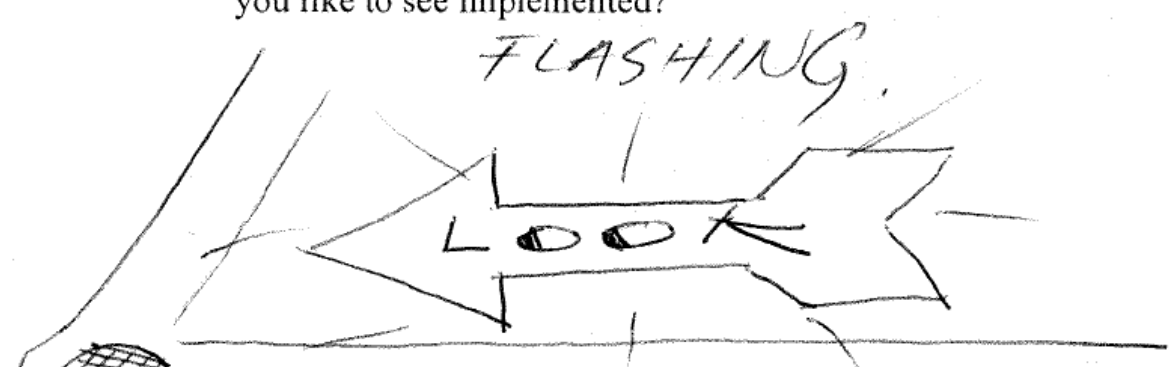

16 If you could design a safety program for the operation of buses in traffic what would you like to see implemented? Stoped For wheel Chair sign merging Multiple Lanes

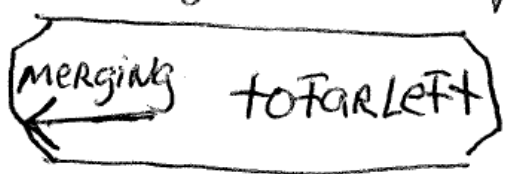

1. separate bus lane 2.less stops in right turn only lanes 3.more distance from last stop on the right before having to make a left hand turn

I would like to see a much larger merge or yield to bus decal or flashing yield to bus sign mounted high enough so motorists could see them easily

Stop signs (like school buses)

Alert flashing sign would make a big difference

To me there is not enough lights on back of buses. Use Tampa buses for example, they

have plenty of lighting

People could not pass buses while they are stopped

Bus lanes

The lit merging sign, at 13C, looks like it would help motorists understand the merging law

Better enforcement (law enforcement does not yield)

Flashing yield signs

Yield to bus at all times when merging

The merging yield sign would be a great sign to add for safety, also notify police to put a little more effort into ticketing people and maybe that would make a change Having a separate bus lane(s) would solve a lot of problems and reduce accidents Bus lane only installed 


\section{Appendix D: (Continued)}

More advertisements needed for public to be aware A public awareness campaign for "let the bus back in" bigger signs (on back of bus) and please add the "merge alert" flashers, also keep strobes

That every person with a vehicle on the road has to take a class on driving with commercial vehicles. This can be done through DMV offices when renewing a driver's license Flashing sign and bell sound indicating bus is merging Some way to enforce violations of the existing rules The laws are fine and in a perfect world there wouldn't be any problems but more drivers than not are rude and totally unwilling to obey the laws as they exist. Just ask ambulance drivers and even police

Some type of public awareness campaign to inform motorists of what a public transit bus needs to do - and give tickets for non-observance and flipping off drivers

I would like to see the bus stops move back more from the right turn lanes or relocated to a safer area

Adding signage $\mathrm{C}$ would be a big improvement. $\mathrm{B}$ would be a significant step; even the largest yield triangle would be an upgrade

Lanes used by buses only

Education [for] the public drivers on TV commercials and learn new drivers on their license when taking their exam driving test. Bigger sign on buses

They should implement lanes to be used for the public bus transportation system if possible

Give bus a designated lane

Bus only lanes or more bus pull out bays

More enforcement of aggressive drivers and proper installation of decals and a request to news media to explain the traffic law to their prescribers

The statute listed in Florida drivers' manuals

(1)We need to implement media coverage on this issue "it's the law" needs to get out. They will get a ticket if they don't. Police need to be more active in helping (2) when a car/truck driver calls to complain about being "pushed" out of the road, they need to be questioned "Did you yield to the driver?" Did the bus driver have on his signals? How far were you from the back of the bus when he signaled? Remind it is "the law" to yield. Bus lanes esp. right turns only except buses. Route 19 corridor also along Ulmerton Road $\mathrm{E}$ and $\mathrm{W}$ when construction is completed Motorists do anything to get around a stopped transit bus. Any tool introduced to make a person aware of our presence and their actions of recklessly going around will be a great help. Something large, bright, bold, animated and stating IT’S THE LAW!

\section{Other Comments/Safety Concerns}

I really feel that no one wants to have a large bus or other vehicle in front of them while on there way to no where. I feel that no sign will change these attitudes; maybe if you advertise that it is a law to let the bus merge. The information needs to get out to the driver. 


\section{Appendix D: (Continued)}

Drivers (car, trucks) in our area are just rude and vicious; they do not care about any one on the road except themselves

Sign is too small, need larger signs on buses

Buses need to be shown more respect by the driving public. They are always in too big of a hurry and can't wait two seconds behind the bus. They try to get in front of the bus and cut in front of us sharply increasing the chance of accidents. Because of this there have been many times I have had to brake very hard Vehicles yielding to the bus when you need to make lane changes (we usually only have a short distance in which to do this)

I believe the vast majority of motorists have no idea what Florida statute 316.0815 states. Before working for PSTA, I didn't. For the safety of our buses, their passengers and the other drivers on the road we need to provide them with the most visible signage available; whatever its additional sot, it will eventually pay for itself in fewer mechanical, medical and legal expenses and money is always the bottom line

These drivers don't yield to the bus, they speed up and then cut us off; where is the justice in this? If we were to hit someone when they cut us off, it's our butts The sign we have now are low in the corner, people are going too fast to read sign. We need something bigger and brighter to make traffic aware of bus movement Current bus decals are too small. Decal must be seen by oncoming car driver at a distance. Add merge alert flashing sign, large size Motorist should yield under all traffic conditions for buses The police don't yield, no one else will; the state could make a lot of money writing tickets on that law Merging is a key issue

I drive at least 40 hours per week in city traffic and only see a motorist stopped by police about twice a week; that's pretty lax law enforcement.

(\#14) No one enforces this law; we need the laws we have enforced not new ones

(\#1) We have this type, the problem is it can’t be used like shown; 4 buses are parked in it

The police pay little or no attention to the yield sign on the back of bus

I think most of the driving public could care less about letting the buses back in

Nobody wants to be behind a bus and at present the yield sign is of no use. What good is a law if it's never enforced?

People tend to look at the size of the bus, not the decal Yield-to-bus signage is not relevant to other drivers. I doubt anyone other than transportation employees know FL statute 316.0815 exists Trying to cross traffic to turn [other condition in which motorists should yield] Most drivers will see a bus trying to get back on the road, $2 \%$ will let the bus back in $98 \%$ will try their best to pass a bus getting back on the roadway by any means Help if you can Automobile drivers are rude, inconsiderate and impatient and have no regards for the laws of the road. Need police and enforce the laws. During rush hour traffic ect ect Cell phone use made illegal while driving

Appendix D: (Continued) 
With my experience moving bus back into traffic safely is to look for traffic before moving back not traffic you can not trust other drivers' skills or decal on the back of the bus, it is up to the bus driver to make sure there is no traffic and safe to move bus back into traffic and the safety of the passenger. There are bus stop signs that need better lighting also bus stop signs are hard to spot at night by placing reflector tape on them will help spot them

Even police cars do not let us in or over in a lane

I have never seen an officer give out a citation for someone not yielding to a bus; let's enforce the laws we have and not add more to be ignored

\section{Leon}

Question 16: If you could design a safety program for the operation of buses in traffic what would you like to see implemented?

A marketing program in the media to emphasize to the public that they should yield to coaches re-entering traffic

Bus lane

Bus have their own lanes

I think the law (statute) should be revised to state that traffic should yield to buses

making a simple lane change

No vehicle too pass bus (on 2 lane) unless there is a 4 lane, same as school bus

Bus lane for buses only

I would like to see more safety and bus rights enforced to the public

Elevate cars going around buses while picking or dropping off passengers

The law is useless unless the law is enforced; in traffic lanes where there is no bus pullout when the driver is pulling to a curb to discharge passengers; all passengers must exit the bus from the rear door except wheelchairs and elderly people or those that have a difficulty climbing into the bus

There are times when you have to get out of traffic to curb the bus because even with the kneel down for example visually impaired or physically impaired not in a wheelchair

\section{Appendix D: (Continued)}


TV Time about

law

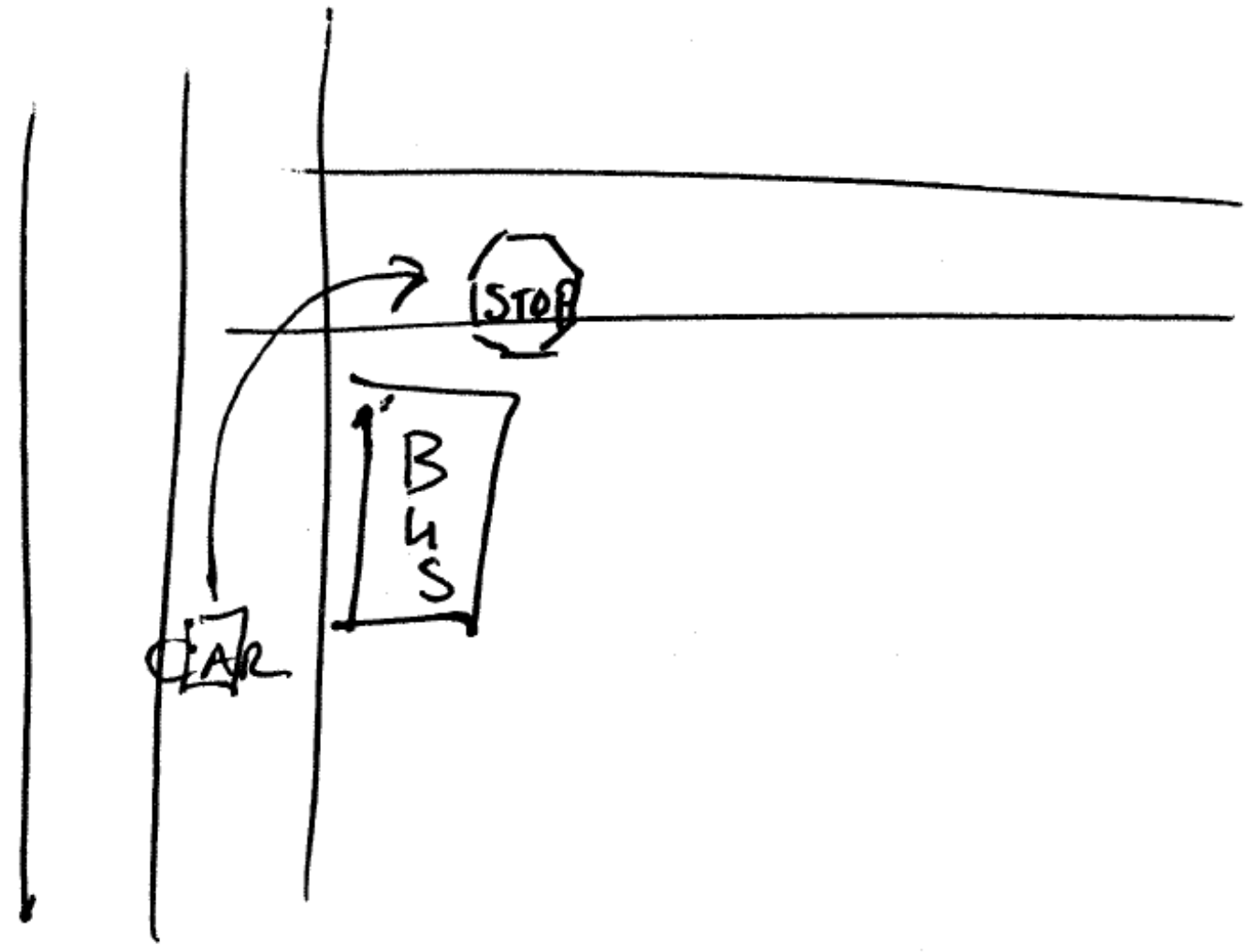

A lane for bus only

Speaker

Put extra set of turn signals up with marker lights

Hire me in that occupation and I promise at lest three real time uses

A sure system where motorist would not pass when loading and unloading

No turning in front of the bus while bus is stopped

\section{Other Comments/Safety Concerns}

Decals just arrived no bus operators really know about them

Not all the buses have this signage, I only seen 1 bus with it

We need to same these signs on all the buses for a while before we do surveys; not every bus driver has driven a bus with the yield sign 
Appendix E: Field Data Collection Locations

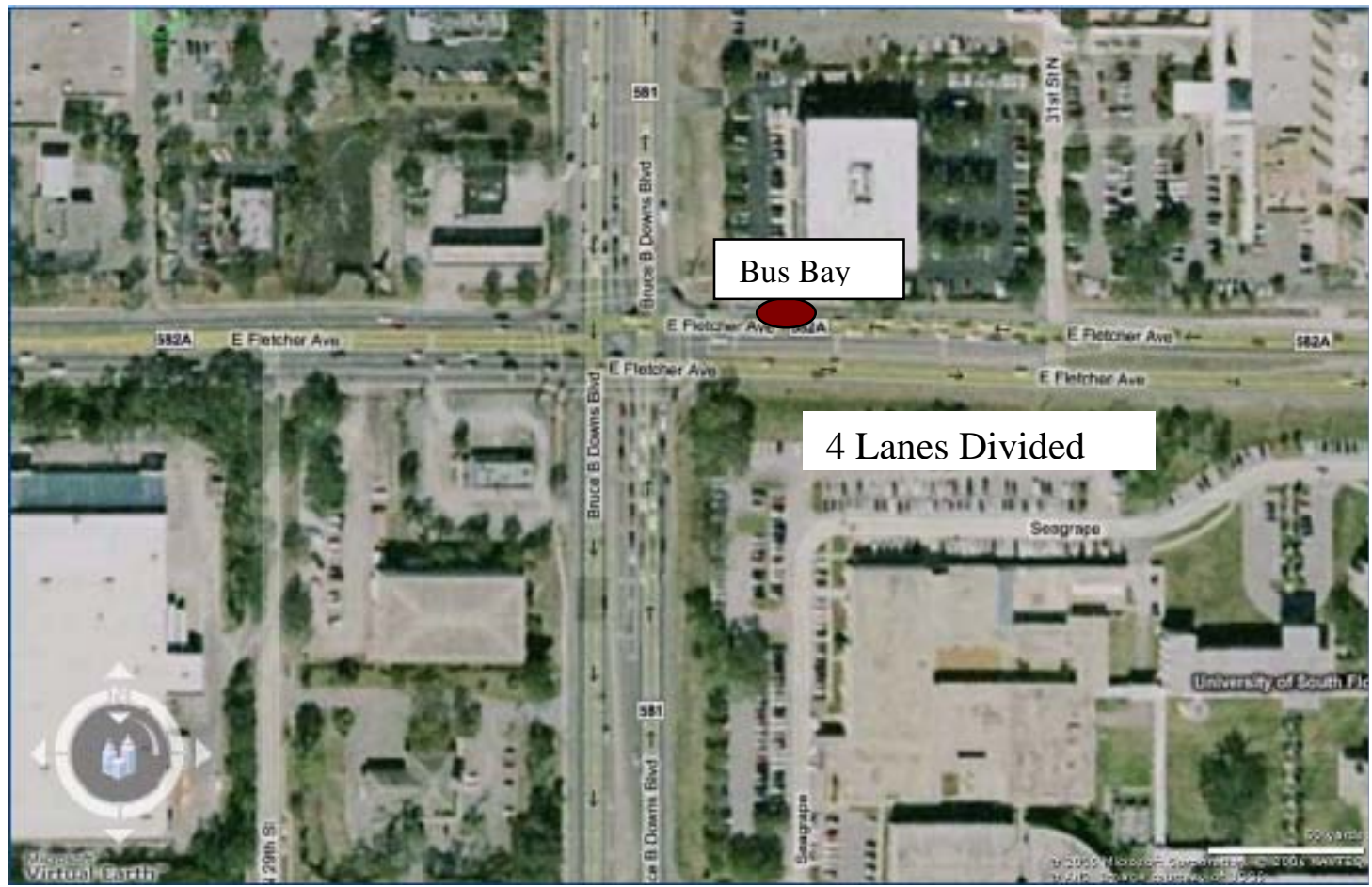

Figure 52 Aerial View of Fletcher Ave and Bruce B Downs Blvd

Fletcher Avenue Speed Limit: 45 mph

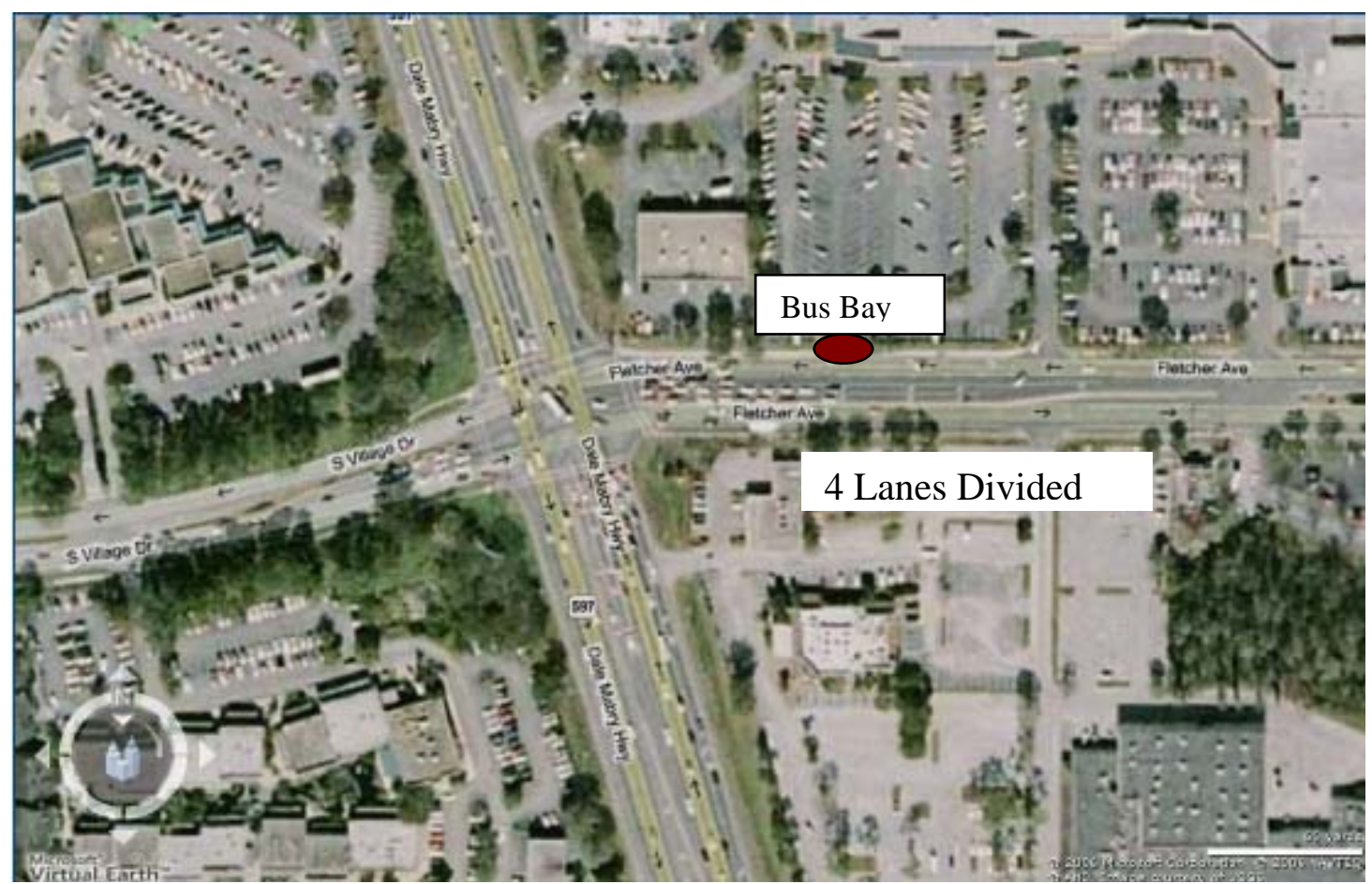

Figure 53 Aerial View of Fletcher Ave and Dale Mabry Blvd

Fletcher Avenue Speed Limit: 40 mph 
Appendix E: (Continued)

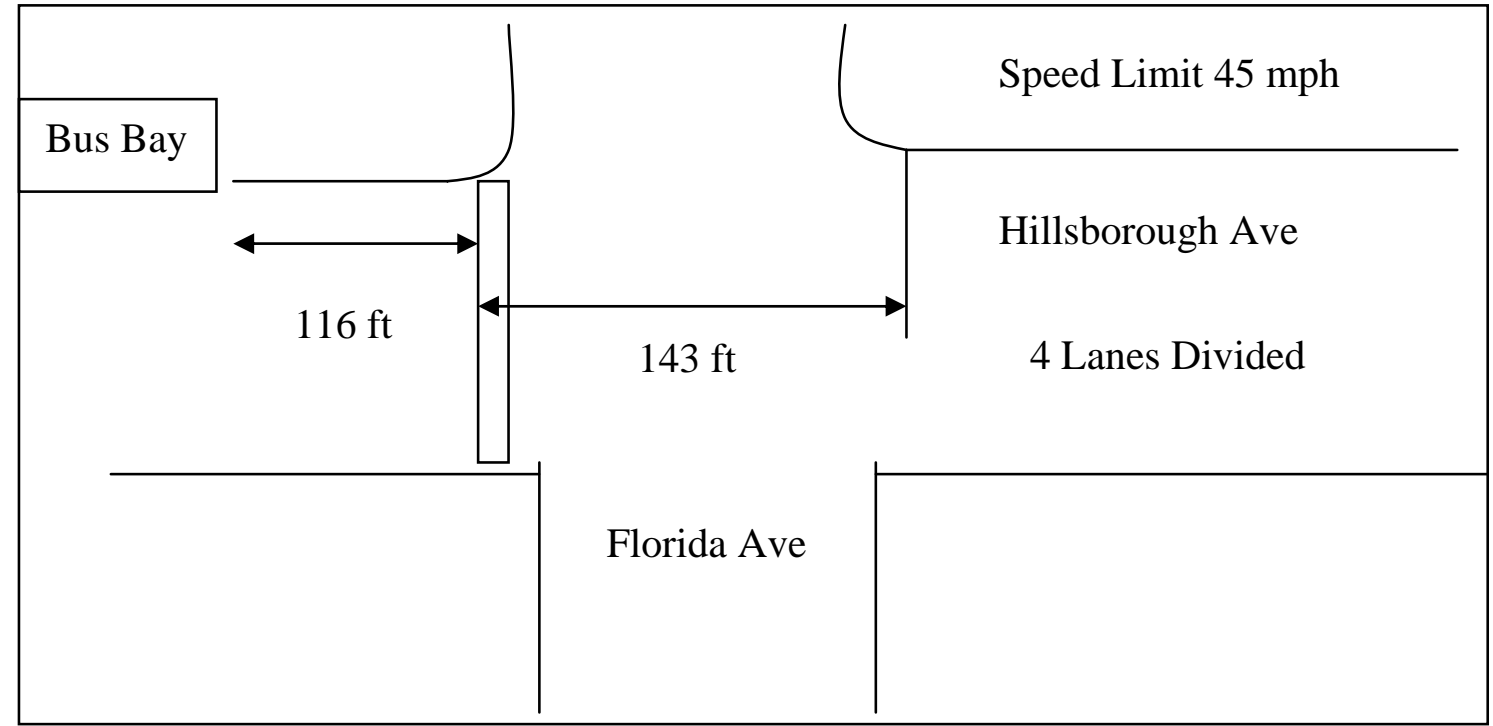

Figure 54 Sketch of Hillsborough Ave and Florida Ave

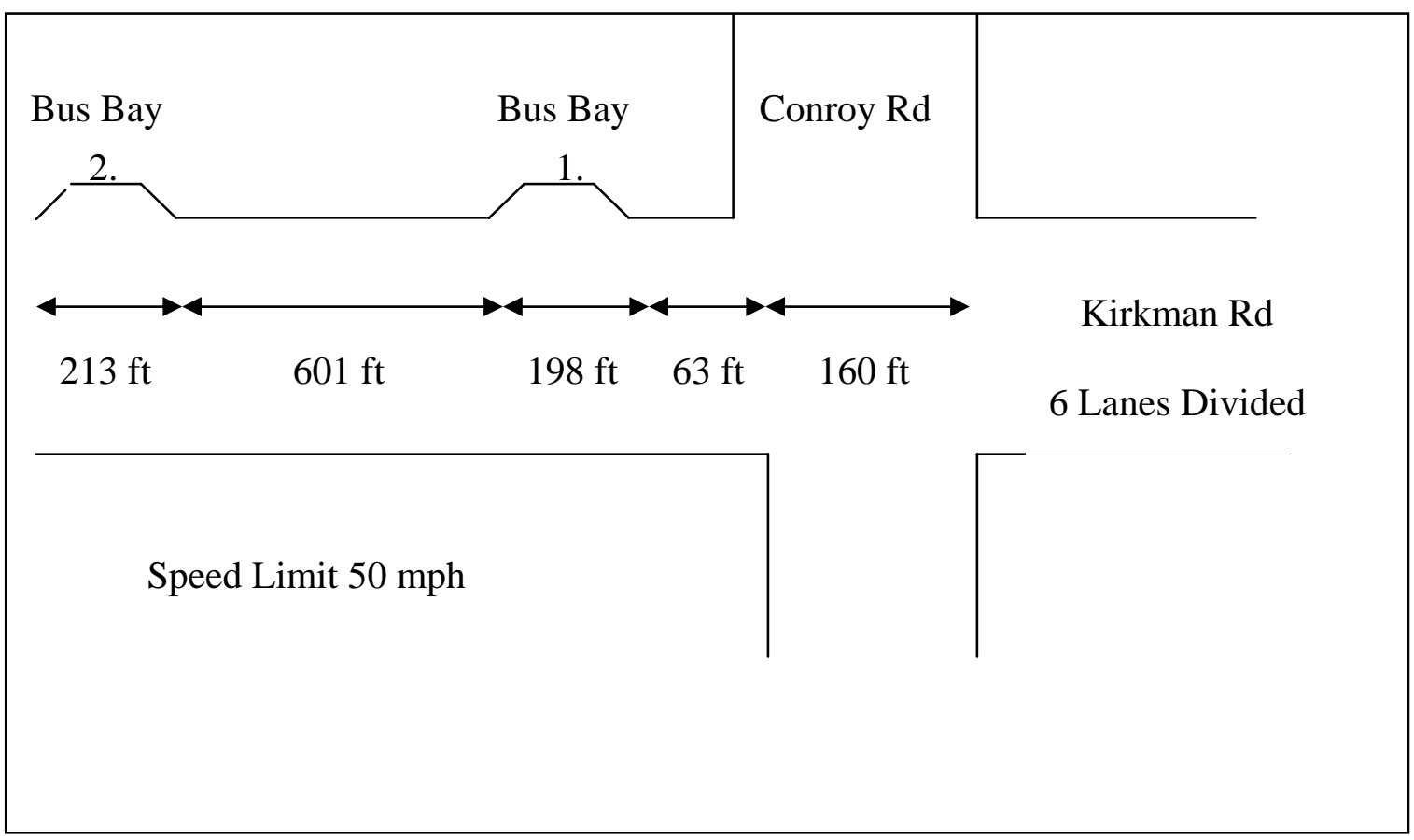

Figure 55 Sketch of Kirkman Rd and Conroy Rd 


\section{Appendix E: (Continued)}

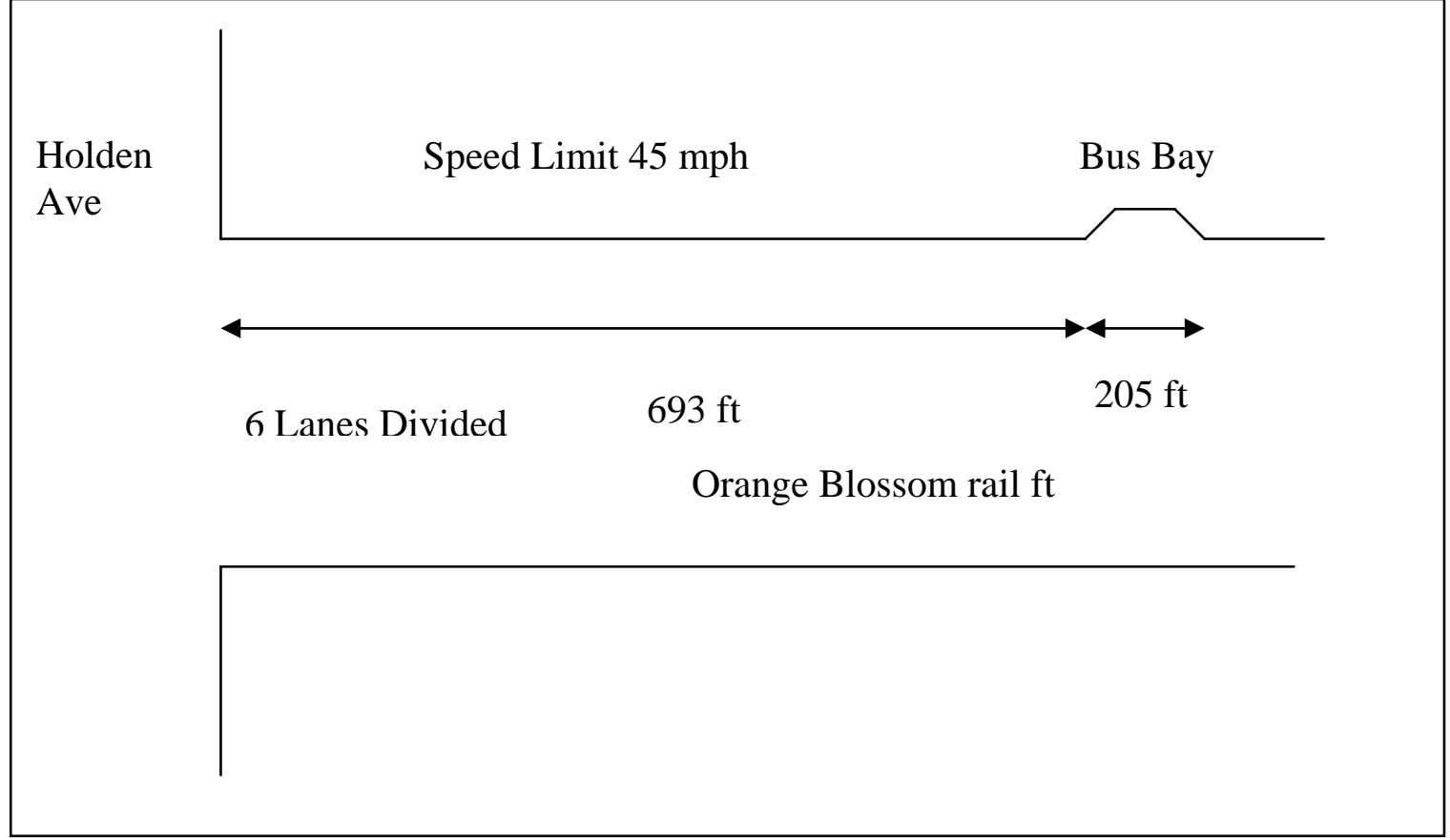

Figure 56 Sketch of Orange Blossom Trail and Holden Ave

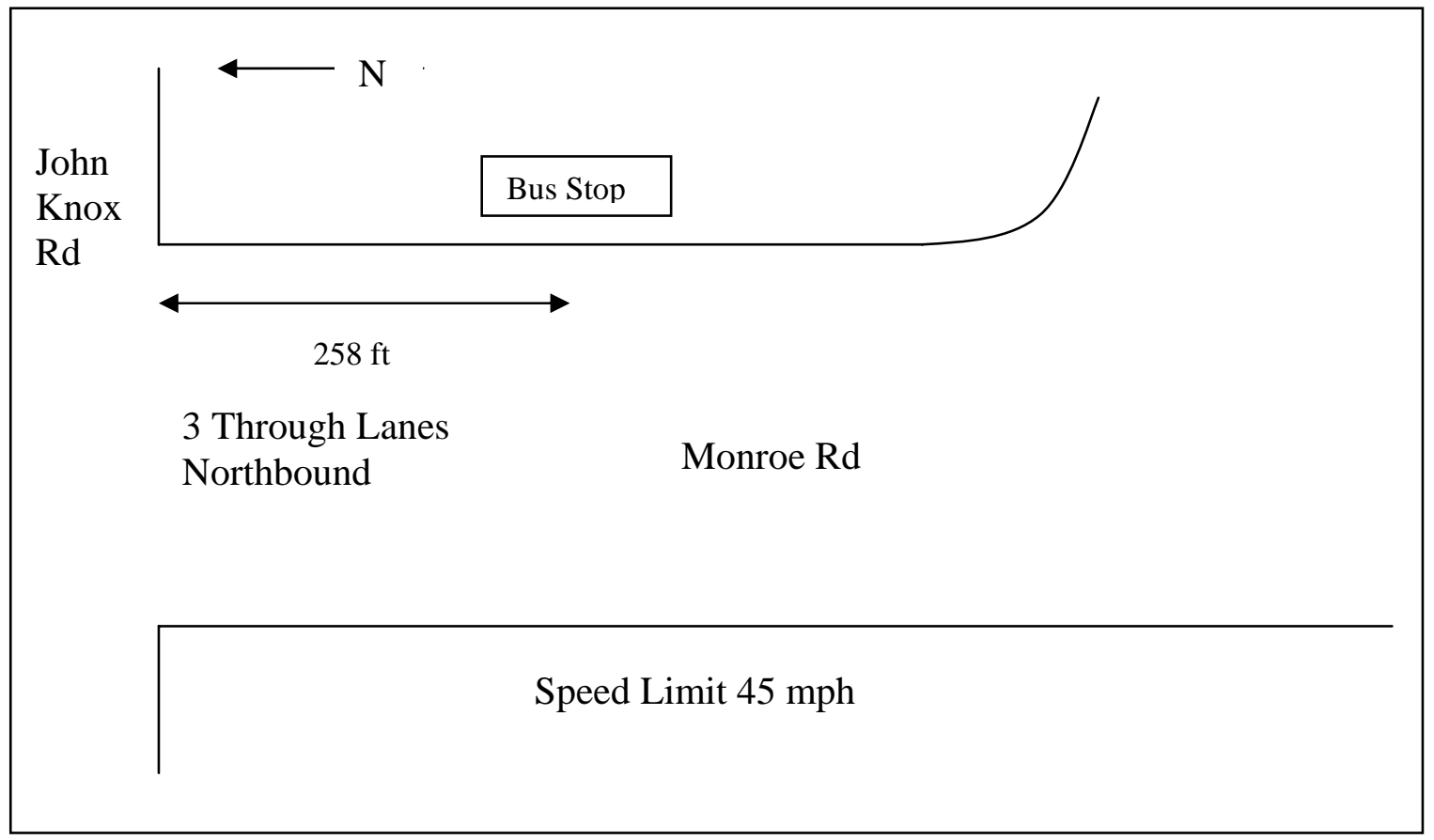

Figure 57 Sketch of John Knox Rd and Monroe St 
Appendix E: (Continued)

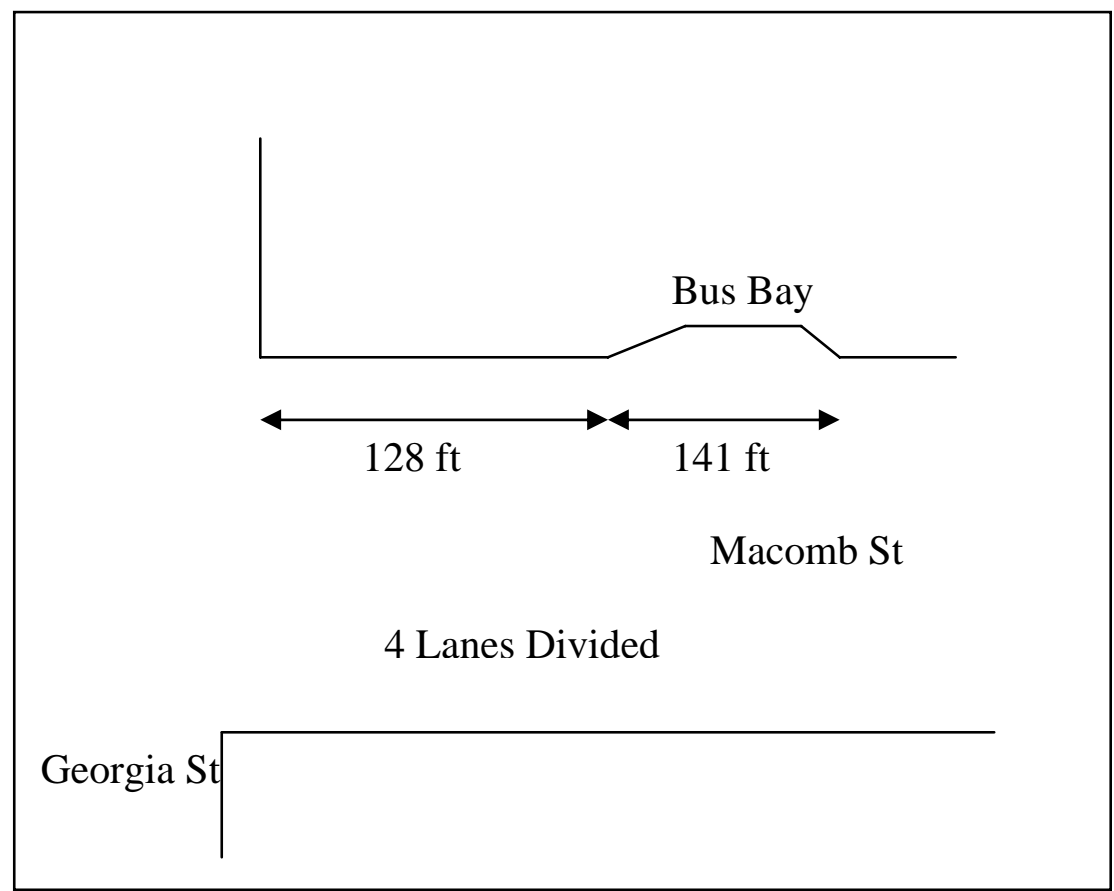

Figure 58 Sketch of Georgia St and Macomb St 


\section{Appendix F: Field Data Pictures}

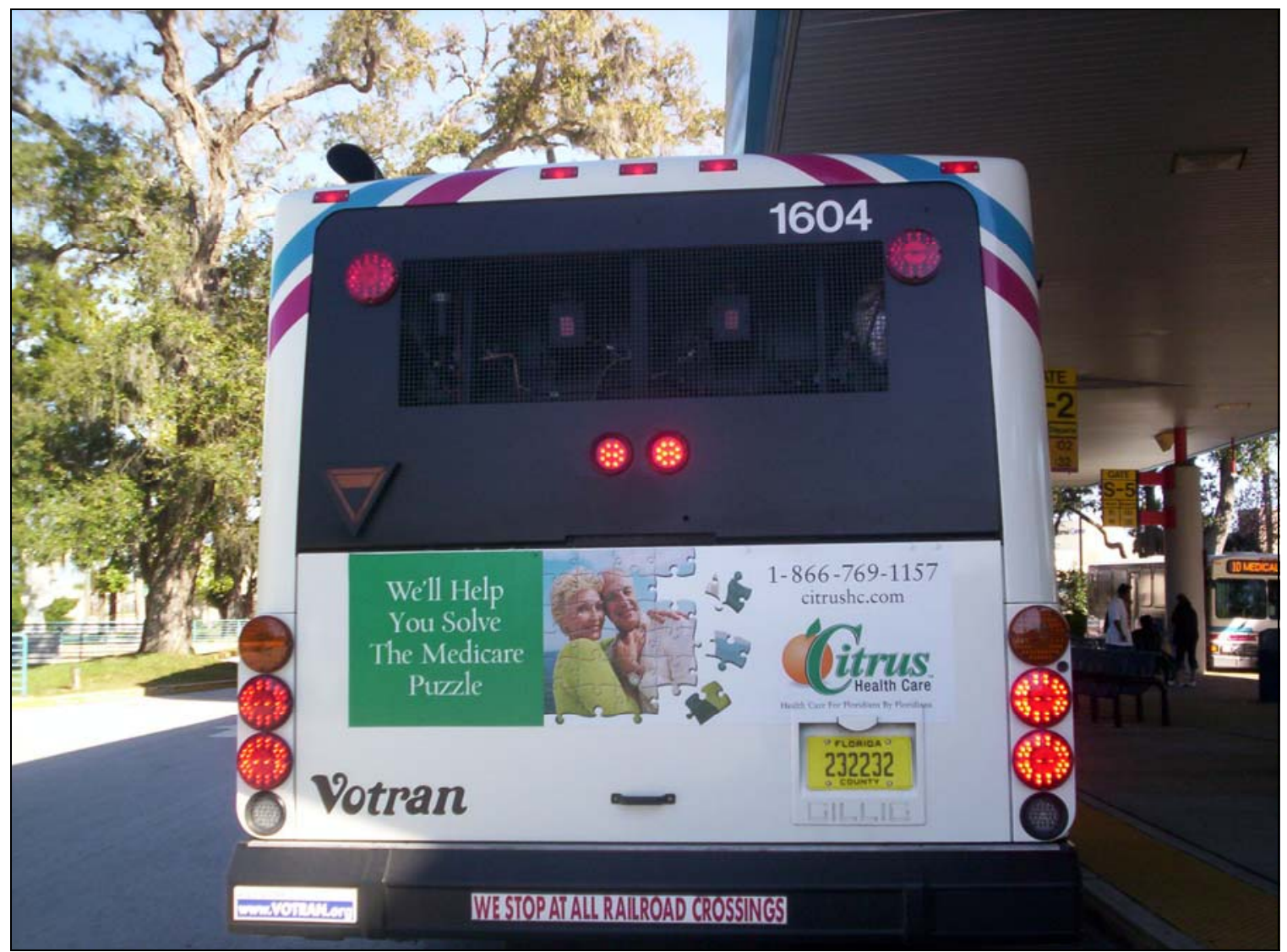

Figure 59 Votran Bus with New LED Sign 
Appendix F: (Continued)

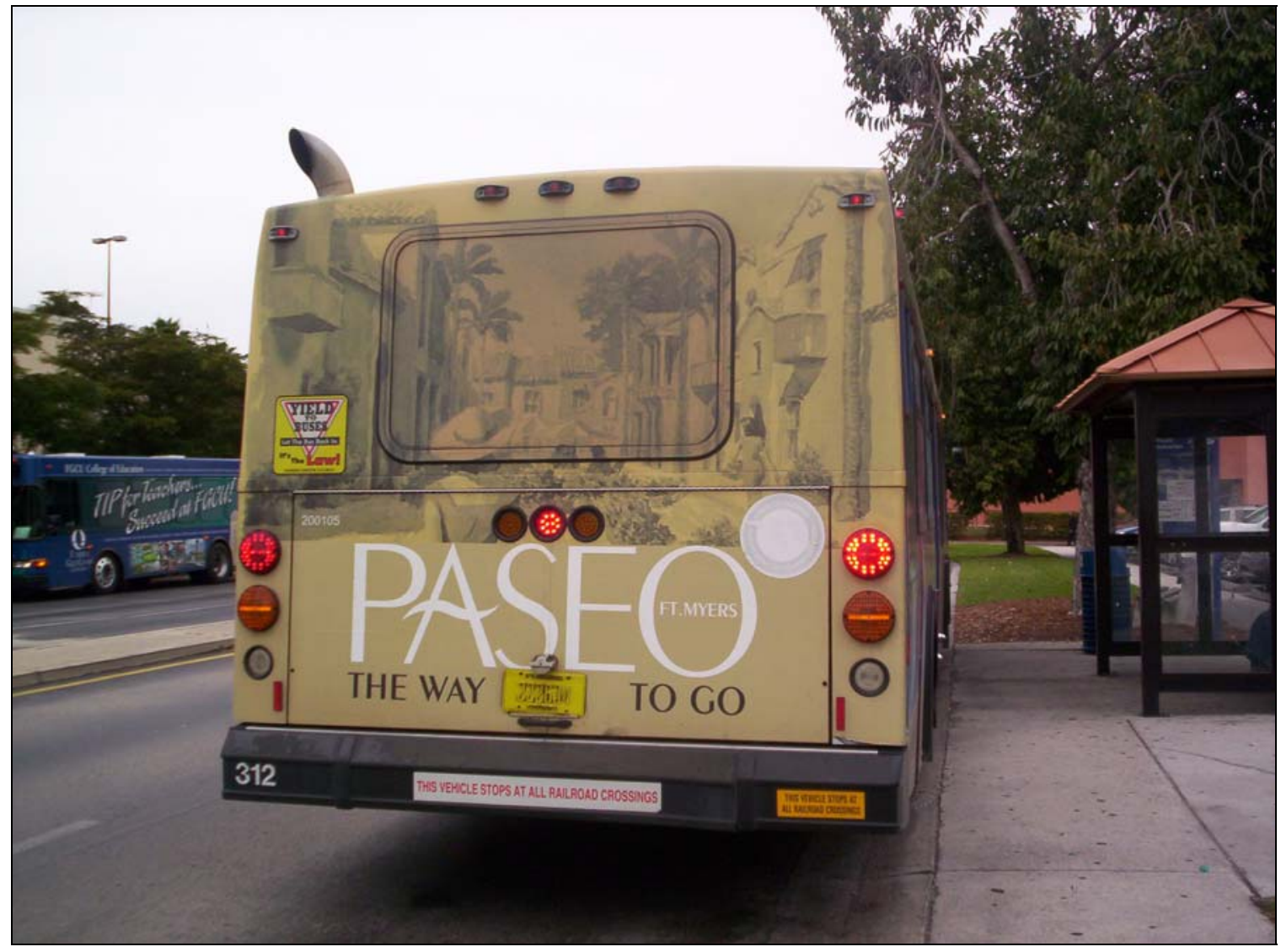

Figure 60 Leetran Bus with YTB Decal on Upper Part of Bus 
Appendix F: (Continued)

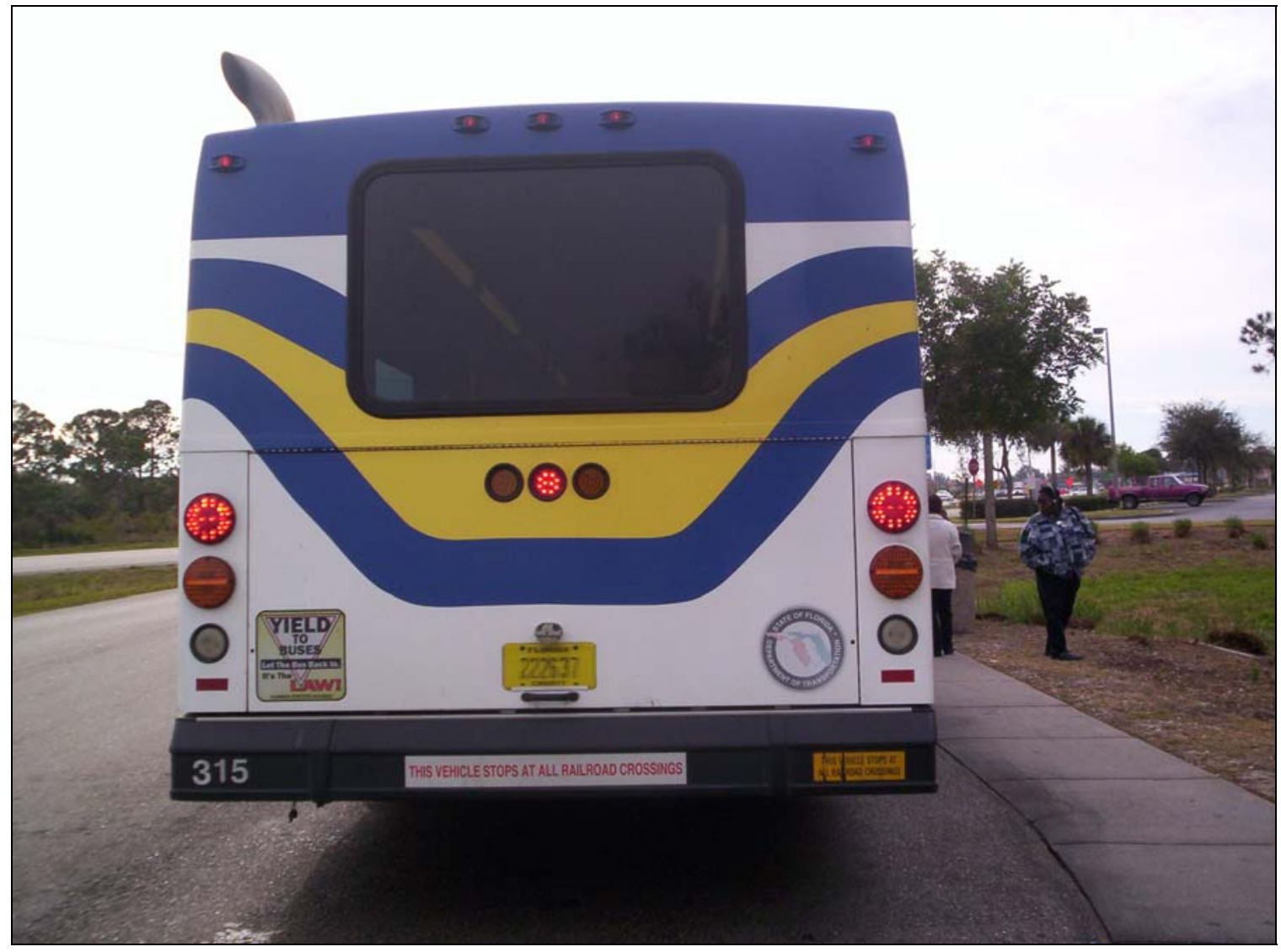

Figure 61 Leetran Bus with YTB Decal on Lower Part of Bus 
Appendix F: (Continued)

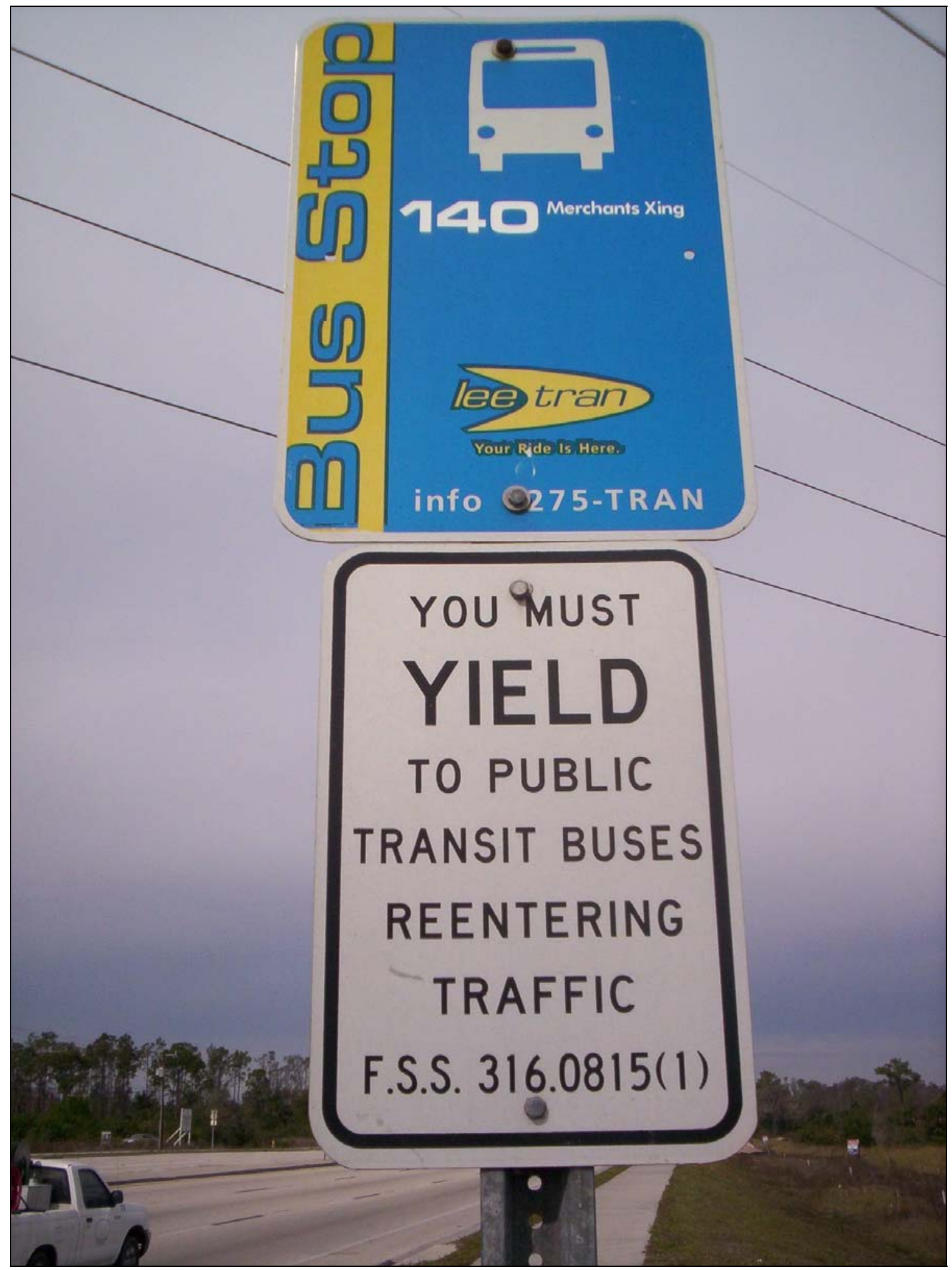

Figure 62 Leetran Bus Stop Sign with YTB Law 
Appendix F: (Continued)

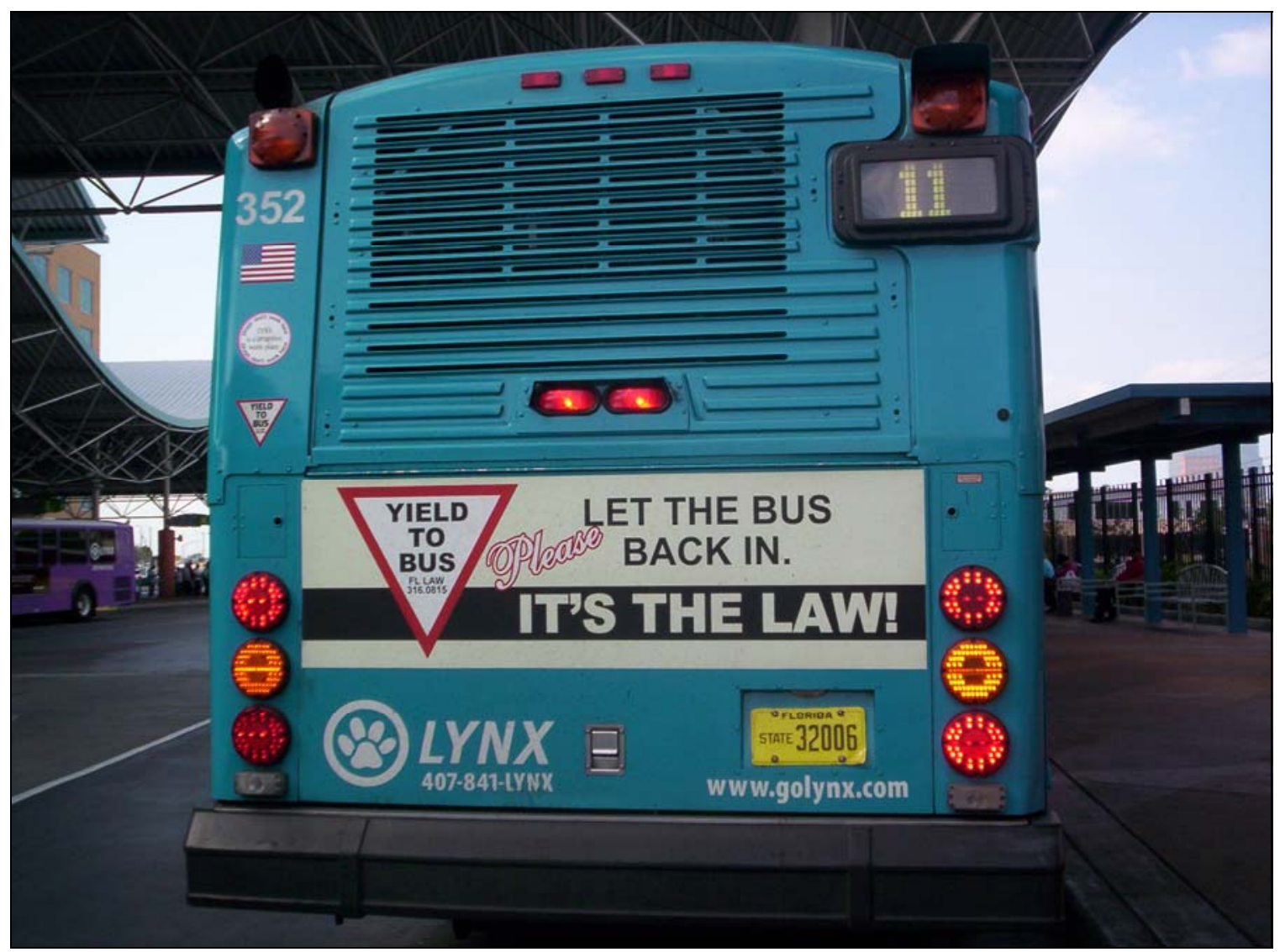

Figure 63 Lynx Bus with Large YTB Decal and Small YTB Decal 
Appendix F: (Continued)

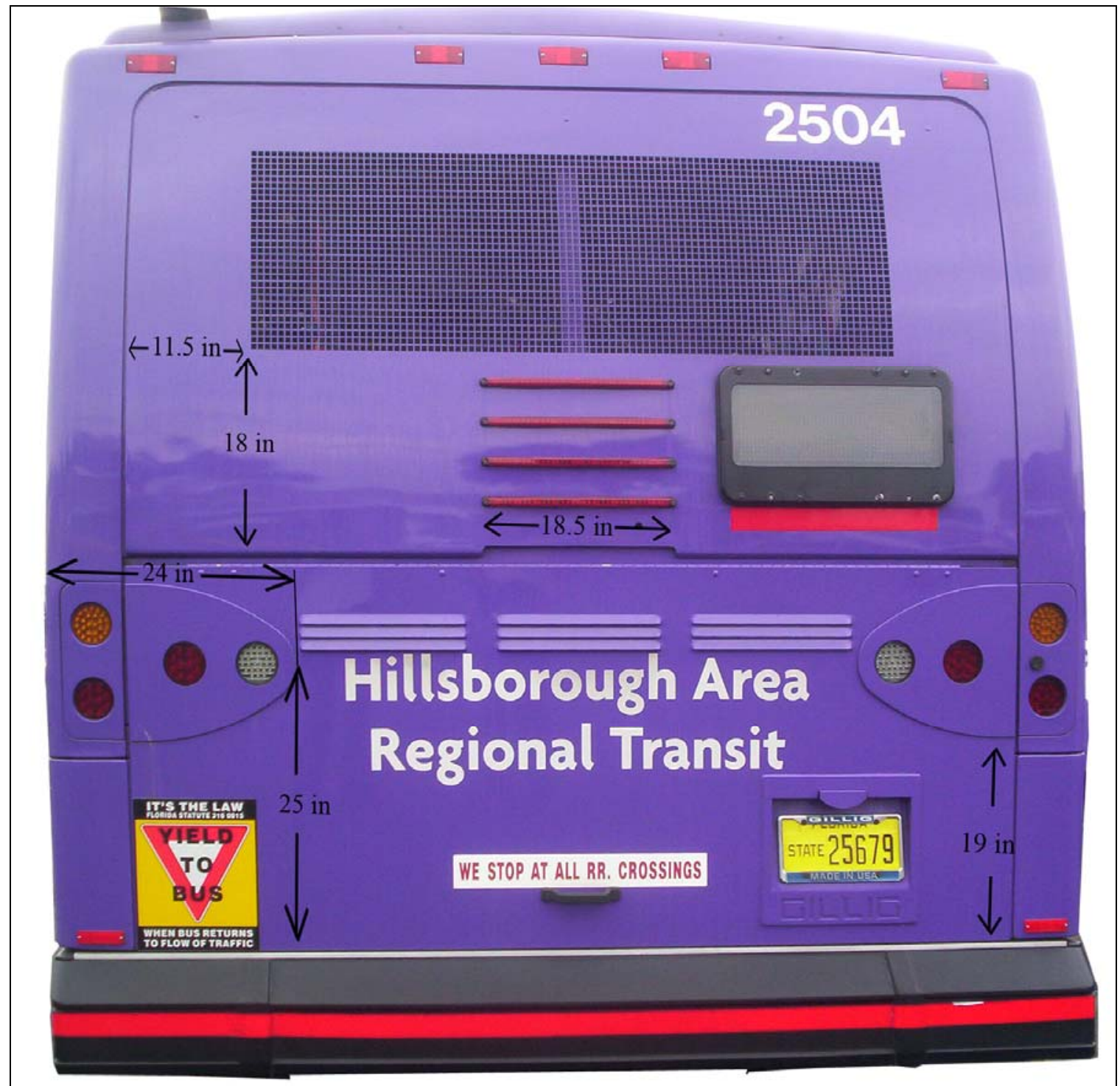

Figure 64 HART Bus with YTB Decal and Dimensions 
Appendix F: (Continued)

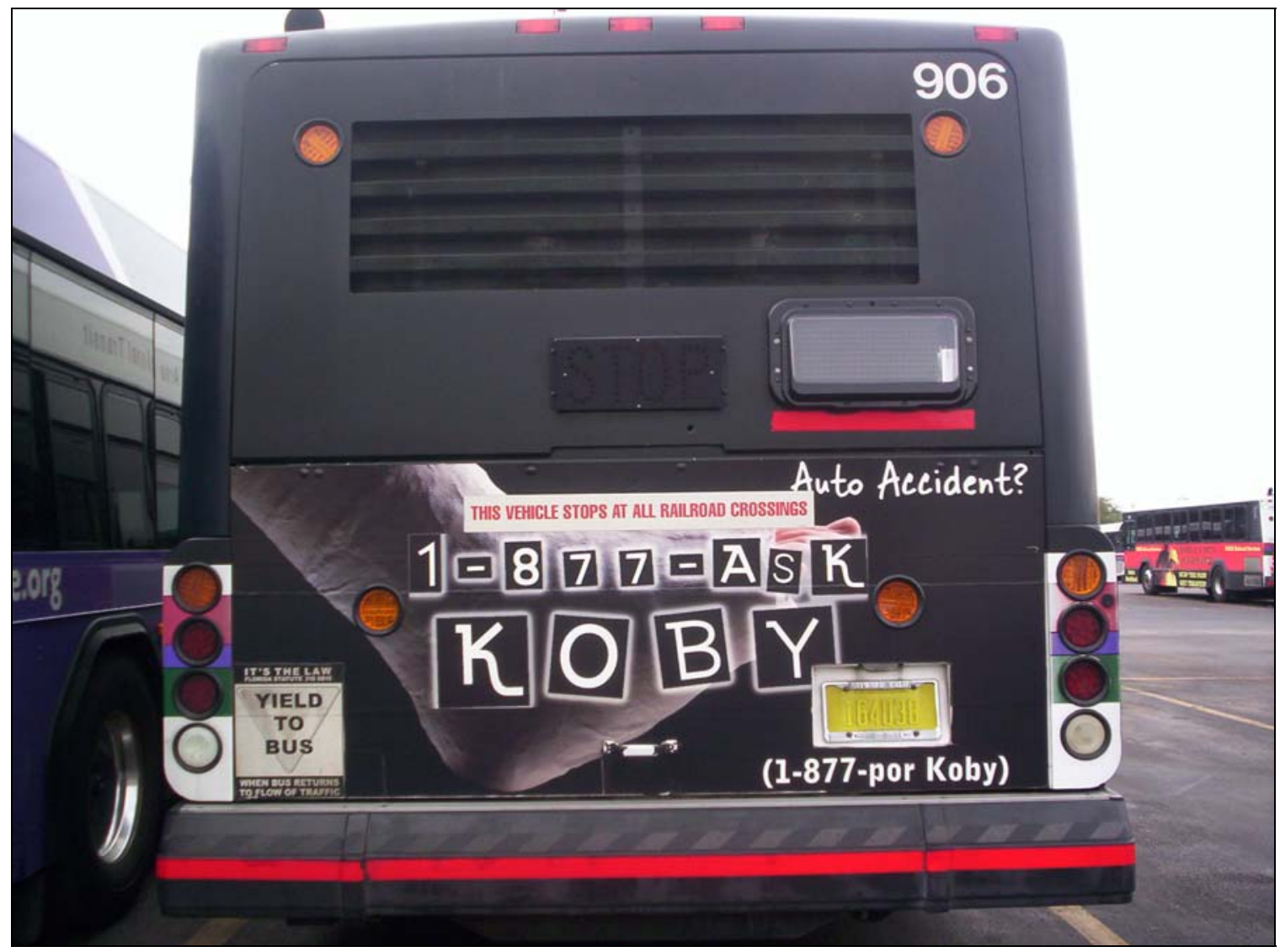

Figure 65 HART Gillig Phantom Bus 
Appendix F: (Continued)

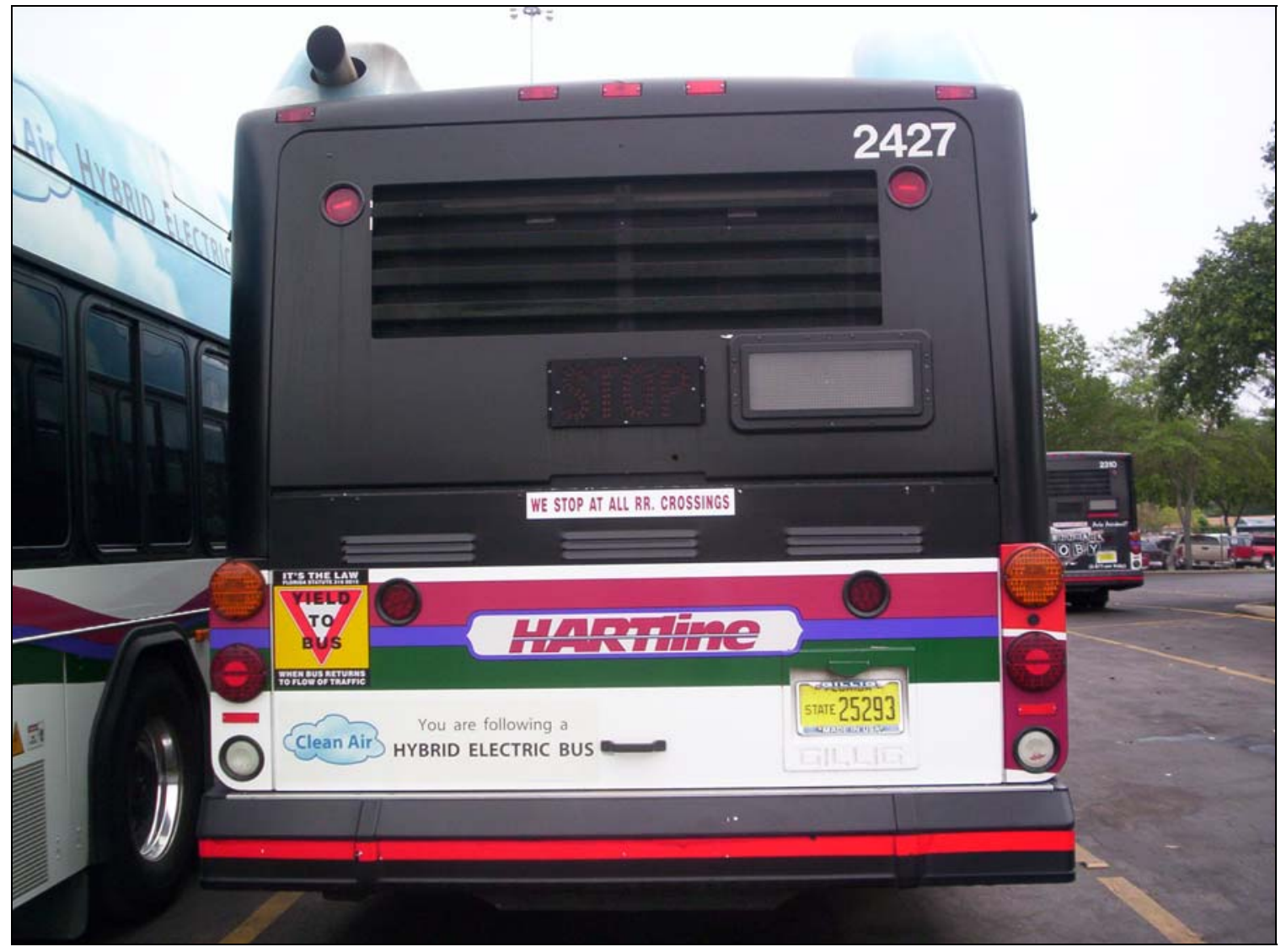

Figure 66 HART Gillig Hybrid Bus 
Appendix F: (Continued)

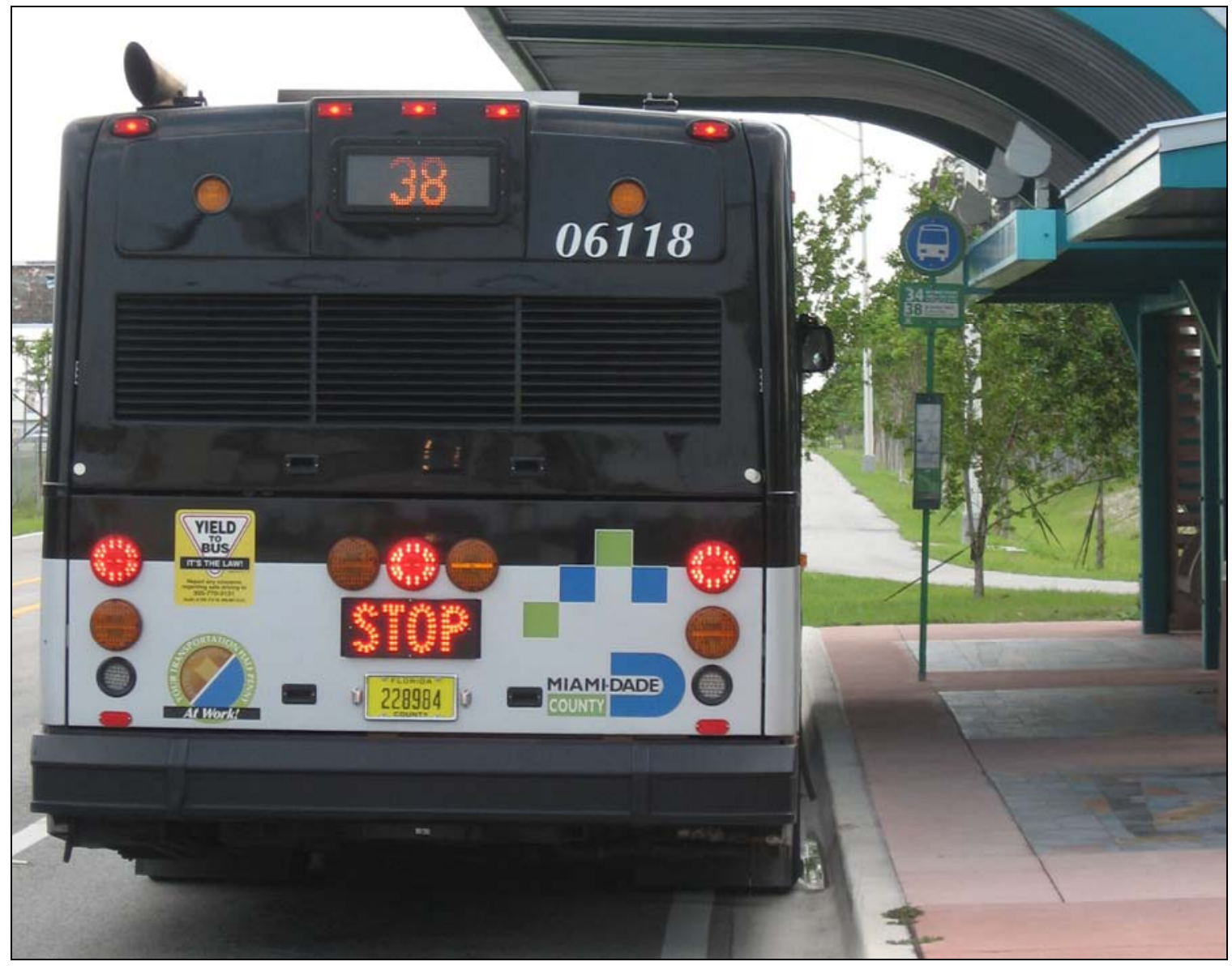

Figure 67 Miami-Dade Bus with YTB Decal 
Appendix F: (Continued)

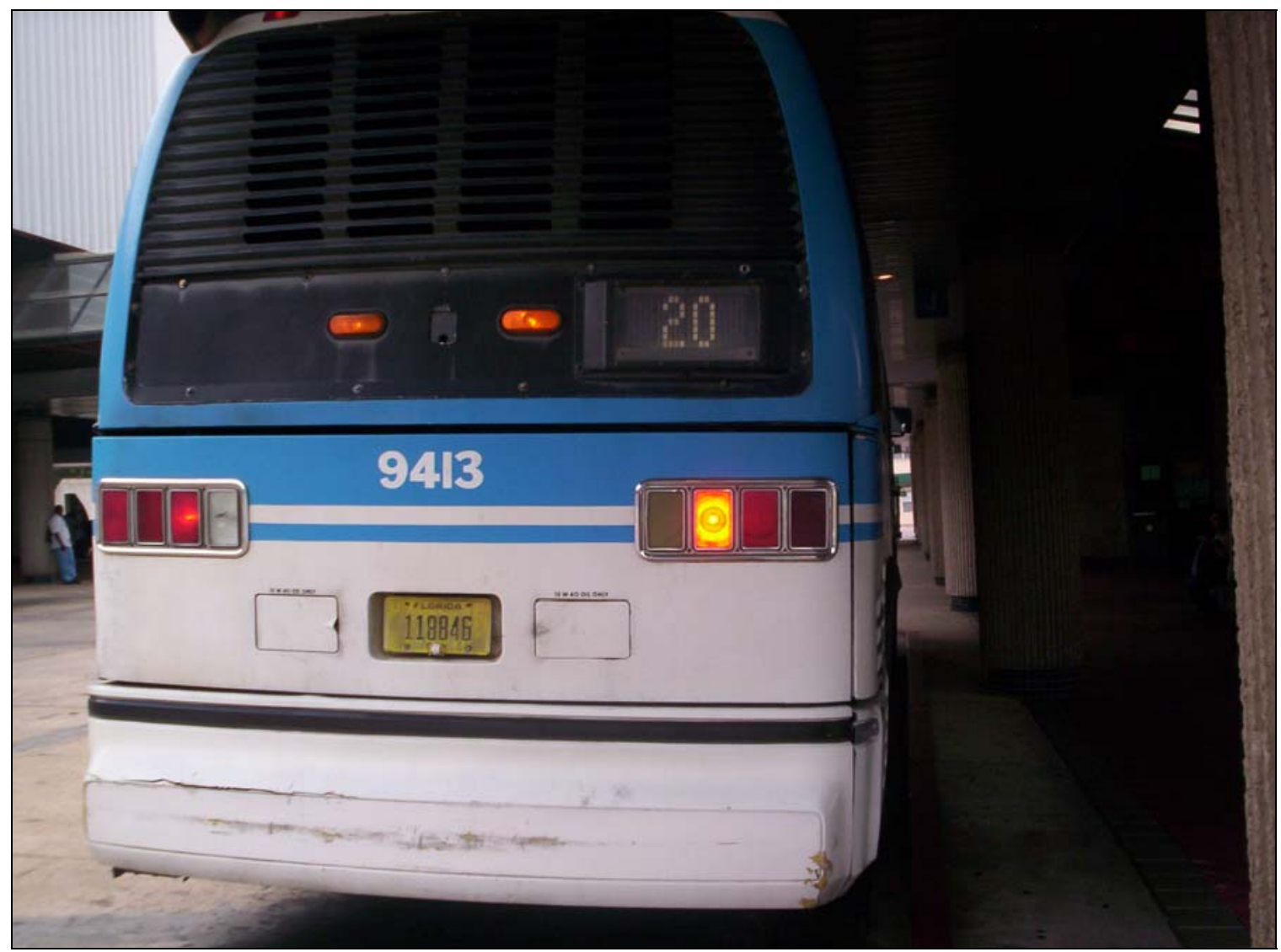

Figure 68 StarMetro RTS Bus 
Appendix F: (Continued)

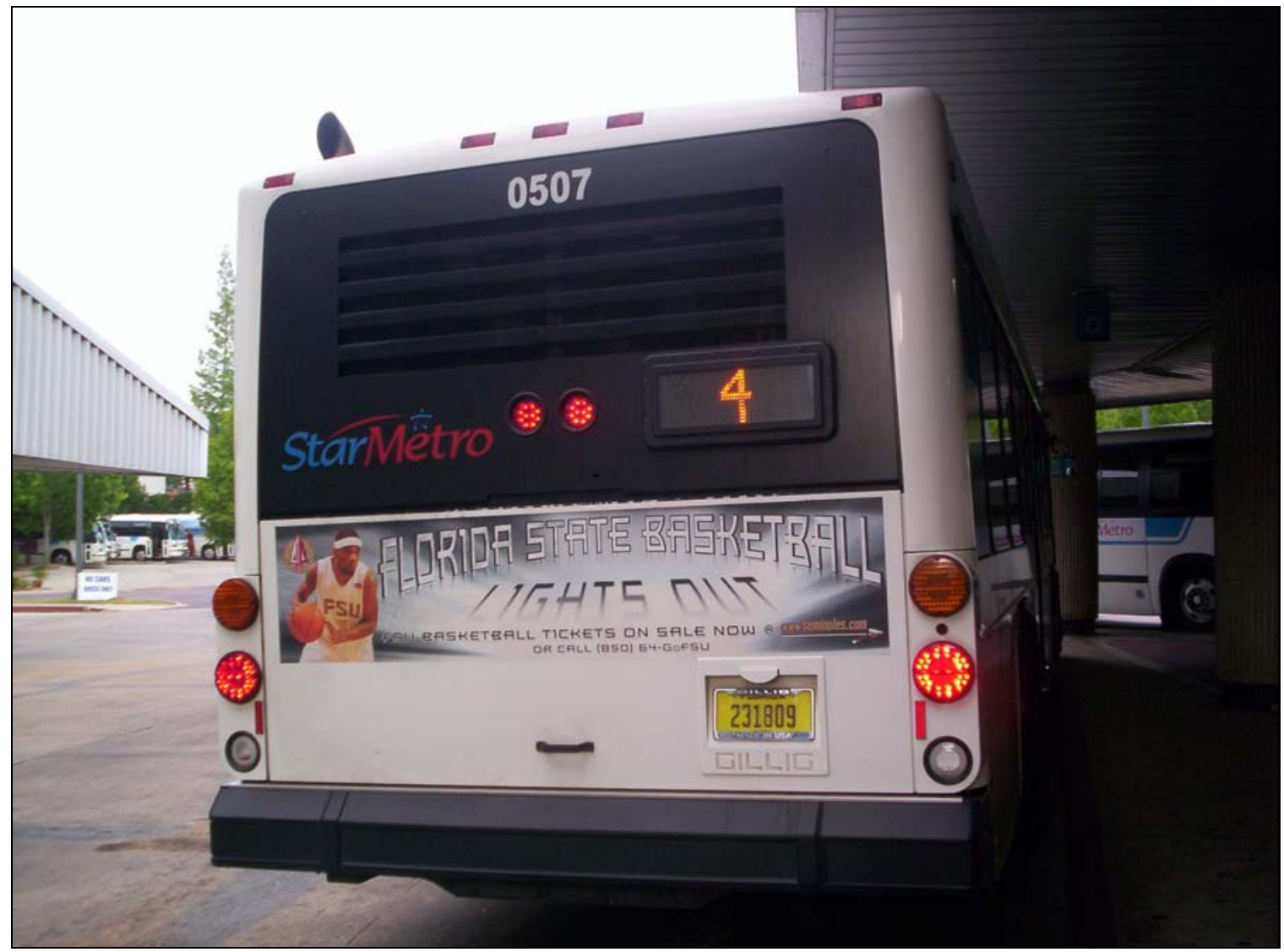

Figure 69 StarMetro Gillig Bus 


\section{Appendix G: Field Data}

Location: $\quad$ Fletcher Ave and Bruce B Downs Blvd, Tampa

Date: $\quad$ Tuesday, December 12, 2006

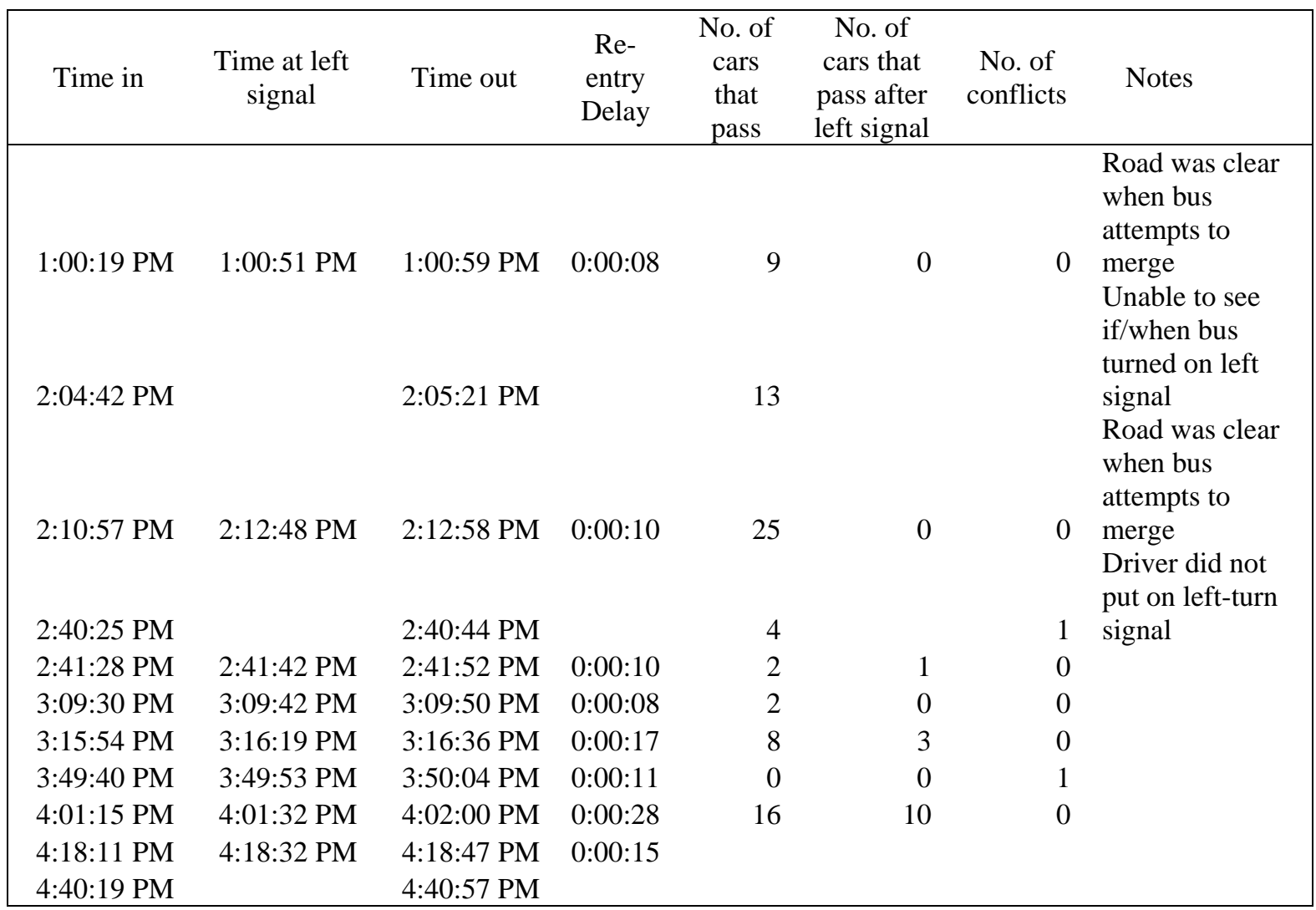




\section{Appendix G: (Continued)}

Location: $\quad$ Hillsborough Ave and Florida Ave, Tampa

Date: $\quad$ Wednesday, December 13, 2006

\begin{tabular}{|c|c|c|c|c|c|c|c|}
\hline Time in & $\begin{array}{c}\text { Time at left } \\
\text { signal }\end{array}$ & Time out & $\begin{array}{l}\text { Re-entry } \\
\text { Delay }\end{array}$ & $\begin{array}{l}\text { No. of } \\
\text { cars that } \\
\text { pass }\end{array}$ & $\begin{array}{l}\text { No. of } \\
\text { cars that } \\
\text { pass after } \\
\text { left signal }\end{array}$ & $\begin{array}{c}\text { No. of } \\
\text { conflicts }\end{array}$ & Notes \\
\hline 2:19:29 PM & 2:19:46 РМ & 2:20:18 PM & 0:00:32 & 14 & 2 & 0 & $\begin{array}{l}\text { Traffic was } \\
\text { stopped for } \\
\text { driver to yield } \\
\text { Traffic was } \\
\text { stopped for }\end{array}$ \\
\hline $2: 49: 10 \mathrm{PM}$ & 2:49:37 PM & $2: 50: 25$ PM & $0: 00: 48$ & 29 & 11 & 0 & $\begin{array}{l}\text { driver to yield } \\
\text { Traffic was } \\
\text { stopped for }\end{array}$ \\
\hline 3:22:23 PM & 3:22:53 PM & 3:23:06 PM & 0:00:13 & 5 & 0 & 0 & $\begin{array}{l}\text { driver to yield } \\
\text { Car changed } \\
\text { lanes and }\end{array}$ \\
\hline 3:52:38 PM & 3:53:03 PM & 3:53:15 PM & 0:00:12 & 7 & 0 & 0 & $\begin{array}{l}\text { avoided yielding } \\
\text { Traffic was } \\
\text { stopped for }\end{array}$ \\
\hline 4:26:30 PM & 4:26:50 PM & 4:27:57 PM & 0:01:07 & 32 & 21 & 0 & $\begin{array}{l}\text { driver to yield } \\
\text { Traffic was } \\
\text { stopped for }\end{array}$ \\
\hline 4:50:04 PM & 4:50:23 PM & 4:50:39 PM & 0:00:16 & 4 & 0 & 0 & $\begin{array}{l}\text { driver to yield } \\
\text { Driver was } \\
\text { stopped and } \\
\text { allowed the bus } \\
\text { to enter when } \\
\text { light turned }\end{array}$ \\
\hline 5:21:40 PM & 5:22:03 PM & 5:22:38 PM & $0: 00: 35$ & 20 & 9 & 0 & green \\
\hline
\end{tabular}

Location: $\quad$ Fletcher Ave and Dale Mabry Blvd, Tampa

Date: $\quad$ Wednesday, December 14, 2006

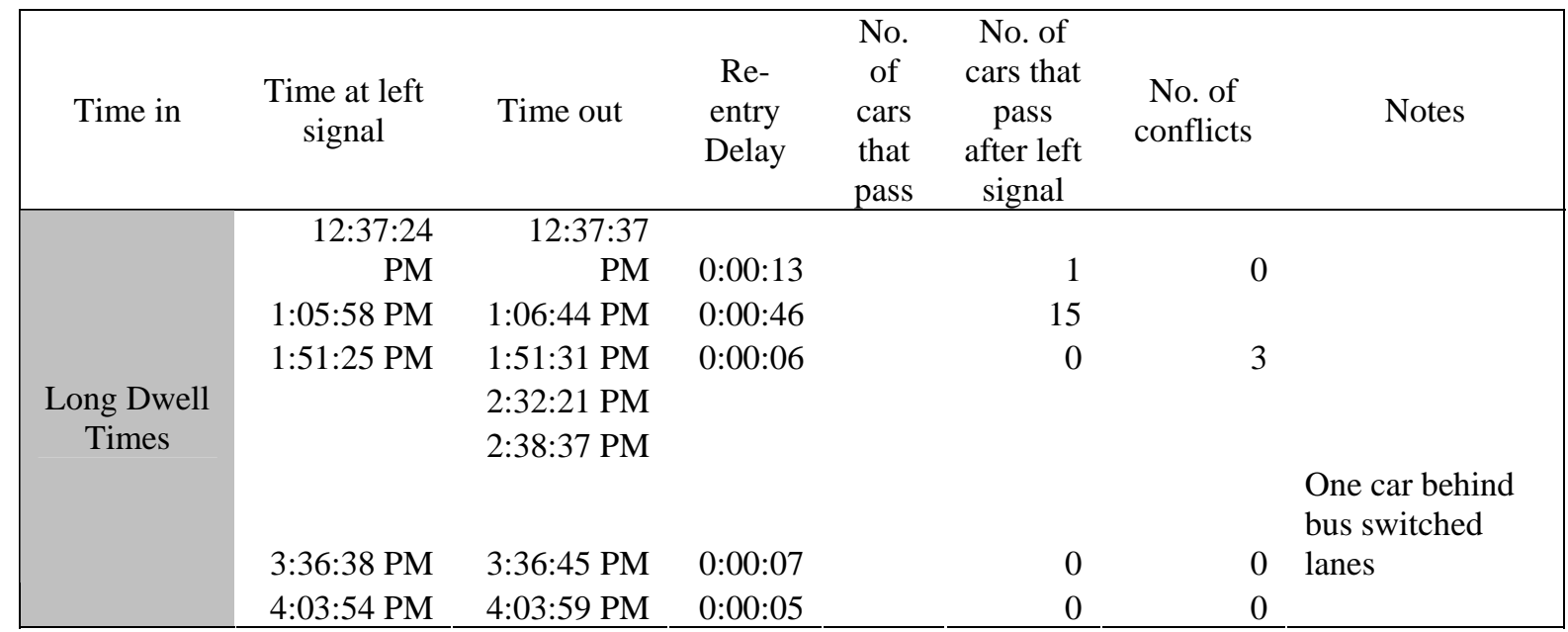




\section{Appendix G: (Continued)}

Location: $\quad$ Kirkman Rd and Conroy Rd, Orlando

Date: $\quad$ Tuesday, April 24, 2007

\begin{tabular}{|c|c|c|c|c|c|c|c|}
\hline Time in & $\begin{array}{l}\text { Time at left } \\
\text { signal }\end{array}$ & Time out & $\begin{array}{l}\text { Re- } \\
\text { entry } \\
\text { delay }\end{array}$ & $\begin{array}{l}\text { No. } \\
\text { cars } \\
\text { pass }\end{array}$ & $\begin{array}{c}\text { No. } \\
\text { cars } \\
\text { pass } \\
\text { after } \\
\text { left } \\
\text { signal }\end{array}$ & $\begin{array}{l}\text { No. of } \\
\text { conflicts }\end{array}$ & Notes \\
\hline 7:56:42 AM & & & & & & 1 & $\begin{array}{l}\text { Bus did not stop in } \\
\text { bus bay }\end{array}$ \\
\hline 8:26:10 AM & & 8:27:36 AM & & 7 & & 1 & $\begin{array}{l}\text { Bus moved into lane } \\
\text { without signaling }\end{array}$ \\
\hline 9:15:16 AM & 9:15:26 AM & 9:15:38 AM & $0: 12$ & 2 & 1 & 0 & No YTB decal \\
\hline 9:33:00 AM & 9:33:22 AM & 9:33:30 AM & $0: 08$ & 3 & 0 & 1 & No YTB decal \\
\hline 9:48:00 AM & 9:48:10 AM & 9:48:14 AM & $0: 04$ & 1 & 0 & 0 & No YTB decal \\
\hline 10:03:00 AM & 10:03:16 AM & 10:03:24 AM & 0:08 & 1 & 0 & 0 & No YTB decal \\
\hline 10:43:00 AM & 10:43:54 AM & 10:44:01 AM & & & & & Cars were stopped in \\
\hline 10:53:58 AM & 10:54:15 AM & 10:54:53 AM & 0:07 & 4 & 0 & 0 & $\begin{array}{l}\text { queue in front of bus } \\
\text { Weaving behind bus } \\
\text { - traffic was backed }\end{array}$ \\
\hline & & & $0: 38$ & 6 & & 0 & up when bus merged \\
\hline 11:45:50 AM & 11:46:03 AM & 11:46:18 AM & $0: 15$ & 5 & 1 & 0 & \\
\hline
\end{tabular}




\section{Appendix G: (Continued)}

Location: $\quad$ Kirkman Rd and Conroy Rd, Tampa

Date: $\quad$ Tuesday, April 24, 2007

\begin{tabular}{|c|c|c|c|c|c|c|c|}
\hline Time in & $\begin{array}{l}\text { Time at left } \\
\text { signal }\end{array}$ & Time out & $\begin{array}{l}\text { Re- } \\
\text { entry } \\
\text { delay }\end{array}$ & $\begin{array}{l}\text { No. } \\
\text { cars } \\
\text { pass }\end{array}$ & $\begin{array}{l}\text { No. cars } \\
\text { pass } \\
\text { after left } \\
\text { signal }\end{array}$ & $\begin{array}{l}\text { No. of } \\
\text { conflicts }\end{array}$ & Notes \\
\hline 6:44:16 AM & 6:44:34 AM & 6:44:51 AM & $0: 17$ & 14 & 6 & 0 & $\begin{array}{l}\text { No YTB decal } \\
\text { No YTB Decal, } \\
\text { Bus stopped in }\end{array}$ \\
\hline 7:56:05 AM & & & & 0 & 0 & 1 & lanes \\
\hline 8:14:06 AM & 8:15:42 AM & 8:15:48 AM & 0:06 & 17 & 0 & 0 & Large YTB decal \\
\hline 8:47:13 AM & 8:47:29 AM & 8:47:52 AM & $0: 23$ & 18 & 9 & 0 & No YTB decal \\
\hline 8:59:13 AM & 8:59:25 AM & 9:00:00 AM & $0: 35$ & 14 & 7 & 0 & No YTB decal \\
\hline 9:32:08 AM & 9:32:35 AM & 9:32:43 AM & $0: 08$ & 7 & 0 & 0 & No YTB decal \\
\hline 9:47:04 AM & 9:47:23 AM & 9:47:31 AM & $0: 08$ & 9 & 0 & 0 & No YTB decal \\
\hline 10:03:38 AM & 10:03:44 AM & 10:04:04 AM & $0: 20$ & 11 & 6 & 0 & $\begin{array}{l}\text { No YTB decal, } \\
\text { Weaving to avoid } \\
\text { bus }\end{array}$ \\
\hline 10:52:38 AM & 10:52:49 AM & 10:52:59 AM & $0: 10$ & 4 & 0 & 0 & $\begin{array}{l}\text { No YTB decal } \\
\text { Weaving behind } \\
\text { bus entering } \\
\text { traffic, operator } \\
\text { did not use left } \\
\text { signals but the }\end{array}$ \\
\hline 11:02:02 AM & 11:02:32 PM & $12: 18$ & $0: 08$ & 11 & 0 & 0 & $\begin{array}{l}\text { flashers } \\
\text { Large YTB decal, } \\
\text { weaving behind } \\
\text { bus }\end{array}$ \\
\hline 11:32:18 AM & 11:45:24 AM & 11:33:01 AM & 0:08 & 13 & 0 & 0 & $\begin{array}{l}\text { Bus did not stop } \\
\text { in pull-out bay } \\
\text { Bus waited until } \\
\text { road was clear } \\
\text { before merging - } \\
\text { no decal }\end{array}$ \\
\hline 12:02:38 PM & & 12:03:06 PM & & 8 & 0 & 0 & $\begin{array}{l}\text { No decal, merged } \\
\text { into traffic with } \\
\text { flashers }\end{array}$ \\
\hline
\end{tabular}

